\title{
Bis(pentamethylcyclopentadienyl)ytterbium: An Investigation of Weak Interactions in Solution Using Multinuclear NMR Spectroscopy
}

\author{
David Joel Schwartz \\ Ph.D. Thesis \\ Department of Chemistry \\ University of California, Berkeley \\ and \\ Chemical Sciences Division \\ Lawrence Berkeley Laboratory \\ University of California \\ Berkeley, CA 94720
}

July 1995

This work was supported by the Director, Office of Energy Research, Office of Basic Energy Sciences, Chemical Sciences Division, of the U.S. Department of Energy under Contract No. DE-AC03-76SF00098. 


\section{DISCLAIMER}

This report was prepared as an account of work sponsored by an agency of the United States Government. Neither the United States Government nor any agency thereof, nor any of their employees, make any warranty, express or implied, or assumes any legal liability or responsibility for the accuracy, completeness, or usefulness of any information, apparatus, product, or process disclosed, or represents that its use would not infringe privately owned rights. Reference herein to any specific commercial product, process, or service by trade name, trademark, manufacturer, or otherwise does not necessarily constitute or imply its endorsement, recommendation, or favoring by the United States Government or any agency thereof. The views and opinions of authors expressed herein do not necessarily state or reflect those of the United States Government or any agency thereof. 


\section{DISCLAIMER}

Portions of this document may be illegible in electronic image products. Images are produced from the best available original document. 


\title{
Bis(pentamethylcyclopentadienyl)ytterbium:
}

\section{An Investigation of Weak Interactions in Solution Using Multinuclear NMR Spectroscopy.}

\author{
by \\ David Joel Schwartz
}

B.S. (University of Michigan, Ann Arbor) 1990

A dissertation submitted in partial satisfaction of the requirement for the degree of

Doctor of Philosophy

in

Chemistry

in the

GRADUATE DIVISION

of the

UNIVERSITY of CALIFORNIA at BERKELEY

Commitee in charge:

Professor Richard A. Andersen, Chair

Professor John Arnold

Professor Glenn T. Seaborg 


\begin{abstract}
Bis(pentamethylcyclopentadienyl)ytterbium: An Investigation of Weak Interactions in Solution Using Multinuclear NMR Spectroscopy.
\end{abstract}

by

\author{
David Joel Schwartz \\ Doctor of Philosophy in Chemistry \\ University of California at Berkeley \\ Professor Richard A. Andersen, Chair
}

$\mathrm{Cp}_{2}{ }_{2} \mathrm{Yb}$ forms 1:1 adducts with the cis dihydride complexes $\mathrm{P}_{2} \mathrm{PtH}_{2}\left(\mathrm{P}_{2}=\right.$ dcype, dcypp) that undergo slow intermolecular exchange at $25^{\circ} \mathrm{C}$, on the NMR timescale. There are significant perturbations in the spectral values from those of the free $\mathrm{P}_{2} \mathrm{PtH}_{2}$ complexes, and $\mathrm{J}_{\mathrm{YbX}}$ coupling $\left(\mathrm{X}={ }^{1} \mathrm{H},{ }^{31} \mathrm{P},{ }^{195} \mathrm{Pt}\right)$ is present. The interactions of $\mathrm{Cp}_{2}{ }_{2} \mathrm{Yb}$ with (dippe)PtMe $\mathrm{Pe}_{2}$ and (dippe) $\mathrm{Pt}(\mathrm{Me})(\mathrm{H})$ have also been investigated. The NMR spectral values of the adducts are discussed in detail, and correlated with the solid state structures.

Several platinum cis dihydride phosphine complexes, $\mathrm{P}_{2} \mathrm{PtH}_{2}\left(\mathrm{P}_{2}=\right.$ dippe, dcype, dtbpe), have been found to be unstable in solution, reversibly losing $\mathrm{H}_{2}$ and forming binuclear complexes of the general formula $\left(\mathrm{P}_{2} \mathrm{PtH}\right)_{2}$. The extent of dimerization is directly related to the steric size of the phosphine ligand, larger phosphines imparting kinetic stability to the monomers. The ${ }^{1} \mathrm{H},{ }^{1}{ }^{1} \mathrm{P}\left\{{ }^{1} \mathrm{H}\right\}$, and ${ }^{195} \mathrm{Pt}\left\{{ }^{1} \mathrm{H}\right\}$ NMR spectra of these dimers at $25^{\circ} \mathrm{C}$ indicate that a fast fluxional process is present on the NMR timescale. The spectral and structural details, solution properties (H/D isotopic exchange), and the nature of the fluxional process, are discussed.

The interactions between $\mathrm{Cp}_{2}{ }_{2} \mathrm{Yb}$ and phosphines and $\mathrm{R}_{3} \mathrm{PX}$ derivatives $(\mathrm{X}=\mathrm{O}$, $\mathrm{NR}^{\prime}, \mathrm{CHR} "$ ) have also been investigated. Intermolecular exchange can be slowed at low 
temperature for $1: 1\left(\mathrm{~J}_{\mathrm{YbP}} \approx 950 \mathrm{~Hz}\right)$ and $1: 2\left(\mathrm{~J}_{\mathrm{YbP}} \approx 600 \mathrm{~Hz}\right)$ phosphine adducts $\left(\mathrm{PMe}_{3}\right.$, $\mathrm{PEt}_{3}$, dmpm, and 1,2-( $\left.\mathrm{PMe}_{2}\right) \mathrm{C}_{6} \mathrm{H}_{4}$ have been investigated). Both 1:1 and 1:2 adducts of $\mathrm{Cp}_{2}{ }_{2} \mathrm{Yb}$ with $\mathrm{Me}{ }_{3} \mathrm{PO}$ and $\mathrm{Et}_{3} \mathrm{PNH}$ have also been isolated. The spectroscopic properties of the ylide adducts $\left.\mathrm{Cp}_{2}{ }_{2} \mathrm{Yb}\left(\mathrm{Me}_{2} \mathrm{PhPCHSiMe}\right)_{3}\right)$ and $\mathrm{Cp}_{2}{ }_{2} \mathrm{Yb}\left(\mathrm{Me}_{2} \mathrm{PhPCH}_{2}\right)$ have been investigated. Intermolecular exchange can be slowed at low temperature. A second, intramolecular process can be slowed at lower temperatures for $\mathrm{Cp}_{2}{ }_{2} \mathrm{Yb}\left(\mathrm{Me}_{2} \mathrm{PhPCHSiMe}\right)$, and the mechanism of this process is discussed. The ${ }^{1} \mathrm{H}$, ${ }^{13} \mathrm{C},{ }^{31} \mathrm{P}$, and ${ }^{171} \mathrm{Yb}$ NMR values of these adducts are discussed in detail.

The potential of using long range ${ }^{171} \mathrm{Yb}-{ }^{1} \mathrm{H}$ spin-spin coupling, to the methyl group protons of the $\mathrm{Cp}^{*}$ rings of $\mathrm{Cp}^{*}{ }_{2} \mathrm{YbL}_{\mathrm{n}}$ adducts, for inverse-detection of ${ }^{171} \mathrm{Yb}$ has been explored. Synthetic attempts towards a $\mathrm{P}_{2} \mathrm{Pt}-\mathrm{YbCp}_{2}{ }_{2}$ heterobimetallic complex are discussed. The spectroscopic properties of a novel ring-metallated complex, (dcype)Pt( $\mu$ $\mathrm{H})\left(\mu-\mathrm{CH}_{2} \mathrm{C}_{4} \mathrm{Me}_{4}\right) \mathrm{YbCp}^{*}$, are discussed. In addition, the results of several NMR experiments on the interactions of $\mathrm{Cp}^{*}{ }_{2} \mathrm{Yb}$ with $\mathrm{H}_{2}, \mathrm{CH}_{4}, \mathrm{Xe}, \mathrm{CO}$, silanes, stannanes, $\mathrm{C}_{6} \mathrm{H}_{6}$, and toluene are documented. 


\section{ACKNOWLEDGMENTS}

Well....I saved the hardest part for last. First off, I should start with Dick. Working with him for the last four years has been truly enjoyable--I would make the same decision over again, and that says something. I will miss our chemistry discussions, trying to figure out what was going on ("what the molecules were trying to tell us"!), and just "wasting time" talking about chemistry in general. In my opinion, one characteristic of a good adviser is one who, when a student is "down" on his/her chemistry or when things just aren't going so well, can get that student excited and motivated again, just by being so excited about the chemistry themself. Dick did that for me many times, and for that I thank him.

Well, that brings me to the two major people who have had to bear the brunt of my whining (though I prefer to think of it as "observing") over the last four years--Ryan and Jackie, of course. There is just too much to say, so I won't try to say it all. Living with

Ryan has made my graduate school experience so much more enjoyable (and has also been the source of some REALLY good stories). Of all the things I'll miss when I leave Berkeley, many of them involve him--coming home at night and watching a Trek and/or whining about our lives, over a beer (and actually buying a VCR, for the sole purpose of taping every Trek on TV); kicking his butt in The Contest (NO, being drunk isn't an excuse!); The Tick; and just going to the Village for lunch. As for Jackie, she deserves more credit than anyone, for dealing with me those many times when I completely lost perspective, and just wanted to whine and whine. Her support over the last four years (and more) has been invaluable.

There are several other people who I would also like to thank: Chris Tagge, truly a class act, for both his scientific help and friendship; Kerren Kalai, who helped make my last year here a bit nicer; the Bergmanites, for putting up with all my inane questions at group meetings ("Did you measure the $\mathrm{C}-\mathrm{H}$ coupling constant??"); and I can't forget Denisha Dawson (even if she wasn't very sympathetic to my whining!), Nora Radu (for 
iv

all the good food, and for commiserating with me), and Harper and Kimball Ingram (for being such fun neighbors). Also, I'd like to thank my "mentors" in the Andersen Group, Marc Weydert (who taught me how to be bitter) and Wayne Lukens (who was never too busy to think/talk about my chemistry). And thanks to the rest of the Andersen Group (especially Phil), for all of their help. Special thanks go to Graham Ball, who showed me the fun of NMP, and without whom this thesis would be VERY different! I also want to acknowledge Fred Hollander's help, who was always willing to answer my X-ray questions, in his typical friendly fashion.

Lastly, I'd like to thank my family for their support through the 22 years (!) of my education. My parents deserve a lot of the credit for this thesis--without their support, I would never have made it to this point. Thanks. 


\section{TABLE OF CONTENTS}

Acknowledgments ..................................................... iii

Table of Contents......................................................... v

Summary of Abbreviations and Compound Designations............................. vii

Introduction ....................................................... 1

Chapter 1. Interactions of $\mathrm{Cp}_{2}{ }_{2} \mathrm{Yb}$ with cis- $\mathrm{P}_{2} \mathrm{PtXY}$

Complexes $(\mathrm{X}, \mathrm{Y}=\mathrm{H}, \mathrm{Me})$.......................................... 9

Interactions with $\left[\mathrm{R}_{2} \mathrm{P}\left(\mathrm{CH}_{2}\right)_{2} \mathrm{PR}_{2}\right] \mathrm{PtH}_{2}$ Complexes.......................... 9

Interaction with (dcypp) $\mathrm{PtH}_{2}$............................................ 19

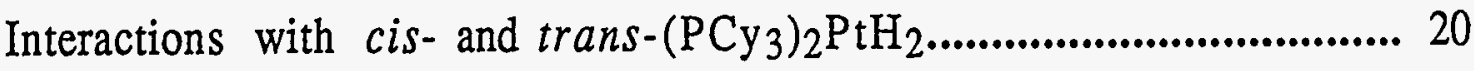

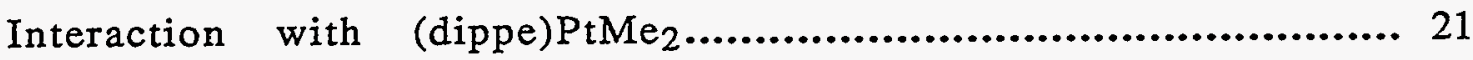

Interaction with (dippe)Pt(Me)(H)......................................... 27

References ...................................................... 38

Chapter 2. Reversible Formation of $\left(\mathrm{P}_{2} \mathrm{PtH}\right)_{2} \mathrm{Pt}(\mathrm{I})$ Complexes from

cis $-\mathrm{P}_{2} \mathrm{PtH}_{2} \mathrm{Complexes.................................................} 44$

Syntheses of $\left(\mathrm{P}_{2} \mathrm{PtH}\right)_{2}$ Complexes............................................4 46

Monomer/Dimer Equilibrium............................................... 48

Solid State Structures of $[(\mathrm{dippe}) \mathrm{PtH}]_{2}$ and $[(\mathrm{dtbpe}) \mathrm{PtH}]_{2} \ldots . . . . . . . . . . . . . . . . . . . . .449$

Room Temperature NMR Spectra............................................. 54

Low Temperature NMR Spectra/Fluxionality..................................... 58

$H / D$ Scrambling of the Dimers............................................. 66

Reactivity with $\mathrm{Cp}^{*}{ }_{2} \mathrm{Y}$ b.............................................. 69

References .................................................... 72

Chapter 3. Interactions of $\mathrm{Cp}_{2}^{*} \mathrm{Yb}$ with Phosphines, $\mathrm{R}_{3} \mathrm{PX}$

Complexes $(\mathrm{X}=\mathrm{O}$, NR', CHR")......................................... 75

Interactions with Phosphines............................................. 75

Interactions with Phosphine Oxides and Imines................................... 80 
Interactions with Phosphine Ylides.......................................... 82

Strengths of the $\mathrm{Yb}-\mathrm{L}$ Interactions.......................................... 90

${ }^{171} \mathrm{Yb}$ Chemical Shifts of $\mathrm{Cp}^{\#}{ }_{2} \mathrm{YbL}_{\mathbf{n}}$ Complexes................................... 92

References....................................................... 95

Chapter 4. Weak Interactions of $\mathrm{Cp}_{2}{ }_{2} \mathrm{Yb}$ with Various Small Molecules

$\left(\mathrm{H}_{2}, \mathrm{Xe}, \mathrm{CH}_{4}, \mathrm{CO}\right.$, toluene, etc.)........................................... 100

Indirect Detection of the ${ }^{171} \mathrm{Yb}$ NMR Spectra of $\mathrm{Cp}^{*}{ }_{2} \mathrm{YbL}_{\mathfrak{n}}$ Complexes.............. 100

Synthetic Attempts Towards a $\mathrm{P}_{2} \mathrm{Pt}-\mathrm{YbCp}_{2}{ }_{2}$ Bimetallic Complex..................... 103

Interactions with Small Molecules............................................... 110

References .................................................... 121

Experimental Details................................................... 124

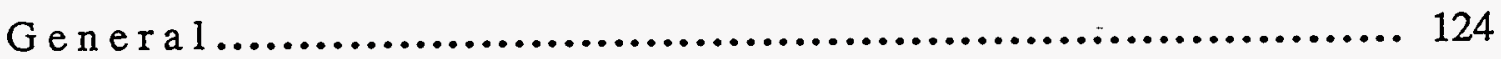

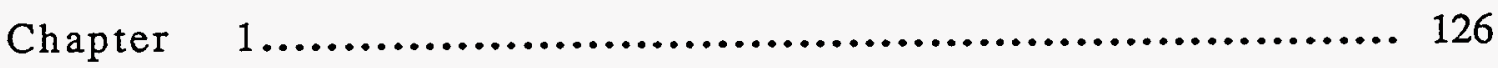

Chapter 2 ....................................................... 130

Chapter 3 ....................................................... 135

Chapter 4 ....................................................... 139

X-ray Crystallographic Studies........................................... 142

References.................................................... 164

Appendix I. Supplementary NMR Spectra.................................... 167

Appendix II. Tables of Positional and Thermal Parameters......................... 173 
NOTE: For purposes of clarity and conciseness, the following abbreviations have been used throughout this work:

- Me: $\quad-\mathrm{CH}_{3}$

- Et: $\quad-\mathrm{CH}_{2} \mathrm{CH}_{3}$

- Ph: $\quad-\mathrm{C}_{6} \mathrm{H}_{5}$

- Cy: $\quad-\mathrm{C}_{6} \mathrm{H}_{11}$

- Np: $\quad-\mathrm{CH}_{2} \mathrm{CMe}_{3}$

- Mes: $\quad-\left(1,3,5-\mathrm{C}_{6} \mathrm{H}_{2} \mathrm{Me}_{3}\right)$

- $\mathrm{Cp}^{*}$ : pentamethylcyclopentadienyl anion

- dmpe: bis(di-methylphosphino)ethane, [ $\left.\mathrm{Me}_{2} \mathrm{P}\left(\mathrm{CH}_{2}\right)_{2} \mathrm{PMe}_{2}\right]$

- dtbpe: bis(di-tertiary-butylphosphino)ethane, $\left[\left(\mathrm{Me}_{3} \mathrm{C}\right)_{2} \mathrm{P}\left(\mathrm{CH}_{2}\right)_{2} \mathrm{P}\left(\mathrm{CMe}_{3}\right)_{2}\right]$

- dcype: bis(di-cyclohexylphosphino)ethane, [Cy2 $\left.\mathrm{P}\left(\mathrm{CH}_{2}\right)_{2} \mathrm{PCy} 2\right]$

- dcypp: bis(di-cyclohexylphosphino)propane, [ $\left.\mathrm{Cy}_{2} \mathrm{P}\left(\mathrm{CH}_{2}\right)_{3} \mathrm{PCy} 2\right]$

- dippe: bis(di-iso-propylphosphino)ethane, $\left[\left(\mathrm{Me}_{2} \mathrm{CH}\right)_{2} \mathrm{P}\left(\mathrm{CH}_{2}\right)_{2} \mathrm{P}\left(\mathrm{CHMe}_{2}\right)_{2}\right]$

- dtbpp: bis(di-tert-butylphosphino)propane, [( $\left.\left.\mathrm{Me}_{3} \mathrm{C}\right)_{2} \mathrm{P}\left(\mathrm{CH}_{2}\right)_{3} \mathrm{P}\left(\mathrm{CMe}_{3}\right)_{2}\right]$

- dppe: bis(di-phenylphosphino)ethane, $\left[\mathrm{Ph}_{2} \mathrm{P}\left(\mathrm{CH}_{2}\right)_{2} \mathrm{PPh}_{2}\right]$

- dmpm: bis(di-methylphosphino)methane, $\left[\mathrm{Me}_{2} \mathrm{P}\left(\mathrm{CH}_{2}\right) \mathrm{PMe}_{2}\right]$ 
NOTE: Again, for clarity and conciseness, compounds that are discussed in the text have been numbered (by Chapter); for the reader's convenience, a summary of these designations is given below:

Complex

Chapter 1:
Designation

1

2

3

4

5

6

7

8

9

10

(dippe) $\operatorname{Pt}(\mu-\mathrm{Me})(\mu-\mathrm{H}) \mathrm{YbCp}_{2}{ }_{2}$

$\begin{array}{lll}\text { Chapter 2: } & {\left[(\text { dippe)PtH }]_{2}\right.} & 1\end{array}$

[(dcype)PtH]2

$\left[(\text { dtbpe)PtH }]_{2}\right.$

(dippe) $\mathrm{PtH}_{2}$

(dcype) $\mathrm{PtH}_{2}$

(dtbpe) $\mathrm{PtH}_{2}$

$\mathrm{Cp}_{2}^{*} \mathrm{Yb}$


$\begin{array}{lll}\text { Chapter 3: } & \mathrm{Cp}^{*}{ }_{2} \mathrm{Yb} & 1\end{array}$

$\begin{array}{cc}\mathrm{Cp}_{2}{ }_{2} \mathrm{Yb}\left(\mathrm{PMe}_{3}\right)_{2} & \mathbf{2} \\ \mathrm{Cp}_{2}{ }_{2} \mathrm{Yb}\left(\mathrm{PEt}_{3}\right) & \mathbf{3} \\ \mathrm{Cp}^{*}{ }_{2} \mathrm{Yb}\left(\mathrm{PMe}_{3}\right) & \mathbf{4} \\ \mathrm{Cp}_{2}{ }_{2} \mathrm{Yb}(\mathrm{dmpm}) & \mathbf{5} \\ \mathrm{Cp}^{*}{ }_{2} \mathrm{Yb}\left(1,2-\left(\mathrm{PMe}_{2}\right) \mathrm{C}_{6} \mathrm{H}_{4}\right) & \mathbf{6} \\ \mathrm{Cp}^{*}{ }_{2} \mathrm{Yb}\left(\mathrm{OPMe}_{3}\right) & \mathbf{7} \\ \mathrm{Cp}^{*}{ }_{2} \mathrm{Yb}\left(\mathrm{OPMe}_{3}\right)_{2} & \mathbf{8} \\ \mathrm{Cp}^{*}{ }_{2} \mathrm{Yb}\left(\mathrm{HNPEt}_{3}\right) & \mathbf{9} \\ \left.\mathrm{Cp}^{*}{ }_{2} \mathrm{Yb}(\mathrm{HNPE})_{3}\right)_{2} & \mathbf{1 0} \\ \mathrm{Cp}^{*}{ }_{2} \mathrm{Yb}\left(\mathrm{Et}_{3} \mathrm{PNSiMe}_{3}\right) & \mathbf{1 1} \\ \mathrm{Cp}^{*}{ }_{2} \mathrm{Yb}\left(\mathrm{Me}_{2} \mathrm{PhPCHSiMe}_{3}\right) & \mathbf{1 2} \\ \mathrm{Cp}_{2}{ }_{2} \mathrm{Yb}\left(\mathrm{Me}_{2} \mathrm{PhPCH}_{2}\right) & \mathbf{1 3}\end{array}$

$\begin{array}{lll}\text { Chapter 4: } & \mathrm{Cp}^{*}{ }_{2} \mathrm{Yb} & 1\end{array}$

$\begin{array}{cc}(\mathrm{dcype}) \mathrm{Pt}(\mathrm{Np})(\mathrm{H}) & 2 \\ (\text { dcype }) \mathrm{Pt}(\mu-\mathrm{H})\left(\mu-\mathrm{CH}_{2} \mathrm{C}_{4} \mathrm{Me}_{4}\right) \mathrm{YbCp}^{*} & 3 \\ \left(\mathrm{Mes}_{2} \mathrm{SiH}\right)_{2} & 4 \\ \mathrm{Me}_{3} \mathrm{SnH} & 5 \\ \mathrm{Cp}_{2}{ }_{2} \mathrm{Yb} \cdot(\text { toluene }) & 6\end{array}$




\section{INTRODUCTION}

Weak interactions in solution between organometallic complexes and organic substrates have been implicated in a variety of important reactions, including $\mathrm{C}-\mathrm{H}$ bond activation, $^{1 a-b}$ the Ziegler-Natta polymerization of olefins, $1 \mathrm{c}-\mathrm{f}$ and more generally, any chemical reaction that occurs in the solution-state. For the purposes of this work, a weak interaction will be considered one whose enthalpy of formation is $\leq 20 \mathrm{kcal} \mathrm{mol}^{-1}$. Chemical forces can be qualitatively ordered as follows: ${ }^{2}$ covalent, ionic, ion-dipole, dipole-dipole, ion-induced dipole, dipole-induced dipole, and London dispersion interactions; the interactions discussed in this work fall into the latter categories of this classification scheme. While solid-state structural studies have been informative with respect to clarifying the structural perturbations that result from such interactions (e.g., structures of agostic complexes, ${ }^{3 a} \eta_{2}-\mathrm{H}_{2}$ complexes, ${ }^{3 b, c}$ etc.), very little is known about the structural and electronic perturbations resulting from such "weak" interactions in the solution state. Consequently, a more thorough understanding of the electronic and geometric consequences of such interactions in solution is desirable.

NMR spectroscopy is an ideal tool for investigating weak interactions in solution. Both chemical shifts and spin-spin coupling constants are sensitive to small electronic and structural changes, as would be expected to result from weak interactions. The abundance of NMR-active nuclei with nuclear spins of $1 / 2$ throughout the Periodic Table makes NMR spectroscopy applicable to many different systems, allowing a thorough study of the effects of weak interactions on a variety of systems. For each individual system, this abundance gives the possibility of several different NMR-active nuclei being present, giving multiple probes of the perturbations that result from the interactions under investigation. Also, the relatively large temperature range accessible using NMR spectroscopy allows the study of a range of interactions of varying strengths. 
Bis(pentamethylcyclopentadienyl)ytterbium, $\mathrm{Cp}_{2}{ }_{2} \mathrm{Yb}$, is an ideal complex for studying weak interactions in solution via NMR spectroscopy. This lanthanide metallocene complex has a bent geometry in both the gas and solid phases, ${ }^{4}$ a fact that has been rationalized in a variety of ways..$^{5}$ The geometry results in a low steric barrier to ligand binding as the molecular geometry changes only slightly upon binding of an additional ligand(s) $\left(\mathrm{Cp}^{*}{ }_{2} \mathrm{Yb}\right.$ can be considered to be "pre-organized" with respect to binding of an additional ligand). The bonding between the $\mathrm{Yb}$ center and the ligands in $\mathrm{Cp}^{*}{ }_{2} \mathrm{YbL}_{\mathrm{n}}$ adducts (and in lanthanide complexes in general) is mainly ionic in nature, ${ }^{6} \mathrm{a}$ result of shielding of the $4 \mathrm{f}$ valence orbitals by the filled $5 \mathrm{~s}$ and $5 \mathrm{p}$ orbitals. This results in a low electronic barrier to ligand binding. Any molecule that possesses a permanent dipole moment, or is relatively easily polarized, is a potential ligand for $\mathrm{Cp}_{2}{ }_{2} \mathrm{Yb}$. The metal center in this complex is in the +2 oxidation state (relatively rare for the lanthanide elements ${ }^{6}$ ), resulting in a $4 \mathrm{f}^{14}$ diamagnetic electronic configuration. This, combined with the ${ }^{171} \mathrm{Yb}$ isotope (14.3\% nat. abundance, $\left.\mathrm{I}=1 / 2\right)$, makes $\mathrm{Cp}^{*}{ }_{2} \mathrm{Yb}$ a favorable complex for NMR spectroscopic investigations. Thus, $\mathrm{Cp}_{2}{ }_{2} \mathrm{Yb}$ is a Lewis acidic, diamagnetic complex with an intrinsically low electronic and steric barrier for ligand binding, and it possesses an NMR-active metal isotope.

Considering these properties, it is not surprising that evidence of weak interactions in solution involving $\mathrm{Cp}_{2}{ }_{2} \mathrm{Yb}$ has been reported. For example, the polymerization of ethylene by $\mathrm{Cp}_{2}{ }_{2} \mathrm{Yb}$ is inhibited by the presence of $\mathrm{H}_{2}, \mathrm{CO}$, methane, and xenon (eqs. 1 , 2), ${ }^{7}$ consistent with a weak interaction between these gaseous molecules and the $\mathrm{Yb}$ center. The polymerization rate was found to be slower in toluene than in aliphatic hydrocarbon solvents (eq. 3), consistent with a weak interaction formed between $\mathrm{Cp}^{*}{ }_{2} \mathrm{Yb}$ and toluene (presumably involving the $\pi$ aromatic system of toluene). Similarly, toluene has been found to enhance the rate of intermolecular exchange for the adduct $\left(\mathrm{PPh}_{3}\right)_{2} \mathrm{Pt}\left(\mu-\mathrm{C}_{2} \mathrm{H}_{4}\right) \mathrm{YbCp}_{2}{ }_{2}$ (eq. 4$)^{7}$ relative to the exchange rate in benzene; toluene 
would be expected to be a better ligand than benzene towards $\mathrm{Cp}^{*}{ }_{2} \mathrm{Yb}$ as a result of its more electron-rich $\pi$ aromatic system.

$$
\begin{aligned}
& \mathrm{Cp}_{2}^{*} \mathrm{Yb} \\
& \stackrel{\mathrm{C}_{2} \mathrm{H}_{4}(7 \mathrm{~atm} .)}{\longrightarrow} \\
& \mathrm{Cp}_{2}^{*} \mathrm{Yb} \\
& \begin{array}{c}
\frac{\mathrm{C}_{2} \mathrm{H}_{4}(7 \mathrm{~atm} .)}{\mathrm{H}_{2}, \mathrm{CO}, \mathrm{CH}_{4}, \mathrm{Xe}(7} \\
\frac{\mathrm{C}_{2} \mathrm{H}_{4}(7 \mathrm{~atm} .)}{\text { Solvent }}
\end{array} \\
& \mathrm{Cp}_{2}^{*} \mathrm{Yb} \\
& \text { polyethylene } \\
& \text { No polymerization. } \\
& \text { polyethylene } \\
& \mathrm{Cp}_{2}{ }_{2} \mathrm{Yb}+\left(\mathrm{PPh}_{3}\right)_{2} \mathrm{Pt}\left(\mathrm{C}_{2} \mathrm{H}_{4}\right) \underset{\text { Solvent }}{\rightleftharpoons}\left(\mathrm{PPh}_{3}\right)_{2} \mathrm{Pt}\left(\mu-\mathrm{C}_{2} \mathrm{H}_{4}\right) \mathrm{YbCp}_{2}{ }_{2} \\
& \text { Exchange rate: Solvent }=\text { toluene }>\text { benzene } \text {. }
\end{aligned}
$$

It has also been reported that a weak interaction is formed in solution between the paramagnetic complex $\mathrm{Cp}_{2}{ }_{2} \mathrm{Eu}$ and $\mathrm{H}_{2}, \mathrm{C}_{2} \mathrm{H}_{4}$, based on the paramagnetic shifting and broadening of the ${ }^{1} \mathrm{H}$ resonances of these small molecules in the presence of $\mathrm{Cp}_{2}{ }_{2} \mathrm{Eu}^{8}{ }^{8}$

Several $\mathrm{Cp}_{2}{ }_{2} \mathrm{YbL}_{\mathrm{n}}$ complexes, where $\mathrm{L}$ is a neutral, non-classical Lewis base, have been structurally characterized, ${ }^{9}$ and three examples of these are shown below (Fig. 1).
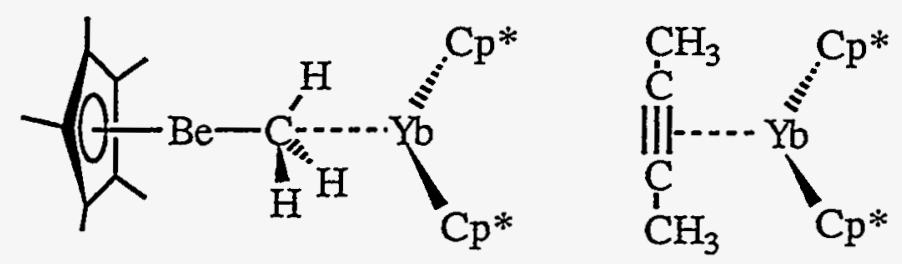

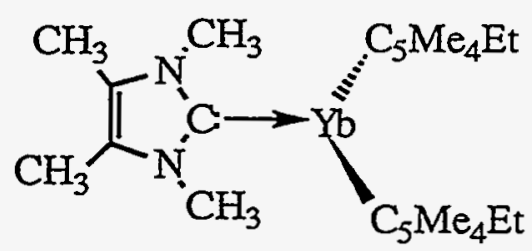

Figure 1. Several $\mathrm{Cp}^{\#} \mathrm{YbL}_{\mathrm{n}}$ complexes $\left(\mathrm{Cp}^{\#}=\mathrm{a} \mathrm{Cp}\right.$ derivative; $\mathrm{L}=$ a neutral ligand) that have been structurally characterized. 9

In general, only minor changes in the solid-state parameters are found upon complexation of a ligand, $\mathrm{L}$, to $\mathrm{Cp}_{2}{ }_{2} \mathrm{Yb}$. The IR spectra of the adducts are also unperturbed relative to the spectra of the free complexes. Given this, it is not surprising that all $\mathrm{Cp}_{2}{ }_{2} \mathrm{YbL}_{\mathrm{n}}$ 
adducts ( $L=$ a neutral ligand) studied to-date have been found to undergo fast intermolecular exchange on the NMR timescale at all temperatures, with relatively minor perturbations in the NMR chemical shift values, relative to those of the free complexes. 7,9 This is a result of small kinetic barriers to intermolecular exchange in solution for $\mathrm{Cp}_{2}{ }_{2} \mathrm{YbL}_{\mathrm{n}}$ complexes, indicative of the thermodynamic weakness of the interactions (a justification of this statement will be given in Chapter 3). Consequently, while indirect evidence of weak interactions in solution involving $\mathrm{Cp}^{*}{ }_{2} \mathrm{Yb}$ has been observed (as discussed above), there has been very little direct investigation of the electronic and structural perturbations that result from these interactions, since only averaged NMR spectra have been observed.

While there have been several recent reports of $\mathrm{Yb}(I I)$ adducts that undergo slow intermolecular exchange in solution on the NMR timescale (based on the observation of coupling between the ${ }^{171} \mathrm{Yb}$ nucleus and nuclei on the ligand), ${ }^{10}$ all of these complexes contain anionic ligands and thus the $\mathrm{Yb}-\mathrm{L}$ interactions are relatively strong, ionic interactions (Fig. 2).

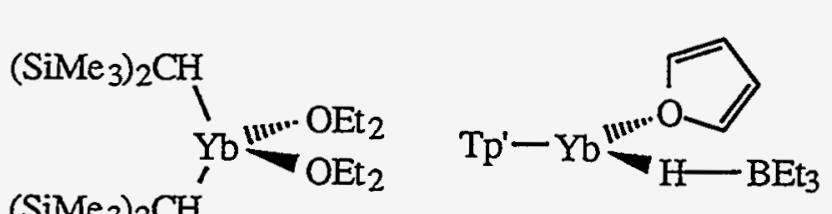
$\left(\mathrm{SiMe}_{3}\right)_{2} \mathrm{CH}$

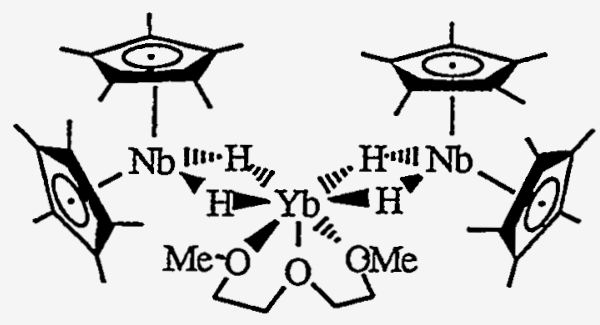

Figure 2. Examples of $\mathrm{Yb}$ (II) complexes that undergo slow exchange in solution, on the NMR timescale ( $\mathrm{Tp}^{\prime}=$ Hydrotris(3-tert-butyl-5-methylpyrazolyl)borate). $10 \mathrm{c}$-e In the first complex, the alkyl groups undergo slow exchange; in the latter two complexes, the hydride ligands undergo slow exchange.

The goal of the present work was to synthesize $\mathrm{Cp}^{*}{ }_{2} \mathrm{YbL}_{\mathrm{n}}$ adducts $(\mathrm{L}=\mathrm{a}$ weakly coordinated, neutral ligand) for which intermolecular exchange is slow on the NMR timescale. For such slow-exchange systems, the discrete spectral values of the adducts will be observable (in contrast to fast-exchange adducts, for which exchange-averaged 
NMR values are observed), thus allowing a thorough, systematic investigation of the solution-state perturbations that result from the weak $\mathrm{Yb}-\mathrm{-} \mathrm{L}$ interactions. Correlation of the solution-state data with the solid-state structural parameters of the adducts is also desirable, in order to gain a more thorough understanding of the electronic.and structural consequences of the weak interactions.

Two classes of ligands that result in slow exchange systems with $\mathrm{Cp}_{2}^{*} \mathrm{Yb}$ have been investigated. The interactions of $\mathrm{Cp}_{2}{ }_{2} \mathrm{Yb}$ with cis- $\mathrm{P}_{2} \mathrm{PtXY}$ complexes $(\mathrm{X}, \mathrm{Y}=\mathrm{H}$, Me) are described in Chapter 1 . Chapter 3 describes the interactions that are formed between $\mathrm{Cp}_{2}{ }_{2} \mathrm{Yb}$ and phosphines and phosphine derivatives. An investigation of the solution state instability of cis- $\mathrm{P}_{2} \mathrm{PtH}_{2}$ complexes, discovered during the investigations described in Chapter 1, is discussed in Chapter 2. Lastly, Chapter 4 describes the results of an investigation of the interactions formed between $\mathrm{Cp}_{2}{ }_{2} \mathrm{Yb}$ and small molecules such as $\mathrm{H}_{2}, \mathrm{C}_{6} \mathrm{H}_{6}, \mathrm{CO}$, etc., as well as synthetic attempts towards a $\mathrm{P}_{2} \mathrm{Pt}-\mathrm{YbCp}_{2}{ }_{2}$ heterobimetallic complex.

The ${ }^{171} \mathrm{Yb}$ isotope allows a direct probe of the electronic perturbations resulting from the weak interactions under investigation, at the metal center itself. Recently, ${ }^{171} \mathrm{Yb}$ NMR has been receiving increasing attention. The first report of direct ${ }^{171} \mathrm{Yb}$ NMR was made in $1989.10 \mathrm{~b}$ There have since been several reports of direct-detected ${ }^{171} \mathrm{Yb}$ NMR ${ }^{10,11}$ and several reports of the observation of J $\mathrm{YbX}_{\text {coupling. }} 10$ However, direct detection of ${ }^{171} \mathrm{Yb}$ is time-consuming, a result of long $\mathrm{T}_{1}$ relaxation times, broad resonances, and relatively low sensitivity. $10 \mathrm{~b}$ Given that the goal of the present work is to study slow-exchange $\mathrm{Cp}_{\mathrm{p}}{ }_{2} \mathrm{YbL}_{\mathrm{n}}$ adducts, $\mathrm{J}_{\mathrm{YbX}}$ coupling ( $\mathrm{X}=$ nuclei on the ligand, $\mathrm{L}$ ) will presumably be present. This allows the use of the Heteronuclear Multiple Quantum Coherence (HMQC) pulse sequence ${ }^{12}$ for indirect detection of ${ }^{171} \mathrm{Yb}$, via the $\mathrm{X}$ nucleus. The HMQC pulse sequence allows detection of ${ }^{171} \mathrm{Yb}$ with the sensitivity of the $\mathrm{X}$ nucleus (i.e., ${ }^{1} \mathrm{H}$ sensitivity for $\mathrm{J}_{\mathrm{YbH}}$ coupling), resulting in a dramatic decrease in acquisition time (roughly 5800X faster for equivalent $\mathrm{S} / \mathrm{N}$ relative to direct detection of 
${ }^{171} \mathrm{Yb}$, for $\left.\mathrm{X}={ }^{1} \mathrm{H}\right)$. The relative signs of coupling constants can also be obtained from HMQC spectra (in contrast to 1-D spectra), giving additional information concerning the interactions under investigation. The use of the HMQC pulse sequence for ${ }^{171} \mathrm{Yb}$ detection has not been previously reported; the application of this technique for indirect detection of $171 \mathrm{Yb}$ is described throughout this work, and is discussed in detail in Chapter 4. 
References.

(1) (a) Brookhart, M.; Green, M. L. H.; Wong, L. L. Prog. Inorg. Chem. 1988, 36, 1. (b) Arndsten, B. A.; Bergman, R. G.; Mobley, T. A.; Peterson, T. H. Acc. Chem. Res. 1995, 28, 154. (c) Jordan, R. F. Adv. Organomet. Chem. 1991, 32, 325. (d) Cossee, P. J. Catal. 1964, 3, 80. (e) Arlman, E. J.; Cossee, P. J. Catal. 1964, 3, 99. (f) Leclerc, M. K.; Brintzinger, H. H. J. Am. Chem. Soc. 1995, 117, 1651.

(2) Huheey, J. E. In Inorganic Chemistry, Principles of Structure and Reactivity, 3rd ed.; Harper \& Row: New York, 1983; Ch. 6.

(3) (a) Crabtree, R. H. Angew. Chem., Int. Ed. Engl. 1993, 32, 789; and references therein. (b) Crabtree, R. H. Acc. Chem. Res. 1990, 23, 95. (c) Kubas, G. J. Acc. Chem. Res. 1988, 21, 120.

(4) Andersen, R. A.; Boncella, J. M.; Burns, C. J.; Blom, R.; Haaland, A.; Volden, H. V. J. Organomet. Chem. 1986, 312, C49.

(5) (a) Andersen, R. A.; Boncella, J. M.; Burns, C. J.; Green, J. C.; Hohl, D.; Rosch, N. J. Chem. Soc., Chem. Commun. 1986, 405. (b) Hollis, T. K.; Burdett, J. K.; Bosnich, B. Organometallics. 1993, 12, 3385. (c) Green, J. C.; Hohl, D.; Rosch, N. Organometallics. 1987, 6, 712. (d) DeKock, R. L.; Peterson, M. A.; Timmer, L. K.; Baerends, E. J.; Vernooijs, P. Polyhedron. 1990, 9, 1919.

(6) Cotton, F. A.; Wilkinson, F. In Advanced Inorganic Chemistry, 5th ed.; John Wiley \& Sons: New York, 1988; Ch. 20.

(7) Burns, C. J., Ph.D. Thesis, University of California, Berkeley, 1987.

(8) Nolan, S. P.; Marks, T. J. J. Am. Chem. Soc. 1989, 111, 8538.

(9) (a) Burns, C. J.; Andersen, R. A. J. Am. Chem. Soc. 1987, 109, 941. (b) Burns, C. J.; Andersen, R. A. J. Am. Chem. Soc. 1987, 109, 5853. (c) Burns, C. J.; Andersen, R. A. J. Am. Chem. Soc. 1987, 109, 915. (d) Schumann, H.; Glanz, M.; Winterfeld, J.; Hemling, H.; Kuhn, N.; Kratz, T. Angew. Chem., Int. Ed. Engl. 1994, $33,1733$. 
(10) (a) Karsch, H. H.; Ferazin, G.; Steigelmann, Ol; Kooijman, H.; Hiller, W. Angew. Chem., Int. Ed. Engl. 1993, 32, 1739. (b) Avent, A. G.; Edelman, M. A.; Lappert, M. F.; Lawless, G. A. J. Am. Chem. Soc. 1989, 11, 3423. (c) Green, M. L. H.; Hughes, A. K.; Michaelidou, D. M.; Mountford, P. J. Chem. Soc., Chem. Commun. 1993, 591. (d) Hasinoff, L.; Takats, J.; Zhang, X. W.; Bond, A. H.; Rogers, R. D. J. Am. Chem. Soc. 1994, 116, 8833. (e) Hitchcock, P. B.; Holmes, S. A.; Lappert, M. F.; Tian, S. J. Chem. Soc., Chem. Commun. 1994, 2691. (f) Cloke, F. G. N.; Dalby, D. I.; Hitchcock, P. B.; Karamallakis, H.; Lawless, G. A. J. Chem. Soc., Chem. Commun. 1991, 779. (g) Nief, F.; Ricard, L.; Mathey, F. Polyhedron. 1993, 12, 19. (h) Fryzuk, M. D.; Haddad, T. S.; Berg, D. J. Coord. Chem. Rev. 1990, 90, 137. (i) Deacon, G. B.; Ravety, W. D.; Vince, D. G.; J. Organomet. Chem. 1977, 135, 103.

(11) (a) Hitchcock, P. B.; Howard, J. A. K.; Lappert, M. F.; Prashar, S. J. Organomet. Chem. 1992, 437, 177. (b) van den Hende, J. R.; Hitchcock, P. B.; Lappert, M. F. J. Organomet. Chem. 1994, 472, 79. (c) Strzelecki, A. R.; Timinski, P. A.; Helsel, B. A.; Bianconi, P. A. J. Am. Chem. Soc. 1992, 114, 3159.

(12) (a) Bax, A.; Griffey, R. H.; Hawkins, B. L. J. Magn. Reson. 1983, 55, 301. (b) Bax, A.; Subramanian, S. J. Magn. Reson. 1986, 67, 565. 


\section{CHAPTER 1}

\section{Interactions of $\mathrm{Cp}_{2}{ }_{2} \mathrm{Yb}$ with cis- $\mathbf{P}_{2}$ PtXY Complexes ( $\mathrm{X}, \mathrm{Y}=\mathrm{H}, \mathrm{Me}$ )}

The recent reports of spin-spin coupling between ytterbium and hydrogen in dtransition metal hydride anions ${ }^{1 \mathrm{a}}$ and in $\mathrm{a}\left(\mu-\mathrm{HBEt}_{3}\right)$ adduct of $\mathrm{Yb}(\mathrm{II})^{1 \mathrm{~b}}$ indicates that the hydride ligand, in the appropriate chemical environment, gives slow exchange systems with $\mathrm{Yb}(\mathrm{I})$ complexes. Considering these reports, cis $-\mathrm{P}_{2} \mathrm{PtH}_{2}$ complexes appeared to be good candidates for giving slow-exchange $\mathrm{Cp}_{2}{ }_{2} \mathrm{YbL}$ adducts amenable to NMR study. These Pt hydride complexes have relatively large dipole moments ${ }^{2}$ and sterically accessible hydride ligands that are expected to bind to $\mathrm{Cp}^{*}{ }_{2} \mathrm{Yb}$ in a bidentate coordination mode, which will presumably favor slow exchange behavior. The resultant compounds possess several NMR-active isotopes $\left({ }^{1} \mathrm{H},{ }^{31} \mathrm{P},{ }^{195} \mathrm{Pt}\right)$ near the Lewis acid-base binding site. These bis(phosphine)platinum complexes should also allow an investigation of the effects of steric and electronic changes upon the $\mathrm{Yb}-\mathrm{L}$ interaction: the P-Pt-P bite angle can easily be changed, the alkyl groups of the bidentate phosphine ligand can be varied, and the $\mathrm{X}$ and $\mathrm{Y}$ ligands of the $\mathrm{P}_{2} \mathrm{PtXY}$ complex can be modified to include other interesting ligands (e.g., Me, larger alkyl groups, $\mathrm{F}, \mathrm{SiR}_{3}$, etc.); and the resulting effects on the Yb-L interactions can be investigated.

Interactions with $\left(\mathrm{R}_{2} \mathbf{P}\left(\mathrm{CH}_{2}\right)_{2} \mathbf{P R}_{2}\right) \mathbf{P t H}_{2}$ Complexes. Addition of a colorless toluene solution of (dtbpe) $\mathrm{PtH}_{2}(2),{ }^{3}$ to a brown toluene solution of $\mathrm{Cp}_{2}{ }_{2} \mathrm{Yb}$ (1) at room temperature results in the immediate precipitation of a maroon solid, formulated as (dtbpe) $\mathrm{Pt}(\mu-\mathrm{H})_{2} \mathrm{YbCp}_{2}{ }_{2}(3)$, in quantitative yield. The solid-state infrared spectrum of this complex shows intense $v(M-H)$ bands at 1925 and $1898 \mathrm{~cm}^{-1}$, shifted from the single broad absorption of $1988 \mathrm{~cm}^{-1}$ for 2 . While this shift to lower energy is characteristic of bridging Pt hydride ligands, it is a smaller perturbation than is generally observed, ${ }^{4}$ indicating that the $\mathrm{Yb}$-hydride interactions are relatively weak. The adduct is 
completely insoluble in hexane, toluene, and diethyl ether. Although it dissolves in tetrahydrofuran-d8 to give a maroon solution, the ${ }^{1} \mathrm{H}$ and ${ }^{31} \mathrm{P}$ NMR data show that the solution contains free 2 and the known $\mathrm{Cp} *_{2} \mathrm{Yb}(\text { thf })_{2}$ adduct. 5 Integration of the proton NMR spectrum of this sample shows that 3 is indeed a 1:1 adduct. The solubility properties of 3 recluded further study of this complex.

Allowing 1 to react with one equivalent of (dcype) $\mathrm{PtH}_{2}$ (4) in toluene gives a dark blue solution. Slow cooling of this solution to $-80^{\circ} \mathrm{C}$ gives dark maroon crystals of the $1: 1$ complex, (dcype) $\mathrm{Pt}(\mu-\mathrm{H})_{2} \mathrm{YbCp}_{2}{ }_{2}(5)$ in $75 \%$ yield. This complex shows a broad band at $1889 \mathrm{~cm}^{-1}$ in its solid-state infrared spectrum, shifted to lower energy relative to the $v(M-H)$ bands for 4, at 1986 and $1979 \mathrm{~cm}^{-1}$. Crystals of 5, isolated from toluene, do not redissolve in toluene. Consequently, the NMR data discussed below were obtained on a sample that was made by dissolving 4 and a slight excess of 1 in $\mathrm{C}_{6} \mathrm{D}_{6}$. This sample will hereafter be referred to as either the 1:1 sample, or simply as the complex 5 . The room temperature ${ }^{1} \mathrm{H}$ and ${ }^{31} \mathrm{P}\left\{{ }^{1} \mathrm{H}\right\}$ NMR spectra of 4 and the $1: 1$ sample are shown in Figure 1. In addition to the expected spin-spin coupling of the hydride nuclei to the two phosphorus nuclei and to the ${ }^{195} \mathrm{Pt}$ isotope ( $\mathrm{I}=1 / 2,33.8 \%$ natural abundance), oupling to ${ }^{171} \mathrm{Yb}$ is also present in the ${ }^{1} \mathrm{H}$ NMR spectrum of 5 (Fig. $1 \mathrm{~b},{ }^{1} \mathrm{~J}_{\mathrm{YbH}}=180$ $\mathrm{Hz}$ ). Coupling of the phosphorus nuclei to ${ }^{171} \mathrm{Yb}$ is also present (Fig. 1d, JYbP $=93$ $\mathrm{Hz}$ ), the intensity of each satellite being $c a .7 \%$ the intensity of the major resonance, as expected. The presence of these couplings indicate that intermolecular exchange is slow on the NMR timescale, at $25^{\circ} \mathrm{C}$.

Interestingly, while intermolecular exchange does not occur at $25^{\circ} \mathrm{C}$ for a sample of 1 and 4 containing a slight excess of $\mathbf{1}$, this is not true for a sample containing an excess of 4. Fast intermolecular exchange is observed at $25^{\circ} \mathrm{C}$ on the NMR timescale, when 1 and 4 are mixed in a 1:2 molar ratio. The spectra show broadened resonances, coupling to ${ }^{171} \mathrm{Yb}$ is no longer observed, and the chemical shift and coupling constant values are averages of the stopped exchange values and the values for free 1 and 4 . 


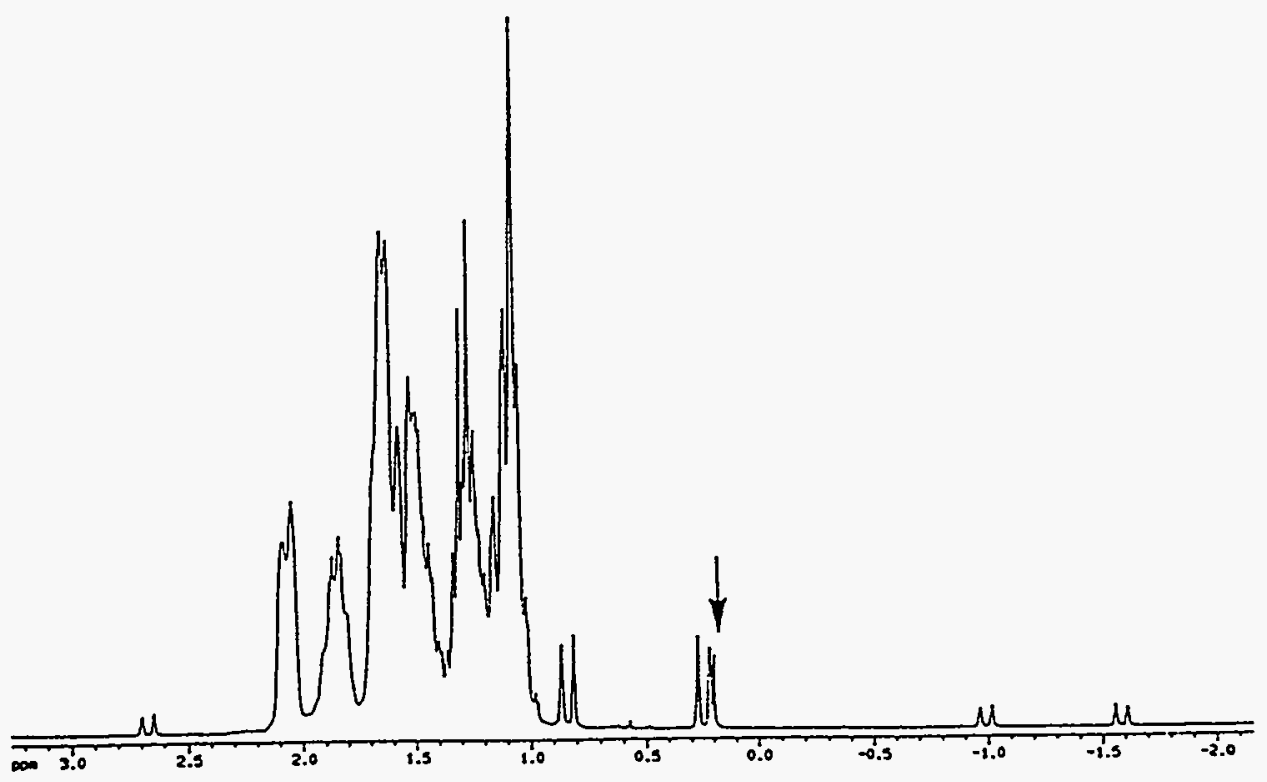

(a)

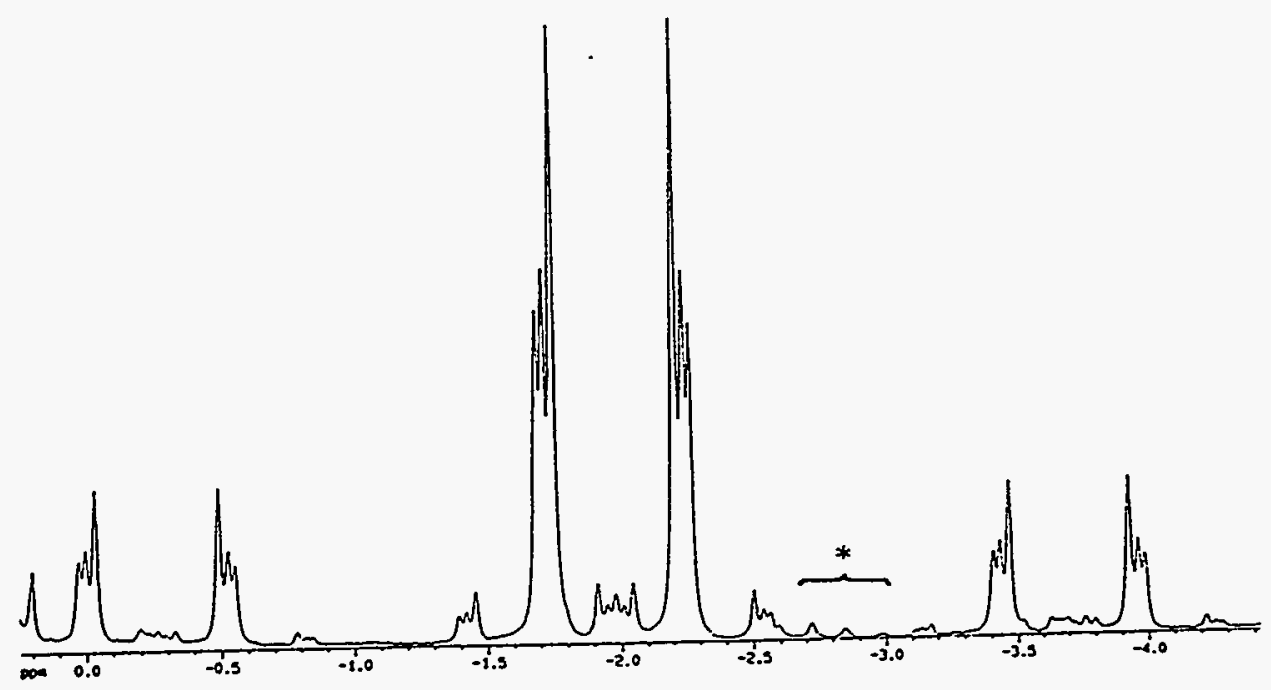

(b)

Figure 1. ${ }^{1} \mathrm{H}$ and ${ }^{31} \mathrm{P}\left\{{ }^{1} \mathrm{H}\right\}$ NMR spectra of 4 and $5\left(\mathrm{C}_{6} \mathrm{D}_{6}, 25^{\circ} \mathrm{C}\right)$, (a) ${ }^{1} \mathrm{H}$ spectrum of $4\left(300 \mathrm{MHz}\right.$; a minor grease impurity is marked with an asterisk, (b) ${ }^{1} \mathrm{H}$ spectrum of 5 ( $300 \mathrm{MHz}$; hydride region; a minor impurity is marked with an asterisk). 


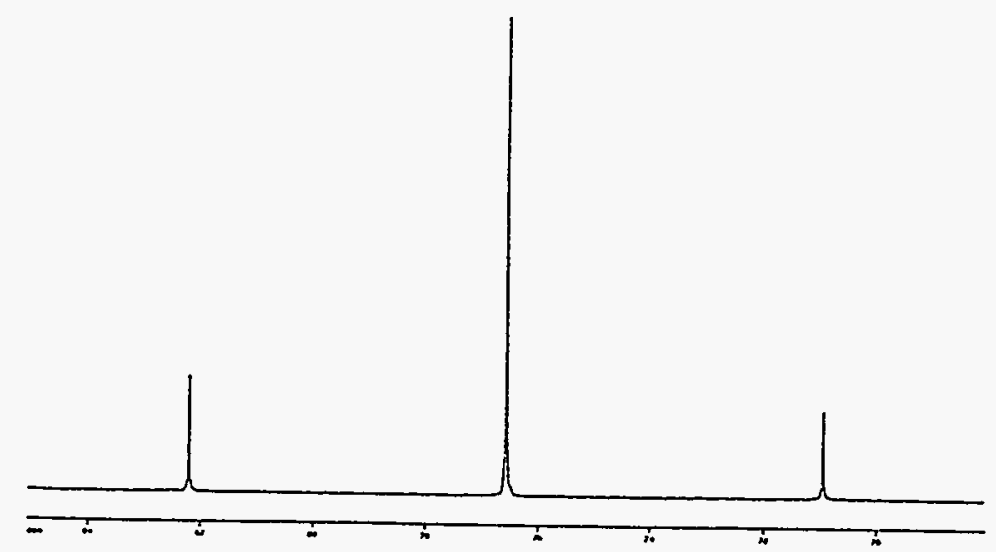

(c)

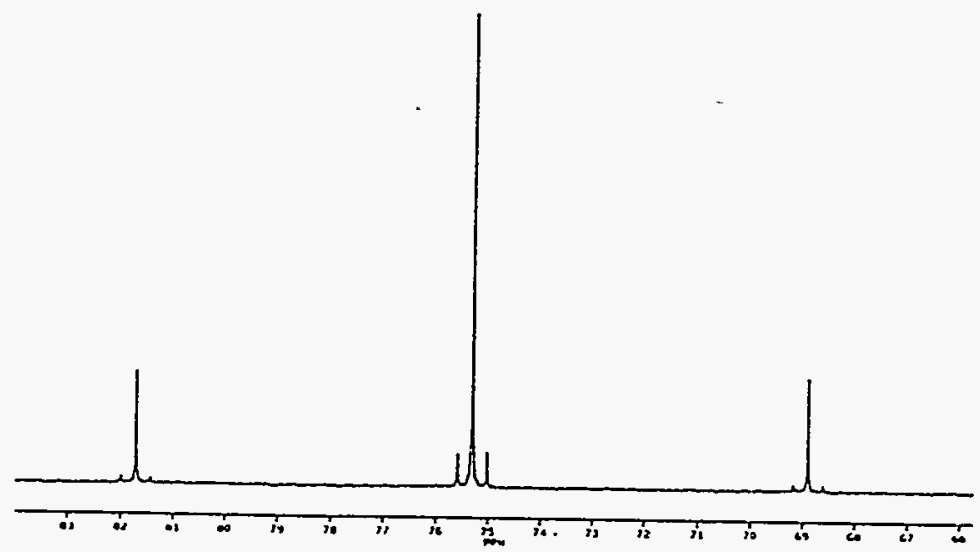

(d)

Figure 1 (continued). ${ }^{1} \mathrm{H}$ and ${ }^{31} \mathrm{P}\left\{{ }^{1} \mathrm{H}\right\}$ NMR spectra of 4 and $5\left(\mathrm{C}_{6} \mathrm{D}_{6}, 25^{\circ} \mathrm{C}\right)$, (c) ${ }^{31} \mathrm{P}\left\{{ }^{1} \mathrm{H}\right\}$ spectrum of $4(162 \mathrm{MHz})$, (d) ${ }^{31} \mathrm{P}\left\{{ }^{1} \mathrm{H}\right\}$ spectrum of $5(162 \mathrm{MHz})$. 
This result may be rationalized by assuming that an associative exchange mechanism occurs when 4 is present in excess, the transition state involving interaction of an $\mathrm{Yb}$ center with one hydride ligand on each of two different molecules of 4 , as shown in Figure 2. If the exchange mechanism were dissociative, the presence of excess 4 would have a negligible effect on the exchange rate. Presumably, the steric bulk of the $\mathrm{Cp}^{*}$ rings prevents two molecules of 1 from simultaneously coordinating to one molecule of 4 (Fig. 2), resulting in a higher barrier and therefore slow exchange behavior for a sample containing excess 1 . It is likely that, in the absence of excess 4 (i.e., when 1 is present in excess) the exchange mechanism is dissociative, with a higher barrier than the barrier for the associative mechanism; this will be discussed in more detail in Chapter 3.

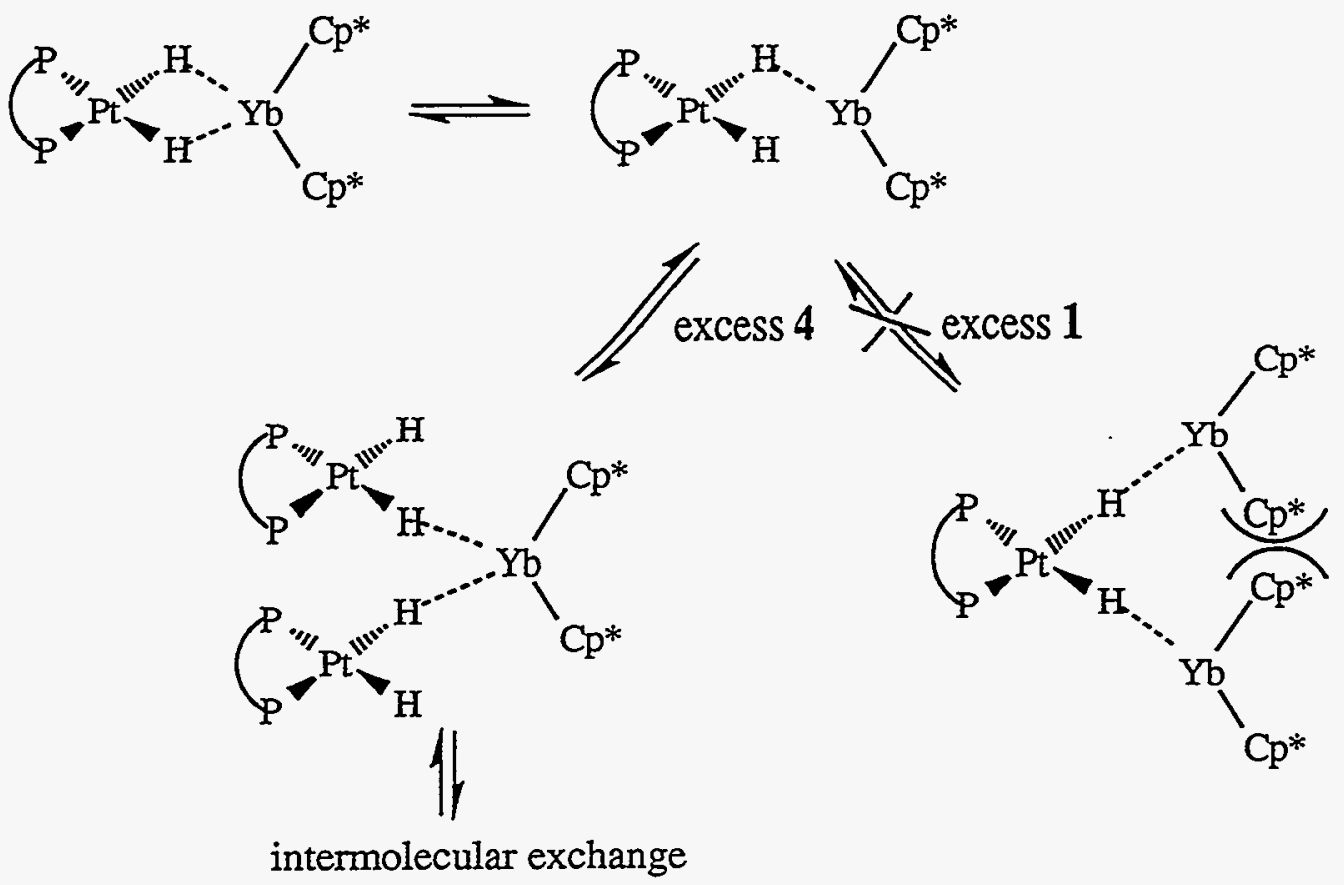

Figure 2. Proposed exchange mechanism for a sample of 1 containing an excess of 4 .

In contrast to 3 , dissolution of 5 in tetrahydrofuran- $\mathrm{d}_{8}$ does not result in complete cleavage of the 1:1 complex formed from 1 and 4 . Rather, values intermediate between the stopped-exchange values of the 1:1 sample (in $\mathrm{C}_{6} \mathrm{D}_{6}$ ) and the values of free 4 in tetrahydrofuran- $\mathrm{d}_{8}$ are observed, along with broadened resonances and loss of coupling 
to ${ }^{171} \mathrm{Yb}$, at $25^{\circ} \mathrm{C}$. Qualitatively, this indicates that 4 and thf are comparable Lewis bases, relative to the Lewis acid $\mathrm{YbCp}^{*} 2$ (keeping in mind that thf is present in large excess in this sample). The apparent relative basicity series is: thf $\approx($ dcype $) \mathrm{PtH}_{2}(4)>$ (dtbpe) $\mathrm{PtH}_{2}$ (2). This difference between 2 and 4 may be the result of steric effects. The dcype derivative possesses a proton on the alpha carbon of the cyclohexyl ring, while the dtbpe derivative has only methyl groups on this carbon; this may result in destabilizing steric interactions between $\mathbf{1}$ and 2 , as compared to the steric interactions formed between 1 and 4 . Such differences in steric effects for dcype vs. dtbpe complexes will be discussed in more detail in Chapter 2.

The room temperature ${ }^{1} \mathrm{H} /{ }^{195} \mathrm{Pt}$ and ${ }^{1} \mathrm{H} /{ }^{171} \mathrm{Yb}$ correlation $2-\mathrm{D}$ spectra obtained on 5 are shown in Figures 3 and 4, respectively. These spectra, and most of the other spectra obtained to measure metal chemical shifts and coupling patterns in this work, were obtained using the 2D-HMQC pulse sequence, ${ }^{6}$ which allows indirect detection of an $\mathrm{X}$ nucleus with ${ }^{1} \mathrm{H}$ sensitivity, utilizing a $\mathrm{J}_{\mathrm{XH}}$ coupling. Couplings to ${ }^{1} \mathrm{H}$ are removed in the $\mathrm{X}$ dimension, while couplings to a different type of nucleus, $\mathrm{Y}$, in an $\mathrm{H}-\mathrm{X}$ correlation are independently retained in both dimensions, resulting in an E.COSY-like splitting pattern, ${ }^{7}$ with respect to the $\mathrm{Y}$ nucleus. Resolution of splittings into two dimensions allows easier identification of coupling constants found in lower intensity isotopomers (e.g., when $\mathrm{Y}={ }^{171} \mathrm{Yb}$ ), particularly when satellites due to these isotopomers would be obscured by other lines in the relevant 1-D spectra. A large splitting due to coupling to $Y$ in one dimension may be used to resolve a small coupling to $\mathrm{Y}$ in the other dimension, even if this small coupling is less than the linewidth in that dimension. Information about the relative signs of coupling constants may also be directly inferred from the direction of the slope in the E.COSY-like pattern. 


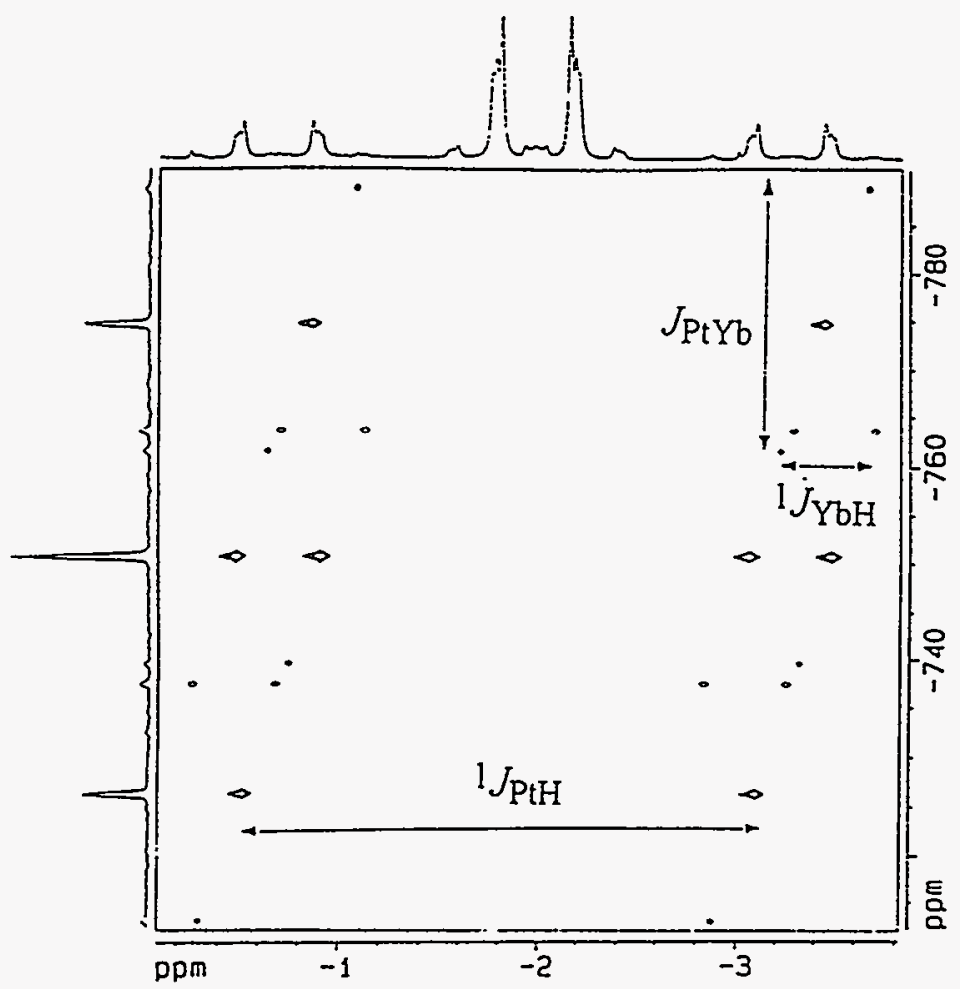

Figure 3. ${ }^{1} \mathrm{H} / 195 \mathrm{Pt}$ HMQC NMR spectrum of $5\left(400 \mathrm{MHz}, \mathrm{C}_{6} \mathrm{D}_{6}, 25^{\circ} \mathrm{C}\right)$. Annotated

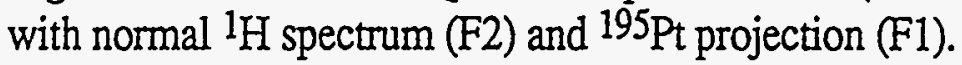

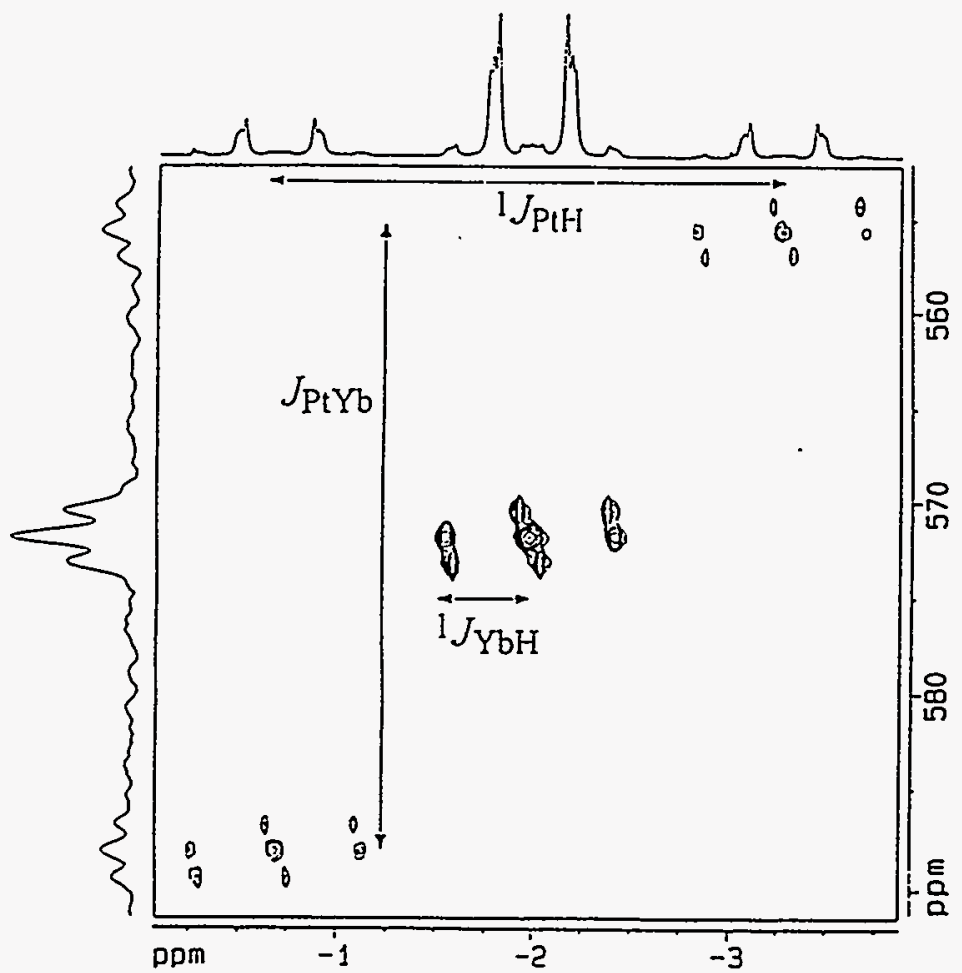

Figure 4. ${ }^{1} \mathrm{H} /{ }^{171} \mathrm{Yb}$ HMQC NMR spectrum of $5\left(400 \mathrm{MHz}, \mathrm{C}_{6} \mathrm{D} 6,25^{\circ} \mathrm{C}\right)$. Annotated with normal ${ }^{1} \mathrm{H}$ spectrum (F2) and ${ }^{171}{ }^{\mathrm{Yb}}$ projection (F1). 
In the case of 5 , the ${ }^{1} \mathrm{H} /{ }^{171} \mathrm{Yb}$ HMQC spectrum confirms that ${ }^{171} \mathrm{Yb}$ is the source of the extra satellites present in the ${ }^{1} \mathrm{H}$ and ${ }^{31} \mathrm{P}\left\{{ }^{1} \mathrm{H}\right\}$ NMR spectra (Fig. 1). In addition, the ${ }^{195 \mathrm{Pt}}$ and ${ }^{171} \mathrm{Yb}$ pseudo-spectra (vertical dimensions in Figs. 3 and 4, respectively) contain a triplet with ${ }^{171} \mathrm{Yb}$ satellites and a triplet with ${ }^{195} \mathrm{Pt}$ satellites, respectively (the triplets arise from coupling to the two phosphorus nuclei), showing that there is coupling between the metal centers. The ${ }^{1} \mathrm{H} /{ }^{195} \mathrm{Pt}$ spectrum (Fig. 3) shows that this coupling, $\mathrm{J}_{\mathrm{PtYb}}$, has the same sign as ${ }^{1} \mathrm{~J}_{\mathrm{PtH}}$. The NMR spectral values measured on 5 are presented in Table 1, along with the values for 4 . Since the signs of ${ }^{1} \mathrm{~J}_{\mathrm{PtH}}$ and ${ }^{1} \mathrm{~J}_{\mathrm{PtP}}$ are known to be positive, ${ }^{8}$ the signs of the other coupling constants can be obtained from the HMQC spectra, and are also given in Table 1.

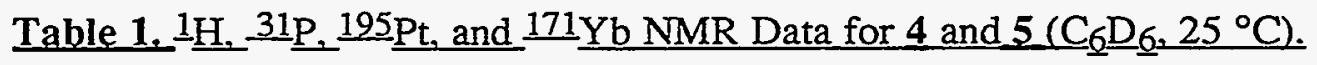

\begin{tabular}{|c|c|c|}
\hline$\delta(\mathrm{Pt}-\underline{\mathrm{H}}), \mathrm{ppm}$ & $\begin{array}{c}\underline{4} \\
0.56\end{array}$ & $\begin{array}{c}\mathbf{5} \\
-1.98\end{array}$ \\
\hline${ }^{2} \mathrm{~J}_{\mathrm{PH}}($ trans, cis), $\mathrm{Hz}$ & $+179,-16$ & $+152,-14$ \\
\hline${ }^{1} \mathrm{~J}_{\mathrm{PtH}}, \mathrm{Hz}$ & +1100 & +1031 \\
\hline$\delta(\mathrm{P}), \mathrm{ppm}$ & 76.5 & 75.4 \\
\hline${ }^{1} \mathrm{~J}_{\mathrm{PtP}}, \mathrm{Hz}$ & +1822 & +2077 \\
\hline$\delta(\mathrm{Cp} *), \mathrm{ppm}$ & $\mathrm{b}$ & 2.42 \\
\hline${ }^{1} \mathrm{~J}_{\mathrm{YbH}}, \mathrm{Hz}$ & --- & +180 \\
\hline $\mathrm{JYbP}_{\mathrm{Y}} \mathrm{Hz}$ & -- & +93 \\
\hline$\delta(\mathrm{Pt}), \mathrm{ppm}^{\mathrm{c}}$ & -862 & -751 \\
\hline$\delta(\mathrm{Yb}), \mathrm{ppm}^{\mathrm{c}}$ & $-30^{d}$ & +572 \\
\hline $\mathrm{J}_{\mathrm{YbPt}}, \mathrm{Hz}$ & -- & +2260 \\
\hline
\end{tabular}

aUnless otherwise stated, $\mathrm{J}_{\mathrm{XH}}$ pertains to the coupling constant involving the nucleus $\mathrm{X}$ and the hydride nuclei, in all Tables.

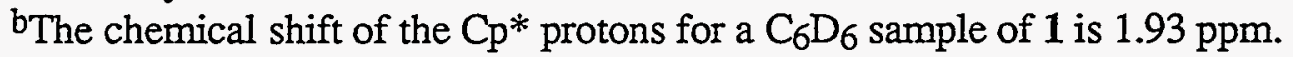

${ }^{c}$ For details of the metal chemical shift referencing, see the Experimental section. dThe ${ }^{171} \mathrm{Yb}$ chemical shift of 1 , measured at $25^{\circ} \mathrm{C}$, using indirect detection (see Chapter 4 for details).

Interaction of 1 with 4 results in several perturbations in the chemical shift and coupling constant values, compared with the values for uncomplexed 4 . Specifically, a 
significant upfield shift of $\delta(\mathrm{Pt}-\underline{\mathrm{H}})$ by $2.54 \mathrm{ppm}$ occurs, indicating that the bridging hydrides of 5 are more shielded, relative to those of 4 . The $\mathrm{Cp}^{*}$ resonance of $\mathbf{1}$ is shifted downfield by $0.47 \mathrm{ppm}$; downfield shifts of this resonance are common for $\mathrm{Cp}_{2}{ }_{2} \mathrm{YbL}_{\mathrm{n}}$ complexes, relative to the value for $1.9 \mathrm{a}, \mathrm{d}$ The interaction between 1 and 4 results in a decrease in the ${ }^{2} \mathrm{~J}_{\mathrm{PH}}$ and ${ }^{1} \mathrm{~J}_{\mathrm{PtH}}$ values, and a large increase in the ${ }^{1} \mathrm{~J}_{\mathrm{PtP}}$ value. These perturbations are easily rationalized by assuming that donation of electron density from the Pt-hydride bonds to the acidic ytterbium metal center results in a decrease in the Pt-H bond strength, and a consequent decrease in the trans influence of the hydride ligands. Bridging hydride ligands in dimeric Pt phosphine complexes generally have a lower trans influence than terminal Pt hydrides. 10 Consistent with the $\mathbb{R}$ data for 5 (see above), the ${ }^{1} \mathrm{~J}_{\mathrm{PLH}}$ value for $5(1031 \mathrm{~Hz})$ is lowered from the value for free 4 , but is still higher than is generally seen for bridging $\mathrm{Pt}$ hydrides, ${ }^{11}$ indicating that the $\mathrm{Yb}$-hydride interaction is relatively weak. Interaction of 1 with the H/D analogue of 4 , (dcype)Pt(H)(D), shows no evidence for ${ }^{1} \mathrm{~J}_{\mathrm{HD}}$ in the ${ }^{1} \mathrm{H}$ NMR spectrum; the half height width of the hydride resonance is $15 \mathrm{~Hz}$, indicating that $\mathrm{J}_{\mathrm{HD}}$ is less than $c a .8 \mathrm{~Hz}$. The ${ }^{1} \mathrm{~J}_{\mathrm{HD}}$ value for free (dcype) $\mathrm{Pt}(\mathrm{H})(\mathrm{D})$, at $25^{\circ} \mathrm{C}$ and at $-80^{\circ} \mathrm{C}$, was found to be near zero. 12

There have been few $J_{Y b H}$ and $J_{Y b P}$ values reported in the literature; the values measured on 5 are similar to the previously reported values. The ${ }^{1} \mathrm{~J}_{Y b H}$ value of $180 \mathrm{~Hz}$ found for 5 can be compared to the values of $170 \mathrm{~Hz}$ for $\left[\left\{\mathrm{Cp}_{2} \mathrm{Nb}(\mu-\right.\right.$ $\left.\mathrm{H}_{2}\right\}_{2} \mathrm{Yb}$ (diglyme)], ${ }^{\mathrm{la}}$ and $200 \mathrm{~Hz}$ for $\left[\left(\mathrm{Tp}^{\prime}\right) \mathrm{Yb}\left(\mu-\mathrm{HBEt}_{3}\right)(\right.$ thf $\left.)\right]\left(\mathrm{Tp}^{\prime}=\right.$ hydrotris(3-tertbutyl-5-methylpyrazolyl)borate). ${ }^{2}$ The ${ }^{3} \mathrm{~J}_{\mathrm{YbP}}$ value of $93 \mathrm{~Hz}$ in 5 is similar to the value of $73 \mathrm{~Hz}$ found for $\left[\left\{\left(\mathrm{PMe}_{3}\right)_{3} \mathrm{WH}_{5}\right\}_{2} \mathrm{Yb}\right.$ (diglyme) $]$, 1a in which the $\mathrm{Yb}-\mathrm{P}$ coupling is via a $\mathrm{P}-\mathrm{M}-\mathrm{H}-\mathrm{-} \mathrm{Yb}$ interaction, as in $\mathbf{5}$ (assuming that direct $\mathrm{Pt}-\mathrm{Yb}$ spin-spin communication is negligible, this will be discussed below).

The ${ }^{171} \mathrm{Yb}$ chemical shift of a sample of 1 dissolved in $\mathrm{C}_{6} \mathrm{D}_{6}$ is $-30 \mathrm{ppm}$, at $25^{\circ} \mathrm{C}$. This is similar to the values reported for $\mathrm{Cp}_{2}{ }_{2} \mathrm{Yb}(\text { thf })_{2}(0 \mathrm{ppm})$ and $\mathrm{Cp}_{2}{ }_{2} \mathrm{Yb}\left(\mathrm{Et}_{2} \mathrm{O}\right)_{2}(+36$ $\mathrm{ppm})$, both measured at $25^{\circ} \mathrm{C} \cdot 13,14 \mathrm{The} \delta(\mathrm{Yb})$ value of $+572 \mathrm{ppm}$ found for 5 at $25^{\circ} \mathrm{C}$ 
indicates a significantly deshielded ytterbium metal center, relative to that in 1 . Given the few examples of ${ }^{171} \mathrm{Yb}$ chemical shift values reported to date for $\mathrm{Cp}^{*}{ }_{2} \mathrm{YbL}_{\mathrm{n}}$ complexes, $13 \mathrm{~b}, 15$ the wide variation in these values, and the presence of fast intermolecular exchange of $\mathrm{L}$ on the NMR timescale for many of these complexes (the complexes reported here being rare examples of stopped-exchange $\mathrm{Cp}_{2}{ }_{2} \mathrm{YbL}_{\mathrm{n}}$ complexes), a correlation of ${ }^{171} \mathrm{Yb}$ chemical shifts with chemical properties is not yet possible (see Chapter 4 for further discussion of ${ }^{171} \mathrm{Yb}$ chemical shifts). The ${ }^{195} \mathrm{Pt}$ chemical shift of $5(-751 \mathrm{ppm})$ is shifted downfield from the value for $4(-862 \mathrm{ppm})$, consistent with less electron density on the platinum center in the adduct. Considering the very large range of platinum chemical shifts ( $c a .13,000 \mathrm{ppm}),{ }^{13 a}$ this is not a large perturbation. The $\mathrm{Pt}-\mathrm{Yb}$ coupling constant, $2260 \mathrm{~Hz}$, is the first transition metalytterbium coupling constant to be reported, and so no comparisons can be made. However, it is clear that there is communication between the metal nuclear spins; this will be discussed in more detail below.

To verify the nature of the Lewis acid-base interaction between 1 and 4 , a single crystal X-ray diffraction study was performed on 5. Unfortunately, the crystal was severely disordered, and only the $\mathrm{Yb}, \mathrm{Pt}$, the two $\mathrm{P}$ atoms, and rough $\mathrm{Cp} *$ ring centroid positions could be located (see the Experimental section for details). While the atomic positions have relatively large esd's associated with them, some useful information can nevertheless be obtained. The heavy atom positions are consistent with a symmetrical $\mathrm{Pt}(\mu-\mathrm{H})_{2} \mathrm{Yb}$ structure, with $\mathrm{P}(1)-\mathrm{Pt}-\mathrm{Yb}=143(1)^{\circ}, \mathrm{P}(2)-\mathrm{Pt}-\mathrm{Yb}=137(2)^{\circ}$, and the P-Pt-P plane oriented roughly perpendicular to the ( $\mathrm{Cp} *$ ring centroid)-Yb-( $\mathrm{Cp}^{*}$ ring centroid) plane, the interplanar angle being $86(2)^{\circ}$. The $\mathrm{Pt}-\mathrm{Yb}$ distance, 3.264(6) $\AA$, is $0.25 \AA$ longer than the sum of the covalent radii (the covalent radii of $\mathrm{Pt}(\mathrm{II})$ and $\mathrm{Yb}(\mathrm{II})$ are 1.31 $\AA^{16}$ and $1.70 \AA,^{17}$ respectively), indicating that the $\mathrm{J}_{\mathrm{PtYb}}$ coupling observed in solution is likely not via a direct $\mathrm{Pt}-\mathrm{Yb}$ interaction. This $\mathrm{Pt}-\mathrm{Yb}$ distance is similar to the $\mathrm{W}-\mathrm{Yb}$ separation found for $\left[\left\{\left(\mathrm{PMe}_{3}\right)_{3} \mathrm{WH}_{5}\right\}_{2} \mathrm{Yb}(\right.$ diglyme $\left.)\right](3.24 \AA)$ and to the $\mathrm{Nb}-\mathrm{Yb}$ 
separation found for $\left[\left\{\mathrm{Cp}_{2} \mathrm{Nb}(\mu-\mathrm{H})_{2}\right\}_{2} \mathrm{Yb}\right.$ (diglyme) $](3.33 \AA$ ) (the van der Waals radii of $\mathrm{W}$ and $\mathrm{Nb}$ are $1.35 \AA$ and $1.45 \AA$, respectively). 1a There has been one previous report of a complex containing both $\mathrm{Yb}$ and $\mathrm{Pt}$ centers; the $\mathrm{Pt}-\mathrm{Yb}$ separation in this complex, $\left[\left(\mathrm{Yb}(\text { thf })_{2}\left(\mathrm{C}_{5} \mathrm{H}_{4} \mathrm{PPh}_{2}\right)_{2} \mathrm{Pt}\left(\mathrm{CH}_{3}\right)_{2}\right\}\right.$ (thf)], is $5.01 \AA .18$

Interaction with (dcypp) $\mathrm{PtH}_{2}$. The energies of the frontier orbitals of a $\mathrm{P}_{2} \mathrm{Pt}$ fragment change as the P-Pt-P angle is varied. ${ }^{19}$ Specifically, the energy of the $\mathrm{P}_{2} \mathrm{Pt}$ HOMO, largely of $d\left(x^{2}-y^{2}\right)$ character, rises as this angle becomes more acute. Thus as this angle changes, the Lewis basicity of the hydride ligands of a cis- $\mathrm{P}_{2} \mathrm{PtH}_{2}$ complex would be expected to change. The P-Pt-P angles in (dcype) $\mathrm{PtH}_{2}$ (4) and (dcypp) $\mathrm{PtH}_{2}$ (6) ${ }^{12,20}$ are ca. $87^{\circ 21}$ and $103^{\circ}, 22$ respectively. The NMR spectra of a sample containing a ca. 1:1 molar ratio of 1 and 6 (with a slight excess of 1 ) indicate that intermolecular exchange is slow on the NMR timescale, at $25^{\circ} \mathrm{C}$. The ${ }^{1} \mathrm{H}$ and ${ }^{31} \mathrm{P}\left\{{ }^{1} \mathrm{H}\right\}$ spectra, as well as the ${ }^{1} \mathrm{H} /{ }^{195} \mathrm{Pt}$ and ${ }^{1} \mathrm{H} / 171 \mathrm{Yb}$ HMQC spectra (these spectra are qualitatively identical to the analogous spectra measured on 5, and are given in Appendix I), were measured on this adduct, 7 , and the spectral values obtained are given in Table 2 , along with the values for 6 .

Table 2. 1 H. 31 $\underline{\mathrm{P}}, 195 \underline{\mathrm{Pt}}$, and $171 \underline{\mathrm{Yb} N M R}$ Data for 6 and $7\left(\mathrm{C}_{6} \underline{\mathrm{D}_{6}}, 25^{\circ} \mathrm{C}\right)$

$\delta(\mathrm{Pt}-\underline{\mathrm{H}}), \mathrm{ppm}$

6

${ }^{2} \mathrm{~J}_{\mathrm{PH}}($ trans, cis), $\mathrm{Hz}$

$-1.13$

7

${ }^{1} \mathrm{JPtH}_{\mathrm{P}}, \mathrm{Hz}$

$+174,-24$

$-3.45$

$\delta(\mathrm{P}), \mathrm{ppm}$

$+1069$

$+148,-21$

${ }^{1} \mathrm{JPLP}_{\mathrm{PL}}, \mathrm{Hz}$

21.6

$+993$

$\delta(\mathrm{Cp} *), \mathrm{ppm}$

$+1897$

15.8

${ }^{1} \mathrm{~J}_{\mathrm{YbH}}, \mathrm{Hz}$

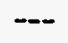

$+2090$

$\mathrm{J}_{\mathrm{YbP}, \mathrm{Hz}}$

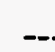

2.44

$\delta(\mathrm{Pt}), \mathrm{ppm}$

$---$

$+168$

$\delta(\mathrm{Yb}), \mathrm{ppm}$

$-861$

$+82$

$-749$

$\mathrm{JPtYb}_{\mathrm{P}} \mathrm{Hz}$

$--$

$+472$

$+2160$ 
Comparing the perturbations resulting from the interaction of 1 with 6 to the perturbations that were observed for 4 (Table 1 ) shows that they are almost identical. Apparently the interaction between cis- $\mathrm{P}_{2} \mathrm{PtH}_{2}$ complexes and $\mathbf{1}$ is not significantly affected by a change in the P-Pt-P angle, a somewhat surprising result. The two cisdihydride complexes, 4 and 6 , also behave similarly with respect to intermolecular exchange with 1 . As found for 4 , an excess of 6 results in averaged spectra, while an excess of 1 does not. The ${ }^{171} \mathrm{Yb}$ chemical shift for 7 is $+472 \mathrm{ppm}$, the analogous value for 5 is $+572 \mathrm{ppm}$; the reason for this difference, and whether it is chemically significant, is unknown. Again, the signs of the coupling constants can be determined, and are given in Table 2; the signs are the same as were found for the analogous values for 5 .

Interactions with cis- and trans-( $\left(\mathrm{PCy}_{3}\right)_{2} \mathrm{PtH}_{2}$. Given the negligible effect of the P-Pt-P angle on the NMR values of 5 and 7, it was of interest to investigate the behavior of the monodentate analogue, $\left(\mathrm{PCy}_{3}\right)_{2} \mathrm{PtH}_{2}$, with 1 . The cis complex, cis$\left(\mathrm{PCy}_{3}\right)_{2} \mathrm{PtH}_{2}$, is not isolable, being unstable with respect to isomerization to the trans complex. There are no perturbations in the room temperature ${ }^{1} \mathrm{H}$ and ${ }^{31} \mathrm{P}\left\{{ }^{1} \mathrm{H}\right\} \mathrm{NMR}$ spectral values of a $\mathrm{C}_{6} \mathrm{D}_{6}$ solution of trans-($\left(\mathrm{PCy}_{3}\right)_{2} \mathrm{PtH}_{2}{ }^{23}$ when 2 eq. of 1 are added. In addition, the chemical shift of the $\mathrm{Cp}^{*}$ resonance of this sample is unshifted relative to that of a sample of pure 1 . In contrast, exposure of a $\mathrm{C}_{6} \mathrm{D}_{6}$ solution of 1 and (PCy $)_{2} \mathrm{Pt}^{24}$ (1:1 molar ratio) to $1 \mathrm{~atm}$. of $\mathrm{H}_{2}$ results in precipitation of a dark blue solid formulated as $\left(\mathrm{PCy}_{3}\right)_{2} \mathrm{Pt}(\mu-\mathrm{H})_{2} \mathrm{YbCp}{ }_{2}$, on the basis of the similarity in color and solubility to 5 and $\mathbf{7}$, in quantitative yield within minutes (there is no interaction between 1 and $(\mathrm{PCy})_{2} \mathrm{Pt}$, even at low temperature, based on ${ }^{1} \mathrm{H}$ and ${ }^{31} \mathrm{P}$ NMR--see Chapter 4 for further details). It has been reported that addition of dihydrogen to $\left.(\mathrm{PCy})_{2}\right)_{2} \mathrm{Pt}$ at low temperature gives NMR spectra that are consistent with the cis-dihydride, but irreversible isomerization occurs at temperatures greater than $-50^{\circ} \mathrm{C} . .^{25}$ It is likely that the rapid precipitation of $(\mathrm{PCy})_{2} \mathrm{Pt}(\mu-\mathrm{H})_{2} \mathrm{YbCp}_{2}{ }_{2}$ prevents the cis-trans isomerization. The solubility properties precluded further studies of this system. 
The lack of an interaction between 1 and trans-($\left(\mathrm{PCy}_{3}\right)_{2} \mathrm{PtH}_{2}$ is intriguing. This may result from the trans orientation of the sterically bulky $\mathrm{PCy}_{3}$ ligands, prohibiting 1 from approaching the hydride ligands. Another possibility is that the lack of an interaction is the result of electronic factors. While cis dihydride complexes possess a permanent dipole moment, trans dihydride complexes do not. As the interaction between the platinum hydride complexes and $\mathbf{1}$ is largely electrostatic in nature (i.e., a Lewis acidbase interaction), it is possible that a permanent electric dipole moment is necessary for this interaction to be significant. Yet another possibility is that a trans orientation of the hydride ligands results in less electron-rich ligands, relative to the hydride ligands in a cis complex, in which the hydrides are trans to electron-rich phosphine ligands.

Interaction with (dippe)PtMe2. Considering the relatively strong interactions formed between 1 and cis- $\mathrm{P}_{2} \mathrm{PtH}_{2}$ complexes, it was of interest to investigate whether substitution of the hydrides by methyl groups would result in a similar interaction between the two complexes, via bridging methyl groups. The exact nature of the bridging methyl interactions is interesting, specifically whether the methyl groups interact with the $\mathrm{Yb}$ center via the carbon atoms (M-C-M' 3-center/2-electron interactions), the electron density in the $\mathrm{C}-\mathrm{H}$ bonds (agostic interactions), or a combination of these two possibilities. Perhaps most interesting is the nature of the interaction in solution, as measured by the methyl-related NMR spectral values, assuming that intermolecular exchange is slow. The dippe analogue, (dippe)PtMe $(8)$, was used instead of the dcype derivative, since it crystallizes more readily (the dcype derivative was found to give qualitatively identical NMR spectra as 8 , when combined with $\mathbf{1}$ ).

The complex (dippe)Pt( $(\mu-\mathrm{Me})_{2} \mathrm{YbCp}_{2}{ }_{2}$ (9) is dark green, in contrast to the maroon color of the dihydride complexes. Crystals of 9 easily dissolve in toluene (giving a dark green solution), in contrast to the behavior observed for 5 . The room temperature NMR values measured on a sample of 1 and 8 (containing a slight excess of 1 ) are shown in Table 3. Intermolecular exchange is rapid on the NMR timescale for this 
Si. le. While the intermediate exchange regime can be reached at $c a .-95^{\circ} \mathrm{C}$ in toluened\& idicated by the presence of broad but distinct resonances for both free and bound $\mathrm{Cp}$ * rings), further cooling to $-110^{\circ} \mathrm{C}$ to try to stop the exchange results in resonances that are too broad to permit the measurement of any coupling constant values $\left({ }^{1} \mathrm{H}\left(\mathrm{w}_{1 / 2}\right)\right.$ $\approx 120 \mathrm{~Hz}$ ). Attempts at using fluorinated hydrocarbon solvents (very low freezing points, and lower viscosities than toluene, at low temperature), and fluorocarbon/toluene solvent mixtures, were unsuccessful due to either low solubility of 9 in these solvents, or low solubility of these solvents in toluene.

Table 3,1 H, 13 , and 31 P NMR Data for 8 and $2\left(\mathrm{C}_{6} \mathrm{D}_{6}, 25^{\circ} \mathrm{C}\right)$.

$\underline{8}$

$\delta\left(\mathrm{Pt}-\mathrm{CH}_{3}\right), \mathrm{ppm}$

$2 \mathrm{JPtCH} 3, \mathrm{~Hz}$

$\delta\left(\mathrm{CH}_{3}\right)$

${ }^{1} \mathrm{~J}_{\mathrm{PtCH} 3}$

${ }^{1} \mathrm{~J}_{\mathrm{CH} 3}{ }^{a}$

$\delta(\mathrm{P})$, ppm

${ }^{1} \mathrm{~J}_{\mathrm{PtP}}, \mathrm{Hz}$

$\delta(\mathrm{Cp} *), \mathrm{ppm}$

${ }^{1} \mathrm{~J}_{\mathrm{YoH}}, \mathrm{Hz}$

$\mathrm{J}_{\mathrm{YbP}}, \mathrm{Hz}$
1.23

68

18.1

17.6

121

70.4

1816

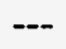

$-$
2

0.68

18.0

17.5

123

70.0

1968

2.28

not observed

not observed

aThe uncertainty in these values is estimated at $\pm 1 \mathrm{~Hz}$.

The directions of the perturbations of the spectral values of 9 , relative to those of 8 , are similar to those observed for the dihydride complexes discussed above (Tables 1 and 2), however the extent of the changes are less. In the hope of gaining some information concerning the nature of the bridging methyl interaction, the (averaged) $\mathrm{C}-\mathrm{H}$ coupling constant was measured at $25^{\circ} \mathrm{C}$. The values obtained for 8 and 9 are identical within experimental error; the values are also unchanged at $-80^{\circ} \mathrm{C}$. The chemical shift of the methyl carbon nuclei of $\mathbf{9}$ is also unperturbed, relative to the analogous value for 8 
(Table 3). Apparently, the interaction between 1 and 8 in solution is too weak to allow investigation of the methyl-Yb interactions via NMR spectroscopy. No low frequency C$\mathrm{H}$ stretches are present in the solid-state infrared spectrum of 9.26

To gain more information about the details of the bridging methyl interactions, a single crystal X-ray diffraction study was performed on 9 . The solid state structure is shown in Figure 5. This is the first crystallographically characterized complex containing bridging methyl groups between a transition metal and an f-element center. Five of the six bridging methyl hydrogens were located from a difference Fourier map, near the end of the structure refinement. The sixth hydrogen, $\mathrm{H} 2 \mathrm{C}$, was added assuming an idealized bonding geometry around $\mathrm{C} 2$ (tetrahedral, $\mathrm{d}(\mathrm{C}-\mathrm{H})=0.95 \AA$ ). These atoms were included in the structure factor calculation, but not refined. Inclusion of these six hydrogens resulted in a slight improvement in the model, providing confirmation of their positions.

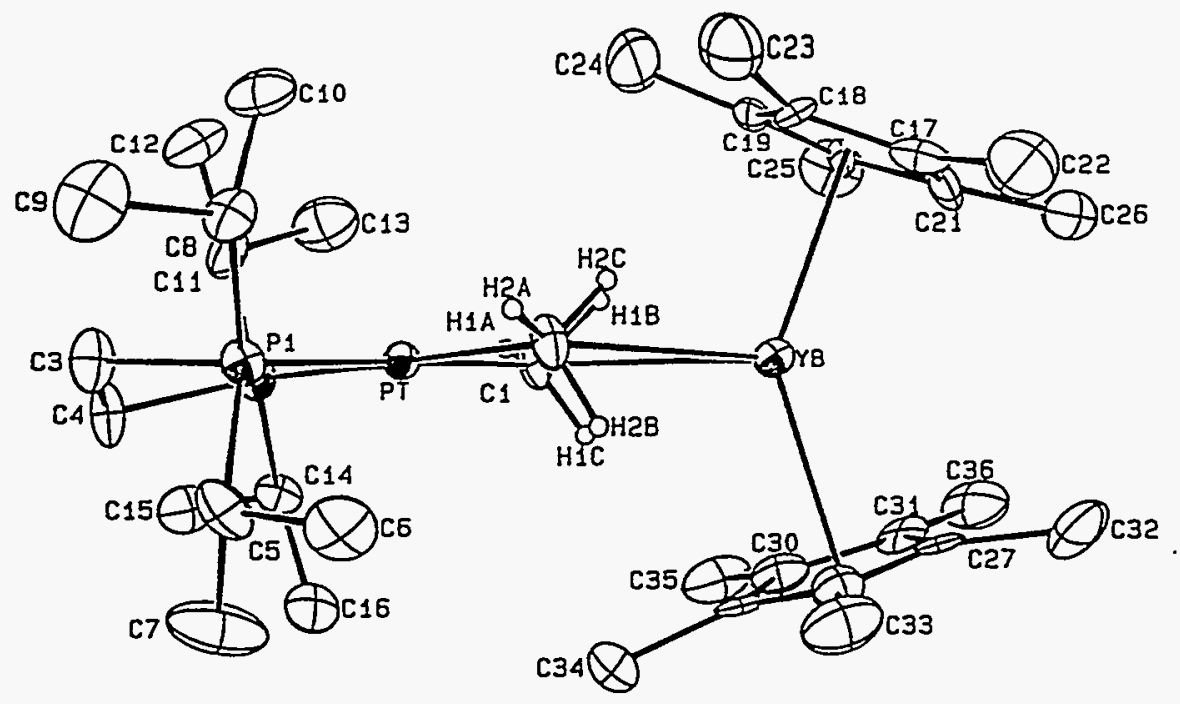

Figure 5. ORTEP diagram of (dippe) $\mathrm{Pt}(\mu-\mathrm{Me})_{2} \mathrm{YbCp}_{2}{ }_{2}(9), 50 \%$ probability thermal ellipsoids.

Selected bond distances and angles for 9 are given in Table 6 . The heavy atom bonding parameters are not unusual. The Pt-Yb separation, 4.0391(5) $\AA$, is $0.78 \AA$ 
longer than the analogous value in $\mathbf{5}$. As expected, the methyl groups are symmetrically bridging, with $\mathrm{Pt}-\mathrm{C} 1-\mathrm{Yb}=106.8(3)^{\circ}, \mathrm{Pt}-\mathrm{C} 2-\mathrm{Yb}=107.5(4)^{\circ}$, and equivalent Pt-C, Pt-P and $\mathrm{Yb}-\mathrm{C}$ distances, within experimental error; this symmetry introduces a pseudo- $\mathrm{C}_{2}$ axis through the $\mathrm{Pt}$ and $\mathrm{Yb}$ metal centers. The $\mathrm{Pt}-\mathrm{P}$ and $\mathrm{Pt}-\mathrm{C}$ distances found for 9 are within the expected range for cis- $\mathrm{P}_{2} \mathrm{PtMe}_{2}$ complexes; 27 no significant perturbations are present as a result of the $\mathrm{Yb}$-methyl interactions. The $\mathrm{P} 1-\mathrm{Pt}-\mathrm{P} 2 / \mathrm{Cp} 1-\mathrm{Yb}-\mathrm{Cp} 2$ torsional angle (84.1(4) $\left.)^{\circ}\right), \mathrm{Yb}-\mathrm{Cp} *$ distances $(2.42 \AA$ for both), and the Cp1-Yb-Cp2 angle $\left.: 139.6(5)^{\circ}\right)$ are within the expected values.

Table 6. Selected Intramolecular Distances ( $\AA$ ) and Angles (deg) in [(dippe)Pt( $\mu$ $\mathrm{Me})_{2} \mathrm{YbCp}_{-2}^{*}$ (9).

\begin{tabular}{cccc}
\multicolumn{4}{c}{ Bond Distances } \\
Pt-Yb & $4.0391(5)$ & Yb-Cp1a & 2.42 \\
Pt-P1 & $2.258(3)$ & Yb-Cp2 & 2.42 \\
Pt-P2 & $2.262(2)$ & Yb-H1A & 3.74 \\
Pt-C1 & $2.089(9)$ & Yb-H1B & 2.38 \\
Pt-C2 & $2.099(8)$ & Yb-H1C & 2.60 \\
Yb-C1 & $2.909(8)$ & Yb-H2A & 3.80 \\
Yb-C2 & $2.88(1)$ & Yb-H2B & 2.63 \\
& & Yb-H2C & 2.30 \\
& & & \\
P1-Pt-P2 & $86.97(9)$ & Bond Angles & $139.6(5)$ \\
C1-Pt-C2 & $86.2(4)$ & Cp1-Yb-Cp2 & $59.3(2)$ \\
Pt-C1-Yb & $106.8(3)$ & C1-Yb-C2 & $107.5(4)$ \\
Yb-C1-H1A & $133.7(6)$ & Pt-C2-Yb & $50.6(4)$ \\
Yb-C1-H1C & $62.5(4)$ & Yb-C1-H1B & $141.2(6)$ \\
Yb-C2-H2B & $65.8(5)$ & Yb-C2-H2A & $45.2(5)$ \\
& & Yb-C2-H2C & $45.2(5)$
\end{tabular}

aAll distances and angles involving Cp* rings were calculated using the ring centroid positions, for this structure and also for the structure of 11 , below.

Clearly, the bridging methyl portion of 9 is the structural feature of principal interest. The $\mathrm{C} 1-\mathrm{Yb}$ and $\mathrm{C} 2-\mathrm{Yb}$ distances are 2.908(8) $\AA$ and 2.88(1) $\AA$, respectively, well within the sum of the van der Waals radii, $3.70 \AA$ (taking the van der Waals radius of a methyl group as $\left.2.00 \AA^{17}\right)$. In $\mathrm{Cp}^{*} \mathrm{Be}(\mu-\mathrm{Me}) \mathrm{YbCp}^{*}$, the $\mathrm{Yb}$-methyl carbon distance is $2.766(4) \AA$, in $\left(\mathrm{PPh}_{3}\right)_{2} \mathrm{Pt}\left(\mu-\mathrm{C}_{2} \mathrm{H}_{4}\right) \mathrm{YbCp}_{2}{ }_{2}$ the average $\mathrm{Yb}$-C(olefin) distance is 2.781(6) $\AA .9 \mathrm{~d}$ Based on the orientation of the methyl hydrogens, the interaction involves 
donation of electron density from the $\mathrm{C}-\mathrm{H}$ bonds of the methyl groups to the electropositive $\mathrm{Yb}$ center (i.e., agostic interactions). The $\mathrm{Pt}-\mathrm{C}-\mathrm{Yb}$ angles, $107^{\circ}$ and $108^{\circ}$, are much less acute than the analogous values found for $M(\mu-M e)_{2} M^{\prime}$ structures containing $\mathrm{M}-\mathrm{C}-\mathrm{M}^{\prime}$ 3-center/2-electron type interactions (e.g., $\left[(\mathrm{Me})_{3} \mathrm{Al}\right]_{2}$ ), in which this angle is $75-90^{\circ} .28$ The analogous angle in $\left[\mathrm{Cp}_{2} \mathrm{Yb}(\mu-\mathrm{Me})\right]_{2}$, which contains $\mathrm{Yb}-\mathrm{C}-\mathrm{Yb}$ type bridges, is $86.6^{\circ}$ and the $\mathrm{Yb}-\mathrm{C}$ distances are 2.49 and $2.54 \AA .29$ The Pt-C-Yb angles in 9 are most consistent with agostic $\mathrm{C}-\mathrm{H}--\mathrm{Yb}$ interactions, as the $\mathrm{Pt}-\mathrm{C}-\mathrm{H}$ angles are $c a .106-121^{\circ}$.

For each methyl group, two of the hydrogens are oriented towards the ytterbium center, with distances ranging from 2.30-2.63 $\AA$, and one hydrogen is oriented away from the ytterbium center, at a distance of $c a .3 .8 \AA$. The van der Waals distance for an Yb--H interaction is $2.9 \AA$, using $1.2 \AA$ as the van der Waals radius for a hydrogen atom. ${ }^{17}$ The average $\mathrm{Yb}-\mathrm{H}$ distance in $\mathrm{Cp}^{*} \mathrm{Be}(\mu-\mathrm{Me}) \mathrm{YbCp}^{*}{ }_{2}$ is 2.59 (8) $\AA, 9 \mathrm{c}$ and in [ $\left\{\mathrm{Cp}_{2} \mathrm{Nb}(\mu-\mathrm{H})_{2}\right\}_{2} \mathrm{Yb}$ (diglyme) $]$ it is $2.33(8) \AA .1 \mathrm{a}$ It is informative to compare the bridging methyl interactions of 9 to the $\mathrm{C}-\mathrm{H}--\mathrm{Yb}$ interactions in $\left(\mathrm{PPh}_{3}\right)_{2} \mathrm{Pt}(\mu-$ $\left.\mathrm{C}_{2} \mathrm{H}_{4}\right) \mathrm{YbCp}_{2}{ }_{2},{ }^{9 \mathrm{~d}}$ in which the $\mathrm{C}-\mathrm{Pt}-\mathrm{C} / \mathrm{C}-\mathrm{Yb}-\mathrm{C}$ interplanar angle is $15.1^{\circ}$, resulting in two pairs of $\mathrm{Yb}-\mathrm{H}$ distances $(2.58,2.64 \AA ; 3.09,3.15 \AA)$ and two pairs of $\mathrm{Yb}-\mathrm{C}-\mathrm{H}$ angles $\left(69.5^{\circ}, 100.0^{\circ}\right.$, average values for the short and long $\mathrm{Yb}-\mathrm{H}$ pairs, respectively). The analogous interplanar angle in 9 is only $4^{\circ}$, however this also results in two pairs of $\mathrm{Yb}$ $\mathrm{H}$ distances (2.30, $2.38 \AA$; and 2.60, $2.63 \AA$; ignoring the long Yb-H1A, H2A interactions) and also two pairs of $\mathrm{Yb}-\mathrm{C}-\mathrm{H}$ angles $\left(47.9^{\circ}\right.$ and $64.2^{\circ}$, average angles for the shorter and longer $\mathrm{Yb}-\mathrm{H}$ pairs, respectively). While the differences in the pairs of $\mathrm{Yb}-\mathrm{H}$ interactions are less pronounced than in $\left(\mathrm{PPh}_{3}\right)_{2} \mathrm{Pt}\left(\mu-\mathrm{C}_{2} \mathrm{H}_{4}\right) \mathrm{YbCp}^{*}{ }_{2}$, they are clearly also present for 9. Given the symmetry of the two complexes, this phenomenon is likely not a steric or crystal packing effect; apparently such pairwise $\mathrm{Yb}-\mathrm{H}$ interactions are energetically more favorable than four equal $\mathrm{Yb}-\mathrm{H}$ interactions. 
The orientation of the methyl groups in 9 , with four of the six $\mathrm{C}-\mathrm{H}$ bonds pointed towards the $\mathrm{Yb}$ center, maximizes the amount of electron donation to the $\mathrm{Yb}$ center that can occur (a itructures containing five and six $\mathrm{C}-\mathrm{H}$ bonds interacting with the $\mathrm{Yb}$ center are clearly chemically unreasonable). This geometry results in an eclipsed geometry of the $\mathrm{C}-\mathrm{H}$ bonds, relative to the $\mathrm{C}-\mathrm{C}$ vector (the three pairs of $\mathrm{C}-\mathrm{Pt}-\mathrm{C}-\mathrm{H}$ torsional angles for analogous H's are all within $7^{\circ}$ of each other). Two cis- $\mathrm{L}_{2} \mathrm{M}(\mathrm{Me})_{2}(\mathrm{M}=\mathrm{Pd}, \mathrm{Pt})$ structures have been reported in which the methyl hydrogens have been located; $27 b, 30$ the methyl hydrogens in both of these structures are not eclipsed, relative to the $\mathrm{C}-\mathrm{C}$ vector. While it is possible that the orientation of the methyl hydrogens in 9 is solely a result of crystal packing and/or steric effects, given the conformations observed in the "free" $\mathrm{L}_{2} \mathrm{M}(\mathrm{Me})_{2}$ complexes and the close $\mathrm{Yb}-\mathrm{H}$ distances in 9 , the observed conformation most likely arises as a result of the agostic $\mathrm{C}-\mathrm{H}--\mathrm{Yb}$ interactions.

The agostic interactions observed in the solid state structure of 9 represent a rare bonding mode for bridging methyl groups. The different orientations of bridging methyl groups that have been structurally characterized are shown in Figure 6 .

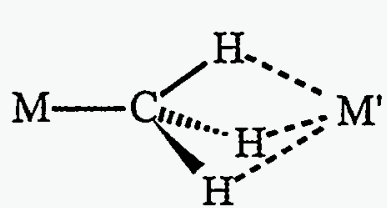

a

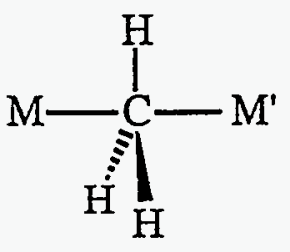

b

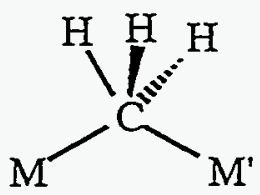

c

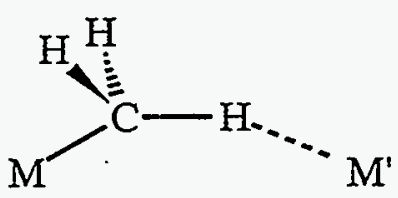

d

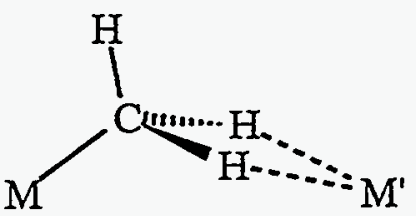

e

Figure 6. Different types of bridging methyl groups that have been crystallographically characterized. 
The most common orientation observed is the M-C-M' type (Fig. 6a), 29,31 the classic example being the trimethylaluminum dimer. 32 Several examples of types $b, 9 c, 33 c, 34$ and $\mathrm{d}^{35}$ have also been observed. To the best of our knowledge, only two examples of type e, the orientation observed for 9 , have been reported. 36

Interaction with (dippe)Pt(Me)(H). It was of interest to see if a methyl hydride complex of platinum would combine the best features of the dihydride and dimethyl complexes, viz., slow intermolecular exchange in solution, while still containing a bridging methyl interaction, so that the spectroscopic changes resulting from the methyl$\mathrm{Yb}$ interaction could be studied. While it has been reported that (dcype) $\mathrm{Pt}(\mathrm{Me})(\mathrm{H})$ can be synthesized from reaction of (dcype) $\mathrm{Pt}(\mathrm{Me})(\mathrm{Cl})$ with excess $\mathrm{NaHB}(\mathrm{OMe})_{3}, 37$ we found that this method did not work reproducibly, and the yield of the desired product was low when successful. The synthesis of (dmpe)Pt(Me)(H) has also been reported, via reduction of (dmpe)Pt(Me)(OCOPh) with excess $\mathrm{LiHBE}_{3}$ or $\mathrm{LiBH}_{4}$ at low temperature, although synthetic details were not given. 38 This method was also found to be irreproducible. While it sometimes gave the desired product cleanly, at other times it gave product mixtures containing many different species, including the desired methyl hydride complex as well as the dihydride complex, the latter presumably arising from reduction of the methyl hydride complex by the excess $\mathrm{LiHBE}_{3} / \mathrm{LiBH}_{4}$. We have found that reaction of (dippe) $\mathrm{Pt}(\mathrm{Me})(\mathrm{OCOPh})$ with the milder hydride source $\mathrm{NaHB}(\mathrm{OMe})_{3}$ in thf results in clean conversion to the desired (dippe) $\mathrm{Pt}(\mathrm{Me})(\mathrm{H})$ complex, in reproducible yields of 70$80 \%$. This reaction can be done at room temperature, excess $\mathrm{NaHB}(\mathrm{OMe})_{3}$ does not result in product decomposition or reduced yields, and purification of the product is simple (see the Experimental section for details). It appears that the combination of a milder hydride source, $\mathrm{NaHB}(\mathrm{OMe})_{3}$, with a platinum benzoate complex (containing a better leaving group than the analogous chloride complex) is a better method for synthesis of cis- $\mathrm{P}_{2} \mathrm{Pt}(\mathrm{Me})(\mathrm{H})$ complexes. 
Reaction of (dippe)Pt(Me)(H) (10) with 1 eq. of 1 in toluene results in a beigeorange solution, from which dark green-brown crystals, formulated as (dippe) $\operatorname{Pt}(\mu$ $\mathrm{Me})(\mu-\mathrm{H}) \mathrm{YbCp}^{*}{ }_{2}(\mathbf{1 1})$ can be isolated in $70 \%$ yield. The crystals are solvent-loss sensitive, and turn gold upon exposure to vacuum. This solid has a $v(M-H)$ band at $1895 \mathrm{~cm}^{-1}$ in its solid-state infrared spectrum, shifted from $1965 \mathrm{~cm}^{-1}$ for 10 . As found for 9, no low frequency $\mathrm{C}-\mathrm{H}$ stretches are present in the infrared spectrum, and crystals of 11 redissolve in toluene. A sample of this solid dissolved in $\mathrm{C}_{6} \mathrm{D}_{6}$ gives NMR spectra that indicate intermolecular exchange is rapid at $25^{\circ} \mathrm{C}$; no coupling to ${ }^{171} \mathrm{Yb}$ is observed and broadened resonances are present. However a toluene-d8 solution of $\mathbf{1}$ and $\mathbf{1 0}$, containing a slight excess of 1 , does not show intermolecular exchange at $25^{\circ} \mathrm{C}$, presumably for the same reasons as mentioned above (Fig. 2, and accompanying discussion). Coupling of ${ }^{171} \mathrm{Yb}$ to the hydride as well as to the phosphorus nucleus that is trans to the hydride is present at $25^{\circ} \mathrm{C}$. However, coupling to ${ }^{171} \mathrm{Yb}$ is not resolved for the methyl platinum-related resonances, in the room temperature 1-D ${ }^{1} \mathrm{H}$ and ${ }^{31} \mathrm{P}\left\{{ }^{1} \mathrm{H}\right\}$ (Ptrans to the methyl group) NMR spectra. The NMR values measured on this sample at $25^{\circ} \mathrm{C}$ and at $-70^{\circ} \mathrm{C}$, are given in Table 7 .

Considering first the room temperature ${ }^{1} \mathrm{H}$ and ${ }^{31} \mathrm{P}$ data, the perturbations in the values resulting from the presence of 1 are roughly equivalent to the perturbations that were observed for the analogous values in the dihydride and dimethyl complexes (Tables 1-3). The ${ }^{1} \mathrm{~J}_{\mathrm{YbH}}$ value of $\mathbf{1 1}$ is slightly smaller than the analogous values for 5 and $\mathbf{7}$, indicative of a slightly weaker Yb-hydride interaction in $\mathbf{1 1}$ than in the dihydride complexes. This may be a result of steric interactions between the $\mathrm{Yb}$ center and the methyl group, preventing the $\mathrm{Yb}$ center from approaching the hydride ligand as closely as in the dihydride complexes. Both the ${ }^{1} \mathrm{H}$ chemical shift perturbation of the methyl protons $(\Delta(\delta)=0.55 \mathrm{ppm}$ for $9,0.80 \mathrm{ppm}$ for 11$)$, as well as the ${ }^{2} \mathrm{JPtCH}_{\mathrm{t} 3}$ perturbation $(\Delta(J)=2 \mathrm{~Hz}$ for $9,14 \mathrm{~Hz}$ for 11$)$, are larger than for 9 , presumably indicating a stronger Yb-methyl interaction in 11, relative to that in 9. 
Table 7, $1 \mathrm{H}, 13 \mathrm{C}, 31 \mathrm{P}, 195 \mathrm{Pt}$, and $171 \mathrm{Yb}$ NMR Data for 10 and 11 (toluene-d8, at 25 ${ }^{\circ} \mathrm{C}$ and $-70^{\circ} \mathrm{C}$.

\begin{tabular}{|c|c|c|c|c|}
\hline & \multicolumn{2}{|c|}{$\underline{25^{\circ} \mathrm{C}}$} & \multicolumn{2}{|c|}{$-70^{\circ} \mathrm{C}$} \\
\hline & 10 & 11 & 10 & 11 \\
\hline$\delta(\mathrm{Pt}-\underline{\mathrm{H}}), \mathrm{ppm}$ & 0.48 & -2.65 & 0.89 & -2.40 \\
\hline 2JPtransH, $\mathrm{Hz}$ & 201 & 163 & 198 & 159 \\
\hline${ }^{1} \mathrm{JPtH}_{\mathrm{PtH}}, \mathrm{Hz}$ & +1158 & +1034 & +1137 & +1020 \\
\hline$\delta(\mathrm{P}), \mathrm{ppm}$ & $85.5,70.1$ & $81.3,69.2$ & $85.6,72.0$ & $82.7,71.2$ \\
\hline${ }^{1} J_{P t P}, H z^{\mathrm{a}}$ & $+1822,+1747$ & $+1978,+2186$ & $+1841,+1775$ & $+1992,+2205$ \\
\hline$\delta(\mathrm{Cp} *), \mathrm{ppm}$ & -- & $2.29,1.94$ & --- & $2.50,2.06$ \\
\hline${ }^{1} \mathrm{~J}_{\mathrm{YbH}}, \mathrm{Hz}$ & -- & +114 & $\cdots$ & +113 \\
\hline $\mathrm{J}_{\mathrm{YbP}}, \mathrm{Hz}^{\mathrm{a}}$ & --- &,--+78 & -- & $-3,+82$ \\
\hline$\delta(\mathrm{CH} 3)$ & 1.44 & 0.64 & 1.65 & 0.72 \\
\hline${ }^{2} \mathrm{~J}_{\mathrm{PtCH} 3}$ & -71 & -57 & -70 & -60 \\
\hline $\mathrm{J}_{\mathrm{YbCH} 3}$ & & & -- & +24 \\
\hline$\delta(\mathrm{CH} 3)$ & & & -13.8 & -15.4 \\
\hline $\mathrm{JYbCH}_{3}$ & & & -- & $+46(4)^{b}$ \\
\hline${ }^{1} \mathrm{~J}_{\mathrm{CH} 3}$ & & & $121(2)^{b}$ & $123(2)^{b}$ \\
\hline$\delta(\mathrm{Pt}), \mathrm{ppm}$ & & & -400 & -520 \\
\hline$\delta(\mathrm{Yb}), \mathrm{ppm}$ & & & $\cdots$ & +340 \\
\hline $\mathrm{JPtYb}_{\mathrm{Pt}} \mathrm{Hz}$ & & & $\ldots$ & +960 \\
\hline
\end{tabular}

aListed as $\mathrm{P}$ trans to methyl, $\mathrm{P}$ trans to hydride, respectively.

bThe estimated uncertainties in these values are given in parentheses.

The ${ }^{1} \mathrm{H}$ and ${ }^{31} \mathrm{P}$ NMR values of 11 are relatively unchanged upon cooling to -70 ${ }^{\circ} \mathrm{C}$, suggesting that the nature of the interaction between 1 and 10 is not changed significantly over this temperature range. The ${ }^{195} \mathrm{Pt}$ chemical shift for 11 at $-70^{\circ} \mathrm{C}$ is shifted upfield from the value for $10(\Delta(\delta)=-120 \mathrm{ppm})$, in contrast to the downfield shifts observed for 5 and $7\left(\Delta(\delta)=+111 \mathrm{ppm}\right.$ and $+112 \mathrm{ppm}$, respectively). The ${ }^{171} \mathrm{Yb}$ shift for 11 at $-70{ }^{\circ} \mathrm{C}$ is $+340 \mathrm{ppm}$, shifted downfield $370 \mathrm{ppm}$ from free 1 . This contrasts with downfield shifts of 602 ppm for 5 and 502 ppm for 7 , perhaps indicative of a weaker interaction between 1 and 10, relative to the interactions formed between 1 
and the cis dihydride complexes. The ${ }^{1} \mathrm{H} /{ }^{195} \mathrm{Pt} \mathrm{HMQC}$ spectrum measured at $-70^{\circ} \mathrm{C}$ (given in Appendix I) shows the presence of spin-spin coupling between ${ }^{195} \mathrm{Pt}$ and ${ }^{171} \mathrm{Yb}$ $\left(\mathrm{JP}_{\mathrm{P} Y \mathrm{~b}}=960 \mathrm{~Hz}\right)$, of roughly half the size of the analogous values measured for 5 and 7.

The presence of coupling between the $\mathrm{Pt}$ and $\mathrm{Yb}$ centers in 5, 7, and 11 indicates that there is communication of the metal nuclear spins, likely via the bridging ligands. Is this $\mathrm{Pt}-\mathrm{Yb}$ nuclear spin-spin communication significant? As mentioned above, there have not been many $\mathrm{J}_{\mathrm{YbX}}$ values reported, and no $\mathrm{Yb}$-transition metal coupling constants. Comparison of the reported $\mathrm{J}_{Y b X}$ values to the $\mathrm{J}_{\mathrm{Pt} Y \mathrm{~b}}$ values measured for 5,7 , and 11 is not valid, as different nuclei are involved, and the different magnetogyric ratios make such a comparison meaningless. Comparison of the reduced coupling constant values is complicated by the fact that, while such values are independent of the magnetogyric ratios involved, they are still dependent on the atomic number and are also strongly affected by relativistic effects, which are large for both ${ }^{195} \mathrm{Pt}$ and ${ }^{171} \mathrm{Yb} .39$ It is known that $\mathrm{JPtPt}_{\mathrm{Pt}}$ values for polynuclear $\mathrm{Pt}$ complexes show no correlation with solid state Pt-Pt distances and a similar possibility has been suggested for $\mathrm{J}_{\mathrm{PtW}}$ values. ${ }^{8}$ Another potential complication is the possibility of two different communication mechanisms, a direct Pt$\mathrm{Yb}$ interaction and interaction via the bridging ligands. The coupling via the first mechanism (1-bond) may be either of the same or of opposite sign to the coupling via the second mechanism ( $>1$-bond), and this can have a large effect on the measured coupling constant value; this has been suggested as a possible reason for the seemingly random $\mathrm{J}_{\mathrm{PtPt}}$ values. ${ }^{8}$ Consequently, the only thing that can be stated with certainty concerning the $\mathrm{J}_{\mathrm{PtYb}}$ values measured on $\mathbf{5 , 7}$, and $\mathbf{1 1}$ is that there is nuclear spin communication between the metal centers, and that this communication is about equal for 5 and $\mathbf{7}$, and roughly halved for 11 . Whether the difference is a consequence of the different bridging ligands in the complexes, of the longer $\mathrm{Pt}-\mathrm{Yb}$ separation for $\mathbf{1 1}$, or a combination of these two possibilities, is unknown. 
The ${ }^{1} \mathrm{H} /{ }^{195} \mathrm{Pt}$ spectrum of 11 at $0{ }^{\circ} \mathrm{C}$ (Figure 7) shows that at this temperature $\mathrm{JPtYb}_{\mathrm{Pt}}$ is identical to the value obtained at $-70^{\circ} \mathrm{C}$ (this spectrum was optimized for the $2 J_{\mathrm{PtH}}$ of the methyl protons, $58 \mathrm{~Hz}$ ). In addition, coupling of the ytterbium center to the methyl hydrogens is observed, $\mathrm{J}_{\mathrm{YbCH} 3}=24 \mathrm{~Hz}$. This value was also measured at $-70^{\circ} \mathrm{C}$, and was found to be identical. These similar spectroscopic values for 11 at $0^{\circ} \mathrm{C}$ and $-70^{\circ} \mathrm{C}$ show that the nature of the interaction is largely unchanged within this temperature range, as suggested by the ${ }^{1} \mathrm{H}$ and ${ }^{31} \mathrm{P}$ data. It is clear from Figure 6 why $\mathrm{J}_{\mathrm{YbCH}} 3$ is not visible in the 1-D ${ }^{1} \mathrm{H}$ spectrum of 11 : it is obscured by the methyl resonance of the non- ${ }^{171} \mathrm{Yb}$ isotopomers. Use of the ${ }^{1} \mathrm{H}-{ }^{195} \mathrm{Pt} \mathrm{HMQC}$ however, makes use of the large ${ }^{195 \mathrm{Pt}-171 \mathrm{Yb}}$ coupling to generate the E.COSY-like pattern, ${ }^{7}$ allowing elucidation of ${ }^{1} \mathrm{~J}_{\mathrm{YbCH}}$.

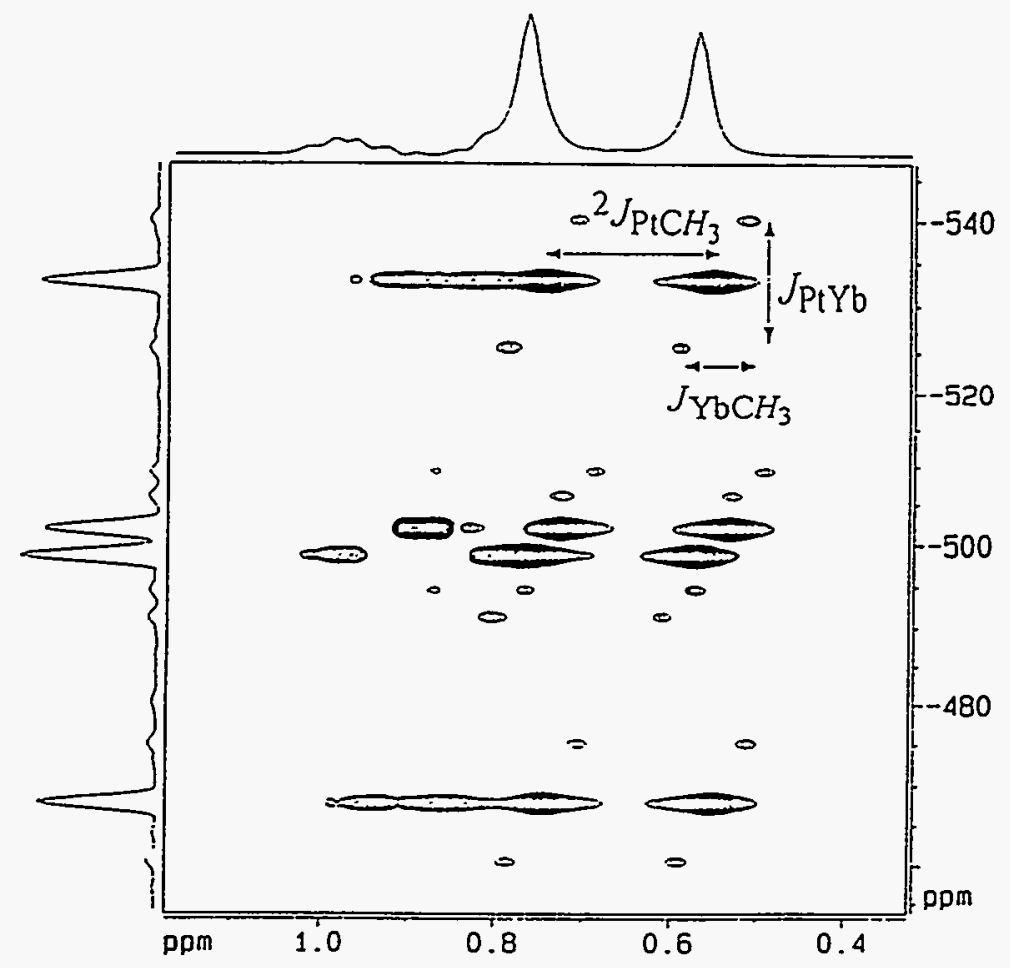

Figure 7. ${ }^{1} \mathrm{H} / 195 \mathrm{Pt}$ HMQC NMR spectrum of $11\left(300 \mathrm{MHz}\right.$, toluene-d8, $\left.0^{\circ} \mathrm{C}\right)$, showing the methyl-platinum cross peak region. Extra correlations are visible to the dippe ligand protons. Annotated with ${ }^{195} \mathrm{Pt}$ and ${ }^{1} \mathrm{H}$ projections in $\mathrm{F} 1$ and $\mathrm{F} 2$, respectively. 
Based on the $24 \mathrm{~Hz}$ value of $\mathrm{J}_{\mathrm{YbCH}}$, there is clearly an $\mathrm{Yb}$-methyl interaction present. A ${ }^{1} \mathrm{H} /{ }^{1}$ P $\mathrm{HMQC}$ spectrum of 11 acquired at $-70^{\circ} \mathrm{C}$ shows coupling of ${ }^{171} \mathrm{Yb}$ to the phosphorus nucleus trans to the methyl group, of $c a .3 \mathrm{~Hz}$ (this spectrum is given in Appendix I). This coupling is not seen in the 1-D ${ }^{31} \mathrm{P}\left\{{ }^{1} \mathrm{H}\right\}$ spectrum, as it is within the linewidth of the major resonance. This coupling is much smaller than the analogous coupling to the phosphorus nucleus that is trans to the hydride ligand, $82 \mathrm{~Hz}$. In a similar manner, the ${ }^{1} \mathrm{H} /{ }^{13} \mathrm{C}$ HSQC 40 spectrum shown in Figure 8 (optimized for ${ }^{1} \mathrm{~J}_{\mathrm{CH} 3}=123$ $\mathrm{Hz}$ ) allows the measurement of $\mathrm{J}_{\mathrm{YbCH} 3}, 46 \pm 4 \mathrm{~Hz}$. As was found for 9 , the ${ }^{1} \mathrm{~J}_{\mathrm{CH} 3}$ coupling constant for the bridging methyl group of 11 is unchanged from that of free 10 . As the signs of ${ }^{1} \mathrm{~J}_{\mathrm{PLH}},{ }^{1} \mathrm{~J}_{\mathrm{PLC}},{ }^{1} \mathrm{~J}_{\mathrm{PLP}}$ are known to be positive, ${ }^{8}$ the signs of the rest of the coupling constants can be obtained from the 2-D spectra, and are given in Table 7, above.

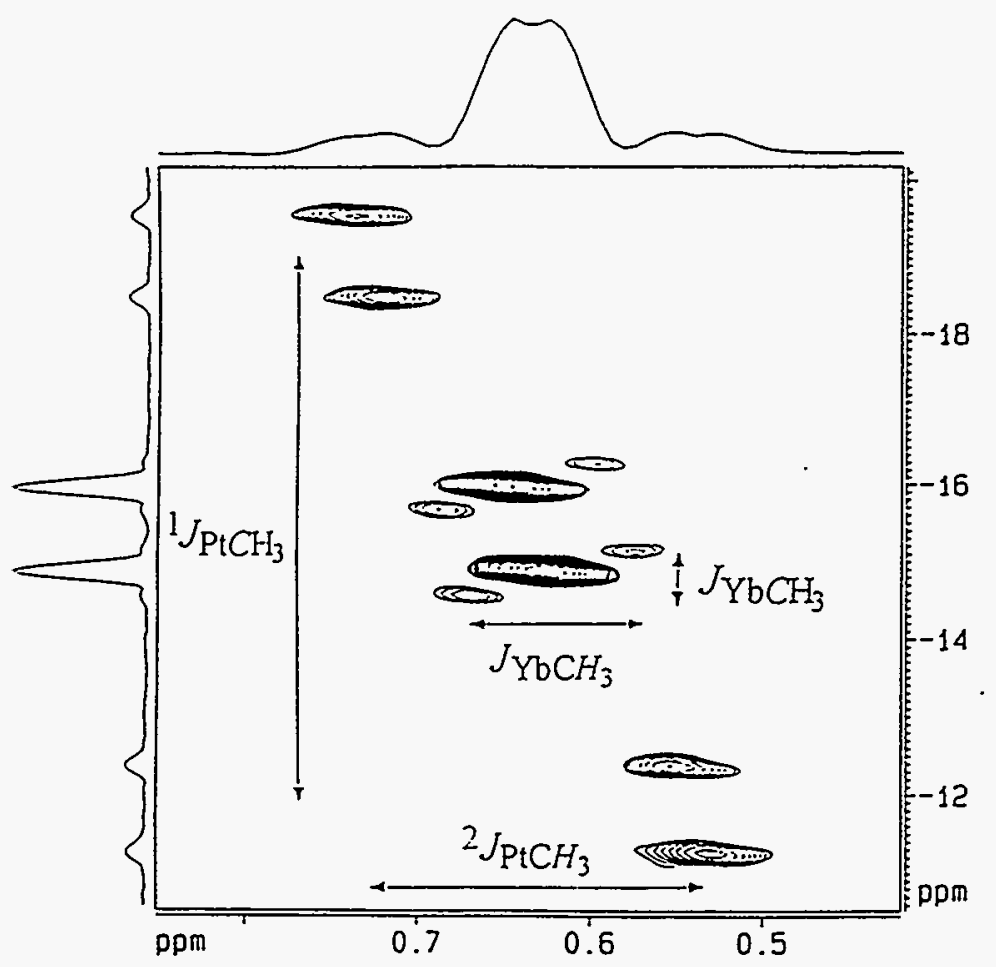

Figure 8. ${ }^{1} \mathrm{H} /{ }^{13} \mathrm{C}$ HSQC NMR spectrum of $11\left(300 \mathrm{MHz}\right.$, toluene-d8, $\left.-70^{\circ} \mathrm{C}\right)$, showing the methyl region. ${ }^{171} \mathrm{Yb}$ satellites are visible only for the major resonance, and not for the ${ }^{195} \mathrm{Pt}$ satellites, due to insufficient signal/noise. Annotated with ${ }^{13} \mathrm{C}$ and ${ }^{1} \mathrm{H}$ projections in $F 1$ and $F 2$, respectively. 
Unfortunately, the NMR data of $\mathbf{1 1}$ do not give a clear answer with respect to distinguishing between agostic interactions, a direct $\mathrm{Yb}$-C interaction, or a combination of both (phenomenologically, a bridging alkyl augmented by an $\alpha$-agostic interaction). The coupling of ${ }^{171} \mathrm{Yb}$ to both the $\mathrm{C}$ and $\mathrm{H}$ nuclei of the bridging methyl group in $\mathbf{1 1}$ is consistent with all three of these possibilities, as is the unchanged ${ }^{1} \mathrm{~J}_{\mathrm{CH} 3}$ value for 11 . It is known that ${ }^{1} \mathrm{~J}_{\mathrm{CH} 3}$ values are not significantly perturbed upon formation of $\mathrm{M}-\mathrm{C}-\mathrm{M}^{\prime}$ bridging interactions. ${ }^{41}$ There have also been several reports of agostic complexes in which ${ }^{1} \mathrm{~J}_{\mathrm{CH}}$ is unchanged or decreases only very slightly (see below). ${ }^{42}$ The observation that $\mathrm{J}_{\mathrm{YbCH} 3}$ and $\mathrm{J}_{\mathrm{YbCH} 3}$ for $\mathbf{1 1}$ have the same signs does not unequivocally rule out a direct $\mathrm{Yb}-\mathrm{C}$ interaction. While ${ }^{1} \mathrm{~J}_{\mathrm{MC}}$ and ${ }^{2} \mathrm{~J}_{\mathrm{MCH}} 3$ generally have opposite signs for transition metal complexes containing direct $\mathrm{M}$-C interactions (where $\mathrm{M}$ is an NMR-active isotope), ${ }^{43}$ the small number of these examples requires that the sign criterion be used critically. However, the same signs of $\mathrm{J}_{\mathrm{YbCH}} 3$ and $\mathrm{J}_{\mathrm{YbCH}}$ for $\mathbf{1 1}$ is certainly least consistent with just a direct $\mathrm{Yb}-\mathrm{C}$ interaction.

While isotopic perturbation of resonance/coupling constant (IPR/IPC) experiments may be informative, ${ }^{44}$ given the small perturbations in the methyl-related spectral values for 11 relative to those of 10 , such experiments will likely give ambiguous results (see especially ref. 44a). The success of the IPR/IPC experiment is dependent on a perturbation in the $\mathrm{C}-\mathrm{H}$ bond strength upon formation of the $\mathrm{C}-\mathrm{H}-\mathrm{M}$ interaction. The $\mathrm{C}-$ $\mathrm{H}$ bonds in $\mathbf{1 1}$ are not significantly perturbed upon formation of the interaction with $\mathbf{1}$, as evidenced by the unchanged ${ }^{1} \mathrm{~J}_{\mathrm{CH} 3}$ value and lack of low frequency $\mathrm{C}-\mathrm{H}$ stretches in the IR spectrum of 11. Related to this, the JYbCH3 value will not change very much upon partial deuteration of the methyl group. If it is assumed that two methyl hydrogens interact with the $\mathrm{Yb}$ center, then the maximum value for $\mathrm{J}_{Y b C D \underline{H} 2}$ for (dippe) $\operatorname{Pt}(\mu$ $\left.\mathrm{CDH}_{2}\right)(\mu-\mathrm{H}) \mathrm{YbCp}_{2}{ }_{2}$ would be $36 \mathrm{~Hz}$. This maximum value would be observed only if the methyl group were not rotating, with both hydrogens interacting with the $\mathrm{Yb}$ center, an unlikely scenario. 
Comparison of the $\mathrm{J}_{\mathrm{YbC}, \mathrm{H}}$ values measured on 11 to $\mathrm{J}_{\mathrm{MC}, \mathrm{H}}$ values of bridging hydride and methyl complexes that have been reported in the literature is informative. While $\mathrm{J}_{\mathrm{YbH}}$ and $\mathrm{J}_{\mathrm{YbC}}$ values cannot be measured on $\left[\mathrm{Cp}_{2} \mathrm{Yb}(\mu-\mathrm{Me})\right]_{2}$, a compound with a $\mathrm{Yb}-\mathrm{C}-\mathrm{Yb}$ interaction in the solid state 28,45 ( $\mathrm{Yb}$ (III) is paramagnetic), both $\mathrm{J}_{\mathrm{YH}}$ and $\mathrm{J}_{\mathrm{YC}}$ have been measured for $\left[\mathrm{Cp}_{2} \mathrm{Y}(\mu-\mathrm{Me})\right]_{2}$, which also possesses $\mathrm{M}-\mathrm{C}-\mathrm{M}$ bridges in the solid state. ${ }^{45}$ The ${ }^{1} \mathrm{~J}_{\mathrm{YC}}$ value for this complex is $25.0 \mathrm{~Hz}$, while $\mathrm{J}_{\mathrm{YH}}$ is $3.6 \mathrm{~Hz}$ (all of the $\mathrm{J}_{\mathrm{YC}, \mathrm{H}}$ values discussed in this paragraph are absolute values, as the signs of the coupling constants have not been reported), consistent with a direct $\mathrm{Y}$-C interaction and longerrange (2-bond) $\mathrm{Y}-\mathrm{H}$ interactions; this gives a ratio of $\mathrm{JYC}_{\mathrm{Y}} / \mathrm{J}_{\mathrm{YH}}$ of 6.94 . The ratio for $\mathrm{Cp}_{2} \mathrm{Y}(\mu-\mathrm{Me})_{2} \mathrm{Al}(\mathrm{Me})_{2},{ }^{46}$ which also has M-C-M' type interactions in the solid state, ${ }^{31}$ is $\mathrm{J}_{\mathrm{YC}} / \mathrm{J}_{\mathrm{YH}}=12.2 \mathrm{~Hz} / 5.0 \mathrm{~Hz}=2.44$. For 11 , the analogous ratio is $\mathrm{J}_{\mathrm{YbC}} / \mathrm{J}_{\mathrm{YbH}}=46$ $\mathrm{Hz} / 24 \mathrm{~Hz}=1.92$ (the use of reduced coupling constants, $\mathrm{K}$, is not necessary, as the nuclei being compared are constant). It is also interesting to compare the JYH value of $3.6 \mathrm{~Hz}$ for $[\mathrm{Cp} 2 \mathrm{Y}(\mu-\mathrm{Me})]_{2}$ to the $\mathrm{J}_{\mathrm{YH}}$ values found for $\left(\mathrm{Cp}_{2}(\operatorname{thf}) \mathrm{Y}(\mu-\mathrm{H})\right]_{2}(27.0 \mathrm{~Hz})^{47}$ and $\left[\mathrm{Cp}^{*}{ }_{2} \mathrm{Y}(\mu-\mathrm{H})\right]_{2}(37.5 \mathrm{~Hz}),{ }^{48}$ giving $\left[\mathrm{J}_{\mathrm{YH}}(\mu-\mathrm{H}\right.$ complex $) / \mathrm{J}_{\mathrm{YH}}(\mu-\mathrm{Me}$ complex $\left.)\right]$ ratios of 7.50 and 10.4, respectively. The analogous values for the $\mathrm{Yb}$ complexes, 11 and 5 , give a ratio of $180 \mathrm{~Hz} / 24 \mathrm{~Hz}=7.50$.

The $J_{P t H}$ and $J_{P t C}$ values have been measured for a series of trans $-\mathrm{PtCl}_{2} \mathrm{LX}$ complexes $\left(\mathrm{L}=\mathrm{PR}_{3}, A s \mathrm{R}_{3}\right.$, olefin; $\mathrm{X}=\mathrm{a}$ quinoline/Schiff base derivative, possessing an aryl/alkyl donor $\mathrm{C}-\mathrm{H}$ bond(s)).42b These complexes have been described as "weak" agostic complexes. They are square planar $\mathrm{Pd}, \mathrm{Pt}$, or $\mathrm{Rh}$ complexes containing the agostic donor held rigidly in place in the pseudo-axial fifth coordination site, and they have an unperturbed ${ }^{1} \mathrm{~J}_{\mathrm{CH}}$ value and a low-field shift of the agostic hydrogen resonance, in contrast to the high-field shift that is commonly observed for agostic complexes. ${ }^{42}$ The $\mathrm{J}_{\mathrm{PtC}} / \mathrm{J}_{\mathrm{PtH}}$ values for these complexes are in the range of $c a$. 2.3-3.2, similar to the $\mathrm{J}_{\mathrm{YbC}} / \mathrm{J}_{\mathrm{YbH}}$ value observed for 11. It is interesting that for $[$ trans $-\mathrm{Rh}(\mathrm{CO})(8-$. methylquinoline)($\left.\left(\mathrm{PPh}_{3}\right)_{2}\right]\left(\mathrm{BF}_{4}\right),{ }^{42 a}$ which also contains a weak agostic interaction, $\mathrm{J}_{\mathrm{RhC}}$ 
is $1.8 \mathrm{~Hz}$ while $\mathrm{J}_{\mathrm{RhH}}$ is not observed. To the best of our knowledge, the only example of a "true" agostic complex for which $J_{M C}$ and $J_{M H}$ have been measured is $\left[\left(\mathrm{Cp}^{*}\right) \mathrm{Rh}\left(\mathrm{C}_{10} \mathrm{H}_{13}\right)\right]\left[\mathrm{PF}_{6}\right]$ (in which ${ }^{1} \mathrm{~J}_{\mathrm{CH}}$ is $83 \mathrm{~Hz}$, lowered from $152 \mathrm{~Hz}$ ); 49 the measured values give a $J_{R h C} / J_{R h H}$ ratio of $3.6 \mathrm{~Hz} / 10.2 \mathrm{~Hz}=0.35,50$ far lower than the value observed for 11.51 Based on the coupling constant ratios in this diverse set of compounds and the unchanged ${ }^{1} \mathrm{~J}_{\mathrm{CH} 3}$ value in 11 , it is reasonable to classify 11 as a weak agostic complex in solution. 52

The hydride ligand in $\mathbf{1 1}$ holds the $\mathrm{Yb}$ center near the methyl group, resulting in the observed Yb--methyl interactions. As in 11, all of the weak agostic complexes in the literature have the $\mathrm{C}-\mathrm{H}$ donor held rigidly near the metal center; consequently, the interaction in this class of complexes is mainly a result of geometrical constraints. This is in contrast to "classical" or "strong" agostic complexes, in which the interaction arises mainly from orbital energy considerations. The distinction between "classical" and "weak" agostic complexes is not unambiguous; the latter class may be characterized by unchanged ${ }^{1} \mathrm{~J}_{\mathrm{CH}}$ values and $\mathrm{J}_{\mathrm{MC}} / \mathrm{J}_{\mathrm{MH}}$ ratios intermediate between $\mathrm{M}-\mathrm{C}-\mathrm{M}$ ' type complexes and agostic complexes in which ${ }^{1} \mathrm{~J}_{\mathrm{CH}}$ is substantially lowered.

An X-ray structure determination was performed on $\mathbf{1 1}$ in order to investigate the details of the interaction between $\mathbf{1}$ and $\mathbf{1 0}$ in the solid state. Selected intramolecular distances and angles are given in Table 8. Unfortunately, three of the four iso-propyl groups are disordered, as are both of the $\mathrm{Cp}^{*}$ rings. While this disorder was satisfactorily modeled (see the Experimental section for details), the hydrogen atoms on the bridging methyl group, as well as the hydride ligand, could not be located in the Fourier difference map. Nevertheless, the core of the structure is well-defined (Fig. 9), and yields some valuable information.

While the hydride ligand was not found, its location is clear from the square planar coordination about the Pt center. The Pt-Yb separation is 3.388(9) $\AA$, compared to 3.264 $\AA$ for 5 and $4.039 \AA$ for 9. The P-Pt-Yb angles (P1-Pt-Yb $=145.8(1)^{\circ}, \mathrm{P} 2-\mathrm{Pt}-\mathrm{Yb}=$ 
$\left.127.2(1)^{\circ}\right)$ show that the $(\mu-\mathrm{Me})(\mu-\mathrm{H})$ bridge is asymmetric, with the $\mathrm{Yb}$ center pulled towards the hydride. The Pt-P distances are equivalent within experimental error (Pt-P1 $\left.=2.256(5) \AA, \mathrm{Pt}_{\mathrm{t}} \mathrm{P} 2=2.252(5) \AA\right)$, and are identical within experimental error to those found for 9 .

Table 8. Selected Intramolecular Distances $(\AA)$ and Angles (deg) in [(dippe)Pt( $\mu$ $\left.\mathrm{Me})(\mathrm{u}-\mathrm{H}) \mathrm{YbCp}_{-2}^{*}\right](11)$.

\begin{tabular}{cccc}
\multicolumn{5}{c}{ Bond Distances } \\
Pt-Yb & $3.388(9)$ & Yb-Cp1 & 2.43 \\
Pt-P1 & $2.256(5)$ & Yb-Cp2 & 2.41 \\
Pt-P2 & $2.252(5)$ & Yb-C35 & $2.79(2)$ \\
Pt-C35 & $2.16(2)$ & & \\
& & Bond Angles & \\
P1-Pt-P2 & $87.0(2)$ & Cp1-Yb-Cp2 & $137(1)$ \\
Pt-C35-Yb & $85.4(6)$ & P1-Pt-Yb & $145.8(1)$ \\
P2-Pt-Yb & $127.2(1)$ & &.
\end{tabular}

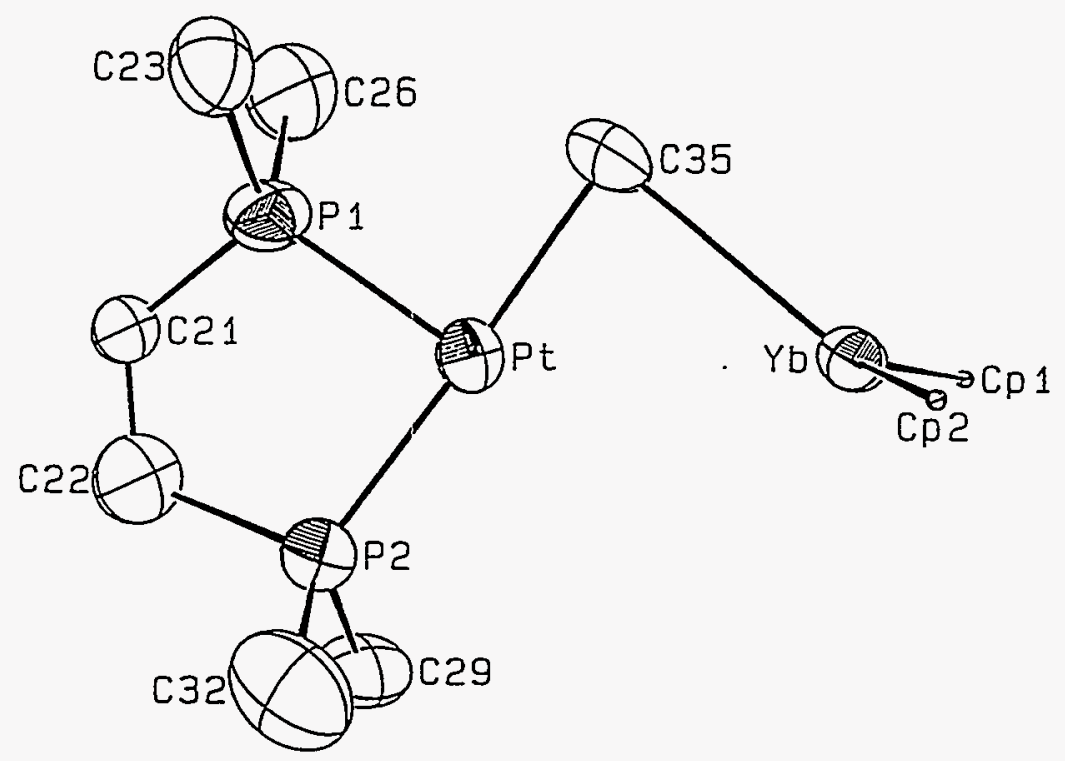

Figure 9. ORTEP diagram of (dippe) $\operatorname{Pt}(\mu-\mathrm{Me})(\mu-\mathrm{H}) \mathrm{YbCp}_{2}{ }_{2}$ (11), $50 \%$ probability thermal ellipsoids. For clarity, the disordered iso-propyl groups and $\mathrm{Cp}^{*}$ rings are not shown (the $\mathrm{Cp}^{*}$ ring centroid positions are shown.)

The normally higher trans influence of the hydride ligand relative to an alkyl group 53 is absent, likely a result of the stronger Yb-hydride interaction vs. the Yb-methyl interaction. The Pt-methyl carbon distance in $\mathbf{1 1}(2.16(2) \AA)$ is identical within 
experimental error to the analogous distances found for 9 (2.089(9) and 2.099(8) $\AA$ ). The P1-Pt-P2/Cp1-Yb-Cp2 torsional angle $\left(92(2)^{\circ}\right), \mathrm{Yb}_{-} \mathrm{Cp}^{*}$ distances (2.41 and 2.43 $\AA)$, and $\mathrm{Cp}^{*}-\mathrm{Yb}-\mathrm{Cp}^{*}$ angle $\left(137(1)^{\circ}\right)$ are normal. The $\mathrm{Pt}-\mathrm{C} 35-\mathrm{Yb}$ angle of $85^{\circ}$ contrasts with the analogous values for $9\left(107^{\circ}\right.$ and $\left.108^{\circ}\right)$, and shows the asymmetry of the bridge. This angle is within the range normally found for $\mathrm{M}(\mu-\mathrm{Me})_{2} \mathrm{M}$ ' structures possessing $\mathrm{M}$ $\mathrm{C}-\mathrm{M}^{\prime}$ three-center/two-electron type interactions, 28 in contrast to the situation found for 9.

The results presented above show that cis- $\mathrm{P}_{2} \mathrm{PtH}_{2}$ and $c i s-\mathrm{P}_{2} \mathrm{Pt}(\mathrm{Me})(\mathrm{H})$ complexes form interactions of significant strength with the bent metallocene $\mathrm{Cp}_{2}{ }_{2} \mathrm{Yb}$, giving stopped-exchange adducts, on the NMR timescale. It is clear that a Pt-bound hydride is a better ligand towards 1 than a Pt-bound methyl group. Strictly speaking, the exchange behavior observed for 9 indicates that the kinetic barrier for the interaction of 1 with 8 is small, relative to the barrier for the dihydride (and methyl hydride) complexes. Given the bent geometry of $\mathbf{1}$ and the overall lack of structural changes in general upon forming the Lewis acid-base adducts from 1 and the cis- $\mathrm{P}_{2} \mathrm{PtX}_{2}$ complexes, it is reasonable to assume that this barrier gives a qualitative indication of the strength of the interaction (this will be discussed in more detail in Chapter 3). Thus, the higher barriers for 5 and 7 (stopped-exchange), relative to the smaller barrier for $\mathbf{9}$ (fast intermolecular exchange), are consistent with $\mathrm{Yb}$-hydride interactions that are thermodynamically stronger than $\mathrm{Yb}$-methyl interactions (the unchanged ${ }^{1} \mathrm{~J}_{\mathrm{CH} 3}$ value and lack of any low frequency $\mathrm{C}-\mathrm{H}$ stretches in the solid-state infrared spectrum of 9 are further indications of the weakness of the $\mathrm{Yb}$-methyl interactions). 
$\underline{\text { References. }}$

(1) (a) Green, M. L. H.; Hughes, A. K.; Michaelidou, D. M.; Mountford, P. J. Chem. Soc., Chem. Commun. 1993, 591. (b) Hasinoff, L.; Takats, J.; Zhang, X. W.; Bond, A. H.; Rogers, R. D. J. Am. Chem. Soc. 1994, 116, 8833.

(2) Chatt, J.; Leigt. G. J. Angew. Chem., Int. Ed. Engl. 1978, 17, 400.

(3) Yoshida, T. Yamagata, T.; Tulip, T. H. Ibers, J. A.; Otsuka, S. J. Am. Chem. Soc. 1978, 100, 2063.

(4) (a) Green, M.; Howard, J. A. K.; Proud, J.; Spencer, J. L.; Stone, F. G. A.; Tsipis, C. A. J. Chem. Soc., Chem. Commun. 1976, 671. (b) Ciriano, M.; Green, M.; Proud, J.; Spencer, J. L.; Stone, F. G. A.; Tsipis, C. A. J. Chem. Soc., Dalton Trans. 1978, 801. (c) Tulip, T. H.; Yamagata, T.; Yoshida, T.; Wilson, R. D.; Ibers, J. A.; Otsuka, S. Inorg. Chem. 1979, $18,2239$.

(5) Watson, P. L. J. Chem. Soc., Chem. Commun. 1980, 652.

(6) (a) Bax, A.; Griffey, R. H.; Hawkins, B. L. J. Magn. Reson. 1983, 55, 301. (b) Bax, A.; Subramanian, S. J. Magn. Reson. 1986, 67, 565.

(7) (a) Emerson, S. D.; Montelione, G. T. J. Am. Chem. Soc. 1992, 114, 354. (b) Griesenger, C.; Sorensen, O. W.; Ernst, R. R. J. Am. Chem. Soc. 1985, 107, 6394.

(8) Pregosin, P. S. In Transition Metal Nuclear Magnetic Resonance; Pregosin, P. S., Ed.; Elsevier Science Publishing Company Inc.: New York, 1991, pp. 234-242; and references therein.

(9) (a) Burns, C. J.; Andersen, R. A. J. Am. Chem. Soc. 1987, 109, 941. (b) Schumann, H.; Glanz, M.; Winterfeld, J.; Hemling, H.; Kuhn, N.; Kratz, T. Angew. Chem. Int. Ed. Engl. 1994, 33, 1733. (c) Burns, C. J.; Andersen, R. A. J. Am. Chem. Soc. 1987, 109, 5853. (d) Burns, C. J.; Andersen, R. A. J. Am. Chem. Soc. 1987, $109,915$. 
(10) Bracher, G.; Grove, D. M.; Pregosin, P. S.; Venanzi, L. M. Angew. Chem., Int. Ed. Engl. 1979, $18,155$.

(11) (a) Naegeli, R.; Togni, A.; Venanzi, L. M. Organometallics. 1983, 2, 926. (b) Boron, P.; Musco, A.; Venanzi, L. M. Inorg. Chem. 1982, 21, 4192.

(12) It has been reported that $\left(\mathrm{Cy}_{2} \mathrm{P}\left(\mathrm{CH}_{2}\right)_{n} \mathrm{PCy}_{2}\right) \mathrm{PtH}_{2}(\mathrm{n}=3,4)$ complexes show evidence for $\eta^{2}$-dihydrogen behavior, based on variable temperature ${ }^{1} \mathrm{H}$ NMR spectroscopy--Clark, H. C.; Hampden Smith, M. J. J. Am. Chem. Soc. 1986, 108, 3829.

(13) (a) Kidd, R. G.; Goodfellow, R. J. In NMR and the Periodic Table; Harris, R. K.; Mann, B. E., Eds.; Academic Press Inc.: New York, 1978. (b) Avent, A.; Edelman, M. A.; Lappert, M. F.; Lawless, G. A. J. Am. Chem. Soc. 1989, 111, 3423.

(14) It is known that ${ }^{171} \mathrm{Yb}$ chemical shifts have a large temperature dependence, ref. $13 \mathrm{~b}$.

(15) van den Hende, J. R.; Hitchcock, P. B.; Lappert, M. F.; Nile, T. A. J. Organomet. Chem. 1994, 472, 79.

(16) Bell, J. D.; Hall, D.; Waters, T. N. Acta Crystallogr. 1966, 2I, 440.

(17) Pauling, L. In The Nature of the Chemical Bond, 3rd ed.; Cornell University Press: Ithaca, New York, 1960; pp. 260-261.

(18) Deacon, G. B.; Dietrich, A.; Forsyth, C. M.; Schumann, H. Angew. Chem., Int. Ed. Engl. 1989, 28, 1370.

(19) (a) Hofmann, P.; Heiss, H.; Muller, G. Z. Naturforsch. 1987, B42, 395; and references cited therein. (b) Otsuka, S. J. Organomet. Chemistry. 1980, 200, 191.

(20) We have found that for (dcypp)Pt(H)(D), $12{ }^{1} \mathrm{~J}_{\mathrm{HD}}$ is $\leq 4 \mathrm{~Hz}$ at $25^{\circ} \mathrm{C}$, using ${ }^{1} \mathrm{H}\left\{{ }^{31} \mathrm{P}\right\}$ NMR spectroscopy.

(21) Hackett, M.; Ibers, J. A.; Whitesides, G. M. J. Am. Chem. Soc. 1988, 110, 1436. 
(22) Barnett, B. L.; Kruger, C.; Tsay, Y-H. Chem. Ber. 1977, 110, 3900.

(23) Green, M.; Howard, J. A.; Spencer, J. L.; Stone, F. G. A. J. Chem. Soc., Chem. Commun. 1975, $1,3$.

(24) Yoshida, T.; Otsuka, S. Inorg. Syn.. 1990, 28, 113.

(25) Clark, H. C.; Hampden-Smith, M. J. Coord. Chem. Rev. 1987, 79, 229.

(26) Barnhart, D. M.; Clark, D. L.; Gordon, J. C.; Huffman, J. C.; Watkin, J. G.; Zwick, B. D. J. Am. Chem. Soc. 1993, 115, 8461. This article reports that the solidand solution-state IR spectra of $\mathrm{Ln}_{4}\left(\mathrm{OCH}_{2} \mathrm{Bu}\right)_{12}(\mathrm{Ln}=\mathrm{La}, \mathrm{Nd})$ contain low frequency $\mathrm{C}-\mathrm{H}$ stretches characteristic of $\mathrm{Ln}-\mathrm{H}-\mathrm{C}$ interactions.

(27) (a) Kirchner, R. M.; Little, R. G.; Tau, K. D.; Meek, D. W. J. Organomet. Chem. 1978, 149, C15. (b) Wisner, J. M.; Bartczak, T. J.; Ibers, J. A. Organometallics. 1986, 5, 2044.

(28) (a) Tilley, T. D.; Andersen, R. A.; Zalkin, A. J. Am. Chem. Soc. 1982, 104, 3725; and references cited therein. (b) Stults, S. D.; Andersen, R. A.; Zalkin, A. J. Organomet. Chem. 1993, 462, 175.

(29) Holton, J.; Lappert, M. F.; Ballard, D. G. H.; Pearce, R.; Atwood, J. L.; Hunter, W. E. J. Chem. Soc., Chem. Commun. 1976, 480.

(30) de Graaf, W.; Boersma, J.; Smeets, W. J. J.; Spek, A. L.; Koten, G. Organometallics. 1989, 8, 2907.

(31) Holton, J.; Lappert, M. F.; Scollary, G. R.; Ballard, D. G. H.; Pearce, R.; Atwood, J. L.; Hunter, W. E. J. Chem. Soc., Chem. Commun. 1976, 425.

(32) (a) Lewis, P. H.; Rundle, R. E., J. Chem. Phys. 1953, 21, 986. (b) Vranka, R. G.; Amma, E. L. J. Am. Chem. Soc. 1967, 89, 3121. (c) Huffman, J. C.; Streib, W. E. J. Chem. Soc., Chem. Commun. 1971, 911. 
(33) (a) Watson, P. L.; Parshall, G. W. Acc. Chem. Res. 1985, 18, 51. (b) Busch, M. A.; Harlow, R.; Watson, P. L. Inorg. Chim. Acta. 1987, 140, 15. (c) Hitchcock, P. B.; Lappert, M. F.; Smith, R. C. J. Chem. Soc., Chem. Commun. 1989, 369.

(34) (a) Waymouth, R. M.; Santarsiero, B. D.; Coots, R. J.; Brownikowski, M. J.; Grubbs, R. H.J. Am. Chem. Soc. 1986, 108, 1427. (b) Waymouth, R. M.; Santarsiero, B. D.; Grubbs, R. H. J. Am. Chem. Soc. 1984, 106, 4050. (c) Waymouth, R. M.; Potter, K. S.; Schaeffer, W. P.; Grubbs, R. H. Organometallics. $1990,2843$.

(35) (a) Ozawa, F.; Park, J. W.; Mackenzie, P. B.; Schaefer, W. P.; Henling, L. M.; Grubbs, R. H. J. Am. Chem. Soc. 1989, 111, 1319. (b) Park, J. W.; Mackenzie, P. B.; Schaefer, W. P.; Grubbs, R. H. J. Am. Chem. Soc. 1986, 108, 6402. (c) Dawkins, G. M.; Green, M.; Orpen, A. G.; Stone, F. G. A. J. Chem. Soc., Chem. Commun. 1982, 41.

(36) (a) Hitchcock, P. B.; Howard, J. A. K.; Lappert, M. F.; Prashar, S. J. Organomet. Chem. 1992, 437, 177. (b) Yang, X.; Stern, C. L.; Marks, T. J. J. Am. Chem. Soc. $1991,113,3623$.

(37) Hackett, M.; Whitesides, G. M. J. Am. Chem. Soc. 1988, 110, 1449.

(38) Alcock, N. W.; Brown, J. M.; MacLean, T. D. J. Chem. Soc., Chem. Commun. 1984, 1689.

(39) Sanders, J. C. P.; Schrobilgen, G. J. In Multinuclear Magnetic Resonance in Liquids and Solids--Chemical Applications; Granger, P.; Harris, R. K., Eds.; Kluwer Academic Publishers: Dordrecht, The Netherlands, 1990, Ch. XI.

(40) Bodenhausen, G.; Ruben, D. J. Chem. Phys. Lett. 1980, 69, 185.

(41) For example, ${ }^{1} \mathrm{~J}_{\mathrm{CH} 3}$ for the terminal and bridging methyl groups of $\left(\left(\mathrm{CH}_{3}\right)_{3} \mathrm{Al}\right)_{2}$ are $112.7 \mathrm{~Hz}$ and $115.3 \mathrm{~Hz}$, respectively (Olah, G. A.; Prakash, K. S.; Liang, G.; Henold, K. L.; Haigh, G. B. Proc. Natl. Acad. Sci. USA. 1977, 74, 5217). 
(42) (a) Neve, F.; Ghedini, M.; Crispini, A. Organometallics. 1992, 11, 3324. (b) Albinati, A.; Pregosin, P. S.; Wombacher, F. Inorg. Chem. 1990, 29, 1812. (c) Albinati, A.; Anklin, C. G.; Ganazoli, F.; Ruegg, H.; Pregosin, P. S. Inorg. Chem. 1987, 26, 503. (d) Albinati, A.; Arz, C.; Pregosin, P. S. Inorg. Chem. 1987, 26, 508. (e) Anklin, C. G.; Pregosin, P. S. Magn. Res. Chem. 1985, 23, 671. (f) Deeming, A. J.; Rothwell, I. P.; Hursthouse, M. B.; Abdul Malik, K. M. J. Chem. Soc., Dalton Trans. 1980, 1974.

(43) Jameson, C. J. In Multinuclear NMR; Mason, J., ed.; Plenum Press: New York, 1987, pp. 106-109.

(44) (a) Green, M. L. H.; Hughes, A. K.; Popham, N. A.; Stephens, A. H. H.; Wong, L.-L. J. Chem. Soc., Dalton Trans. 1992, 3077. (b) Calvert, R. B.; Shapley, J. R. J. Am. Chem. Soc. 1978, 100, 7726. (c) Casey, C. P.; Fagan, P. J.; Miles, W. H. J. Am. Chem. Soc. 1982, 104, 1134.

(45) Holton, J.; Lappert, M. F.; Ballard, D. G. H.; Pearce, R.; Atwood, J. L.; Hunter, W. E. J. Chem. Soc., Dalton Trans. 1979, 54.

(46) Holton, J.; Lappert, M. F.; Ballard, D. G. H.; Pearce, R.; Atwood, J. L.; Hunter, W. E. J. Chem. Soc., Dalton Trans. 1979, 45.

(47) Evans, W. J.; Meadows, J. H.; Wayda, A. L.; Hunter, W. E.; Atwood, J. L. J. Am. Chem. Soc. 1982, 104, 2008.

(48) Booij, M.; Deelman, B.-J.; Duchateau, R.; Postma, D. S.; Meetsma, A.; Teuben, J. H. Organometallics. 1993, 12, 3531.

(49) Bennett, M. A.; McMahon, I. J.; Pelling, S.; Robertson, G. B.; Wickramasinghe, W. A. Organometallics. 1985, 4, 754.

(50) G. E. Ball, unpublished results.

(51) Two examples of $\mathrm{Pt}(\mathrm{II})$ complexes containing $\mathrm{B}$-agostic $\mathrm{CH}_{3}$ interactions, in which rotation about the $\mathrm{C}_{\alpha}-\mathrm{C}_{\text {agostic }}$ bond can be frozen out, have been reported (Carr, N.; Mole, L.; Orpen, A. G.; Spencer, J. L. J. Chem. Soc., Dalton Trans. 1992, 2653); 
unfortunately, the coupling constants between the agostic $\mathrm{C}$ and $\mathrm{H}$ nuclei and the $\mathrm{Pt}$ center were not reported.

(52) The $\delta\left(\mathrm{CH}_{3}\right)$ resonance for 11 is shifted upfield, relative to the analogous value in 10. Ref. $42 \mathrm{~b}$ contains a discussion concerning the origin of the low-field ${ }^{1} \mathrm{H}$ shifts for weak agostic complexes.

(53) Hackett, M.; Ibers, J. A.; Jernakoff, P.; Whitesides, G. M. J. Am. Chem. Soc. 1986, 108, 8094. This paper reports that for the solid state structure of (dcype) $\mathrm{Pt}\left(\mathrm{CH}_{2} \mathrm{C}\left(\mathrm{CH}_{3}\right)_{3}(\mathrm{H})\right.$, the Pt-P distances are 2.278(2) $\AA$ (trans to hydride) and 2.253(2) $\AA$ (trans to alkyl group), respectively). 


\section{CHAPTER 2}

\section{Reversible Formation of $\left(\mathrm{P}_{2} \mathrm{PtH}\right)_{2} \mathrm{Pt}(\mathrm{I})$ Complexes from cis- $\mathbf{P}_{2} \mathbf{P t H}_{2}$ Complexes}

In the course of preparing the cis-(P-P)PtH2 complexes discussed in Chapter 1, it was observed that these complexes are not stable in solution (under $1 \mathrm{~atm} . \mathrm{N}_{2}$ ), and that conversion to dimeric complexes occurs over time (the "P-P" abbreviation will be used to signify a bidentate phosphine ligand, $\mathrm{R}_{2} \mathrm{P}\left(\mathrm{CH}_{2}\right)_{\mathrm{n}} \mathrm{PR}$, throughout this chapter). Replacing the dinitrogen atmosphere over the samples with $1 \mathrm{~atm} . \mathrm{H}_{2}$ results in clean conversion back to the original cis-(P-P) $\mathrm{PtH}_{2}$ monomeric complexes, which are stable indefinitely under the dihydrogen atmosphere. While there have been reports in the literature concerning the solution-state instability of $c i s-\mathrm{P}_{2} \mathrm{PtH}_{2}$ complexes, these reports are scarce, and the area has not been subjected to detailed investigation. Consequently, it was considered worthwhile to investigate these dimeric complexes in more detail.

In 1976 Moulton and Shaw, in the first report of a cis dihydride complex of $\mathrm{Pt}, 1$ reported that cis dihydride platinum complexes are isolable only when bidentate, sterically bulky phosphines are used as ancillary ligands, in order to prevent decomposition via loss of dihydrogen. ${ }^{2}$ Since then, only one paper has been published that investigates this decomposition in detail: ${ }^{3}$ in the course of preparing $c i s-(\mathrm{P}-\mathrm{P}) \mathrm{PtH}_{2}$ complexes with various phosphines, Otsuka and co-workers found that only the derivatives containing sterically bulky phosphines were stable in solution. Solutions of the derivatives containing smaller phosphines gradually darkened in color, and the intensity of the

hydride resonance in the ${ }^{1} \mathrm{H}$ NMR spectrum as well as the $\mathrm{Pt}-\mathrm{H}$ stretch in the infrared spectrum, diminished over time. Otsuka et al. suggested that for the $\mathrm{P}_{2} \mathrm{PtH}_{2}$ derivatives containing sterically smaller phosphines, reversible loss of dihydrogen was occurring to give $\left(\mathrm{P}_{2} \mathrm{Pt}\right)_{2}$ dimers in solution. This postulate was made based on the above observations, and the fact that reduction of (dtbpp) $\mathrm{PtCl}_{2}$ in tetrahydrofuran under $1 \mathrm{~atm}$. 
of $\mathrm{N}_{2}$ yields only the hydride-free compound $[\mathrm{Pt}(\mathrm{dtbpp})]_{2}$. However, this reddishorange $\mathrm{Pt}(0)$ dimer is controversial as some of its chemical reactions imply the presence of hydride ligands, ${ }^{3}$ suggesting that perhaps more than one species is present in solution.

Several other papers have briefly mentioned the solution-state instability of cis$\mathrm{P}_{2} \mathrm{PtH}_{2}$ complexes. Clark and Hampden-Smith have reported that the hydrides in (dcypp) $\mathrm{PtH}_{2}$ are fluxional, undergoing mutual exchange on the NMR timescale; they posulated that $\eta^{2}$-hydrogen complexes are involved.4a,c This same paper also reports that (P-P) $\mathrm{PtH}_{2}$ complexes, for $\mathrm{P}_{2}=$ dcype or dcypp, lose dihydrogen in solution and generate species that were identified as dimers of the formula $[(\mathrm{P}-\mathrm{P}) \mathrm{PtH}]_{2}$, on the basis of ${ }^{1} \mathrm{H}$ and ${ }^{31} \mathrm{P}$ NMR spectroscopy. This deduction was questioned by Pidcock and coworkers, ${ }^{4 \mathrm{~b}}$ as they showed that warming a solution of (dppe) $\mathrm{PtH}_{2}$, formed at low temperature, to room temperature yields the dimer $[(\mathrm{dppe}) \mathrm{Pt} H]_{2}$, whose ${ }^{1} \mathrm{H}$ and ${ }^{31} \mathrm{P}\left\{{ }^{1} \mathrm{H}\right\}$ NMR spectra are very different from those of the (dcype) and (dcypp) derivatives in ref. 4a. The latter complexes give NMR spectra that are similar to those that have been observed for cationic complexes of the type $\left[(\mathrm{P}-\mathrm{P})_{2} \mathrm{Pt}_{2} \mathrm{H}_{3}\right][\mathrm{X}](\mathrm{X}=$ an anion $){ }^{5}$ the proton source in this case is presumably $\mathrm{H}_{2} \mathrm{O}$, the anion [OH].

The fluxional cation, $\left[\mathrm{P}_{4} \mathrm{Pt}_{2} \mathrm{H}_{3}\right][\mathrm{X}]$, with either one or two bridging hydrides in the solid state, is a pervasive structural feature in platinum hydride chemistry. 5 These cationic complexes are generally synthesized either by reaction of a $\mathrm{P}_{2} \mathrm{PtX} \mathrm{X}_{2}$ complex $(\mathrm{X}=$ a leaving group, usually a halide) with an excess of a hydride reagent (e.g., $\mathrm{KBH}_{4}$, $\mathrm{NaBH}_{4}$, etc.) in a protic solvent, or by reaction of a $\mathrm{P}_{2} \mathrm{PtH}_{2}$ "intermediate" (almost always formed in situ), with a $\mathrm{P}_{2} \mathrm{PtY}_{2}$ complex ( $\mathrm{Y}=$ an anion or a leaving group). The use of protic solvents in the first case, and the in situ formation and immediate use of the $\mathrm{P}_{2} \mathrm{PtH}_{2}$ complexes in the latter case, preclude a detailed study of the hydride-containing intermediates, and assures cationic products. Consequently, while the structure and reactivity of these $\left[\mathrm{P}_{4} \mathrm{Pt}_{2} \mathrm{H}_{3}\right][\mathrm{X}]$ complexes have been studied in great detail, the mechanism(s) of their formation is largely unknown. 
In contrast to the detailed structural studies of the cationic complexes, no crystal structures of neutral dimeric platinum hydrides of the type $\left(\mathrm{P}_{2} \mathrm{PtH}\right)_{2}$ have been reported, though they are generally written as if they contain symetrically bridging hydride ligands, ${ }^{4}$ in analogy with $[(\mathrm{dcypp}) \mathrm{Ni}(\mu-\mathrm{H})]_{2} \cdot{ }^{6 \mathrm{a}}, \mathrm{b}$ Recently, the related palladium hydride dimer, $[(\operatorname{dippp}) \operatorname{Pd}(\mu-\mathrm{H})]_{2}$, has been described.6c Both the $\mathrm{Ni}$ and $\mathrm{Pd}$ dimers were prepared by reduction of a phosphine dihalide complex with an excess of a hydride reagent (NaHBMe 3 for the the Ni dimer, $\mathrm{KHBEt}_{3}$ for the Pd dimer); the details of the .eactions were not investigated, though hydride intermediates are presumably involved. The present study was undertaken to remedy the lack of knowledge concerning the $\mathrm{Pt}$ dimer analogues and the solution-state instability of cis- $\mathrm{P}_{2} \mathrm{PtH}_{2}$ complexes.

Syntheses of $\left[\mathrm{P}_{2} \mathrm{PtH}\right]_{2}$ Complexes. Stirring a thf solution of (dippe) $\mathrm{PtCl}_{2}$ with sodium amalgam under $1 \mathrm{~atm}$. of $\mathrm{H}_{2}$ for one day gives the dimer $[(\text { dippe }) \mathrm{PtH}]_{2}(\mathbf{1})$ as the sole product, isolated in $62 \%$ yield. This result was unexpected as the synthetic method is identical (except for the identity of the phosphine) to that used by Otsuka to synthesize (dtbpe) $\mathrm{PtH}_{2} \cdot{ }^{3}$ The dimer 1 is light brown in color, soluble in aliphatic hydrocarbons, and is volatile enough to give a molecular ion in the mass spectrum. The dimeric nature of 1 is clear from the ${ }^{31} \mathrm{P}\left\{{ }^{1} \mathrm{H}\right\}$ NMR spectrum, in which two different $195 \mathrm{Pt}-31 \mathrm{P}$ coupling constants are observed. The solid state infrared spectrum shows two strong bands, at 1939 and $1926 \mathrm{~cm}^{-1}$, indicating the presence of terminal hydride ligands. Thi ${ }^{1} \mathrm{H}$-coupled ${ }^{195 P t}$ INEPT NMR spectrum (given in Appendix $\mathrm{I}$ ) shows that there are two hydrides/dimer. The hydride region of the ${ }^{1} \mathrm{H}$ NMR spectrum of 1 shows an apparent 'quintet of quintets', $5 \mathrm{a}, 5 \mathrm{~g}$ indicating equivalency on the NMR timescale within the sets of four phosphorus, two platinum, and two hydride nuclei, at $25^{\circ} \mathrm{C}$. This results from a fast fluxional process (on the NMR timescale), which will be discussed in detail below.

A similar synthetic procedure using (dcype) $\mathrm{PtCl}_{2}$ yields the known monomer (dcype) $\mathrm{PtH}_{2}(5)^{4 \mathrm{a}}$ as colorless crystals, in $85 \%$ yield after crystallization from thf. 
Inspection of the ${ }^{31} \mathrm{P}\left\{{ }^{1} \mathrm{H}\right\}$ NMR spectrum of the crude reaction mixture in $\mathrm{C}_{6} \mathrm{D}_{6}$ showed that it contained a ca. 9:1 ratio of 5 and a material shown to be the dimer [(dcype)PtH]2 (2). This ratio is unchanged indefinitely under nitrogen at room temperature, and is also unchanged after prolonged heating at $90^{\circ} \mathrm{C}$ in a closed system. However heating a sample of 5 in toluene at reflux for 16 hours, under a slow purge of nitrogen (i.e, in an open system), gives 2 as a yellow powder in 58\% isolated yield. Clearly, the removal of $\mathrm{H}_{2}$ from the reaction system drives the reaction towards the dimer. The ${ }^{1} \mathrm{H}$ and ${ }^{31} \mathrm{P}\left\{{ }^{1} \mathrm{H}\right\}$ NMR data of $\mathbf{2}$ are similar to those of $\mathbf{1}$. The solid state infrared spectrum shows two features at 1965 and $1937 \mathrm{~cm}^{-1}$, due to terminal Pt-H stretches.

As mentioned above, conversion of 5 to $\mathbf{2}$ in solution has been reported in the literature. ${ }^{4 a}$ In contrast to our findings, these authors reported that room temperature solutions of 5 gave complete conversion to 2 within one hour. In addition, as mentioned above, Pidcock and co-workers have suggested that the species identified by Clark and Hampden-Smith as "[(dcype) $\mathrm{Pt}(\mu-\mathrm{H})]_{2}$ " is actually [(dcype $\left.{ }_{2} \mathrm{Pt}_{2} \mathrm{H}_{3}\right][\mathrm{OH}]$. We have found that adding several drops of water to a benzene solution of 5 results in clean conversion to $\left[(\mathrm{dcype}){ }_{2} \mathrm{Pt}_{2} \mathrm{H}_{3}\right][\mathrm{OH}]$. The NMR values of this cationic complex (see later discussion) show that this is indeed the complex that Clark and Hampden-Smith identified as 2 , confirming the suggestion made by Pidcock et al. $4 \mathrm{~b}$

A benzene solution of (dtbpe) $\mathrm{PtH}_{2}$ (6), prepared using Otsuka's method, ${ }^{3}$ is stable indefinitely at room temperature under nitrogen, as was found for 5 . In contrast to 5 , no evidence of a dimeric complex is seen in the ${ }^{1} \mathrm{H}$ and ${ }^{31} \mathrm{P}\left\{{ }^{1} \mathrm{H}\right\}$ NMR spectra of the crude reaction mixture. Otsuka and co-workers reported that $\mathbf{6}$ is stable in solution up to temperatures of $100^{\circ} \mathrm{C}$. We found that this is indeed true for a toluene solution of 6 in a closed system. However, analogous to 5 , heating a toluene solution of 6 at $90^{\circ} \mathrm{C}$ for 16 hours under a slow purge of nitrogen gives a reddish-brown solution from which [(dtbpe) $\mathrm{PtH}_{2}$ (3) can be isolated in $73 \%$ yield, as dark orange crystals. This dimer also shows two terminal Pt-H stretching frequencies in the infrared spectrum, at 1975 and 
$1951 \mathrm{~cm}^{-1}$. The dimer 3 is stable indefinitely in benzene under nitrogen at room temperature, and has similar ${ }^{1} \mathrm{H}$ and ${ }^{31} \mathrm{P}\left\{{ }^{1} \mathrm{H}\right\}$ NMR spectrat values to those of 1 and 2 .

Monomer/Dimer Equilibrium. Benzene solutions of all three of the dimers, 1-3, are stable at room temperature under a dinitrogen atmosphere. However, when the dinitrogen is replaced by dihydrogen gas ( $1 \mathrm{~atm}$ ), quantitative conversion to the cisdihydride monomers occurs within 24 hours for all three samples; conversion was followed by ${ }^{31} \mathrm{P}\left\{{ }^{1} \mathrm{H}\right\} \mathrm{NMR}$ spectroscopy. The (dippe) $\mathrm{PtH}_{2}$ monomer (4) was not isolated as it was found to be stable only under an atmosphere of dihydrogen gas; its identity was deduced by the similarity of its ${ }^{1} \mathrm{H}$ and ${ }^{31} \mathrm{P}\left\{{ }^{1} \mathrm{H}\right\}$ NMR spectral values to those of 5 and 6 (Table 1).

Table 1, $1 \mathrm{H}$ and 31 P $\{\underline{\mathrm{H}}\}$ NMR Data for the Monomers $4-6\left(25^{\circ} \mathrm{C}, \mathrm{C}_{6} \mathrm{D}_{6}\right)$.

\begin{tabular}{lcccccc} 
& $\begin{array}{c}\delta(\mathrm{Pt}-\mathrm{H}) \\
\mathrm{ppm}\end{array}$ & $\begin{array}{c}{ }^{2 J_{\mathrm{PtransH}},} \\
\mathrm{Hz}\end{array}$ & $\begin{array}{c}{ }^{2} \mathrm{JP}_{\mathrm{PisH}}, \\
\mathrm{Hz}\end{array}$ & $\begin{array}{c}{ }^{1} \mathrm{~J}_{\mathrm{PtH}}, \\
\mathrm{Hz}\end{array}$ & $\begin{array}{c}\delta(\mathrm{P}), \\
\mathrm{ppm}\end{array}$ & $\begin{array}{c}{ }^{1} \mathrm{~J}_{\mathrm{PtP}}, \\
\mathrm{Hz}\end{array}$ \\
\hline $4^{\mathrm{a}}$ & 0.46 & 179 & 16 & 1097 & 87.9 & 1829 \\
5 & 0.56 & 179 & 16 & 1100 & 78.2 & 1822 \\
6 & -0.54 & 180 & 16 & 1096 & 107.8 & 1872
\end{tabular}

aNot isolated, see text.

Solutions of 5 and 6 (converted from 2 and 3) are then stable indefinitely when the dihydrogen is replaced by $1 \mathrm{~atm}$. dinitrogen. In contrast, the sample of 4 slowly reverts to 1 when the dihydrogen atmosphere is replaced by dinitrogen; the sample consists of a ca. 2:1 ratio of $1: 4$ after 100 hours at room temperature under dinitrogen. Interconversion of $\mathbf{1}$ and 4 was found to be facile, depending upon whether $\mathrm{N}_{2}$ or $\mathrm{H}_{2}$ is present over the solution (eq. 1). This interconversion is clean, with no by-products observed in the ${ }^{31} \mathrm{P}\left\{{ }^{1} \mathrm{H}\right\}$ spectrum, indicating that eq. 1 is a reversible chemical equilibrium. 


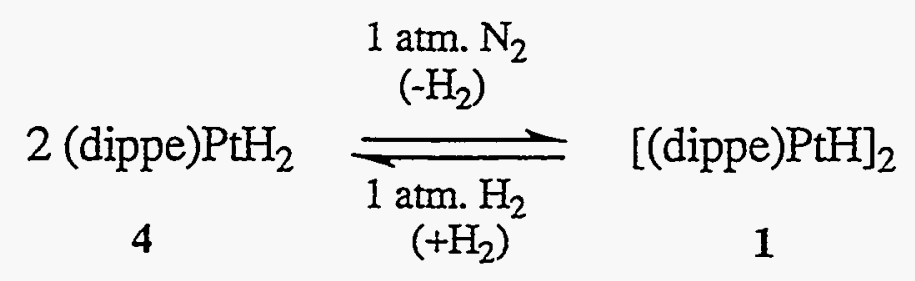

Solid State Structures of $[(\text { dippe }) \mathrm{PtH}]_{2}$ and $[(\mathrm{dtbpe}) \mathrm{PtH}]_{2}$. The ORTEP diagrams of 1 and 3 are shown in Figures 1 and 2, respectively; selected bond lengths and angles (Table 2) are also given. The hydride ligands could not be located, but their positions are inferred from the square planar geometry about each platinum center. Qualitatively, both structures contain two square planar platinum centers, the coordination sphere of each consisting of two phosphorus atoms, one hydride, and the other platinum atom; the idealized symmetry is $\mathrm{C}_{2}$. Formally, both metal centers are in the $+\mathrm{I}$ oxidation state and a metal-metal bond is present, accounting for the observed diamagnetism. Dimeric platinum hydride complexes possessing an unbridged Pt-Pt bond have not been structurally characterized before.

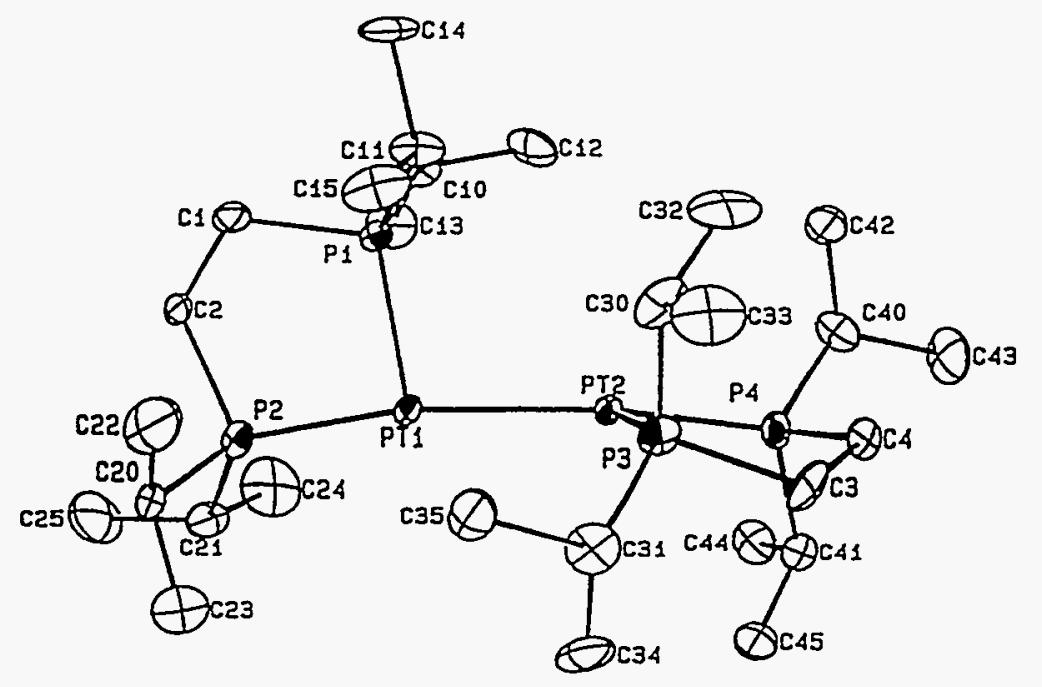

Figure 1. ORTEP diagram of [(dippe) $\mathrm{PtH}]_{2}$ (1), $50 \%$ probability ellipsoids. 


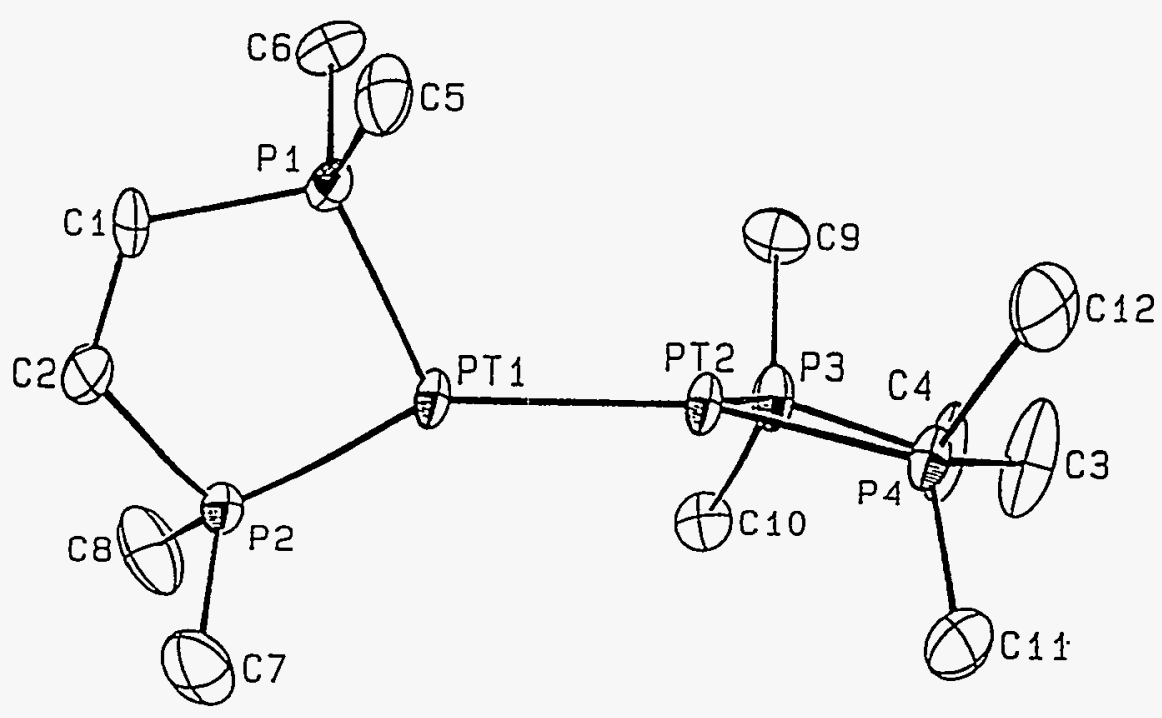

Figure 2. ORTEP diagram of [(dtbpe)PtH] 2 (3), 50\% probability ellipsoids. For clarity, the disordered methyl groups and the toluene solvate are not shown. No hydrogen atoms were included in the model (see Experimental chapter for details).

Table 2. Selected Intramolecular Distances $(\AA)$ and Angles (deg) in [(dippe) $\mathrm{PtH}]_{2}(1)$ and [(dtbpe) $\mathrm{PtH}_{2}(3)$

\begin{tabular}{|c|c|c|}
\hline & 1 & 3 \\
\hline $\begin{array}{l}\mathrm{Pt}(1)-\mathrm{Pt}(2) \\
\mathrm{Pt}(1)-\mathrm{P}(1) \\
\mathrm{Pt}(1)-\mathrm{P}(2) \\
\mathrm{Pt}(2)-\mathrm{P}(3) \\
\mathrm{Pt}(2)-\mathrm{P}(4)\end{array}$ & $\begin{array}{l}2.5777(5) \\
2.257(3) \\
2.242(3) \\
2.254(3) \\
2.244(3)\end{array}$ & $\begin{array}{l}2.6094(6) \\
2.274(3) \\
2.248(3) \\
2.281(3) \\
2.260(3)\end{array}$ \\
\hline $\begin{array}{l}\mathrm{Pt}(1)-\mathrm{Pt}(2)-\mathrm{P}(3) \\
\mathrm{Pt}(1)-\mathrm{Pt}(2)-\mathrm{P}(4) \\
\mathrm{Pt}(2)-\mathrm{Pt}(1)-\mathrm{P}(1) \\
\mathrm{Pt}(2)-\mathrm{Pt}(1)-\mathrm{P}(2) \\
\mathrm{P}(1)-\mathrm{Pt}(1)-\mathrm{P}(2) \\
\mathrm{P}(3)-\mathrm{Pt}(2)-\mathrm{P}(4)\end{array}$ & $\begin{array}{l}102.12(8) \\
167.43(8) \\
100.53(7) \\
168.59(9) \\
88.56(10) \\
88.23(11)\end{array}$ & $\begin{array}{l}114.71(8) \\
153.75(9) \\
115.70(8) \\
152.31(9) \\
89.76(12) \\
89.58(11)\end{array}$ \\
\hline
\end{tabular}

Considering first the structure of 1 , the Pt-P bond distances are in the expected range. 3,7 The distances for the pair of phosphorus atoms trans to the hydrides $(\mathrm{Pt}(1)$ $\mathrm{P}(1), 2.257(3) \AA ; \operatorname{Pt}(2)-\mathrm{P}(3), 2.254(3) \AA)$ are identical within experimental error to the analogous distances for the pair trans to the other platinum atom ( $P(1)-P(2), 2.242(3) \AA$, 
$\mathrm{Pt}(2)-\mathrm{P}(4), 2.244(3) \AA)$, indicating that the terminal $\mathrm{Pt}-\mathrm{H}$ bond and the Pt-Pt bond have similar trans influences. The $\operatorname{Pt}(1)-\operatorname{Pt}(2)$ separation of $2.5777(5) \AA$ for $\mathbf{1}$ is consistent with a direct, unbridged $\operatorname{Pt}(\mathrm{I})-\mathrm{Pt}(\mathrm{I})$ bond, and is within the range found in the four $\operatorname{Pt}(\mathrm{I})$ dimers containing unbridged Pt-Pt bonds that have been crystallographically characterized (2.53-2.63 $\AA$ ). ${ }^{8}$ These distances are shorter than expected, considering that the covalent radius of $\mathrm{Pt}(\mathrm{O})$ is $1.38 \AA^{9}$ and that of $\mathrm{Pt}(\mathrm{II})$ is $1.31 \AA^{10}$ Many $\mathrm{Pt}(\mathrm{I})$ dimers with bridging ligands are known and they have been reviewed. ${ }^{11}$

The P-Pt-Pt angles, $102.1^{\circ}(\mathrm{P}(3)-\mathrm{Pt}(2)-\mathrm{Pt}(1)), 100.5^{\circ}(\mathrm{P}(1)-\mathrm{Pt}(1)-\mathrm{Pt}(2)), 168.6^{\circ}$ $(\mathrm{P}(2)-\operatorname{Pt}(1)-\operatorname{Pt}(2))$, and $167.4^{\circ}(\mathrm{P}(4)-\operatorname{Pt}(2)-\operatorname{Pt}(1))$, none of which deviate from the idealized square planar values ( $90^{\circ}$ for the first pair, $180^{\circ}$ for the latter pair) by more than $13^{\circ}$, are also consistent with the presence of two terminal hydrides. The analogous values for $\left(\left[\left(\mathrm{PCy}_{3}\right)\left(\mathrm{SiEt}_{3}\right) \mathrm{Pt}(\mu-\mathrm{H})\right]_{2}\right.$ are $123-134^{\circ} .12$ This lack of deviation from idealized square planar values indicates that steric interactions between iso-propyl groups of the phosphines are negligible, as such interactions would result in an opening of the $\mathrm{P}(3)-\operatorname{Pt}(2)-\operatorname{Pt}(1)$ and $\mathrm{P}(1)-\operatorname{Pt}(1)-\operatorname{Pt}(2)$ angles from the idealized value of $90^{\circ}$. Examination of the iso-propyl groups on $\mathrm{P}(1)$ and $\mathrm{P}(3)$ shows that these steric interactions are minimized by the orientation of the alkyl groups; the methine hydrogen atoms on $C(11)$ and $C(30)$ point towards, while the larger methyl groups point away from, each other.

The dihedral angle between the planes defined by $\mathrm{P}(1)-\mathrm{Pt}(1)-\mathrm{P}(2) / \mathrm{P}(3)-\mathrm{Pt}(2)-\mathrm{P}(4)$ is $93^{\circ}$. The analogous angle in $[(\mathrm{dtbpp}) \mathrm{Pt}]_{2}$ is $82^{\circ} .3$ For the latter structure, in which the $\mathrm{P}-\mathrm{Pt}-\mathrm{Pt}$ angles are $\mathrm{ca} .128^{\circ}$, a $90^{\circ}$ dihedral angle would minimize steric interactions between the large tert-butyl groups on the phosphine ligands, and this is probably the reason for the $82^{\circ}$ angle. However, since the $\mathrm{P}(1)-\mathrm{Pt}(1)-\mathrm{Pt}(2), \mathrm{P}(3)-\mathrm{Pt}(2)-\mathrm{Pt}(1)$ angles in 1 are $c a .101^{\circ}$, such steric interactions would be minimized if this dihedral angle were $180^{\circ}$ (there are actually two $180^{\circ}$ orientations, the orientation being discussed has the hydrides trans to each other, relative to the Pt-Pt vector, Fig. 3). 


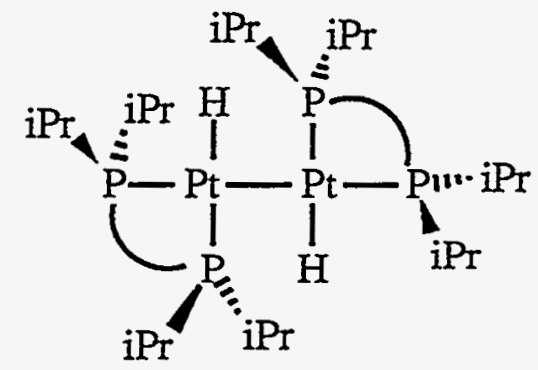

(a)

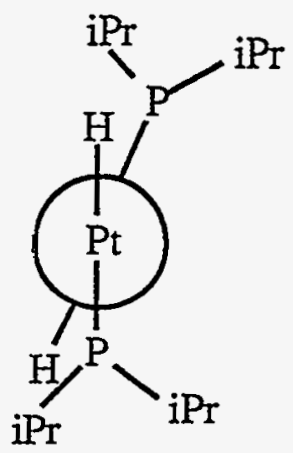

(b)

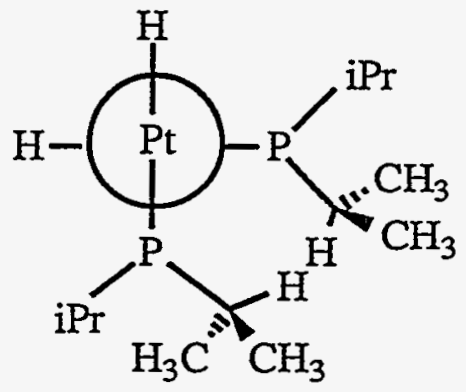

Figure 3. (a) Idealized geometry of 1 that would minimize steric interactions between the alkyl groups of the phosphine ligands, (b) Newman projections of both the $180^{\circ}$ and $90^{\circ}$ geometries, down the P-Pt-Pt-P vector, showing the increased steric interactions in the latter conformation (for clarity, the P nuclei trans to the Pt centers are not shown). Note the orientation of the iso-propyl methine H's, as in the solid state structure of $\mathbf{1}$, minimizing the steric interactions.

This geometry places all of the alkyl groups of the phosphine ligands near hydrides, as opposed to near other alkyl groups, and minimizes the steric interactions discussed in the previous paragraph. The dihedral angle in the nickel analogue, $[(\mathrm{dcypp}) \mathrm{Ni}(\mu-\mathrm{H})]_{2}, 6 \mathrm{~b}$ is $63^{\circ}$, and this was rationalized based on a steric argument. In the palladium analogue, $[(\text { dippp }) \operatorname{Pd}(\mu-\mathrm{H})]_{2}, 6 \mathrm{c}$ it is $20^{\circ}$, and this was rationalized by assuming that the larger size of Pd results in minimal steric interactions between the iso-propyl groups on opposite ends of the dimer. The main difference between the $\mathrm{Ni}$ and Pd dimers and $\mathbf{1}$ is the presence of terminal hydrides in the latter complex, resulting in more acute $\mathrm{P}(1)-\mathrm{Pt}(1)$ $\mathrm{Pt}(2), \mathrm{P}(3)-\mathrm{Pt}(2)-\mathrm{Pt}(1)$ angles, making the $180^{\circ}$ geometry the sterically favored one, relative to the $90^{\circ}$ geometry (Figure 3). While the $180^{\circ}$ geometry is favored on steric grounds, the $90^{\circ}$ geometry is assumed to be the thermodynamically preferred conformation, as it is observed in the solid state structures of both $\mathbf{1}$ and $\mathbf{3}$.

The structure of 3 is qualitatively similar to that of $\mathbf{1}$, however there are several significant differences. The $\operatorname{Pt}(1)-\operatorname{Pt}(2)$ distance in 3 is $2.609(1) \AA, 0.03 \AA$ longer than in 1. This lengthening is most reasonably ascribed to steric interactions between the larger tert-butyl groups on the two phosphine ligands, specifically between the $C(6)$ and 
$\mathrm{C}(9)$ tert-butyl groups. In contrast to 1 , in which the methine hydrogens on these analogous carbon atoms can be oriented so as to minimize steric interactions, such a lower energy conformation does not exist for 3. In addition, the P-Pt-Pt angles $\left(114.7^{\circ}\right.$ $(\mathrm{P}(3)-\operatorname{Pt}(2)-\operatorname{Pt}(1)), 115.7^{\circ}(\mathrm{P}(1)-\operatorname{Pt}(1)-\operatorname{Pt}(2)), 152.3^{\circ}(\mathrm{P}(2)-\operatorname{Pt}(1)-\operatorname{Pt}(2))$, and $153.8^{\circ}$ $(\mathrm{P}(4)-\operatorname{Pt}(2)-\operatorname{Pt}(1))$, deviate from the ideal square planar values by $c a .26^{\circ}$, compared to $c a .13^{\circ}$ in 1 . This distortion is also consistent with steric interactions between the larger tert-butyl groups.

The $\mathrm{P}(1)-\mathrm{Pt}(1)-\mathrm{Pt}(2)-\mathrm{P}(3)$ torsional angle may also be used as evidence that steric interactions play a role in the structural distortions in 3 . In 3 , this angle is $108^{\circ}$, in 1 it is $97^{\circ}$. The steric interactions between the $\mathrm{C}(6)$ and $\mathrm{C}(9)$ tert-butyl groups (on $\mathrm{P}(1)$ and $\mathrm{P}(3)$ ) result in an opening of this angle by $11^{\circ}$, relative to 1 . There are no close intramolecular non-bonded interactions between the $C(6)$ and $C(9)$ alkyl groups, presumably because the distortions discussed above relieve such interactions. This is illustrated clearly by the observation that the $\mathrm{C}(17)-\mathrm{C}(27)$ distance (methyl carbons on $\mathrm{C}(6)$ and $\mathrm{C}(9)$, respectively), $3.80 \AA$, decreases to $2.25 \AA$ when the P-Pt-Pt angles, Pt-Pt distance, and P-Pt-Pt-P dihedral angles are set equal to their analogous values in the structure of 1.

It can be argued that all of these perturbations are also consistent with a distortion towards a bridging hydride structure for 3 . However, the solid state infrared data show that the hydrides are terminal in both $\mathbf{1}$ and 3 . No terminal $\mathrm{M}-\mathrm{H}$ stretches are present in the infrared spectrum of $[(\mathrm{dcypp}) \mathrm{Ni}(\mu-\mathrm{H})]_{2} ; 6 \mathrm{a}$ unfortunately, infrared data were not reported for $[(\operatorname{dippp}) \operatorname{Pd}(\mu-\mathrm{H})]_{2} .6 \mathrm{c}$ Also, if the solid state structure of 3 did contain bridging or semi-bridging hydride ligands, the $\mathrm{P}(1)-\operatorname{Pt}(1)-\mathrm{Pt}(2)-\mathrm{P}(3)$ torsional angle would be closer to $180^{\circ}, 12$ as is observed in Fryzuk's palladium analogue, $6 \mathrm{c}$ to satisfy the square planar coordination of the platinum centers. The observed angle is $108.1^{\circ}$. It seems reasonable to conclude that the distortions observed in the structure of $\mathbf{3}$ arise as a result of the steric interactions discussed above. 
The geometry of the $[(\mathrm{P}-\mathrm{P}) \mathrm{MH}]_{2}$ dimers changes on descending the Group 8 metals; the hydrides in the Ni complex are symmetrically bridging, ${ }^{6} \mathrm{~b}$ those in the $\mathrm{Pd}$ complex are semi-bridging, ${ }^{6 c}$ and those in the $P t$ complexes described above are strictly terminal. These structural differences may be rationalized on the basis of relativistic effects. ${ }^{13}$ In the gas phase the Au-H distance of $1.52 \AA$ is less than the Ag-H distance of $1.62 \AA$, even though the $\mathrm{M}-\mathrm{M}$ distances in the homonuclear diatomic molecules are virtually identical $(\mathrm{d}(\mathrm{Ag}-\mathrm{Ag})=2.48 \AA, \mathrm{d}(\mathrm{Au}-\mathrm{Au})=2.47 \AA)$. It is also known that protonation of the heterobimetallic complex $\mathrm{CpM}(\mathrm{CO})\left(\mu-\mathrm{PPh}_{2}\right) \mathrm{Pt}(\mathrm{CO})\left(\mathrm{PPh}_{3}\right)(\mathrm{M}=\mathrm{Mo}$, W) results in a terminal hydride ligand for the $\mathrm{M}=\mathrm{W}$ derivative, but a bridging hydride ligand for the $M=$ Mo derivative. ${ }^{13 d}$ These differences are a result of the relativistic stabilization of the $6 \mathrm{~s}$ orbitals of third row metals relative to the $5 \mathrm{~s}$ orbitals of second row metals. ${ }^{13 c}$ As Group 10 is descended, the valence s orbital energy is stabilized by relativistic effects, favoring the terminal $\mathrm{M}-\mathrm{H}$ bonding mode over the bridging bonding mode, for $[(\mathrm{P}-\mathrm{P}) \mathrm{MH}]_{2}$ dimers.

Room Temperature NMR Spectra. The ${ }^{1} \mathrm{H},{ }^{31} \mathrm{P}\left\{{ }^{1} \mathrm{H}\right\}$, and ${ }^{195} \mathrm{Pt}\left\{{ }^{1} \mathrm{H}\right\}$ (INEPT) NMR spectra of 1 at $25^{\circ} \mathrm{C}$ (Fig. 4) show that all four phosphorus nuclei, both platinum nuclei, and the two hydride nuclei, are equivalent on the NMR timescale. Qualitatively, the ${ }^{1} \mathrm{H}$ and ${ }^{31} \mathrm{P}\left\{{ }^{1} \mathrm{H}\right\}$ spectra of 2 and 3 are identical with those of 1 . The ${ }^{1} \mathrm{H},{ }^{31} \mathrm{P}\left\{{ }^{1} \mathrm{H}\right\}$, and ${ }^{195} \mathrm{Pt}\left\{{ }^{1} \mathrm{H}\right\}$ spectra of $1-3$ (and all other $\mathrm{Pt}$ dimers) consist of the superposition of three subspectra, arising from the three different isotopomeric combinations of platinum nuclei having different nuclear spins $(\mathrm{Pt} / \mathrm{Pt}, 43.8 \% ; \mathrm{Pt} / 195 \mathrm{Pt}$, $44.8 \% ; 195 \mathrm{Pt} / 195 \mathrm{Pt}, 11.4 \%$--the percentages arise from the $33.8 \%$ natural abundance of ${ }^{195} \mathrm{Pt}$ ). The splitting in the ${ }^{1} \mathrm{H}$ spectrum (Fig. 5) consists of an apparent quintet of quintets, arising from the superposition of an $\mathrm{A}_{2} \mathrm{X}_{4}$ spin system $(\mathrm{Pt} / \mathrm{Pt}$ isotopomer, central quintet, $43.8 \%$ of the total hydride resonance intensity), an $\mathrm{A}_{2} \mathrm{X}_{4} \mathrm{M}$ spin system ( $\mathrm{Pt} /{ }^{195} \mathrm{Pt}$ isotopomer, doublet of quintets, $44.8 \%$ of total intensity), and an $\mathrm{A}_{2} \mathrm{X}_{4} \mathrm{MM}$ ' spin system (195Pt/195Pt isotopomer, triplet of quintets, $11.4 \%$ of total intensity); the 
superposition of these spin systems, giving the observed apparent quintet of quintets, has been discussed in detail in the literature, with respect to $\left[\mathrm{P}_{4} \mathrm{Pt}_{2} \mathrm{H}_{3}\right]^{+}[\mathrm{X}]-$ complexes. $5 \mathrm{a}, 5 \mathrm{~g}$

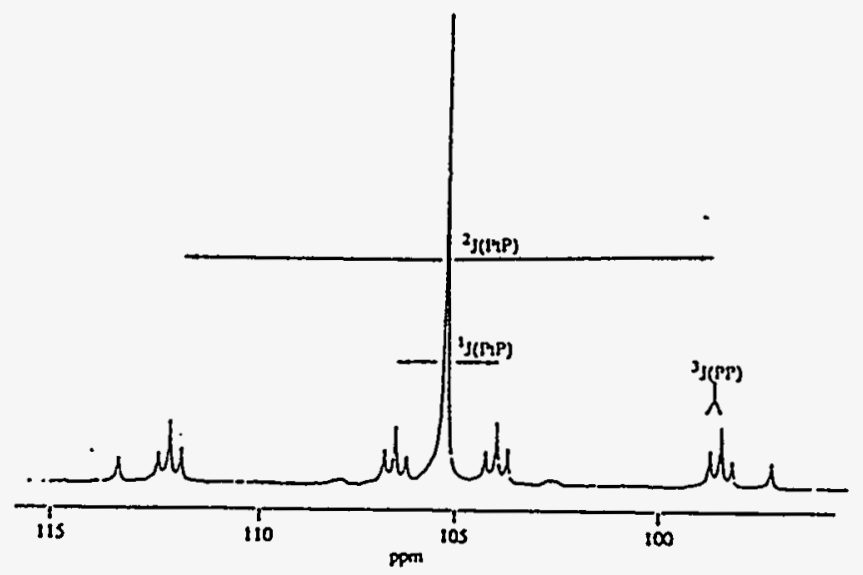

(a)

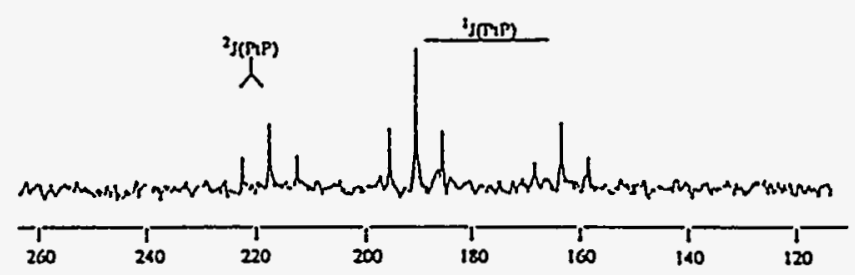

(b)

Figure 4. NMR spectra of $1\left(25^{\circ} \mathrm{C}, \mathrm{C}_{6} \mathrm{D}_{6}\right)$, a) ${ }^{31} \mathrm{P}\left\{{ }^{1} \mathrm{H}\right\}$ spectrum (162 MHz), ${ }^{195 \mathrm{Pt}}\{1 \mathrm{H}\}$ INEPT spectrum $(85.6 \mathrm{MHz})$.

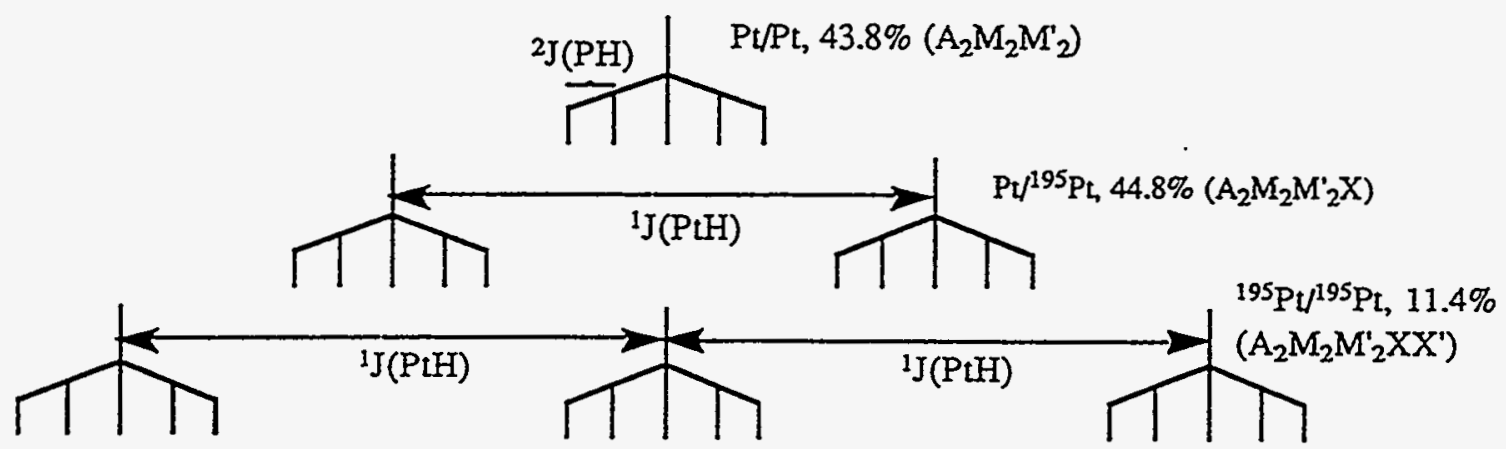

Figure 5. Splitting diagram for the hydride region of the $25^{\circ} \mathrm{C}^{1 \mathrm{H}}$ spectrum of 1 .

The pattern observed in the ${ }^{31} \mathrm{P}\{1 \mathrm{H}\}$ spectrum (Fig. 4b) arises from a combination of an $\mathrm{A}_{2} \mathrm{~A}_{2}^{\prime}$ spin system ( $\mathrm{Pt} / \mathrm{Pt}$ isotopomer, a singlet), an $\mathrm{A}_{2} \mathrm{~A}_{2}^{\prime} \mathrm{X}$ spin system $(\mathrm{Pt} / 195 \mathrm{Pt}$ isotopomer, giving rise to all of the observed splitting in the experimental spectrum, see 
labels on spectrum); and an $\mathrm{A}_{2} \mathrm{~A}_{2}^{\prime} \mathrm{XX}$ ' spin system (195 $\mathrm{Pt} / 195 \mathrm{Pt}$ isotopomer, a second order pattern), the latter of which is only partially observed in the experimental spectrum (the outermost visible lines correspond to half of the total intensity of this subspectrum), $5 \mathrm{a}$ as a result of the $11.4 \%$ abundance of this isotopomer and of the multiple couplings present for this spin system. Again, the superposition of these spin systems has been discussed in the literature, with respect to $\left[\mathrm{P}_{4} \mathrm{Pt}_{2} \mathrm{H}_{3}\right]^{+}[\mathrm{X}]^{-}$ complexes. ${ }^{5 a, 5 \mathrm{~g}}$ The ${ }^{195} \mathrm{Pt}-{ }^{195} \mathrm{Pt}$ coupling constants of the dimers can be directly measured from the ${ }^{195} \mathrm{Pt} / 195 \mathrm{Pt}$ subspectrum; $5 a$ these values are $1450 \mathrm{~Hz}$ and $1750 \mathrm{~Hz}$ for $\mathbf{I}$ and 3, respectively. These values are within the expected range for $\mathrm{Pt}-\mathrm{Pt}$ dimers, ${ }^{14}$ however ${ }^{1} \mathrm{JPtPt}_{\mathrm{Pt}}$ values for $\mathrm{Pt}$ dimers range from $c a .90-10300 \mathrm{~Hz},{ }^{14}$ and it has been noted that ${ }^{1} \mathrm{JPtPt}_{\mathrm{Pl}}$ values for polynuclear Pt complexes show no correlation with solid-state Pt-Pt distances. 15

The experimental ${ }^{195} \mathrm{Pt}\left\{{ }^{1} \mathrm{H}\right\}$ spectrum (Fig. 4b) is also a superposition of subspectra: an $\mathrm{A}_{2} \mathrm{~A}_{2}^{\prime} \mathrm{X}$ spin system ( $\mathrm{P}_{\mathrm{t}} / 195 \mathrm{Pt}$, triplet of triplets, see labels on spectrum) and an $\mathrm{A}_{2} \mathrm{~A}_{2}{ }_{2} \mathrm{XX}^{\prime}$ spin system $\left({ }^{195} \mathrm{Pt} /{ }^{195} \mathrm{Pt}\right.$, second order pattern). The latter subspectrum is not observed in the experimental spectrum, a result of its low relative abundance and multiple couplings. As expected, the ${ }^{1,2} \mathrm{~J}_{\mathrm{PtP}}$ values obtained from the ${ }^{31} \mathrm{P}\left\{{ }^{1} \mathrm{H}\right\}$ spectrum (Table 3) are identical to those measured from the ${ }^{195} \mathrm{Pt}\left\{{ }^{1} \mathrm{H}\right\}$ spectrum.

The NMR values for 1-3 (Table 3) are similar to the values reported for $[(\mathrm{dppe}) \mathrm{PtH}]_{2}$ by Pidcock and co-workers (also in Table 3$)_{.} 4 \mathrm{~b}$ Comparison of these values to the values for trihydride cationic complexes of the type $\left[(\mathrm{P}-\mathrm{P})_{2} \mathrm{Pt}_{2} \mathrm{H}_{3}\right][\mathrm{X}]$ (Table 4) shows significant differences; the cationic complexes exhibit several different structures, $5 \mathrm{~g}$ however all contain at least one bridging hydride in the solid state. 
Table $3.1 \mathrm{H}$ and $31 \underline{\mathrm{P}}\{\underline{\mathrm{H}}\}$ NMR Data for the Dimers $1-3\left(25^{\circ} \mathrm{C}, \mathrm{C}_{6} \mathrm{D}_{6}\right)$ and [(dippe) $\mathrm{P} t \mathrm{H}] 2$.

\begin{tabular}{|c|c|c|c|c|c|c|}
\hline 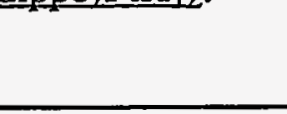 & $\begin{array}{c}\delta(\mathrm{Pt}-\underline{\mathrm{H}}) \\
\mathrm{ppm}\end{array}$ & $\begin{array}{r}{ }^{2} \mathrm{~J}_{\mathrm{PH}}, \\
\mathrm{Hz}\end{array}$ & $\begin{array}{r}{ }^{1} \mathrm{~J}_{\mathrm{PtH}}, \\
\mathrm{Hz} \\
\end{array}$ & $\begin{array}{l}\delta(\mathrm{P}) \\
\mathrm{ppm}\end{array}$ & $\begin{array}{c}1,2 \mathrm{~J}_{\mathrm{PtP}}, \\
\mathrm{Hz} \\
\end{array}$ & $\begin{array}{c}{ }^{3} \mathrm{JPP}_{\mathrm{PP}}{ }^{\mathrm{a}} \\
\mathrm{Hz}\end{array}$ \\
\hline 1 & 0.49 & 40 & 516 & 105.5 & $\begin{array}{c}2210 \\
410\end{array}$ & 45 \\
\hline 2 & 0.49 & 40 & 512 & 92.8 & $\begin{array}{c}2180 \\
420\end{array}$ & 44 \\
\hline 3 & 0.05 & 42 & 570 & 119.9 & $\begin{array}{c}3112 \\
362\end{array}$ & 47 \\
\hline$[(\text { dppe }) \mathrm{PtH}]_{2}{ }^{\mathrm{b}}$ & 0.30 & 42 & 564 & 70.9 & $\begin{array}{c}2201 \\
388\end{array}$ & 44 \\
\hline
\end{tabular}

aThis coupling is expressed only in the $\mathrm{Pt} / 195 \mathrm{Pt}$ and ${ }^{195 \mathrm{Pt} / 195 \mathrm{Pt} \text { subspectra. }}$ bValues taken from reference $4 \mathrm{~b}$, measured in $d_{8}$-thf.

Table 4. $1 \mathrm{H}$ and $31 \mathrm{P}[1 \mathrm{H}\}$ NMR Data for Selected $\left[(\mathrm{P}-\mathrm{P})_{2} \mathrm{P}_{2} \mathrm{H}_{3}\right][\mathrm{X}]$ Complexes (25 ${ }^{\circ} \mathrm{C}, \mathrm{CDCl}_{2}{ }_{2}$

\begin{tabular}{|c|c|c|c|c|c|c|c|}
\hline Con & $\begin{array}{c}\delta(\mathrm{Pt}-\underline{\mathrm{H}}) \\
\mathrm{ppm}\end{array}$ & $\begin{array}{r}2 \mathrm{~J}_{\mathrm{PH}}, \\
\mathrm{Hz}\end{array}$ & $\begin{array}{c}{ }^{1} \mathrm{~J}_{\mathrm{PLH}}, \\
\mathrm{Hz} \\
\end{array}$ & $\begin{array}{l}\delta(\mathrm{P}), \\
\mathrm{ppm}\end{array}$ & $\begin{array}{c}{ }^{1} \mathrm{~J}_{\mathrm{PtP}}, \\
\mathrm{Hz} \\
\end{array}$ & $\begin{array}{l}\mathrm{JPP}_{\mathrm{PP}} \\
\mathrm{Hz}\end{array}$ & Reference \\
\hline$\left[(\text { dcype })_{2} \mathrm{Pt}_{2} \mathrm{H}_{3}\right][\mathrm{OH}]$ & -2.81 & 39 & 480 & 84.2 & 2802,149 & 8 & this work \\
\hline$\left[(\mathrm{dtbpe})_{2} \mathrm{Pt}_{2} \mathrm{H}_{3}\right][\mathrm{BPh} 4$ & -3.85 & 40 & 443 & 109 & 2946,161 & 8 & $5 a$ \\
\hline$\left[(\mathrm{dppe})_{2} \mathrm{Pt}_{2} \mathrm{H}_{3}\right]\left[\mathrm{BF}_{4}\right]$ & -2.8 & 41 & 500 & 57.2 & 2925,171 & 10 & $5 \mathrm{~g}$ \\
\hline
\end{tabular}

The neutral dimers 1-3 have a much larger average ${ }^{3} J_{P P}$ value than the average longrange $J_{P P}$ value for the cationic complexes. In addition, the average ${ }^{2} J_{P t P}$ value for the neutral dimers 1-3 are much larger than the analogous value for the cationic complexes (e.g, ${ }^{2} \mathrm{~J}_{\mathrm{PtP}}=420 \mathrm{~Hz}$ for $2 ; \mathrm{J}_{\mathrm{PtP}}=149 \mathrm{~Hz}$ for the analogous cationic complex, $\left.\left[(\mathrm{dcype})_{2} \mathrm{Pt}_{2} \mathrm{H}_{3}\right][\mathrm{OH}]\right)$. These differences indicate that there is more spin-spin communication between the two halves of the neutral dimers, relative to the cationic complexes. The direct, unbridged $\mathrm{Pt}-\mathrm{Pt}$ bond in the solid state for the complexes 1-3 transmits spin-spin coupling more efficiently than the bridged $\mathrm{Pt}-\mathrm{Pt}$ bond in the cationic complexes. 
Comparison of the averaged spectral values for the neutral dimers to those of monomeric cis $-\mathrm{P}_{2} \mathrm{~F}^{\mathrm{t}} \mathrm{H}_{2}$ complexes (Table 1) shows that the ${ }^{1} \mathrm{~J}_{\mathrm{PtH}}$ values are much smaller, and the ${ }^{1} \mathrm{~J}_{\mathrm{PtP}}$ values are larger, for the former complexes. These differences are indicative of bridging or semi-bridging hydride ligands in the neutral dimers (on the NMR timescale, at room temperature), ${ }^{14}$ inconsistent with the terminal hydride coordination found in the solid state structures of 1 and 3. Lastly, comparison of the values among the three dimers shows that 1 and 2 possess very similar values, while the values for 3 are slightly different (this difference being most pronounced in the $J_{P t P}$ values), perhaps indicative of slight structural differences in solution for 3.

Low Temperature NMR Spectra/Fluxionality. Clearly, some sort of fluxional process is occurring that makes the two hydrides, the four phosphorus nuclei, and the two platinum nuclei equivalent on the NMR timescale at $25^{\circ} \mathrm{C}$, as the spectra are not consistent with the solid state structures of $\mathbf{1}$ and $\mathbf{3}$. Such a process, in which there is equivalency within the sets of $\mathrm{H}, \mathrm{P}$, and $\mathrm{Pt}$ nuclei, has been reported for several [(PP) $\left.{ }_{2} \mathrm{Pt}_{2} \mathrm{H}_{3}\right][\mathrm{X}]$ complexes. $5 \mathrm{a}, 5 \mathrm{~g}$ A static planar $[(\mathrm{P}-\mathrm{P}) \mathrm{Pt}(\mu-\mathrm{H})]_{2}$ structure of $\mathrm{D}_{2 \mathrm{~h}}$ symmetry is not consistent with the observed equivalency, although this has been suggested in the literature. $4 \mathrm{a}, 6 \mathrm{c}$ Both averaged ${ }^{5 \mathrm{a}, 5 \mathrm{~g}}$ and stopped-exchange ${ }^{5 c, 5 e, 5 \mathrm{j}, 16}$ cases have been reported for $\left[\mathrm{P}_{4} \mathrm{Pt}_{2} \mathrm{H}_{3}\right][\mathrm{X}]$ complexes; complexes with chelating phosphines :ield averaged spectra at all temperatures and complexes with monodentate phosphines yield stereochemically rigid spectra at all temperatures. The palladium dimer $\left[(\text { dippp)PtH }]_{2}\right.$ is fluxional at all temperatures. ${ }^{6 c}$ Thus, complexes 1 and 2 represent the first cases in which both regimes, fluxional and stereochemically rigid, are accessible. An interesting study has yielded an estimate of $17.2 \mathrm{~kJ} \mathrm{~mol}^{-1}$ for the fluxional process in $\left[(\mathrm{dppe})_{2} \mathrm{Pt}_{2} \mathrm{H}_{3}\right]\left[\mathrm{BF}_{4}\right]$, based on proton $\mathrm{T}_{1}$ and $\mathrm{T}_{2}$ measurements. ${ }^{17}$

In order to learn more about the fluxional process, NMR samples of 1,2 , and 3 in d8-toluene were cooled to $-90^{\circ} \mathrm{C}$, and the ${ }^{1} \mathrm{H}$ and ${ }^{31} \mathrm{P}\left\{{ }^{1} \mathrm{H}\right\}$ NMR spectra were recorded. The spectra of 3 were virtually identical with the room temperature spectra, with sharp 
resonances, implying that the fluxional process is still rapid. However, the spectra of 1 and 2 were significantly different from the room temperature spectra, due to stopping of the fluxional process(es) that occur(s) at room temperature. The temperature at which the fluxional process is stopped is $-54^{\circ} \mathrm{C}$ for 1 and $-36^{\circ} \mathrm{C}$ for 2 ; assuming equal population, non-coupled spin systems (roughly true for the $\mathrm{Pt} / \mathrm{Pt}{ }^{31} \mathrm{P}\left\{{ }^{1} \mathrm{H}\right\}$ subspectrum, as no P-P coupling is resolved in this subspectrum, see detailed discussion below), approximate $\Delta \mathrm{G}^{\ddagger}$ values of $9.1(2) \mathrm{kcal} \mathrm{mol}^{-1}$ (for 1) and 10.1(2) kcal mol-1 (for 2) for the fluxional process can be calculated. 18 Assuming that $\Delta v$ for 3 (the frequency difference between the two ${ }^{31} \mathrm{P}$ resonances in the slow-exchange regime) is slightly larger than the values for 1 and 2 (i.e.,ca. $1800 \mathrm{~Hz}$; this will give an upper limit estimate on the fluxional barrier), and knowing that the coalescence temperature is below $180 \mathrm{~K}$, the barrier for the fluxional process for 3 must be $\leq 7.4 \mathrm{kcal} \mathrm{mol}^{-1}$.

The ${ }^{31} \mathrm{P}\left[{ }^{1} \mathrm{H}\right\}$ spectrum of 1 taken at $-90^{\circ} \mathrm{C}$ is shown in Figure 6. The low temperature ${ }^{1} \mathrm{H}$ and ${ }^{31} \mathrm{P}\left\{{ }^{1} \mathrm{H}\right\}$ spectra of 2 are qualitatively identical to those of 1 .

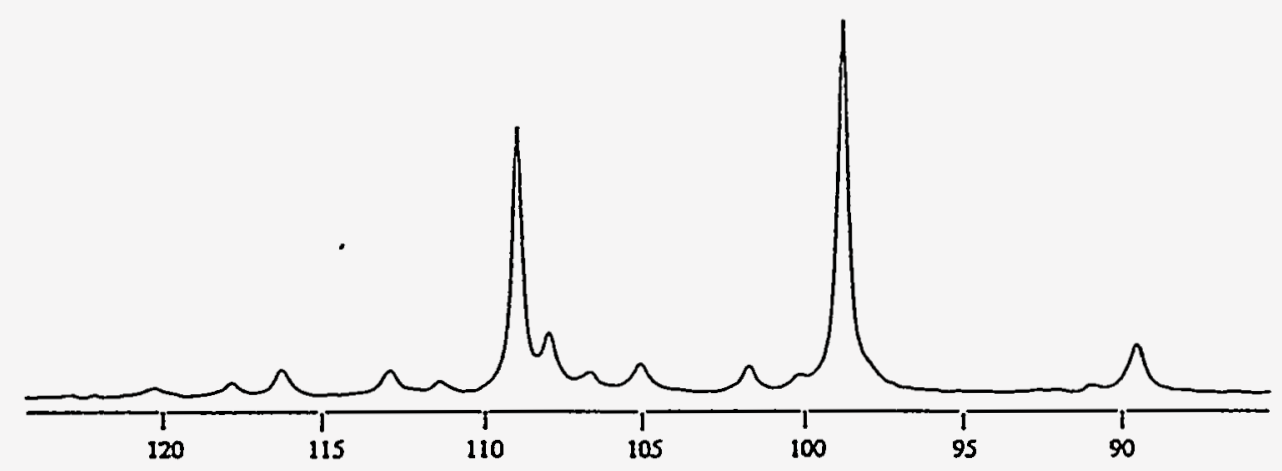

Figure 6. ${ }^{31} \mathrm{P}\left\{{ }^{1} \mathrm{H}\right\}$ spectrum of 1 at $-90^{\circ} \mathrm{C}(121 \mathrm{MHz}$, d8-toluene).

While the $90^{\circ}$ and $180^{\circ}$ geometries (Fig. 3) cannot be distinguished based on the low temperature ${ }^{1} \mathrm{H}, 31 \mathrm{P}$, and ${ }^{195} \mathrm{Pt}$ NMR data, the data are entirely consistent with the solid state structure found for 1 , as discussed below, and so it is reasonable to assume that the low temperature solution structure is similar to the observed solid state structure. Since 
the low temperature spectra of $\mathbf{1}$ and $\mathbf{2}$ are similar, it is assumed that they have similar solid state structures. The assignments shown in Figure 7 will be used to discuss the low temperature spectra; unless otherwise stated, only one half of the dimer will be explicitly discussed, the other half being related by a $\mathrm{C}_{2}$ axis (e.g, ${ }^{1} \mathrm{~J}_{\mathrm{PtaHa}}$ implies ${ }^{1} \mathrm{~J}_{\mathrm{PtbHb}}$; while the ${ }^{195} \mathrm{Pt} / \mathrm{Pt}$ isotopomer of the dimer does not formally possess a true $\mathrm{C}_{2}$ axis, any exceptions will be explicitly stated when necessary). The low temperature ${ }^{1} \mathrm{H}$ and ${ }^{31} \mathrm{P}\left\{{ }^{1} \mathrm{H}\right\}$ spectral values for $\mathbf{1}$ and $\mathbf{2}$ are presented in Table 5 .

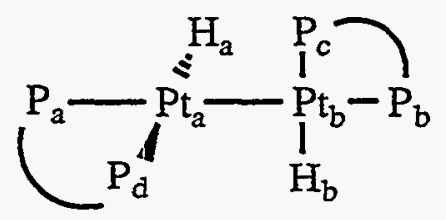

Figure 7. Assignments used to discuss the low temperature NMR values of $\mathbf{1}$ and $\mathbf{2}$.

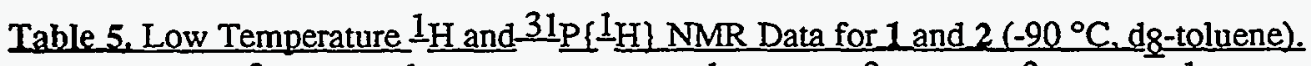

\begin{tabular}{|c|c|c|c|c|c|c|c|c|c|}
\hline & $\begin{array}{l}\delta(\mathrm{Pt}-H) \\
\mathrm{jpm}\end{array}$ & $\begin{array}{c}{ }^{2} \mathrm{JPdHa}, \\
\mathrm{Hz}\end{array}$ & $\begin{array}{c}{ }^{1}{ }_{\mathrm{PtaHa}}, \\
\mathrm{Hz}\end{array}$ & $\begin{array}{l}\delta(\mathrm{P}) \\
\mathrm{ppm}\end{array}$ & $\begin{array}{c}{ }^{1} \mathrm{JtaPa}_{\mathrm{Pt}}, \\
\mathrm{Hz}\end{array}$ & $\begin{array}{c}{ }^{2} \mathrm{~J}_{\mathrm{PtaPb}}, \\
\mathrm{Hz}\end{array}$ & $\begin{array}{c}{ }^{2} \mathrm{JPaPc}^{2} \\
\mathrm{~Hz}\end{array}$ & $\begin{array}{c}{ }^{1} \mathrm{JPaPd}_{\mathrm{Pta}}, \\
\mathrm{Hz}\end{array}$ & $\begin{array}{r}{ }^{3} \mathrm{JaPb}_{\mathrm{Paz}} \\
\mathrm{Hz}\end{array}$ \\
\hline 1 & 1.04 & 163 & 996 & 109.1, & $\begin{array}{c}2030^{\mathrm{a}} \\
98.5\end{array}$ & 785 & b & 2320 & $200^{c}$ \\
\hline 2 & d & 170 & d & 96.9 & $\begin{array}{l}2000 \\
90.1\end{array}$ & 800 & b & 2320 & 210 \\
\hline
\end{tabular}

$a_{A}$ ll of the $\mathrm{J}_{\mathrm{PtP}}$ values in this table were measured from the $\mathrm{Pt} /{ }^{195} \mathrm{Pt}$ subspectrum, as the $\mathrm{Pt} / \mathrm{Pt}$ subspectrum has no ${ }^{195} \mathrm{Pt}$ and the ${ }^{195} \mathrm{Pt} /{ }^{195} \mathrm{Pt}$ subspectrum is not visible in the experimental spectrum. bunresolved, see text.

${ }^{c}$ The ${ }^{3} \mathrm{~J}_{\mathrm{PaPb}}$ values arise from the $\mathrm{Pt} /{ }^{195} \mathrm{Pt}$ and ${ }^{195} \mathrm{Pt} /{ }^{195} \mathrm{Pt}$ subspectra, and were measured from the for er subspectrum.

$\mathrm{d}_{\mathrm{T}}$; io the cyclohexyl resonances obscuring the hydride resonance, these values could not be measured-onis the higher field platinum satellite (a doublet) was visible.

The hydride region of the low temperature ${ }^{1} \mathrm{H}$ spectrum contains a broad doublet with symmetrically-spaced satellites. This pattern arises from coupling to the trans phosphorus nucleus and to the nearer ${ }^{195} \mathrm{Pt}$ nucleus $\left({ }^{2} \mathrm{~J}_{\mathrm{PdHa}}\right.$ and ${ }^{1} \mathrm{~J}_{\mathrm{PtaHa}}$, respectively). Comparison of these $\mathrm{J}_{\mathrm{PtH}}$ and $\mathrm{J}_{\mathrm{PH}}$ values to the analogous values for the cis- $\mathrm{P}_{2} \mathrm{PtH}_{2}$ complexes (Table 1) shows that, in contrast to the room temperature values for the dimers (Table 3 , and accompanying discussion), the values are very similar, providing 
support for a low temperature structure containing terminal hydride ligands located trans to a phosphorus nucleus. The couplings between $\mathrm{H}_{\mathrm{a}}$ and the three other phosphorus nuclei $\left(\mathrm{P}_{\mathrm{a}}, \mathrm{P}_{\mathrm{b}}, \mathrm{P}_{\mathrm{c}}\right)$ and the other platinum center $\left(\mathrm{Pt}_{\mathrm{b}}\right)$ are presumably too small to be resolved.

The low temperature ${ }^{31} \mathrm{P}\left\{{ }^{1} \mathrm{H}\right\}$ spectrum (Fig. 6 ) is also consistent with the solid state structure found for 1 . There are now two different phosphorus environments, $\mathrm{P}_{a} / \mathrm{P}_{b}$ which are trans to $\mathrm{Pt}$ centers, and $\mathrm{P}_{c} / \mathrm{P}_{d}$ which are trans to hydrides. Again, this spectrum is a superposition of the three subspectra arising from the three different isotopomers present. The $\mathrm{Pt} / \mathrm{Pt}$ isotopomer gives two singlets, for the two different pairs of phosphorus environments (an AA'MM' spin system), which are observed as the two major resonances in the experimental spectrum. The ${ }^{195} \mathrm{Pt} / 195 \mathrm{Pt}$ subspectrum (an AA'MM'XX' system) is not visible in the experimental spectrum due to its low relative abundance, and so the remainder of the spectrum arises from the $\mathrm{Pt} /{ }^{195} \mathrm{Pt}$ isotopomer (an AA'MM'X spin system). A splitting diagram for this spin system is shown in Figure 8.

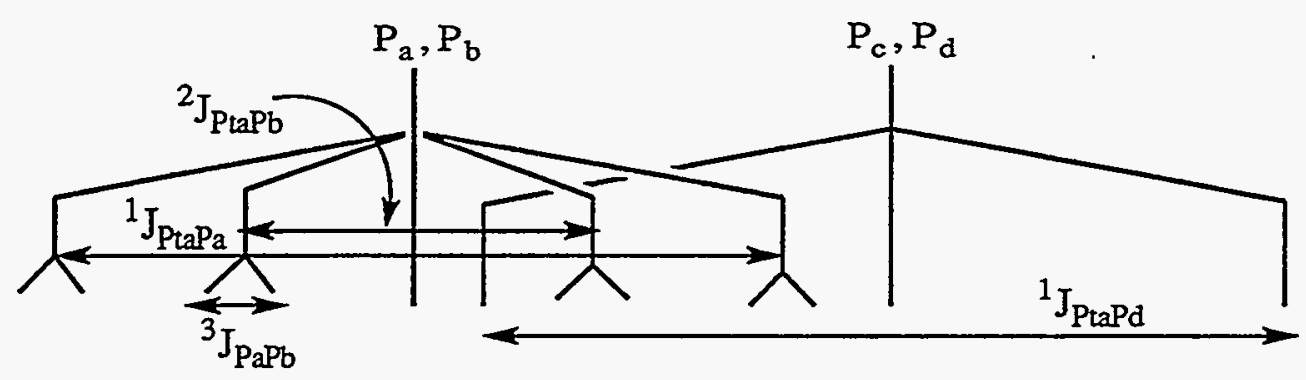

Figure 8. Proposed coupling scheme for the low temperature ${ }^{31} \mathrm{P}\left\{{ }^{1} \mathrm{H}\right\} \mathrm{Pt} /{ }^{195 \mathrm{Pt}}$ subspectrum (AA'MM'X spin system) of 1 .

The higher-field $(98.5 \mathrm{ppm})$ resonance is assigned to $\mathrm{P}_{\mathcal{C}} / \mathrm{P}_{\mathrm{d}}$. This assignment was confirmed by a ${ }^{1} \mathrm{H} / 31 \mathrm{P}$ HMQC ${ }^{19}$ spectrum (Fig. 9); this spectrum, optimized for the $2 \mathrm{~J}_{\mathrm{PdHa}}$ value of $163 \mathrm{~Hz}$, gives a strong correlation to the ${ }^{31} \mathrm{P}$ resonance at $98.5 \mathrm{ppm}$ (the less intense resonances correlated to the ${ }^{31} \mathrm{P}$ resonance at $109.1 \mathrm{ppm}$ arise from the 
protons of the dippe ligand, which are also coupled to $31 \mathrm{P}$ and therefore also give rise to some signal).

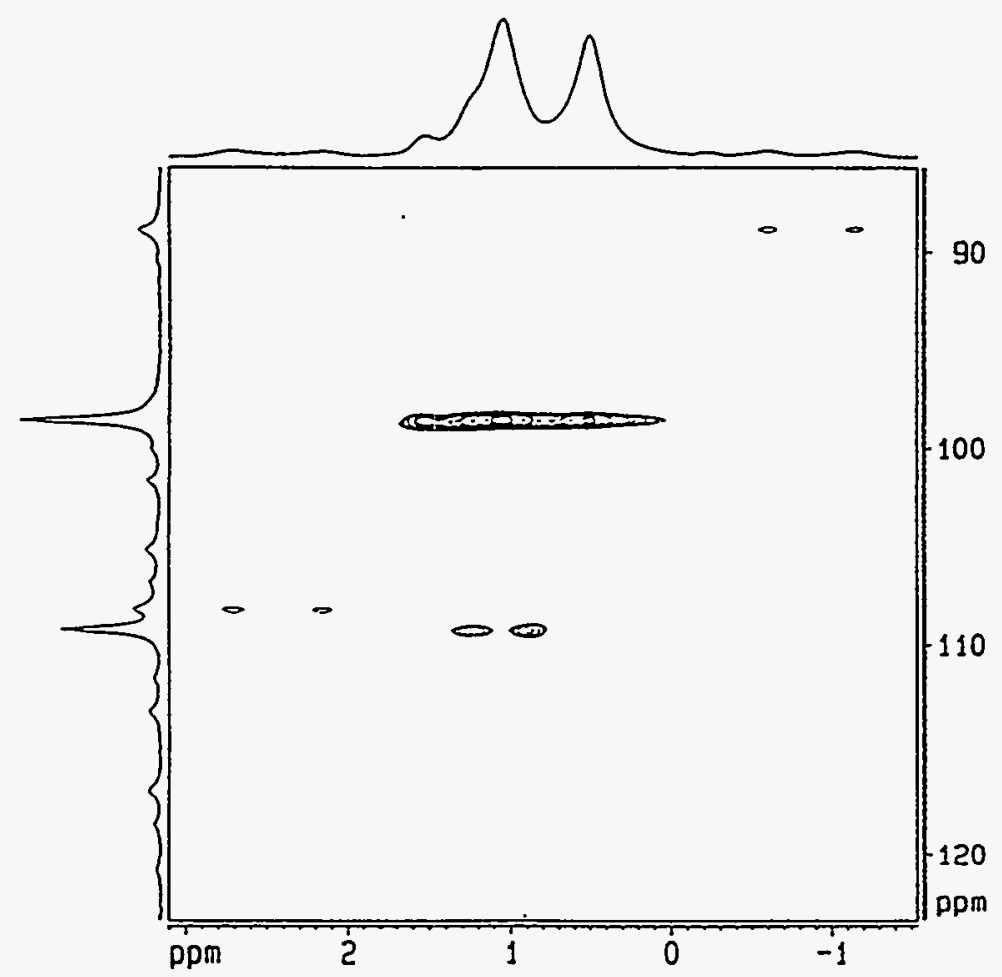

Figure 9. ${ }^{1} \mathrm{H} / 31 \mathrm{P}$ HMQC spectrum of 1 at $-90^{\circ} \mathrm{C}$ (300 $\mathrm{MHz}$, d8-toluene), showing that the higher-field ${ }^{31} \mathrm{P}$ resonance arises from $\mathrm{P}_{\mathrm{d}} / \mathrm{P}_{\mathrm{d}}$.

The splitting of this resonance is ${ }^{1} \mathrm{~J}_{\mathrm{PtaPd}}$; ${ }^{2} \mathrm{~J}_{\mathrm{PtbPd}}$ is unresolved. It is not very surprising that the P-P couplings are unresolved as the cis coupling ${ }^{2} \mathrm{~J}_{\mathrm{PaPd}}$ is expected to be the largest coupling involving $\mathrm{P}_{\mathrm{d}}$, and ${ }^{2} \mathrm{~J}_{\mathrm{PP}}$ values in cis-(P-P) $\mathrm{PtX}_{2}$ complexes $(\mathrm{X}=\mathrm{H}$, alkyl group; $\mathrm{P}-\mathrm{P}=\mathrm{a} \mathrm{C}_{2}$-bridged chelating phosphine) can be $<3 \mathrm{~Hz} .{ }^{20}$ The lower-field resonance arises from $\mathrm{P}_{\mathrm{a}}$ and $\mathrm{P}_{\mathrm{b}}$, which are trans to platinum centers. The two different $\mathrm{J}_{\mathrm{PtP}}$ values observed are ${ }^{1} \mathrm{~J}_{\mathrm{PtaPa}}$ and ${ }^{2} \mathrm{~J}_{\mathrm{PtaPb}}$, the additional coupling observed being ${ }^{3} \mathrm{~J}_{\mathrm{PaPb}}$ (Fig. 8). This $\mathrm{P}-\mathrm{P}$ coupling cannot be ${ }^{2} \mathrm{~J}_{\mathrm{PaPd}}$, since it is not seen in the higherfield resonance. Again, as for the high field resonance, ${ }^{2} \mathrm{JPaPd}_{\mathrm{Pa} d}{ }^{3} \mathrm{~J}_{\mathrm{PaPc}}$ are unresolved (this is partially a result of the relatively broad resonances in this spectrum, $w_{1 / 2} \approx 40$ 
$\mathrm{Hz}$ ). Simulation of the experimental spectrum using these assignments gives good agreement with the experimental spectrum (Figure 10). ${ }^{21}$

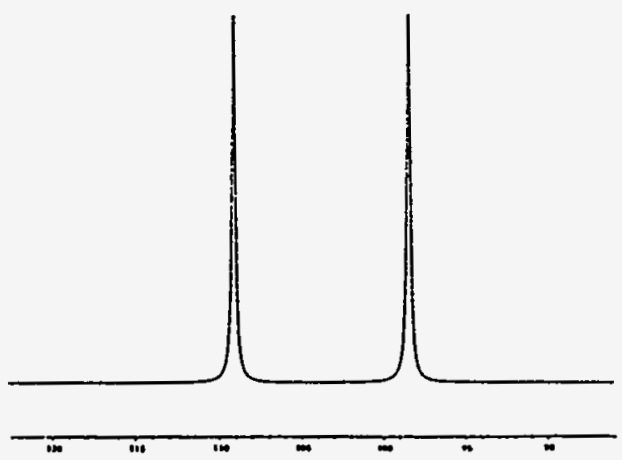

(a)

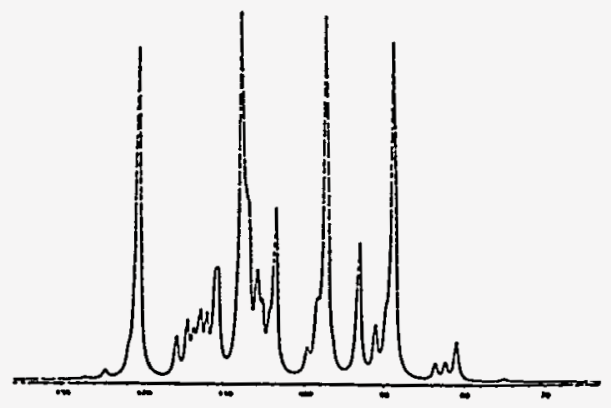

(c)

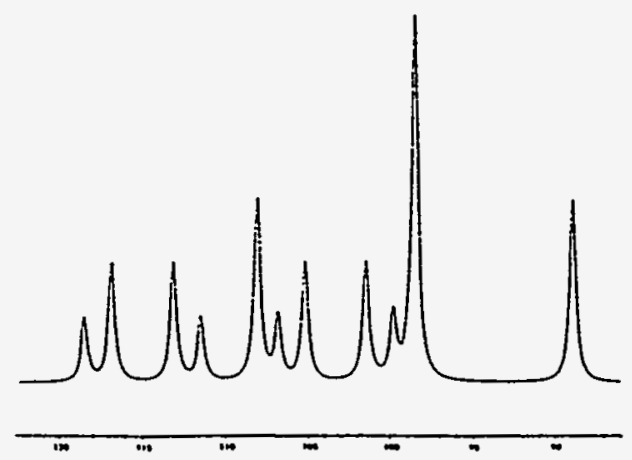

(b)

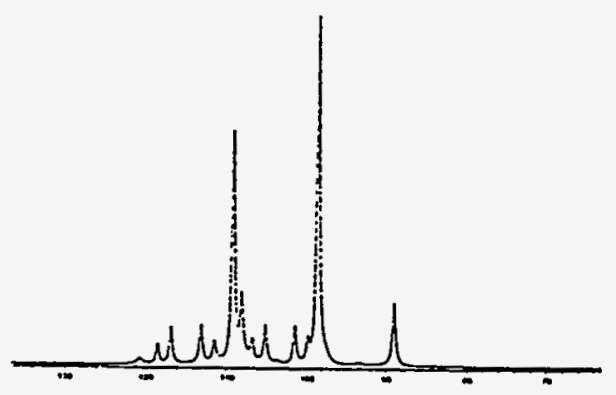

(d)

Figure 10. Simulated subspectra of the ${ }^{31} \mathrm{P}\left\{{ }^{1} \mathrm{H}\right\}$ spectrum of 1 at $-90{ }^{\circ} \mathrm{C}$ (Fig. 6): a) simulated $\mathrm{Pt} / \mathrm{Pt}$ subspectrum, b) simulated $\mathrm{Pt} / 195 \mathrm{Pt}$ subspectrum, c) simulated $195 \mathrm{Pt} / 195 \mathrm{Pt}$ subspectrum, d) sum spectrum, giving the simulated ${ }^{31} \mathrm{P}\left\{{ }^{1} \mathrm{H}\right\}$ spectrum.

The low temperature ${ }^{1} \mathrm{H} /{ }^{195} \mathrm{Pt}$ HMQC spectrum (given in Appendix $\mathrm{I}$ ) is also consistent with the solid-state structure of 1 . The ${ }^{195} \mathrm{Pt} / 195 \mathrm{Pt}$ subspectrum (an AA'MM'XX' spin system) is not visible in the experimental spectrum, and consequently the entire experimental spectrum arises from the $\mathrm{Pt}_{\mathrm{t}}{ }^{195} \mathrm{Pt}_{\mathrm{t}}$ subspectrum (an AA'MM'X spin system). Simulation of this second-order subspectrum (also given in Appendix I), using the coupling constant values obtained from the ${ }^{31} \mathrm{P}\left\{{ }^{1} \mathrm{H}\right\}$ spectrum (Table 5), gives good agreement with the experimental spectrum. 
Any postulate concerning the fluxionality of these dimers must adequately explain the equivalence of all four phosphorus nuclei, both hydrides, and both platinum centers in the rapid exchange temperature region. In addition, the proposed process must be consistent with the lower barrier observed for the derivative with the bulkiest phosphine, 3. The simplest process that is consistent with these observations (Fig. 11) involves rotation of one of the $\left(\mathrm{P}_{2} \mathrm{PtH}\right)$ moieties by $90^{\circ}$ around the $\mathrm{Pt}-\mathrm{Pt}$ vector (Step $\mathrm{A}$ ) to give the $180^{\circ}$ geometry discussed above (Fig. 3), followed by hydride exchange between metal centers with simultaneous twisting of the phosphine ligands by $90^{\circ}$ relative to the plane defined by the square planar metal centers (Step B).

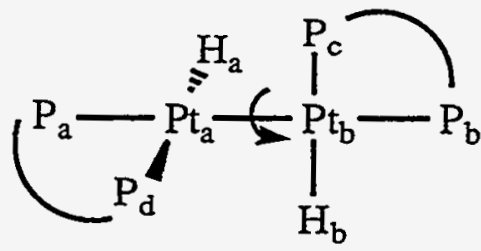<smiles>CC(C)[GeH3]</smiles>

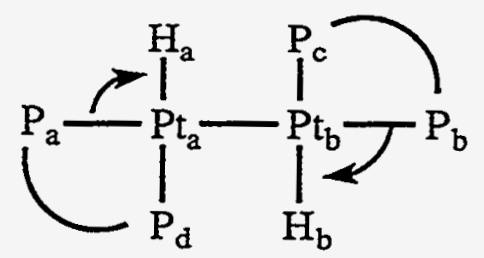

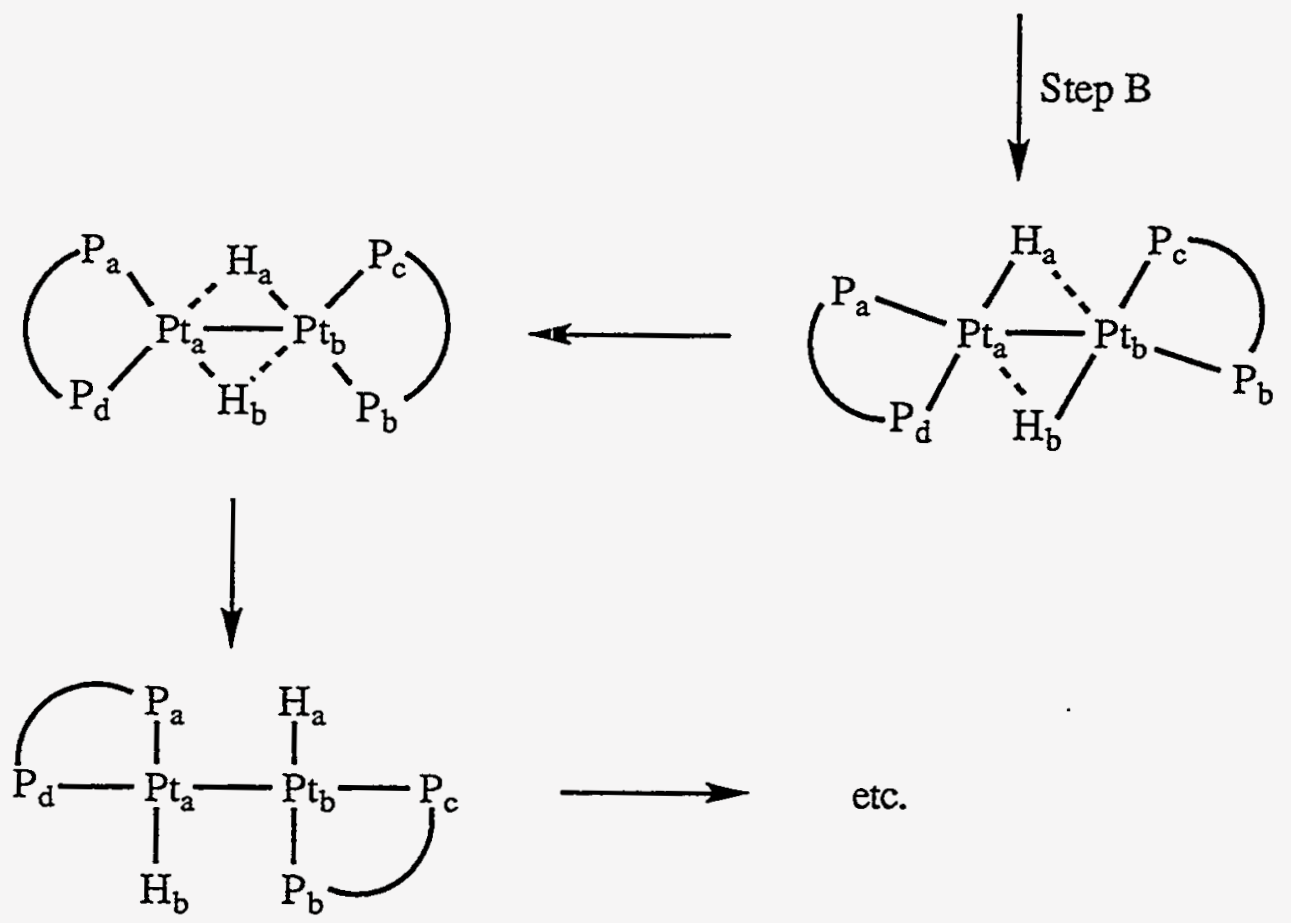

Figure 11. Proposed fluxional process for the dimers 1, 2, and 3. 
Such a fluxional process, if fast on the NMR timescale, would result in equivalent hydrides and would exchange $P_{a}$ and $P_{b}$ with $P_{d}$ and $P_{c}$, respectively, making all four phosphorus nuclei equivalent.

If it is assumed that the first stage of the process depicted above (Step A) has the higher barrier, with the hydride exchange/phosphine-twisting process (Step B) possessing a relatively small barrier, then stopping the fluxional process is a result of freezing out the conformation that is observed in the solid state; i.e, a geometry in which the two square planes of the platinum coordination spheres are oriented roughly $90^{\circ}$ relative to each other. As discussed above, the low temperature NMR data for 1 and 2 are consistent with the solid state geometry found for 1 . If the $180^{\circ}$ orientation were frozen out, then hydride exchange between the platinum centers would not cease, as the barrier to this process (B) is assumed to be small. Consistent with the assumption that the $90^{\circ}$ orientation is thermodynamically more stable than the $180^{\circ}$ orientation is the fact that both 1 and 3 crystallize in the former geometry.

Why, though, does 3 have a lower barrier for the fluxional process (i.e., Step A) than 1 and 2? As discussed above, there are several distortions in the solid state structure of 3 , relative to that of 1 , that result from increased steric interactions between the tert-butyl groups. These distortions destabilize the $90^{\circ}$ conformation of 3 , relative to the analogous conformation for 1 . This destabilization results in a lower barrier to interconversion between the $90^{\circ}$ and $180^{\circ}$ orientations for 3 (Fig. 12), as is experimentally observed. This argument assumes that the thermodynamic stability of the $180^{\circ}$ orientation for all three dimers is roughly equal; i.e, the destabilization of the $90^{\circ}$ orientation of 3 is not offset by a corresponding destabilization of the $180^{\circ}$ geometry. This is reasonable, as this geometry minimizes steric interactions between the alkyl groups of the phosphine ligands. The similar barriers for $\mathbf{1}$ and $\mathbf{2}$ are consistent with this proposal as the phosphine on 2 (dcype), as in the case of 1 , also possesses a methine hydrogen which can be oriented in such a way as to relieve steric interactions between 
alkyl groups (Fig. 3). As discussed above, this stabilizes the $90^{\circ}$ geometry. The close agreement of the room temperature NMR values for 1 and 2 , relative to the slightly different values for 3 (Table 3), may also be indicative of these differences.

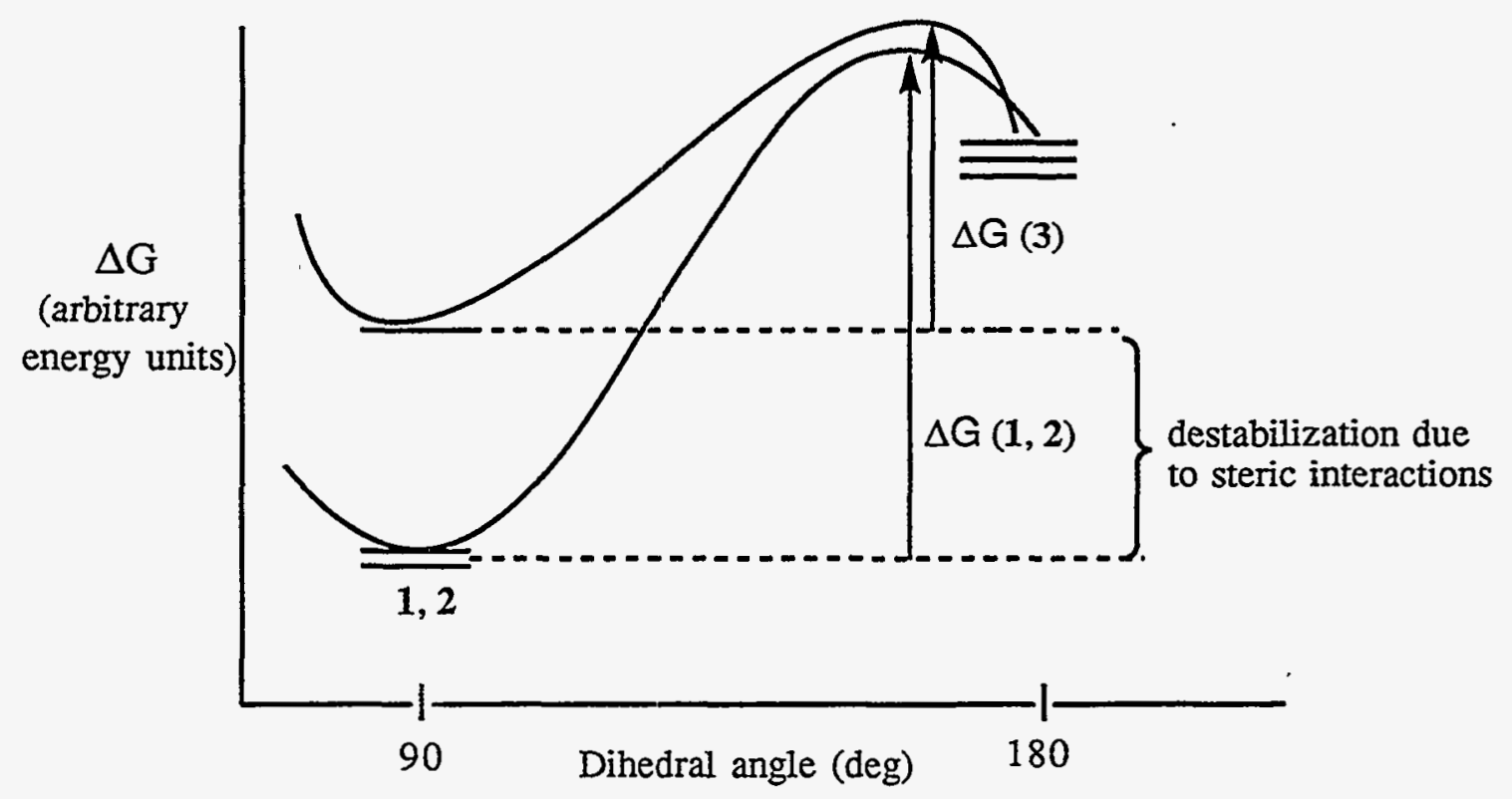

Figure 12. Illustration of the proposed cause of the differences in the fluxional barriers for 1,2 and 3 .

H/D Isotopic Scrambling. A 1:1 mixture of 5 and its deuterated analogue, (dcype) $P_{t D}\left(d_{2}-5\right)$, in $C_{6} D_{6}$ reaches the 1:2:1 5:(dcype) $P t(H)(D): d_{2}-5$ equilibrium ratio within one hour. The same result was found for the analogous reaction using 6 and its deuterated derivative. In both cases, the reactions were followed by ${ }^{31} \mathrm{P}\left\{{ }^{1} \mathrm{H}\right\}$ and ${ }^{1} \mathrm{H}$ NMR spectroscopy As a control, no evidence of $H / D$ exchange of the protiated monomers 5 and 6 with $\mathrm{C}_{6} \mathrm{D}_{6}$ at room temperature was observed in the ${ }^{1} \mathrm{H}$ and ${ }^{3}{ }^{1} \mathrm{P}\left\{{ }^{1} \mathrm{H}\right\}$ spectra over several days. In contrast, a 1:1 sample of 1 and its deuterated analogue, $\left\{(\text { dippe) } P t D\}_{2}\left(\mathrm{~d}_{2}-1\right)\right.$, scrambles much more slowly than the monomers; the half-life is ca. 90 hours at room temperature (eq. 2). Dimer 1 does not undergo H/D exchange with $\mathrm{C}_{6} \mathrm{D}_{6}$ at room temperature at any appreciable rate. However, heating a $\mathrm{C}_{6} \mathrm{D}_{6}$ solution of 
1,2 , or 3 for 12 hours at $90-100^{\circ} \mathrm{C}$ results in complete deuterium incorporation at the hydride positions, for all three samples.

The scrambling process has not been studied in detail, however several qualitative experiments were done. No evidence of scrambling was observed for a 1:1 sample of 3: $\mathrm{d}_{2}-6$ after 51 hours at room temperature (eq. 3). A 1:1 sample of 1:d2-6 in $\mathrm{C}_{6} \mathrm{D}_{6}$ scrambles completely within 48 hours (eq. 4). Also, no evidence of scrambling is observed for a 1:1 $\mathrm{d}_{2}-1: 3$ sample after 72 hours (eq. 5).

$$
\begin{aligned}
& \begin{array}{ccc}
\text { (dtbpe)PtD } \\
\mathrm{d}_{2}-6
\end{array}+\underset{3}{\left[(\mathrm{dtbpe}) \mathrm{PtH}_{2}\right.} \stackrel{\mathrm{C}_{6} \mathrm{D}_{6}, \mathrm{rt} / 51 \mathrm{~h}}{\longrightarrow} \quad \begin{array}{l}
\text { no H/D } \\
\text { scrambling }
\end{array}
\end{aligned}
$$

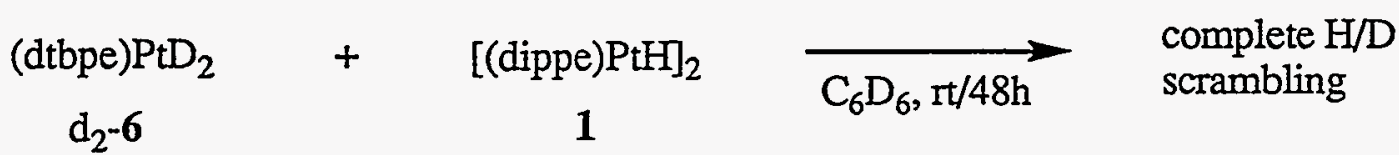

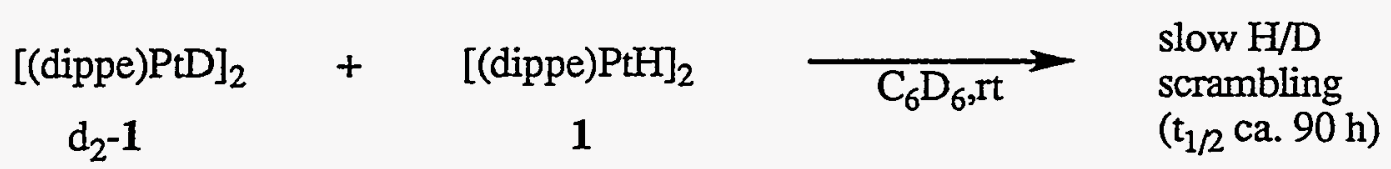

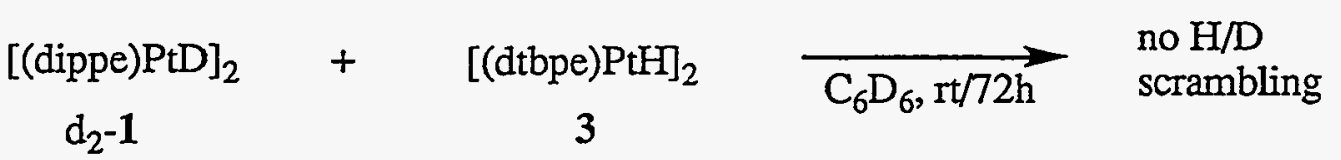

Clearly, there are differences in the reactivity of 1 , relative to that of 3 . The lower rates in 3 are likely due to the increased steric protection of the $\mathrm{Pt}-\mathrm{Pt}$ bond by the tert-butyl groups, as discussed in detail in the structural discussion above.

A small amount of "mixed dimer", $\left[\left(\mathrm{R}_{2} \mathrm{P}\left(\mathrm{CH}_{2}\right)_{2} \mathrm{PR} 2\right)(\mathrm{H}) \mathrm{Pt}-\right.$ $\left.\mathrm{Pt}(\mathrm{H})\left(\mathrm{R}_{2}^{\prime} \mathrm{P}\left(\mathrm{CH}_{2}\right)_{2} \mathrm{PR}_{2}\right)\right]$, was present in all samples for which $\mathrm{H} / \mathrm{D}$ scrambling was observed. The identity of these mixed dimers was confirmed by a $1 \mathrm{H} / 31 \mathrm{P}$ HMQC spectrum (given in Appendix I) on a sample containing a mixture of 1, 2, and [(dippe)(H)Pt-Pt $(\mathrm{H})($ dcype) $]$ (made by heating a $\mathrm{C}_{6} \mathrm{H}_{6}$ sample of 1 and 2 ), in which 
three different hydride resonances are correlated with the three different dimeric complexes present. While no more than $c a .10-20 \%$ of this "mixed dimer" was present in the samples, it may be responsible for the H/D scrambling that occurs. The mechanism of formation of such "mixed dimers" was not investigated; however, based on the low lability of bidentate phosphine ligands bound to platinum, it is not unreasonable to postulate that it involves cleavage of the $\mathrm{Pt}-\mathrm{Pt}$ bond to generate $\mathrm{P}_{2} \mathrm{Pt}$ and $\mathrm{P}_{2} \mathrm{PtH}_{2}$ fragments, which can then scramble to give the mixed dimer. This is possibly the reverse of the mechanism of formation of the $[(\mathrm{P}-\mathrm{P}) \mathrm{PtH}]_{2}$ dimers: loss of $\mathrm{H}_{2}$ from a (P-P) $\mathrm{PtH}_{2}$ complex, followed by oxidative addition of the $\mathrm{Pt}-\mathrm{H}$ bond of another ( $\mathrm{P}-$ P) $\mathrm{PtH}_{2}$ complex to the $\mathrm{Pt}$ center of the $\mathrm{P}_{2} \mathrm{Pt}$ intermediate.

Theoretical calculations have shown that there is essentially no barrier to reductive elimination of dihydrogen from cis- $\mathrm{P}_{2} \mathrm{PtH}_{2}$ complexes. ${ }^{23}$ Otsuka and co-workers have suggested that bulky phosphines kinetically stabilize the cis-dihydride monomers, thus allowing their isolation. ${ }^{3,5 a}$ The results described above support this explanation: the stabilities of the monomeric cis-dihydride complexes that have been prepared in this study (i.e, the tendency not to dimerize in solution) correlate directly with the steric sizes of the phosphines $\left(\mathbf{3}>\mathbf{2}>\mathbf{1}\right.$; the cone angles for the monodentate analogues, $P R_{3}$, are $182,170,160^{\circ}$, for $\mathrm{P}(\mathrm{t}-\mathrm{Bu})_{3}, \mathrm{PCy}, \mathrm{P}(\mathrm{i}-\mathrm{Pr})_{3}$, respectively $\left.{ }^{24}\right)$.

For cis-dihydride complexes containing sterically smaller phosphine ligands (e.g, 4), the kinetic barrier for loss of $\mathrm{H}_{2}$ is small and occurs in solution at room temperature. The resulting product of such a reaction is a neutral $[(\mathrm{P}-\mathrm{P}) \mathrm{PtH}] 2$ dimer, presumably arising from reaction of cis-(P-P) $\mathrm{PtH}_{2}$ with a (P-P)Pt intermediate, although other mechanisms of formation of the dimeric complexes are possible (e.g., such as oxidative addition of the $\mathrm{Pt}-\mathrm{H}$ bond of a $\mathrm{P}_{2} \mathrm{PtH}_{2}$ molecule to the $\mathrm{Pt}$ center of another $\mathrm{P}_{2} \mathrm{PtH}_{2}$ molecule, followed by reductive elimination of $\mathrm{H}_{2}$ ). This contrasts with the postulate made by Otsuka et al ${ }^{3}$ that loss of dihydrogen from cis-(P-P)PtH $\mathrm{P}_{2}$ complexes gives solutions of $[(\mathrm{P}-\mathrm{P}) \mathrm{Pt}]_{2}$ dimers. The Otsuka postulate was based on several lines of 
evidence: the structure of $[(\mathrm{dtbpp}) \mathrm{Pt}] 2$, which showed no evidence for hydrides; a decrease in the intensity of the hydride resonance in the ${ }^{1} \mathrm{H}$ NMR spectra and of the $\mathrm{M}-\mathrm{H}$ stretch in the $\mathbb{R}$ spectrum as solutions of the cis-dihydride monomers were heated, and a color change from colorless to reddish-brown as the solutions were heated. The last three observations are also consistent with loss of dihydrogen to give $[(\mathrm{P}-\mathrm{P}) \mathrm{PtH}]_{2}$ dimers, as discussed above.

In contrast to the reddish-brown solutions formed upon heating solutions of cis-(PP) $\mathrm{PtH}_{2}$ complexes, the $[(\mathrm{P}-\mathrm{P}) \mathrm{Pt}]_{2}$ dimer was prepared by the sodium amalgam reduction of a thf solution of (dtbpp) $\mathrm{PtCl}_{2}$ under nitrogen. As mentioned by Otsuka et al., it is possible that a cis-(P-P) $\mathrm{PtH}_{2}$ intermediate is never formed in this reaction, and that the $[(\mathrm{P}-\mathrm{P}) \mathrm{Pt}]_{2}$ dimer results from reduction of the $(\mathrm{P}-\mathrm{P}) \mathrm{PtCl}_{2}$ starting material to a $(\mathrm{P}-\mathrm{P}) \mathrm{Pt}$ intermediate, which then dimerizes to give the observed product. Based on the results presented above, the formation of $[(\mathrm{P}-\mathrm{P}) \mathrm{Pt}]_{2}$ dimeric complexes from solutions of cis-(PP) $\mathrm{PtH}_{2}$ complexes is not a general process; it appears that formation of $\mathrm{Pt}(\mathrm{I})$ hydridecontaining dimers such as 1-3 is favored, at least with the chelating phosphines used in this study.

Reactivity with $\mathrm{Cp}_{2}^{*} \mathrm{Yb}$. The reactivity of the $[(\mathrm{P}-\mathrm{P}) \mathrm{PtH}]_{2}$ dimers with $\mathrm{Cp}_{2}{ }_{2} \mathrm{Yb}(7)$ has also been investigated. The dimer 1 does not interact with 7 in a d8toluene solution, at room temperature or at $-90^{\circ} \mathrm{C}$, based on ${ }^{1} \mathrm{H}$ and ${ }^{31} \mathrm{P}$ NMR data (both 1:1 and 2:1 samples of 7:1 were investigated). When a $\mathrm{C}_{6} \mathrm{H}_{6}$ sample containing a 2:1 molar ratio of 7 and $\mathbf{1}$ is heated for 5 hours at $90^{\circ} \mathrm{C}$, a $1: 1$ ratio of the dihydride and phenyl hydride monomers, both complexed to 7 , is produced (eq. 6 , most of the (dippe) $\mathrm{Pt}(\mu-\mathrm{H})_{2} \mathrm{YbCp}_{2}{ }_{2}$ falls out of solution as a dark blue solid). In contrast, heating a sample of 1 in benzene at $90^{\circ} \mathrm{C}$ for 5 hours, in the absence of 7 , gives no reaction (eq. 7). Heating a $\mathrm{C}_{6} \mathrm{H}_{6}$ sample of 3 and 7 (a $1: 2$ molar ratio) at $90^{\circ} \mathrm{C}$ for 12 hours, gives only a small amount (ca. $20 \%$ ) of conversion to the monomeric ((dtbpe) $\mathrm{PtH}_{2}$ and 
(dtbpe) $\mathrm{Pt}(\mathrm{Ph})(\mathrm{H})$ ) complexes (eq. 8). Again the lower reactivity of $\mathbf{3}$ relative to that of $\mathbf{1}$ is observed.

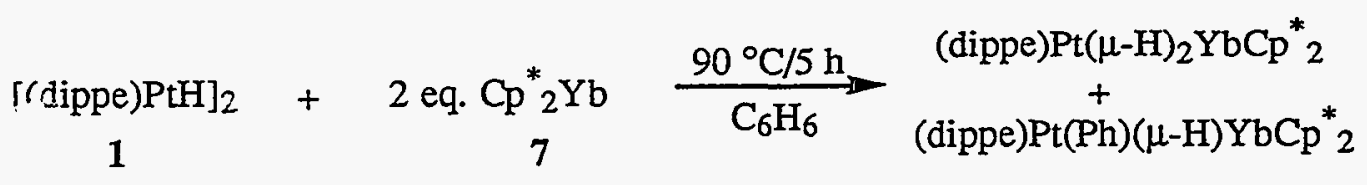

$$
\begin{aligned}
& \underset{1}{[(\text { dippe }) \mathrm{PtH}]_{2}} \stackrel{90^{\circ} \mathrm{C} / 5 \mathrm{~h}}{\mathrm{C}_{6} \mathrm{H}_{6}} \underset{\text { No reaction }}{\longrightarrow} \text {. }
\end{aligned}
$$

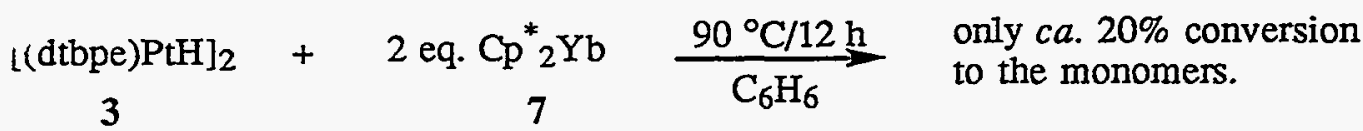

$$
\begin{aligned}
& {[(\text { dippe }) \mathrm{PtH}]_{2}+2 \text { eq. } \mathrm{Cp}_{2}^{*} \mathrm{Yb} \frac{80^{\circ} \mathrm{C} / 32 \mathrm{~h}}{\text { hexanes }} \text { No reaction }}
\end{aligned}
$$

Interestingly, no reaction occurs upon heating a sample of 1 and 7 (1:2 molar ratio) in hexanes at $80^{\circ} \mathrm{C}$ for 32 hours (eq. 9). A mechanism involving dissociation of 1 into the corresponding (dippe) $\mathrm{Pt}$ and (dippe) $\mathrm{PtH}_{2}$ fragments, followed by activation of benzene, does not explain these results, as (dippe)Pt can most likely also activate hexane, 22 and so the dimer 1 would not be the expected 'product' of eq. 9 . However, a mechanism involving a $\mathrm{C}_{6} \mathrm{H}_{6}$-assisted fragmentation of the dimer $\mathbf{1}$, is consistent with the observations. In other words a molecule of $\mathrm{C}_{6} \mathrm{H}_{6}$ has to first oxidatively add to one of the $\mathrm{Pt}$ centers of 1 in order for dimer fragmentation to occur. Assuming $\mathrm{C}_{6} \mathrm{H}_{6}$ is a better ligand towards 1 than a molecule of hexane, and can thus cause fragmentation of 1 while hexane cannot, the lack of reactivity of 1 in hexane is reasonable. Such a mechanism also explains the decreased reactivity of 3, relative to that of $\mathbf{1}$ (eqs. 6 and 8); the increased steric bulk of the dtbpe ligands in 3 results in slower association of $\mathrm{C}_{6} \mathrm{H}_{6}$ and consequently slower fragmentation of 3 . However, this mechanism is inconsistent with the lack of reaction of 1 in $\mathrm{C}_{6} \mathrm{H}_{6}$, in the absence of 7 (eq. 7); if this mechamism were operating, conversion to the dihydride and phenyl hydride monomers would be the 
expected products. However, if it is assumed that the dihydride and phenyl hydride complexes convert back to the dimer $\mathbf{1}$, in the absence of a "trapping" agent such as $\mathbf{7}$, the postulated mechanism is still valid. Consistent with this, (dippe) $\mathrm{PtH}_{2}$ is stable only under an atmosphere of $\mathrm{H}_{2}$ (Chapter 1). However, the mechanism of the reaction of 1 with $\mathrm{C}_{6} \mathrm{H}_{6}$, in the presence of 7 , has not been investigated in detail. 
References.

(1) Moulton, C. ' Shaw, B. L. J. Chem. Soc., Chem. Commun. 1976, 365.

(2) (a) Transition Metal Complexes of Phosphorus, Arsenic, and Antimony Ligands; McAuliffe, C. A., ed.; John Wiley: New York, 1973. (b) McAuliffe, C. A.; Levason, W. In Phosphine, Arsine, and Stibine Complexes of the Transition Elements; Elsevier: New York, 1979.

(3) Yoshida, T.; Yamagata, T.; Tulip, T. H.; Ibers, J. A.; Otsuka, S. J. Am. Chem. Soc. 1978, 100, 2063.

(4) (a) Clark, H. C.; Hampden Smith, M. J. J. Am. Chem. Soc. 1986, 108, 3829. (b) Carmichael, D.; Hitchcock, P. B.; Nixon, J. F.; Pidcock, A. J. Chem. Soc., Chem. Commun. 1988, 1554. (c) Serivanti, A.; Campustrini, R.; Caruran, G. Inorg. Chim. Acta. 1988, 142, 187.

(5) (a) Tulip, T. H.; Yamagata, T.; Yoshida, Y.; Wilson, R. D.; Ibers, J. A.; Otsuka, S. Inorg. Chem. 1979, 18, 2239. (b) Otsuka, S. J. Organomet. Chem. 1980, 200, 191. (c) Bracher, G.; Grove, D. M.; Pregosin, P. S.; Venanzi, L. M. Angew. Chem., Int. Ed. Engl. 1979, 18, 155. (d) Carmona, D.; Thouvenot, R.; Venanzi, L. M.; Bachechi, F.; Zambonelli, L. J. Organomet. Chem. 1983, 250, 589. (e) Bachechi, F.; Bracher, G.; Grove, D.; Kellenberger, D. M.; Pregosin, P. S.; Venanzi, L. M.; Zambonelli, L. Inorg. Chem. 1983, 22, 1031. (f) Bachechi, F. Acta Crystallogr. 1993, C49, 460. (g) Knobler, C. B.; Kaesz, H. D.; Minghetti, G.; Bandini, A. L.; Banditelli, G.; Bonati, F. Inorg. Chem. 1983, 22, 2324. (h) Chiang, M. Y.; Bau, R.; Minghetti, G.; Bandini, A. L.; Banditelli, G.; Koetzle, T. F. Ibid. 1984, 23, 122. (i) Aime, S.; Gobetto, R.; Bandini, A. L.; Banditelli, G.; Minghetti, G. Ibid. 1991, 30, 316. (j) Paonessa, R. S.; Trogler, W. C. Ibid. 1983, 22, 1038.

(6) (a) Jonas, K.; Wilke, G. Angew. Chem., Int. Ed. Engl. 1970, 9, 312. (b) Barnett, B. L.; Kruger, C.; Tsay, Y-H.; Summerville, R. H.; Hoffmann, R. Chem. Ber. 1977, 110, 3900. (c) Fryzuk, M. D.; Lloyd, B. R.; Clentsmith, G. K. B.; Rettig, S. J. J. Am. Chem. Soc. 1994, 116, 3804. 
(7) Orpen, A. G.; Brammer, L.; Allen, F. H.; Kennard, O.; Watson, D. G.; Taylor, R. J. Chem. Soc., Dalton Trans. 1989, 51. This article lists Pt-P distances for a variety of compounds in various oxidation states and coordination numbers.

(8) (a) Boag, N. M.; Browning, J.; Crocker, C.; Goggin, P. L.; Goodfellow, R. J.; Murray, M.; Spencer, J. L. J. Chem. Res (S). 1978, 228. (b) Boag, N. M.; Browning, J.; Crocker, C.; Goggin, P. L.; Goodfellow, R. J.; Murray, M.; Spencer, J. L. J. Chem. Res. (M). 1978, 2962. (c) Yamamoto, Y.; Takahashi, K.; Yamazaki, H. Chem. Let. 1985, 201. (d) Couture, C.; Farrar, D. H.; Fisher, D. S.; Gukathasan, R. R. Organometallics. 1987, 6, 532.

(9) Otsuka, S.; Yoshida, T.; Matsumoto, M.; Nakatsu, K. J. Am. Chem. Soc. 1976, 98,5850 .

(10) Bell, J. D.; Hall, D.; Waters, T. N.; Acta. Crystallogr. 1966, 21, 440.

(11) Anderson, G. K. Adv. Organomet. Chem. 1993, 35, 1.

(12) (a) Ciriano, M.; Green, M.; Howard, J. A. K.; Proud, J.; Spencer, J. L.; Stone, F. G. A.; Tsipis, C. A. J. Chem. Soc., Dalton Trans. 1978, 801. (b) Green, M.; Howard, J. A. K.; Proud, J.; Spencer, J. L.; Stone, F. G. A.; Tsipis, C. A. J. Chem. Soc., Chem. Commun. 1976, 671.

(13) (a) Pitzer, K. Acc. Chem. Res. 1979, 12, 271. (b) Pyykko, P.; Desclaux, J. P. Ibid. 1979, 12, 276. (c) Pyykko, P. Chem. Rev. 1988, 88, 563. (d) Powell, J.; Sawyer, J. F.; Smith, S. J. J. Chem. Soc., Chem. Commun. 1985, 1312.

(14) Pregosin, P. S. In Annual Reports on NMR Spectroscopy, Vol. 17; Webb, G. A., Ed.; Academic Press Inc.: London, 1986.

(15) Pregosin, P. S. In Transition Metal Nuclear Magnetic Resonance; Pregosin, P. S.; Ed.; Elsevier Science Publishing Company Inc.: New York, 1991, pp. 234-242; and references therein.

(16) Bracher, G.; Grove, D. M.; Venanzi, L. M.; Bachechi, F.; Mura, P. Zambonelli, L. Angew. Chem., Int. Ed. Engl. 1978, 17, 778. 
(17) Aime, S.; Gobetto, R.; Bandini, A. L.; Banditelli, G.; Minghetti, G. Inorg. Chem. 1991, 30, 316.

(18) Bryant, R. G. J. Chem. Ed. 1983, 60, 933.

(19) (a) Bax, A.; Griffey, R. H.; Hawkins, B. L. J. Magn. Reson. 1983, 55, 301. (b) Bax, A.; Subramanian, S. J. Magn. Reson. 1986, 67, 565.

(20) Garrou, P. E. Chem. Rev. 1985, 85, 171. (b) Hackett, M. Ibers, J. A.; Whitesides, G. M. J. Am. Chem. Soc. 1988, 110, 1436.

(21) The following variables were used for the simulated spectra: a) the coupling constant and chemical shift values given in the text were used; b) the line broadening used for the individual subspectra was estimated from that observed in the experimental spectrum; c) all of the coupling constant values were assigned as positive: it is known that all of the ${ }^{1} \mathrm{~J}_{\mathrm{PtP}}$ values are of the same sign, and that ${ }^{2} \mathrm{~J}_{\mathrm{PtaPb}}$ is of the same sign (from the appearance of the low temperature ${ }^{1}{ }^{1} \mathrm{P}\left\{{ }^{1} \mathrm{H}\right\} \mathrm{Pt} /{ }^{195} \mathrm{Pt}$ simulated subspectrum). Variation of the signs of the remaining coupling constants had no significant effect on the appearance of the simulated subspectra; d) all of the unresolved ${ }^{2,3} \mathrm{~J}_{\mathrm{PP}}$ values (see text) were set equal to zero for the simulations.

(22) Hackett, M.; Ibers, J. A.; Jernakoff, P.; Whitesides, G. M. J. Am. Chem. Soc. 1986, 108, 8094.

(23) (a) Low, J. J.; Goddard III, W. A. J. Am. Chem. Soc. 1984, 106, 6928. (b) Low, J. J.; Goddard III, W. A. Organometallics. 1986, 5, 609.

(24) Otsuka, S. J. Organomet. Chem. 1980, 191. 


\section{CHAPTER 3}

\section{Interactions of $\mathrm{Cp}_{2}{ }_{2} \mathrm{Yb}$ with Phosphines, $R_{3} P X$ Complexes ( $X=O$, NR', CHR").}

Phosphine complexes of the lanthanides and actinides are relatively rare, a result of the hard nature of these metal centers and the soft nature of phosphines. ${ }^{1}$ Almost no solution-state investigations have been reported for lanthanide and actinide complexes in general (a result of the paramagnetism of almost all $\mathrm{Ln} / \mathrm{An}$ complexes $^{2}$ ), and for phosphine derivative complexes, more specifically. Given the diamagnetism of $\mathrm{Cp}_{2}{ }_{2} \mathrm{Yb}$ and the favorable properties of phosphines and phosphine derivatives for NMR studies, it was thought worthwhile to investigate the solution-state interactions formed between $\mathrm{Cp}_{2}{ }_{2} \mathrm{Yb}$ and phosphines, phosphine oxides $\left(\mathrm{R}_{3} \mathrm{PO}\right)$, phosphine imines $\left(\mathrm{R}_{3} \mathrm{PNR}\right)$, and phosphine ylides ( $\left.{ }_{3} \mathrm{PCHR} "\right)$. The strength and nature of the interactions formed between $\mathrm{Cp}_{2}{ }_{2} \mathrm{Yb}$ and phosphines, phosphine oxides and imines, and the isoelectronic (to phosphine oxides and imines) ylides, have been found to vary significantly. In addition, a novel intramolecular dynamic process of an ylide adduct of 1 , has been elucidated.

Interactions with Phosphines. Addition of 2 eq. of $\mathrm{PMe}_{3}$ to a dark brown toluene solution of 1 gives a bright green solution, from which green crystals of $\mathrm{Cp}_{2}{ }_{2} \mathrm{Yb}\left(\mathrm{PMe}_{3}\right)_{2}$ (2) may be isolated in $88 \%$ yield upon cooling to $-80^{\circ} \mathrm{C}$. A similar synthetic procedure with 2 eq. of PEt3 yields dark blue crystals of the 1:1 adduct $\mathrm{Cp}_{2}{ }_{2} \mathrm{Yb}\left(\mathrm{PEt}_{3}\right)(3)$, presumably a result of the larger size of $\mathrm{PEt} 3$ relative to $\mathrm{PMe}_{3}$. The ${ }^{1} \mathrm{H}$ and ${ }^{31 P}\left\{{ }^{1} \mathrm{H}\right\}$ NMR spectral values of 2 and 3 at $25^{\circ} \mathrm{C}$ are very similar to the spectral values for the free compounds, showing that the solution-state interaction between $\mathbf{1}$ and these phosphines is relatively weak. The phosphine alkyl group protons and the phosphorus nucleus are not coupled to the ${ }^{171} \mathrm{Yb}$ nucleus, indicating fast intermolecular exchange occurs on the NMR timescale for both 2 and 3. 
Cooling a toluene- $\mathrm{d}_{8}$ sample of the $1: 2 \mathrm{PMe}_{3}$ adduct 2 to $-101{ }^{\circ} \mathrm{C}$ results in broadened resonances in both the ${ }^{1} \mathrm{H}$ and ${ }^{31} \mathrm{P}$ spectra (the values are given in Table 1), suggesting that the intermediate exchange region has been reached. Even though the width at half height of the ${ }^{31} \mathrm{P}\left\{{ }^{1} \mathrm{H}\right\}$ resonance (at $-49.2 \mathrm{ppm}$ ) is $135 \mathrm{~Hz}$, a ${ }^{1} \mathrm{~J}_{\mathrm{YbP}}$ value of ca. $600 \mathrm{~Hz}$ is resolved.

Table 1. Low Temperature 1 H. 31 P NMR Data for Phosphine Adducts of 1 (toluened 8$)^{a}$

\begin{tabular}{|c|c|c|c|c|c|}
\hline Sample & \multicolumn{2}{|c|}{ Temp. $\left({ }^{\circ} \mathrm{C}\right) \delta(\mathrm{P})$} & $1 \mathrm{~J}_{\mathrm{YbP}}$ & $\delta(\mathrm{Cp} * \underline{\mathrm{b}}$ & $\delta(\mathrm{H})$ \\
\hline $\mathrm{PMe}_{3}$ & -93 & -62.0 & -- & -- & 0.78 \\
\hline 1:1 adduct, 2 & -101 & -49.2 & $600(20)^{c}$ & 2.28 & 0.64 \\
\hline $1: 2$ adduct, $4^{d}$ & -93 & -45.4 & 956 & 2.20 & 0.54 \\
\hline $\mathrm{PEt}_{3}$ & -93 & -23.0 & -- & -- & $1.02(\mathrm{Me}), 1.18\left(\mathrm{CH}_{2}\right)$ \\
\hline 1:1 adduct, $\mathbf{3}$ & -103 & -3.7 & 950 & 2.24 & $0.51(\mathrm{Me}), 1.15\left(\mathrm{CH}_{2}\right)$ \\
\hline $1+\mathrm{xs} \mathrm{PEt}_{3}$ & -103 & $-16.3^{e}$ & not resolved & 2.24 & $0.80(\mathrm{Me}), 1.16\left(\mathrm{CH}_{2}\right)$ \\
\hline dmpm & -65 & -57.1 & -- & -- & not measured \\
\hline 5 & -65 & -35.6 & 580 & 2.27 & not measured \\
\hline $1,2-\left(\mathrm{PMe}_{2}\right)_{2} \mathrm{C}_{6} \mathrm{H}_{4}$ & $4-20$ & -52.9 & -- & --- & 1.18 \\
\hline $6^{f}$ & -20 & -38.4 & 656 & 2.06 & 1.02 \\
\hline
\end{tabular}

aFor this and all other Tables in this chapter, chemical shift values are given in ppm, and coupling constants are given in $\mathrm{Hz}$.

bAs mentioned in the text, many of the samples were made with a slight excess of 1 , to minimize intermolecular exchange; consequently, a free $\mathrm{Cp}^{*}$ resonance at $c a .2 .00 \mathrm{ppm}$ was also present for these low temperature samples.

${ }^{\mathrm{C} F o r}$ this and all other Tables containing NMR data, estimated experimental uncertainties are given in parentheses, for values where the uncertainty is relatively large.

dValues given were measured from a sample containing 0.8 eq. PMe3/1 eq. 1 , see text. eThe half height width of this resonance is $c a .900 \mathrm{~Hz}$, see text.

fIn addition, a ${ }^{3}\left(\mathrm{YbPCH}_{3}\right)$ of $2.7 \mathrm{~Hz}$ was resolved, see text.

The ${ }^{31} \mathrm{P}\left\{{ }^{1} \mathrm{H}\right\}$ spectrum of a sample of 1 with $\mathrm{ca} .0 .8$ eq of $\mathrm{PMe}_{3}$, at $-83^{\circ} \mathrm{C}$, contains a sharp singlet at $-45.4 \mathrm{ppm}$ with ${ }^{171} \mathrm{Yb}$ satellites (Fig. 1, the area of each satellite is 
approximately $7 \%$ of the area of the major resonance, as expected), presumably arising from the $1: 1$ adduct $\mathrm{Cp}^{*}{ }_{2} \mathrm{Yb}\left(\mathrm{PMe}_{3}\right)(4)$.

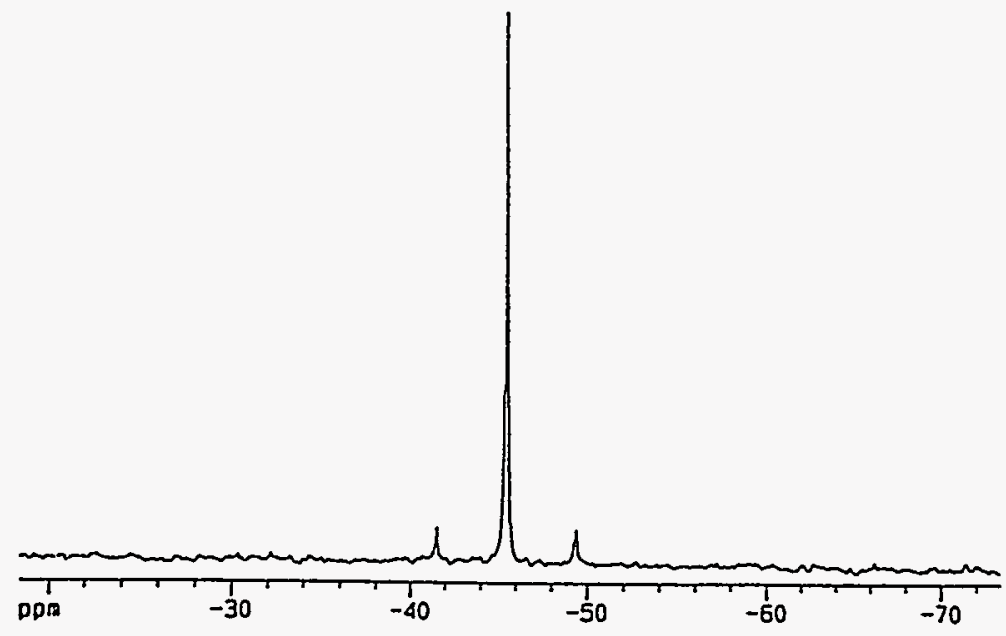

Figure 1. ${ }^{31} \mathrm{P}\left\{{ }^{1} \mathrm{H}\right\}$ spectrum of 2 at $-83^{\circ} \mathrm{C}$, showing ${ }^{171} \mathrm{Yb}-31 \mathrm{P}$ coupling of $956 \mathrm{~Hz}$ (121.5 MHz, toluene-d8).

The ${ }^{171} \mathrm{Yb}-{ }^{31} \mathrm{P}$ coupling is $956 \mathrm{~Hz}$, roughly $2 / 3$ larger than the analogous value for the 1:2 $\mathrm{PMe}_{3}$ adduct 2 . The ${ }^{1} \mathrm{H}$ spectrum of this sample at $-83^{\circ} \mathrm{C}$ contains resonances for both free and bound 1 (the spectral values are given in Table 1); coupling of ${ }^{171}{ }^{Y b}$ to the alkyl protons of the bound phosphine $\left({ }^{3} \mathrm{~J}_{\mathrm{YbH}}\right)$ is not resolved. The slow exchange behavior of this sample at $-83^{\circ} \mathrm{C}$, compared to the intermediate exchange observed for 2 at $-101^{\circ} \mathrm{C}$, indicates that the barrier for intermolecular exchange is higher for 4 than for 2 ; this will be discussed below.

Cooling a toluene- $\mathrm{d}_{8}$ sample of the $1: 1 \mathrm{PEt} 3$ adduct, 3 , to $-103^{\circ} \mathrm{C}$ results in slow intermolecular exchange on the NMR timescale; the observed ${ }^{1} J_{Y b P}$ value of $950 \mathrm{~Hz}$ is similar to the analogous value observed for the $1: 1 \mathrm{PMe}_{3}$ derivative, 4. Again, $3,4 \mathrm{~J}_{\mathrm{YbH}}$ is not resolved (the NMR values for this sample are also given in Table 1). The coalescence temperature of the free and bound $\mathrm{Cp}^{*}$ resonances is $-89^{\circ} \mathrm{C} .3,4$ A sample of 1 and 2 eq. of $\mathrm{PEt} 3$ was cooled to $-103^{\circ} \mathrm{C}$. The ${ }^{1} \mathrm{H}$ and ${ }^{31} \mathrm{P}\left\{{ }^{1} \mathrm{H}\right\}$ spectra at this temperature contain broad resonances $\left({ }^{31} \mathrm{P}\right.$ resonance, $\mathrm{w}_{1 / 2} \mathrm{ca} .900 \mathrm{~Hz}$ ), indicating that the exchange barrier 
is lower for the 2:1 $\mathrm{PEt}_{3}$ derivative, relative to the $1: 1$ adduct, similar to the situation observed for the $\mathrm{PMe}_{3}$ derivatives above.

At this point, it was of interest to investigate the behavior of chelating phosphines with 1. While $\mathrm{Cp}_{2}{ }_{2} \mathrm{Yb}(\mathrm{dmpm})(5)$ has been reported, ${ }^{1 \mathrm{~b}}$ only the exchange-averaged room temperature NMR data were measured. Cooling a sample of 5 to $-65^{\circ} \mathrm{C}$ results in slow exchange, with a ${ }^{1} \mathrm{JYbP}$ coupling of $580 \mathrm{~Hz}$ (values given in Table 1); this value is unchanged at $-90^{\circ} \mathrm{C}$. As found for the monodentate phosphine-analogues above, coupling of ${ }^{171} \mathrm{Yb}$ to the phosphine alkyl protons is not resolved. A sample of $\mathbf{5}$ containing a slight excess of dmpm exhibits intermediate exchange behavior at $-65^{\circ} \mathrm{C}$; although two resonances are visible in the ${ }^{31} \mathrm{P}\left\{{ }^{1} \mathrm{H}\right\}$ spectrum, arising from free dmpm and 5 , both are broad, with widths at half height of $c a .450 \mathrm{~Hz}$. This contrasts with the slow exchange behavior at this temperature for 5 , in the absence of added dmpm; this result will be discussed below.

The dmpe complex, $\mathrm{Cp}^{*}{ }_{2} \mathrm{Yb}(\mathrm{dmpe})$, is insoluble in toluene and diethyl ether, but dissolves in thf to give $\mathrm{Cp}^{*}{ }_{2} \mathrm{Yb}(\text { thf })_{2}$ and the free phosphine. ${ }^{1 \mathrm{~b}}$ This behavior indicates that $\mathrm{Cp}_{2}{ }_{2} \mathrm{Yb}(\mathrm{dmpe})$ likely has a polymeric structure, with dmpe acting as a bridging rather than a chelating ligand. Addition of $\mathrm{Me}_{2} \mathrm{PCH}_{2} \mathrm{P}(\mathrm{Me}) \mathrm{CH}_{2} \mathrm{PMe}_{2}$ to a toluene solution of 1 results in the instantaneous precipitation of a bright green solid, presumably also with a polymeric structure; the ${ }^{1} \mathrm{H}$ NMR spectrum of this solid dissolved in thf-d8 indicates the presence of $\mathrm{Cp}^{*}{ }_{2} \mathrm{Yb}(\text { thf })_{2}$ and the free phosphine, in a 1:1 ratio. A toluene solution of 1 and 1,2-( $\left.\mathrm{PMe}_{2}\right)_{2} \mathrm{C}_{6} \mathrm{H}_{4}$, in a ca. 2:1 molar ratio, is dark green-brown. The ${ }^{1} \mathrm{H}$ spectrum of this sample at $25^{\circ} \mathrm{C}$ contains a broad $\mathrm{Cp}^{*}$ resonance $\left(\mathrm{w}_{1 / 2}=35 \mathrm{~Hz}\right.$ at $\left.400 \mathrm{MHz}\right)$, indicating intermediate intermolecular exchange; however, ${ }^{1} \mathrm{~J}$ YbP of $656 \mathrm{~Hz}$ is resolved in the ${ }^{31} \mathrm{P}\left\{{ }^{1} \mathrm{H}\right\}$ spectrum at this temperature (a result of the larger ${ }^{1} \mathrm{~J}_{Y b P}$ value, relative to the frequency difference between the free and bound $\mathrm{Cp}^{*}$ resonances ${ }^{5}$ ). Cooling this sample results in decoalescence of the $C p *$ resonance into free and bound resonances $\left(T_{c}\right.$ $\left.=23^{\circ} \mathrm{C}^{4}\right)$, the latter arising from the $1: 1$ adduct $\mathrm{Cp}_{2}{ }_{2} \mathrm{Yb}\left(1,2-\left(\mathrm{PMe}_{2}\right)_{2} \mathrm{C}_{6} \mathrm{H}_{4}\right)(6)$; the 
${ }^{1} \mathrm{~J}_{\mathrm{YbP}}$ value is unchanged upon cooling. It is likely that the cis disposition of the $\mathrm{Me}_{2} \mathrm{P}$ groups in 1,2-( $\left.\mathrm{PMe}_{2}\right)_{2} \mathrm{C}_{6} \mathrm{H}_{4}$, in contrast to dmpe and $\mathrm{Me}_{2} \mathrm{PCH}_{2} \mathrm{P}(\mathrm{Me}) \mathrm{CH}_{2} \mathrm{PMe}_{2}$, enforces bidentate rather than bridging interactions. ${ }^{6}$ The ${ }^{1} \mathrm{H}$ and ${ }^{31} \mathrm{P}\left\{{ }^{1} \mathrm{H}\right\}$ NMR values measured on 6 at $-20^{\circ} \mathrm{C}$ are given in Table 1. Coupling of the ${ }^{171} \mathrm{Yb}$ nucleus to the methyl protons of the phosphine ligand, ${ }^{3} \mathrm{~J}_{\mathrm{YbPCH}}$, is resolved and is $2.7 \mathrm{~Hz}$ (measured at $\left.-30^{\circ} \mathrm{C}\right) .{ }^{7}$ Using this coupling constant, the HMQC pulse sequence 8 was utilized to acquire a ${ }^{1} \mathrm{H} /{ }^{171} \mathrm{Yb}$ spectrum, at $-30^{\circ} \mathrm{C}$ (Fig. 2). The ${ }^{171} \mathrm{Yb}$ (vertical) dimension of this spectrum shows that the ${ }^{171} \mathrm{Yb}$ chemical shift of 6 is $+782 \mathrm{ppm}$ (this value will be discussed below); ${ }^{171} \mathrm{Yb}-31 \mathrm{P}$ coupling is resolved, and is identical to the value measured from the $1-\mathrm{D}^{31} \mathrm{P}\left\{{ }^{1} \mathrm{H}\right\}$ spectrum.

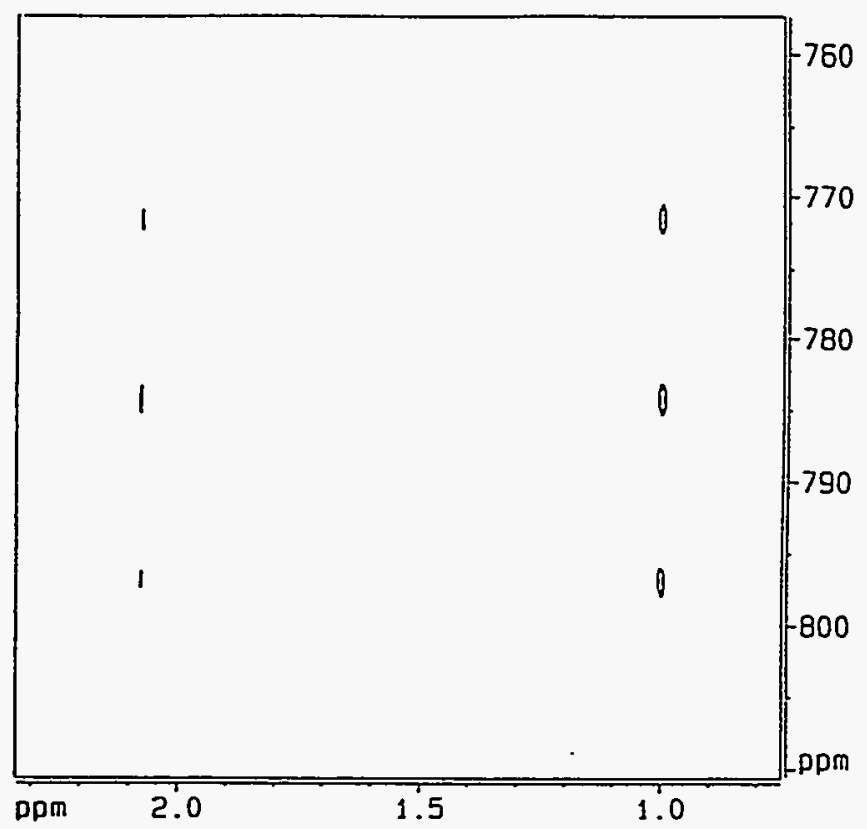

Figure 2. ${ }^{1} \mathrm{H} /{ }^{171} \mathrm{Yb}$ HMQC spectrum of $6\left(300 \mathrm{MHz}\right.$, toluene-d8, $\left.-30^{\circ} \mathrm{C}\right)$.

From Table 1 it can be seen that a low field shift of the $\mathrm{CP}^{*}$ resonance of 1 , of $c a$. $0.20 \mathrm{ppm}$, occurs upon binding of a phosphine ligand. Such low field shifts of the $\mathrm{Cp}^{*}$ resonance are common upon coordination of a ligand to 1 , as observed in the adducts discussed in Chapter 1 . The ${ }^{1} \mathrm{H}$ chemical shifts of the phosphine alkyl groups move 
slightly upfield upon coordination to 1 ; the shift for the $1: 1$ adduct $4(\Delta(\delta)=-0.24 \mathrm{ppm})$ is roughly twice the shift for the 1:2 adduct, $2(\Delta(\delta)=-0.14 \mathrm{ppm})$. While the $\delta\left(\mathrm{CH}_{2}\right)$ resonance of $\mathrm{PEt}_{3}$ is shifted upfield by only $0.03 \mathrm{ppm}$ upon coordination to 1 , the $\delta(\mathrm{Me})$ resonance is shifted upfield by a surprisingly large $0.51 \mathrm{ppm}$. This shift may be indicative of a $\gamma$-agostic interaction; agostic interactions have been observed in the solid state for adducts of $1.9^{2}$ However, the ${ }^{1} \mathrm{~J}_{\mathrm{CH} 3}$ value of 3 at $-103{ }^{\circ} \mathrm{C}$ is $127(1) \mathrm{Hz}$, unchanged from the analogous value for free $\mathrm{PE}_{3}$ at this temperature. ${ }^{10}$

The ${ }^{31} \mathrm{P}$ resonances for all of the phosphine complexes discussed above are shifted downfield $c a$. 13-21 ppm, consistent with the phosphines acting as Lewis bases towards the $\mathrm{Yb}$ center of 1 . The ${ }^{1} \mathrm{~J}_{\mathrm{YbP}}$ values for the $1: 1$ adducts 3 and $4(956 \mathrm{~Hz}$ and $950 \mathrm{~Hz}$, respectively) are roughly $60 \%$ larger than the analogous values for the 1:2 $\mathrm{PMe}_{3}$ adduct 2 and the dmpm and 1,2-(( $\left.\left.\mathrm{PMe}_{2}\right) \mathrm{C}_{6} \mathrm{H}_{4}\right)$ adducts, 5 and 6, respectively. This indicates that each $\mathrm{Yb}-\mathrm{P}$ interaction in the 1:2 adducts (considering 5 and 6 as $1: 2$ adducts, as they each have two $\mathrm{P}$ donors $/ \mathrm{Yb}$ center) is enthalpically weaker than the single $\mathrm{Yb}-\mathrm{P}$ interaction in the 1:1 adducts. ${ }^{11}$ The similar spectral values for the $1: 2 \mathrm{PMe}_{3}$ and the dmpm adducts, 2 and $5\left(\delta\left({ }^{1} \mathrm{P}\right)\right.$ perturbations, ${ }^{1} \mathrm{~J}_{Y b P}$ values), indicate that chelation does not have a significant affect on the interactions formed between 1 and phosphines. ${ }^{13}$

Interactions with Phosphine Oxides and Imines. The $\mathrm{Cp}^{*}{ }_{2} \mathrm{Yb}\left(\mathrm{OPMe}_{3}\right)$ adduct (7), isolated in $83 \%$ yield as a yellow-orange crystalline solid, undergoes slow intermolecular exchange in $\mathrm{C}_{6} \mathrm{D}_{6}$ at $25^{\circ} \mathrm{C}$. This contrasts with the fast exchange behavior at $25^{\circ} \mathrm{C}$ that was observed for all of the phosphine adducts discussed above. While ${ }^{171} \mathrm{Yb}-31 \mathrm{P}$ coupling is observed for $\left.7{ }^{2} \mathrm{~J}_{\mathrm{YbP}}=94.6 \mathrm{~Hz}\right)$, long-range ${ }^{171} \mathrm{Yb}-{ }^{1} \mathrm{H}$ coupling $\left({ }^{4} \mathrm{~J}_{\mathrm{YbH}}\right)$ is not resolved. The ${ }^{1} \mathrm{H}$ and ${ }^{31} \mathrm{P}$ spectral values for 7 and $\mathrm{Me}_{3} \mathrm{PO}$ are given in Table 2. When a toluene-d8 sample of 7 (with 1 eq. of excess $\mathbf{1}^{4}$ ) is heated in the NMR probe, coalescence of the free and bound $\mathrm{Cp}^{*}$ resonances occurs at $110^{\circ} \mathrm{C} .3$ The ${ }^{31} \mathrm{P}\left\{{ }^{1} \mathrm{H}\right\}$ spectrum of a sample of $\mathrm{Cp}^{*}{ }_{2} \mathrm{Yb}\left(\mathrm{SPPh}_{3}\right)$ in $\mathrm{C}_{6} \mathrm{D}_{6}$ shows ${ }^{2} \mathrm{~J}_{\mathrm{YbP}}$ of $87 \mathrm{~Hz},{ }^{14}$ similar to the analogous value found for 7 . 
Addition of 2 eq. of $\mathrm{Me}_{3} \mathrm{PO}$ to a toluene solution of 1 results in the precipitation of an orange solid, $\mathrm{Cp}_{2}{ }_{2} \mathrm{Yb}\left(\mathrm{OPMe}_{3}\right)_{2}(8)$, which is insoluble in toluene and aliphatic hydrocarbon solvents. The 1:2 adduct 8 dissolves in thf-d8 with a slight darkening in color; the ${ }^{1} \mathrm{H}$ and ${ }^{31} \mathrm{P}\left\{{ }^{1} \mathrm{H}\right\}$ spectral features (broadened resonances, and slightly shifted $\mathrm{Me}_{3} \mathrm{PO}$ chemical shift values, relative to those of free $\mathrm{Me}_{3} \mathrm{PO}$ in thf- $\mathrm{d}_{8}$ ) indicate competitive exchange with the solvent. While thf is competitive with $\mathrm{Me}_{3} \mathrm{PO}$ as a ligand towards the $\mathrm{Yb}$ center of $\mathbf{1}$, when thf is removed under reduced pressure, the pure complex 8 is re-isolated. When $\mathrm{Et}_{2} \mathrm{O}$ is added to a sample of the $1: 1$ adduct 7, a green solution with an orange precipitate results. Apparently, $\mathrm{Et}_{2} \mathrm{O}$ can coordinate to an empty coordination site on the $\mathrm{Yb}$ center, lowering the barrier to disproportionation (similar to the phenomenon discussed above for samples of 1 containing excess phosphine). The result is precipitation of the orange 1:2 adduct 8 and a solution containing the green $\mathrm{Cp}_{2}{ }_{2} \mathrm{Yb}\left(\mathrm{Et}_{2} \mathrm{O}\right)$ adduct, the identity of which was confirmed by ${ }^{1} \mathrm{H}$ NMR spectroscopy. ${ }^{16}$

The interaction formed between 1 and the phosphine imine Et3PNH is similar to that found for $\mathrm{Me}_{3} \mathrm{PO}$. The ${ }^{1} \mathrm{H}$ NMR spectrum at $25^{\circ} \mathrm{C}$ of a toluene-d8 sample of the light orange $\mathrm{Cp}^{*}{ }_{2} \mathrm{Yb}\left(\mathrm{HNPEt}_{3}\right)$ adduct (9) indicates slow intermolecular exchange; a ${ }^{2} \mathrm{~J}_{\mathrm{YbP}}$ value of $91.6 \mathrm{~Hz}$ can be measured from the ${ }^{31} \mathrm{P}\left\{{ }^{1} \mathrm{H}\right\}$ spectrum. The values for this sample, and for uncomplexed Et ${ }_{3} \mathrm{PNH}$, are given in Table 2. Unfortunately, the ${ }^{1} \mathrm{H}$ resonance for the $\mathrm{N}-\mathrm{H}$ proton is not resolved in either of these samples, at $25^{\circ} \mathrm{C}$ or at -90 ${ }^{\circ} \mathrm{C}$, presumably a result of ${ }^{14} \mathrm{~N}$ quadrupolar or exchange broadening. 12 When 2 eq. of $\mathrm{Et}_{3} \mathrm{PNH}$ are added to a toluene solution of 1 , the orange $1: 2$ adduct $\mathrm{Cp}_{2}{ }_{2} \mathrm{Yb}\left(\mathrm{HNPEt}_{3}\right)_{2}$ (10) precipitates from solution. Similar to 8 , this solid dissolves in thf-d8, giving ${ }^{1} \mathrm{H}$ and ${ }^{31} \mathrm{P}\left\{{ }^{1} \mathrm{H}\right\}$ spectra that indicate competitive exchange with the solvent. A sample of 1 (2 eq.) and $\mathrm{Et}_{3} \mathrm{PN}\left(\mathrm{SiMe}_{3}\right)^{17}$ undergoes fast exchange at $25^{\circ} \mathrm{C}$, on the NMR timescale. However the ${ }^{1} \mathrm{H}$ spectrum of this sample at $-83^{\circ} \mathrm{C}$ contains resonances for both free and bound $\mathrm{Cp} *$ rings $\left(\mathrm{T}_{\mathrm{c}}=-50^{\circ} \mathrm{C}^{3}\right)$, and ${ }^{171} \mathrm{Yb}-31 \mathrm{P}$ coupling is resolved in the ${ }^{31} \mathrm{P}\left\{{ }^{1} \mathrm{H}\right\}$ spectrum ${ }^{2} \mathrm{~J}_{\mathrm{YbP}}=7(1) \mathrm{Hz}$, values given in Table 2). 
Table 2. 1 H, 31 NMR Values for Phosphine Oxide and Imine Complexes of 1.

\begin{tabular}{|c|c|c|c|c|c|}
\hline Sample & Temp. $\left({ }^{\circ} \mathrm{C}\right)$ & $\delta(P)$ & $\underline{2} \mathrm{IbP}$ & $\delta(\mathrm{Cp} *)$ & $\delta(H)$ \\
\hline $\mathrm{Me}_{3} \mathrm{PO}$ & 25 & 29.4 & --- & & $0.83^{a}$ \\
\hline 7 & 25 & 45.6 & 94.6 & 2.14 & 0.65 \\
\hline $\mathrm{Et}_{3} \mathrm{PNH}$ & 25 & 44.6 & --- & --- & $\begin{array}{l}1.15\left(\mathrm{CH}_{2}\right) \\
0.86(\mathrm{Me})\end{array}$ \\
\hline $9 b$ & 25 & 60.1 & 91.6 & 2.12 & $\begin{array}{l}1.20\left(\mathrm{CH}_{2}\right) \\
0.61(\mathrm{Me})\end{array}$ \\
\hline $\mathrm{E}_{3} \mathrm{PNSiMe}_{3} \mathrm{~b}$ & -83 & 18.2 & --- & --- & $\begin{array}{l}1.00\left(\mathrm{CH}_{2}\right) \\
0.79(\mathrm{Me}) \\
0.42\left(\mathrm{SiMe}_{3}\right)\end{array}$ \\
\hline $11^{b}$ & -83 & 33.6 & $7(1)$ & 2.34 & $\begin{array}{c}1.22\left(\mathrm{CH}_{2}\right) \\
0.47(\mathrm{Me}) \\
0.18\left(\mathrm{SiMe}_{3}\right)\end{array}$ \\
\hline
\end{tabular}

aThe ${ }^{2} \mathrm{~J}_{\mathrm{PH}}$ values for $\mathrm{Me}_{3} \mathrm{PO}$ and 7 are identical, $12.8 \mathrm{~Hz}$.

${ }^{b}$ These samples in toluene- $\mathrm{d}_{8}$, the others in $\mathrm{C}_{6} \mathrm{D}_{6}$.

The fast intermolecular exchange at $25^{\circ} \mathrm{C}$ for $\mathrm{Cp}_{2}{ }_{2} \mathrm{Yb}\left(\mathrm{Et}_{3} \mathrm{PNSiMe}_{3}\right)(\mathbf{1 1})$, as well as the much smaller ${ }^{2} \mathrm{~J}_{\mathrm{YbP}}$ value as compared to $9\left({ }^{2} \mathrm{~J}_{\mathrm{YbP}}=91.6 \mathrm{~Hz}\right)$, likely result from the sterically bulky $\mathrm{SiMe}_{3}$ group preventing the $\mathrm{Yb}$ center from approaching the nitrogen nucleus as closely as in the Et $3 \mathrm{PNH}$ derivative, 9.

Interactions with Phosphine Ylides. Considering the relatively strong interactions formed between 1 and phosphine oxides and imines, it was of interest to examine the interaction of $\mathbf{1}$ with isoelectronic phosphine ylides. Two resonance forms can be drawn for phosphine ylides (Fig. 3), and the chemical properties of ylides show that both forms are important.<smiles></smiles><smiles></smiles>

Figure 3. The two resonance structures for phosphine ylides. 
It is known that ylides generally have a slightly pyramidal geometry about the ylide carbon atom in the solid state, ${ }^{18,19}{ }^{1} \mathrm{~J}_{\mathrm{CH}}$ coupling constants suggesting $\mathrm{sp}^{2}$ hybridization, ${ }^{20,21} \mathrm{P}-\mathrm{C}$ distances consistent with a $\mathrm{P}=\mathrm{C}$ double bond, ${ }^{19,20}$ a low barrier to rotation about the P-C bond, 18,22 and bind strongly to alkali metals via the carbon center. $^{20}$ Ylides typically also interact with transition metalsvia the carbon center. ${ }^{18,23}$ Recent $a b$ initio molecular orbital calculations have found that the dominant resonance structure for phosphine ylides is the dipolar one. ${ }^{18}$

Adding 1 eq. of $\mathrm{Me}_{2} \mathrm{PhPCHSiMe}_{3}{ }^{24}$ to a toluene solution of 1 results in a dark green solution from which dark green crystals of $\mathrm{Cp}_{2}{ }_{2} \mathrm{Yb}\left(\mathrm{Me}_{2} \mathrm{PhPCHSiMe}_{3}\right)$ (12) can be isolated in $55 \%$ yield. The ${ }^{1} \mathrm{H}$ and ${ }^{31} \mathrm{P}\left\{{ }^{1} \mathrm{H}\right\}$ spectra of a toluene-d8 sample of 12 , containing an additional equivalent of 1 , indicate fast intermolecular exchange is occurring at $25^{\circ} \mathrm{C}$. On cooling, two different fluxional processes can be distinguished, as indicated by the variable temperature ${ }^{1} \mathrm{H}$ spectra, from $-3^{\circ} \mathrm{C}$ to $-98^{\circ} \mathrm{C}$ (Fig. 4).

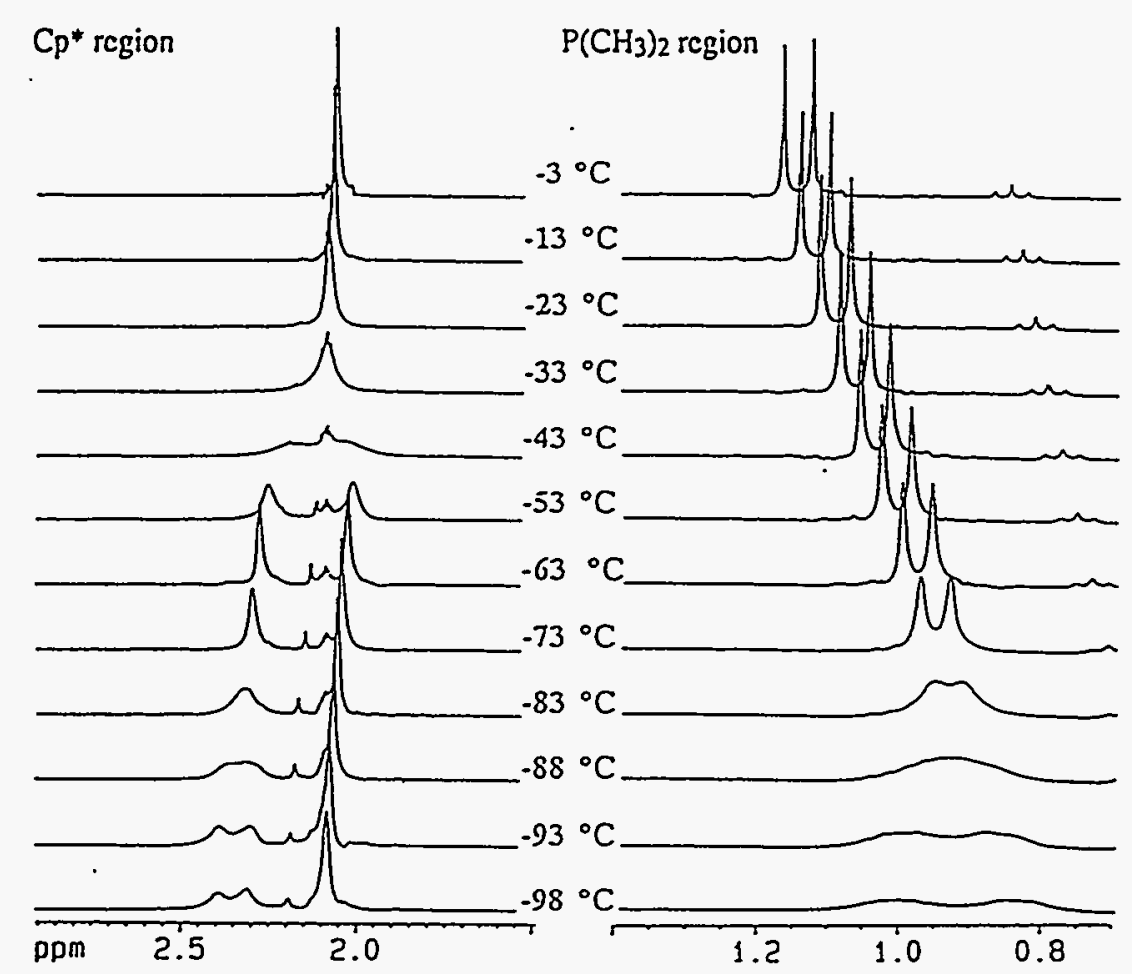

Figure 4. Variable temperature ${ }^{1} \mathrm{H}$ spectra of 12 , with 1 eq. excess of $1(300 \mathrm{MHz}$, toluene- $\mathrm{d}_{8},-3^{\circ} \mathrm{C}$ to $-98^{\circ} \mathrm{C}$ ). 
The slower process is intermolecular exchange of free and bound 1; the averaged Cp* resonance decoalesces into free and bound resonances upon cooling, with a $T_{C}=-40^{\circ} \mathrm{C}$. Further cooling results in inequivalent $\mathrm{Cp}^{*}$ rings, as well as two inequivaient phosphorus-bound methyl groups. The coalescence temperatures (two slightly different temperatures for this one process, as a result of the frequency differences between the inequivalent $\mathrm{Cp} *$ rings and the inequivalent methyl groups ${ }^{5}$ ) gives an approximate $\Delta \mathrm{G}^{\ddagger}$ value of $9.2(2) \mathrm{kcal} \mathrm{mol}^{-1}$ for this fluxional process. The nature of these fluxional processes will be discussed in detail below.

A toluene-d8 sample of the $\mathrm{Me}_{2} \mathrm{PhPCH}_{2}{ }^{24}$ adduct, $\mathrm{Cp}{ }_{2} \mathrm{Yb}_{2}\left(\mathrm{Me}_{2} \mathrm{PhPCH}_{2}\right)(13)$, with an additional equivalent of 1 , also undergoes fast intermolecular exchange at $25^{\circ} \mathrm{C}$; this exchange is slowed upon cooling $\left(\mathrm{T}_{\mathrm{c}}\left(\mathrm{Cp}^{*}\right)=-68^{\circ} \mathrm{C}\right)$. The two identical groups on the ylide carbon necessarily result in equivalent $\mathrm{Cp}^{*}$ and $\mathrm{PMe}_{2}$ groups at all temperatures. To investigate the details of the interactions between 1 and the ylides in solution, the ${ }^{1} \mathrm{H}$, ${ }^{13} \mathrm{C}\left\{{ }^{1} \mathrm{H}\right\}$ and ${ }^{31} \mathrm{P}\left\{{ }^{1} \mathrm{H}\right\}$ NMR spectra were measured on samples of 12 and 13 (both samples containing a slight excess of 1 ), at $-78^{\circ} \mathrm{C}$ and $-93^{\circ} \mathrm{C}$, respectively. 25 The spectral values of the two samples, as well as those of the two ylides at the same temperatures, are given in Table 3.

Examination of the values in Table 3 shows the usual downfield shifts of the $\mathrm{Cp}^{*}$ rings of 1 , and of the ${ }^{31 P}$ chemical shifts (the $\Delta(\delta P)$ values are slightly less than were observed for the phosphine, oxide, and imine derivatives, above), upon adduct formation. The ${ }^{31} \mathrm{P}$ chemical shifts of ylides nearly always shifts downfield upon coordination to a metal. 23 Interestingly, the ylide proton resonance of 12 is shifted 0.69 ppm downfield from the value for the free ylide, while the analogous resonance for $\mathbf{1 3}$ is shifted in the opposite direction, by $0.65 \mathrm{ppm}$. The methyl and $\mathrm{SiMe}_{3}$ spectral values are perturbed only slightly, consistent with a direct Yb-C interaction. The ${ }^{2 J} \mathrm{YbP}$ value for 12 is significantly smaller than the analogous value for $\mathbf{1 3}$. 
Table 3. Low Temperature 1 H, 13 , 31 P NMR Values for the Phosphine Ylide Complexes 12 and 13,

\begin{tabular}{|c|c|c|c|c|}
\hline Value $^{b}$ & $\mathrm{Me}_{2} \mathrm{PhPCHSiMe}_{3}$ & $1^{c}$ & $\mathrm{Me}_{2} \mathrm{PhPCH}_{2}$ & $13^{\mathrm{c}}$ \\
\hline$\delta\left(\mathrm{Cp}^{*}\right)$ & -- & 2.31 & -- & 2.27 \\
\hline$\delta(\mathrm{CH}) / 2 \mathrm{~J}_{\mathrm{PH}}$ & $-0.30 / 8.7$ & $0.39 / 20.3$ & $0.37 / 5.3$ & $-0.28 / 12.6$ \\
\hline$\delta\left(\underline{\mathrm{CH}}_{3}\right) / 2 \mathrm{~J}_{\mathrm{PH}}$ & $1.05 / 12.6$ & $0.94 / 11.9$ & $1.16 / 12.8$ & $0.65 / 12.6$ \\
\hline$\delta\left(\mathrm{Si}\left(\mathrm{CH}_{3}\right)_{3}\right)$ & 0.50 & 0.20 & --- & -- \\
\hline${ }^{1} \mathrm{~J}_{\mathrm{CH}}(\mathrm{C}-\mathrm{H})$ & $136(1)$ & $111(2)$ & $150(1)$ & $119(2)$ \\
\hline${ }^{1} \mathrm{~J}_{\mathrm{CH}}(\mathrm{Me})$ & $128(1)$ & $129(1)$ & $128(1)$ & $129(1)$ \\
\hline${ }^{1} \mathrm{~J}_{\mathrm{CH}}\left(\mathrm{SiMe}_{3}\right)$ & $116(1)$ & $116(1)$ & --- & -- \\
\hline$\delta(\mathrm{P})$ & 4.6 & 14.4 & 5.1 & 20.0 \\
\hline${ }^{2} \mathrm{~J}_{\mathrm{YbP}}$ & $\ldots$ & $8(1)$ & --- & $37(1)$ \\
\hline$\delta(\mathrm{CH}) / 1 \mathrm{~J}_{\mathrm{PC}}$ & $-4.2 / 94$ & $-2.5 / 53(2)$ & $-6.1 / 92$ & $-1.0 / 42(2)$ \\
\hline$\delta\left(\mathrm{CH}_{3}\right) /{ }^{1} \mathrm{~J}_{\mathrm{PC}}$ & $16.9 / 63$ & $18.0 / 65(2)$ & $15.7 / 67$ & $15.1 / 62(2)$ \\
\hline$\delta\left(\mathrm{Si}\left(\mathrm{CH}_{3}\right)_{3}\right) \beta \mathrm{J}_{\mathrm{PC}}$ & $4.9 / 4.2$ & 3.5/unresolved & -- & -- \\
\hline
\end{tabular}

aThe values for $\mathrm{Me}_{2} \mathrm{PhPCHSiMe} 3$ and 12 were acquired at $-78^{\circ} \mathrm{C}$. The values for $\mathrm{Me}_{2} \mathrm{PhPCH}_{2}$ and 13 were acquired at $-93^{\circ} \mathrm{C}$.

bAll of these values were obtained from typical 1-D direct-detected spectra, with the exceptions of the ${ }^{1} \mathrm{~J}_{\mathrm{CH}}$ values (obtained from ${ }^{13} \mathrm{C}$-filtered ${ }^{1} \mathrm{H}$ spectra) and the $\delta(\mathrm{C}), \mathrm{J}_{\mathrm{PC}}$ values for 12 and 13 (obtained from ${ }^{1} \mathrm{H} /{ }^{13} \mathrm{C}$ HMQC $2-\mathrm{D}$ spectra).

cThese samples contained 1 eq. excess of 1 .

This may be either a steric or an electronic effect; the sterically bulky SiMe3 group is known to stabilize (i.e., delocalize) the ylidic negative charge. ${ }^{20}$ The ${ }^{13} \mathrm{C}$ chemical shifts of the ylide carbons are shifted downfield slightly for both 12 and 13 upon adduct formation, consistent with $\mathrm{C} \rightarrow \mathrm{Yb}$ electron donation. The ${ }^{1} \mathrm{~J}_{\mathrm{PC}}$ values involving this carbon are roughly halved upon formation of the adducts; the values for $\mathbf{1 2}$ and $\mathbf{1 3}$ are similar to the analogous values for phosphonium salts, $\left(\mathrm{R}_{3} \mathrm{PCHR} \mathrm{R}^{\prime \prime}\right)^{+}, 18$ and for previously-reported M-ylide complexes. ${ }^{26}$ Unfortunately, coupling between ${ }^{171} \mathrm{Yb}$ and the ylide ${ }^{1} \mathrm{H}$ and ${ }^{13} \mathrm{C}$ nuclei was not resolved, most likely a result of line broadening from the low temperature required to slow intermolecular exchange. 27

To investigate the details of the Yb-ylide interaction in the solid state, 12 was characterized by X-ray crystallography and an ORTEP diagram is shown in Figure 5. 
There are relatively few structurally characterized lanthanide-ylide complexes. ${ }^{29}$ Selected intramolecular distances and angles are given in Table 4. Although the ylide- $\mathrm{H}$ could not be located, it is assumed to be oriented roughly downwards in Figure 5, based on the positions of the $\mathrm{Yb}, \mathrm{Si}$, and $\mathrm{P}$ atoms. The quality of the data was not sufficient to allow anisotropic refinement on the carbon atoms, see the Experimental section for details.

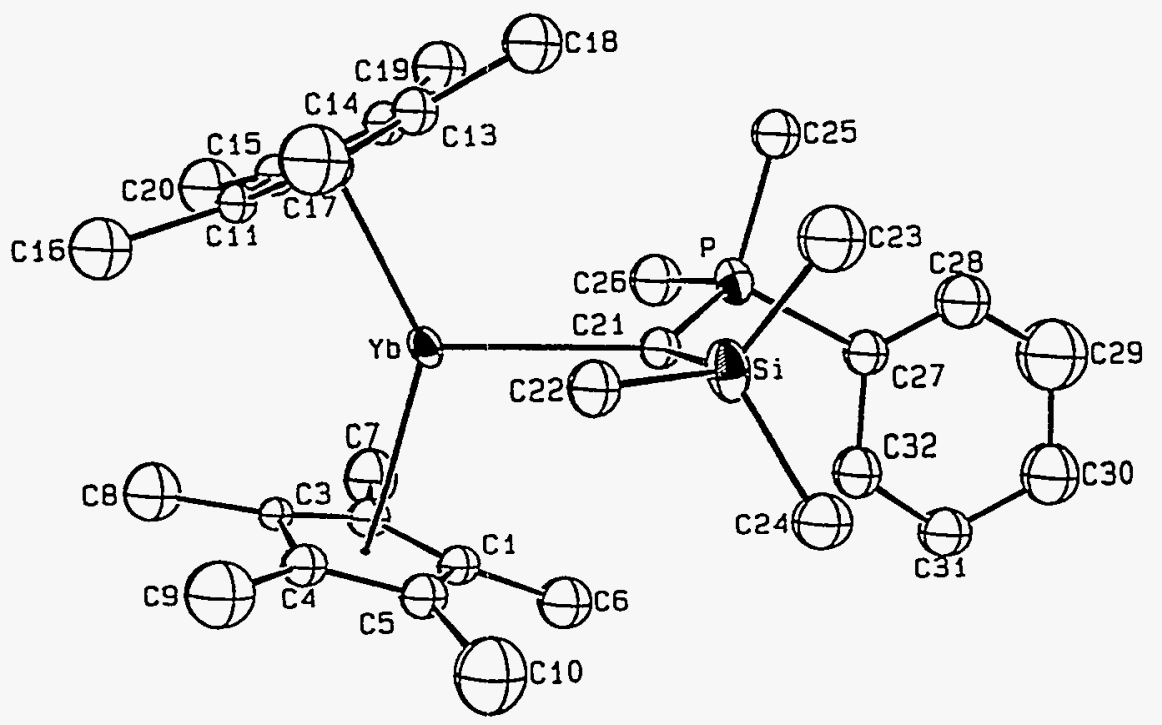

Figure 5. ORTEP diagram of $\mathrm{Cp}_{2}{ }_{2} \mathrm{Yb}\left(\mathrm{Me}_{2} \mathrm{PhPCHSiMe}_{3}\right)$ (13), $50 \%$ probability thermal ellipsoids.

Table 4. Selected Intramolecular Distances $(\AA)$ and Angles (deg) in 12.

\begin{tabular}{cccc}
\multicolumn{5}{c}{ Bond Distances } \\
Yb-C21 & $2.69(2)$ & Yb-Cp1 & 2.44 \\
. Si-C21 & $1.85(2)$ & Yb-Cp2 & 2.43 \\
P-C21 & $1.69(2)$ & Yb-P & $3.963(5)$ \\
Yb-C22 & $3.15(2)$ & Yb-Si & $3.624(6)$ \\
\multicolumn{4}{c}{ Bond Angles } \\
Yb-C21-Si & $104.6(6)$ & Yb-C21-P & $128.4(9)$ \\
Cp1-Yb-Cp2 & $134.9(6)$ & Si-C21-P & $120(1)$ \\
C21-Si-C22 & $106.2(9)$ & C21-Si-C23 & $116.5(9)$ \\
C21-Si-C24 & $111.7(8)$ & &
\end{tabular}

\footnotetext{
aAll distances and angles involving $\mathrm{Cp}^{*}$ rings were calculated using the ring centroid positions.
} 
The $\mathrm{Cp} *-\mathrm{Yb}-\mathrm{Cp} *$ angle, $\mathrm{Yb}-\mathrm{Cp} *$ distances, and $\mathrm{Cp} *-\mathrm{Yb}-\mathrm{Cp} * / \mathrm{Si}-\mathrm{C} 24-\mathrm{P}$ torsional angle $\left(84^{\circ}\right)$, are within the expected ranges. 30 The Yb-C21 distance, 2.69(2) $\AA$, is indicative of a direct $\mathrm{Yb}-\mathrm{C}$ interaction. $9 \mathrm{a}, 28,30 \mathrm{~b}, 31$ The $\mathrm{P}-\mathrm{C} 21$ distance of $1.69(2) \AA$ is within the range observed for $\mathrm{M}$-ylide complexes. ${ }^{20,34}$ The $\mathrm{Yb}-\mathrm{C} 21-\mathrm{Si}$ angle $\left(105^{\circ}\right)$ is more acute than the $\mathrm{Yb}-\mathrm{C} 21-\mathrm{P}$ angle $\left(128^{\circ}\right)$, resulting in a short $\mathrm{Yb}$-methyl contact involving one of the methyl carbons on the $\mathrm{Si}$ atom $(\mathrm{Yb}-\mathrm{C} 22=3.15(2) \AA)$. This likely results from a secondary Yb-methyl interaction, as the sum of the Van der Waals radii 35 for a methyl group $(2.00 \AA)$ and $\mathrm{Yb}(\mathrm{II})$ is $3.70 \AA .9 \mathrm{~b}, 34$ Consistent with this, the $\mathrm{C}$ (ylide)-Si-C(methyl) angle involving this methyl carbon center is slightly smaller than the other two C-Si-C angles (C21-Si-C22, 106 ${ }^{\circ}$; C21-Si-C23, 116 $; 6^{\circ}$ C21-Si-C24, 112 ${ }^{\circ}$ ). As the hydrogen atoms were not located in the structure of 12 , further discussion on this point is not warranted. The $\mathrm{Yb}-\mathrm{C} 21-\mathrm{P}$ angle, $128^{\circ}$, is within the expected range for $\mathrm{M}$ ylide structures. ${ }^{26 \mathrm{~b}, 35}$ Thus, interaction of 1 with $\mathrm{Me}_{2} \mathrm{PhPCHSiMe} 3$ involves a direct Yb-C interaction, supplemented by a secondary $\gamma-\mathrm{CH}_{3}$ interaction, and adduct formation does not result in any unexpected perturbations of the ylide structure. The solid-state structure of 12 , with $C_{1}$ symmetry, is consistent with the low temperature NMR data for this complex.

Two different fluxional processes can be slowed upon cooling a sample of 12 from $25^{\circ} \mathrm{C}$ to $-98^{\circ} \mathrm{C}$. The first process involves intermolecular exchange of free and bound 1 , and slowing of the second process results in inequivalent $\mathrm{PMe}_{2}$ groups and inequivalent $\mathrm{Cp}^{*}$ rings. Since the $\mathrm{Yb}$ center is bound via the ylide carbon center, this carbon becomes chiral once intermolecular exchange is stopped, resulting in diastereotopic methyl groups. However, the methyl groups do not become inequivalent until the $\mathrm{Cp}^{*}$ rings become inequivalent, and this occurs at a much lower temperature. Fast inversion of the chirality at the ylide carbon would make the $\mathrm{PMe}_{2}$ groups equivalent. This fluxional process has an identical barrier as the process that results in equivalency of the bound $\mathrm{Cp}$ * rings of 12 between $-40^{\circ} \mathrm{C}$ and $-84^{\circ} \mathrm{C}$, and is most likely the same physical process. It is important 
to note that while fast rotation about the Yb-ylide carbon "bond" would average the $\mathrm{Cp}^{*}$ environments, this would not average the P-bound methyl group environments.

Certain metal-ylide complexes are known to undergo phosphine exchangevia metal carbene intermediates. ${ }^{18,20}$ Addition of $\mathrm{PMe}_{3}$ to a sample of 12 shows no evidence for phosphine exchange after several hours at $25^{\circ} \mathrm{C}$, ruling out such a process. Consequently, the only way for fast inversion to occur at the ylide carbon is via fast interchange of the bound ylide enantioface (Figure 6; the term enantioface is used with the $\mathrm{P}=\mathrm{C}$ planar resonance form in mind). Since intermolecular exchange is slow below -40 ${ }^{\circ} \mathrm{C}$, this process must occur without exchange of free and bound molecules of $\mathbf{1}$.

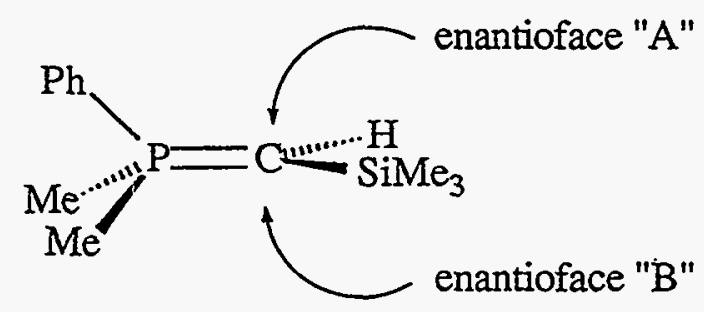

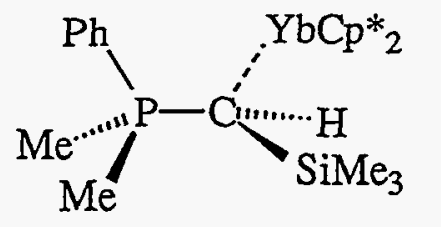

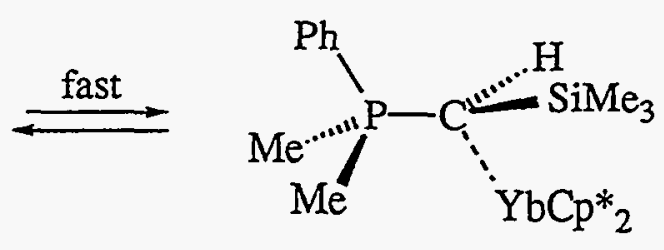

Figure 6. Fast inversion of the bound ylide enantioface results in inversion of the chirality at the ylide carbon, as required for P-bound methyl and $\mathrm{Cp}^{*}$ group equivalency.

It is reasonable to assume that inversion at the ylide carbon involves the $\mathrm{Yb}$ center, as this is the only "labile" ligand. One possible mechanism for this inversion involves movement of 1 to the opposite ylide enantioface (the planar ylide resonance form is used for this discussion, for purposes of clarity)via a $\sigma$-complex involving the ylide $\mathrm{C}-\mathrm{H}$ bond in the transition state (Fig. 7). 36 


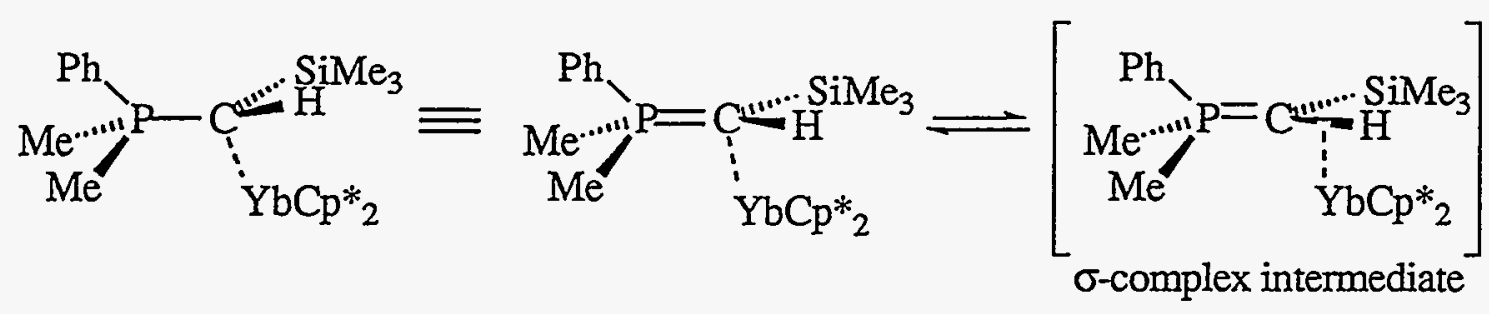

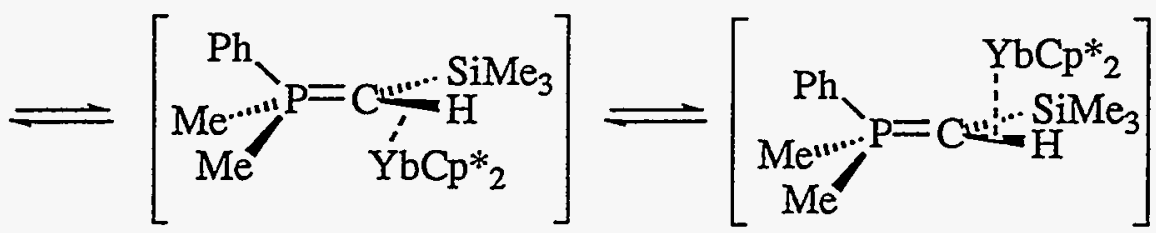

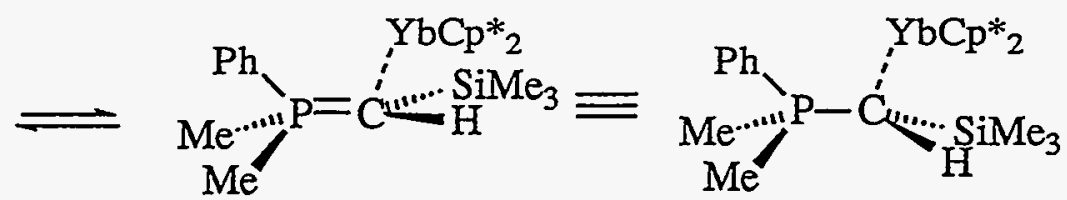

Figure 7. Proposed mechanism of the fluxional process that results in equivalent $\mathrm{PMe}_{2}$ groups and equivalent $\mathrm{Cp}^{*}$ rings, without intermolecular exchange.

This process, if fast on the NMR timescale, results in identical averaged environments for the two $\mathrm{PMe}_{2}$ groups and for the two $\mathrm{Cp}^{*}$ rings. A similar process with enantioface migration via a $\sigma$-complex, involving an olefinic $\mathrm{C}-\mathrm{H}$ bond, has recently been invoked by Peng and Gladysz to explain the observation of intramolecular equilibration of the diastereomeric chiral Re complex [CpRe(NO) $\left.\left.\mathrm{PPh}_{3}\right)\left(\mathrm{H}_{2} \mathrm{C}=\mathrm{CHR}\right)\right]\left[\mathrm{BF}_{4}\right] .37,38$ As Peng and Gladysz have noted, $\sigma$-complex interactions have been estimated at $c a .10 \mathrm{kcal} \mathrm{mol}^{-1}$ and consequently, can stabilize the transition state with respect to dissociation (i.e., intermolecular exchange). ${ }^{37}$ Interaction of the electron-rich C-H bond of the ylide with the electrophilic $\mathrm{Yb}$ center is likely a favorable interaction.

Another possible mechanism for this fluxional process involves complete cleavage of the Yb-ylide interaction with rapid exchange of $\mathbf{1}$ between the ylide enantiofaces, without intermolecular dissociation; this possibility assumes the presence of a solventcaged species, to account for the lack of intermolecular exchange. Considering the $\mathrm{Yb}-$ methyl interaction that is present in the solid state structure of 12 (Fig. 5 and 
accompanying discussion), it is also possible that inversion at the ylide carbon center occurs via an Yb-methyl interaction; this possibility is very similar to the $\sigma$-complex mechanism discussed above. The barrier for this fluxional process has been found to be identical in both toluene and methylcyclohexane. However this result, or any of the results discussed above, does not rigorously rule out any of these three possible mechanisms (as both toluene and methylcyclohexane are relatively viscous at $c a .-90^{\circ} \mathrm{C}$, it is not unreasonable that the barrier to dissociation (i.e., breaking up a solvent-caged species) is relatively similar in both these solvents).

The ${ }^{1 \mathrm{~J}_{\mathrm{CH}}}$ value of the ylide $\mathrm{C}-\mathrm{H}$ bond of 12 decreases by $25 \mathrm{~Hz}$ upon formation of an interaction with 1 , consistent with a direct $\mathrm{Yb}-\mathrm{C}$ interaction. Protonation of $\mathrm{Me}_{3} \mathrm{PCH}_{2}$ results in a decrease in ${ }^{1} \mathrm{~J}_{\mathrm{CH}}$ from $149 \mathrm{~Hz}$ to $133 \mathrm{~Hz},{ }^{39}$ while ${ }^{1} \mathrm{~J}_{\mathrm{CH}}$ for $\mathrm{Me}_{3} \mathrm{PCH}_{2}\left(\mathrm{Ni}(\mathrm{CO})_{3}\right)$ (in which the Ni interacts with the carbon, based on the solid-state structure of a related complex $)^{21}$ is $123 \mathrm{~Hz}$. If there were a $\mathrm{C}-\mathrm{H}-\mathrm{Yb}$ interaction present in the ground state structure of 12 , the ${ }^{1} \mathrm{~J}_{\mathrm{CH}}$ value would probably be significantly smaller than the observed value of $111 \mathrm{~Hz}$. Analogous ${ }^{1} \mathrm{~J}_{\mathrm{CH}}$ values for transition metal agostic complexes are reduced by as much as $50 \%$, relative to the "free" values. ${ }^{40} \mathrm{It}$ is clear that the ground state $\mathrm{Yb}$-ylide interaction involves a direct $\mathrm{Yb}-\mathrm{C}$ interaction in solution; this does not rule out the presence of a $\sigma$-complex in the transition state of the fluxional process, as discussed above.

Strengths of the Yb-L Interactions. As mentioned above, the barrier to intermolecular exchange for the dmpm adduct 5 is lowered when excess dmpm is present. A similar phenomenon, with a faster exchange rate in the presence of excess phosphine, was found for many of the phosphine adducts, and is likely a result of associative exchange, as was observed for the $\mathrm{P}_{2} \mathrm{PtX}_{2} / \mathrm{YbCp}^{*}{ }_{2}$ adducts in the presence of excess $\mathrm{P}_{2} \mathrm{PtX}_{2}$ (Chapter 1 ). In the absence of excess ligand (i.e., in the presence of excess 1 ), the exchange barrier is higher; in these cases, the exchange mechanism is likely dissociative. Given the sterically bulky $\mathrm{Cp}^{*}$ rings of $\mathbf{1}$, and the intermediate 
required for an associative process (two molecules of 1 interacting with one ligand molecule), a dissociative mechanism is likely. Indeed, the barrier to exchange is identical for the phosphine adduct $\mathbf{6}$, regardless of the number of excess equivalents of 1 present, indicating a dissociative exhange process. Given this and the presumed low kinetic barrier for ligand binding to 1 (see Introduction), it is expected that the kinetic barrier to exchange will be small relative to the strength of the Yb-ligand interaction (Fig. 8). Therefore, the kinetic exchange barriers for $\mathrm{Cp}^{*}{ }_{2} \mathrm{YbL}_{\mathrm{n}}$ adducts can be directly correlated with the thermodynamic strengths of the Yb-ligand interactions. Again, this correlation is only valid for adducts that undergo dissociative intermolecular exchange.

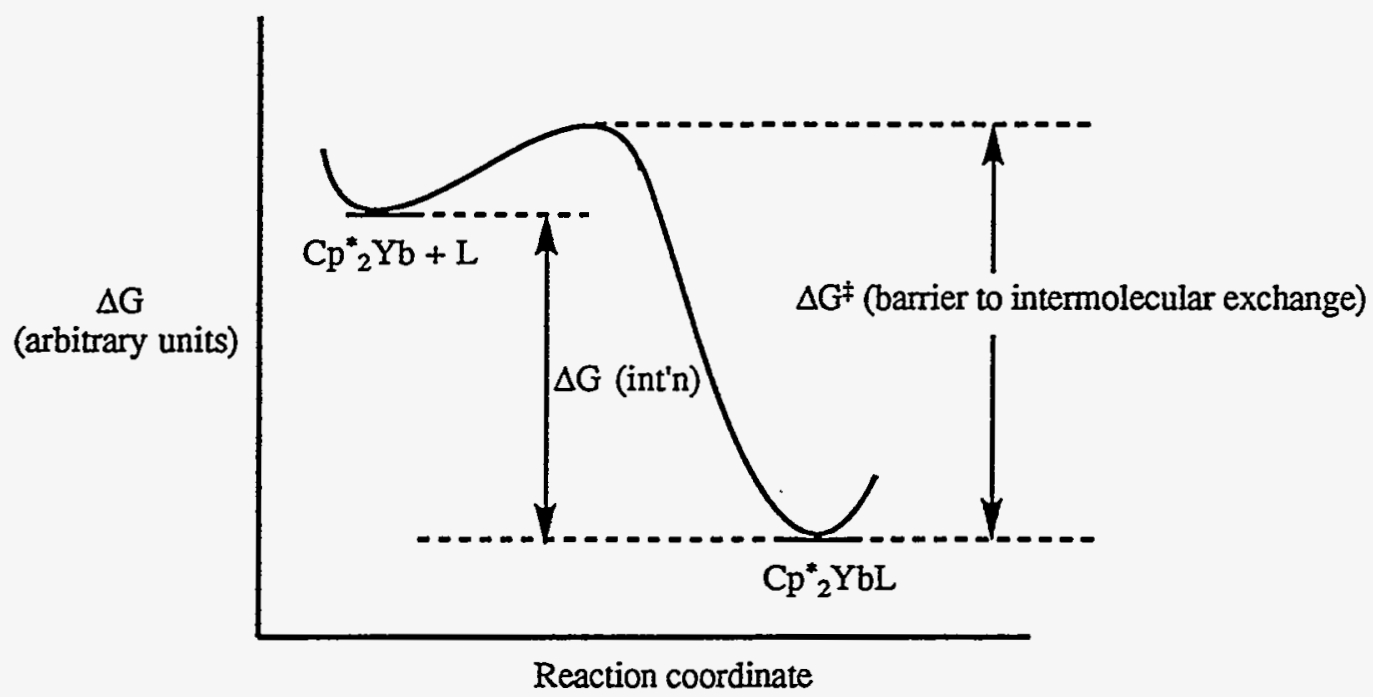

Figure 8. Energy diagram showing how the kinetic barriers to intermolecular exchange for $\mathrm{Cp}_{2}{ }_{2} \mathrm{YbL}_{\mathrm{n}}$ systems can be correlated to the thermodynamic strengths of the $\mathrm{Yb}-\mathrm{L}$ interactions. This diagram assumes a dissociative exchange mechanism, as mentioned in the text.

Assuming this, the ligands studied above can be roughly ordered in decreasing strength of interaction towards 1 . For the $1: 1$ adducts, $\mathrm{Me}_{3} \mathrm{PO}, \mathrm{Et}_{3} \mathrm{PNH}>$ ylides, $\mathrm{PMe}_{3}$, PEt3. This is easily rationalized by noting that the best ligands have hard heteroatom donors with lone pairs. Ylides and monodentate phosphines are roughly similar with respect to binding strength to 1 . For the 1:2 adducts (including the bidentate phosphine derivatives in this class), dmpm and $1,2-\left(\mathrm{PMe}_{2}\right)_{2} \mathrm{C}_{6} \mathrm{H}_{4}$ form stronger interactions with 1 
than $\left(\mathrm{PMe}_{3}\right)_{2}$ and $\left(\mathrm{PEt}_{3}\right)_{2}$, the chelate effect resulting in a slightly better interaction relative to the monodentate analogues. ${ }^{13}$ The five membered chelate ring present in the 1,2-( $\left.\mathrm{PMe}_{2}\right) \mathrm{C}_{6} \mathrm{H}_{4}$ derivative results in a slightly stronger overall interaction than the four membered chelate ring present in the dmpm derivative, as expected from ring strain considerations. The 1:2 phosphine adducts have a lower kinetic barrier to intermolecular exchange than the analogous 1:1 adducts, indicating weaker $\mathrm{Yb}-\mathrm{P}$ interactions in the former adducts; this result is consistent with the smaller ${ }^{171} \mathrm{Yb}-31 \mathrm{P}$ coupling constants for the 1:2 adducts (i.e., an enthalpically weaker $\mathrm{Yb}-\mathrm{P}$ interaction). ${ }^{11}$

Comparison of the $J_{Y b P}$ values found for the complexes studied in this work to $J_{M P}$ values that have been reported in the literature is informative. There have been four ${ }^{1} \mathrm{~J}_{\mathrm{YbP}}$ values reported, 41 the most applicable being the values for $\left(\mathrm{Me}_{2} \stackrel{\left.\mathrm{PC}\left(\mathrm{SiMe}_{3}\right) \mathrm{PMe}_{2}\right)_{2} \mathrm{Yb}}{\mathrm{LiI}}\right)_{2}(\text { thf })_{3}(497 \mathrm{~Hz}), 41 \mathrm{~b}$ and $\left.\left.\widetilde{\mathrm{Yb}\left[\mathrm{N}\left(\mathrm{SiMe}_{2} \mathrm{CH}_{2} \mathrm{PR}_{2}\right.\right.}\right)_{2}\right]_{2}(\mathrm{R}=$ $\mathrm{Me}, 665 \mathrm{~Hz} ; \mathrm{R}=\mathrm{Ph}, 522 \mathrm{~Hz}) ; 4 \mathrm{c}$ the ligands in these complexes all bear a negative charge, in contrast to the neutral phosphine ligands used in the present study. The reported values are similar to the ${ }^{1} \mathrm{~J}_{\mathrm{YbP}}$ values found for the 1:2 phosphine adducts in this study. There have been several ${ }^{2} J_{M P}$ values reported for transition metal-ylide complexes. The values reported (reduced coupling constants, $\mathrm{K}$, in parentheses), ${ }^{42} \mathrm{cis}$ $\left(\mathrm{Me}_{3} \mathrm{PCH}_{2}\right)_{2} \mathrm{PtMe}_{2}, 92 \mathrm{~Hz}(8.77) ; 43\left[\left(\mathrm{Me}_{3} \mathrm{PCH}_{2}\right) \mathrm{Rh}\left(\mathrm{PMe}_{3}\right)_{2}(\mathrm{CP})\right] \mathrm{I}_{2}, 4.5 \mathrm{~Hz}(-2.92) ; 44$ trans- $\left[\mathrm{Pt}\left(\mathrm{CH}_{2} \mathrm{PR}_{3}\right)\left(\mathrm{PR}_{3}\right)_{2} \mathrm{X}\right][\mathrm{Y}](\mathrm{X}, \mathrm{Y}=$ halides$), c a .100 \mathrm{~Hz}(9.53) ; 35 \mathrm{~b}$ andcis$\left[\mathrm{Pt}\left(\mathrm{CH}_{2} \mathrm{PR}_{3}\right)\left(\mathrm{PR}_{3}\right)_{2} \mathrm{X}\right][\mathrm{Y}](\mathrm{X}, \mathrm{Y}=$ halides$), \mathrm{ca} .50 \mathrm{~Hz}(4.76) ; 35 \mathrm{~b}$ are similar to the values found for $12\left({ }^{2} \mathrm{~J} \mathrm{YbP}=8 \mathrm{~Hz}, \mathrm{~K}=0.933\right)$ and $13\left({ }^{2} \mathrm{~J} \mathrm{YbP}=37 \mathrm{~Hz}, \mathrm{~K}=4.32\right)$. In addition, the slight increase in the ylide $2 \mathrm{~J}_{\mathrm{PC} \underline{H}}$ value, as observed in 12 and 13 , is a common result of coordination of ylides to metal centers. ${ }^{26}$

${ }^{171} \mathrm{Yb}$ Chemical Shifts of $\mathrm{Cp}^{\#} \mathrm{YbL}_{\mathbf{n}}$ Complexes $\left(\mathrm{Cp}^{\#}=\mathrm{a} \mathbf{C p}\right.$ derivative). Examination of Figure 2 shows that, in addition to the ${ }^{171} \mathrm{Yb}$ correlations from the $\mathrm{PMe}_{2}$ protons, correlations to the bound $\mathrm{Cp}^{*}$ methyl protons are also present. This shows that spin-spin coupling between ${ }^{171} \mathrm{Yb}$ and these protons is present in 6 . We 
have measured the analogous value for 1 , and it is $2.5 \mathrm{~Hz}$; this coupling will not vary much with the ligand, $\mathrm{L}$, in $\mathrm{Cp}^{*}{ }_{2} \mathrm{YbL}_{\mathrm{n}}$ complexes. $\mathrm{A}^{1} \mathrm{H} /{ }^{171} \mathrm{Yb}$ HMQC spectrum of 7 at $-7^{\circ} \mathrm{C}, 45$ optimized for this $\mathrm{J}_{\mathrm{YbH}}$ value, gives a ${ }^{171} \mathrm{Yb}$ resonance at $+139 \mathrm{ppm}$, correlated to the $\mathrm{Cp}^{*}$ protons. A similar experiment gives a ${ }^{171} \mathrm{Yb}$ resonance at $+140 \mathrm{ppm}$ for 12 (at $-73^{\circ} \mathrm{C}$ ); this resonance is correlated with the $\mathrm{SiMe}_{3}$ protons, indicating that long-range (4-bond) $\mathrm{Yb}-\mathrm{H}$ communication is present. The method of indirectly detecting ${ }^{171} \mathrm{Yb}$ resonances, via long-range $\mathrm{J}_{\mathrm{YbH}}$ coupling (involving either the $\mathrm{Cp} *$ protons or protons on the ligand, L), will be discussed in more detail in Chapter 4.

Table 5 lists the ${ }^{171} \mathrm{Yb}$ chemical shifts of $\mathrm{Cp}^{\#}{ }_{2} \mathrm{YbL}_{\mathrm{n}}$ complexes $\left(\mathrm{Cp}^{\#}=\right.$ any $\mathrm{Cp}$ derivative) that have been reported to-date. ${ }^{46}$ A rough correlation of the ${ }^{171} \mathrm{Yb}$ chemical shift with coordination number can be made. Specifically, the base-free adducts $\mathrm{Cp}_{2}^{*} \mathrm{Yb}$ (1) and (1,3-( $\left.\left.\mathrm{SiMe}_{3}\right)_{2} \mathrm{C}_{5} \mathrm{H}_{3}\right)_{2} \mathrm{Yb}$ have chemical shifts of -30 and $-16 \mathrm{ppm}$, respectively. The 1:1 adducts resonate slightly downfield, from 0 to $+140 \mathrm{ppm}$ (with the value for (1,3-( $\left.\left.\mathrm{SiMe}_{3}\right)_{2} \mathrm{C}_{5} \mathrm{H}_{3}\right)_{2} \mathrm{Yb}\left(\mathrm{OEt}_{2}\right)$ being an exception), and the 1:2 adducts have chemical shifts from +340 to $+950 \mathrm{ppm}$ (with the value for $\mathrm{Cp}^{*}{ }_{2} \mathrm{Yb}$ (thf) $)_{2}$ being an exception). Several of the values were measured under fast-exchange conditions (including the values for $\left(1,3-\left(\mathrm{SiMe}_{3}\right)_{2} \mathrm{C}_{5} \mathrm{H}_{3}\right)_{2} \mathrm{Yb}\left(\mathrm{OEt}_{2}\right)$ and $\left.\mathrm{Cp}_{2}{ }_{2} \mathrm{Yb}(\text { thf })_{2}\right)$, as noted in the Table, and so these chemical shift values are averaged values.

While a dependence on coordination number is a common feature for metal chemical shifts, correlation of metal chemical shifts with specific chemical properties (as is frequently done for ${ }^{1} \mathrm{H}$ and ${ }^{13} \mathrm{C}$ chemical shifts) is often ambiguous. ${ }^{12}$ The paramagnetic shielding contribution to the chemical shift, the dominant factor for metal chemical shifts, includes terms that are dependent on low-lying magnetic dipole-allowed transitions to excited states of the complex, the inverse cube of the distance of the valence $p$ and $d$ electrons from the metal nucleus, and the imbalance of electron distribution on the metal center. ${ }^{12}$ 
Table 5. Reported ${ }^{171} \mathrm{Yb} \mathrm{C}^{3}$ mical Shifts of $\mathrm{Cp}^{\#} \mathrm{YbL}_{\mathrm{M}}$ Complexes $\left(\mathrm{Cp}^{\#}=\mathrm{a} \mathrm{Cp}\right.$ derivative).

Complex

$\mathrm{Cp}_{2}{ }_{2} \mathrm{Yb}, \mathbf{1}^{\mathrm{b}}$

$\left(\mathrm{Cp}^{+}\right)_{2} \mathrm{Yb}, \mathrm{c}$

$\left(\mathrm{Cp}^{+}\right)_{2} \mathrm{Yb}(\mathrm{OEt})^{\mathrm{b}, \mathrm{c}, \mathrm{d}}$

$\mathrm{Cp}^{*}{ }_{2} \mathrm{Yb}\left(\mathrm{OEt}_{2}\right)^{\mathrm{d}}$

$\mathrm{Cp}_{2}^{*} \mathrm{Yb}(\mathrm{thf})_{2}^{\mathrm{d}}$

$\mathrm{Cp}_{2}{ }_{2} \mathrm{Yb}\left(\mathrm{NC}_{5} \mathrm{H}_{5}\right)_{2}{ }^{\mathrm{d}}$

$\mathrm{Cp}_{2}^{*} \mathrm{Yb}(\mu-\mathrm{H})_{2} \mathrm{Pt}(\mathrm{dcype})$

$\mathrm{Cp}_{2}^{*} \mathrm{Yb}(\mu-\mathrm{H})_{2} \mathrm{Pt}(\mathrm{dcypp})$

$\mathrm{Cp}^{*}{ }_{2} \mathrm{Yb}(\mu-\mathrm{H})(\mu-\mathrm{Me}) \operatorname{Pt}($ dippe $)$

$\mathrm{Cp}^{*}{ }_{2} \mathrm{Yb}\left(1,2-\left(\mathrm{PMe}_{2}\right) \mathrm{C}_{6} \mathrm{H}_{4}\right), 6$

$\mathrm{Cp}_{2}^{*} \mathrm{Yb}\left(\mathrm{OPMe}_{3}\right), 7$

$\mathrm{Cp}_{2}^{*} \mathrm{Yb}\left(\mathrm{Me}_{2} \mathrm{PhPCHSiMe}\right), 12$

$(\mathrm{Cp})_{2} \mathrm{Yb}(\mathrm{thf})_{2} \mathrm{~d}_{\mathrm{d}, \mathrm{e}}$

$(\mathrm{Cp})_{2} \mathrm{Yb}(\mathrm{thf})_{2} \mathrm{~d}, \mathrm{e}$

$(\mathrm{Cppy})_{2} \mathrm{Yb}^{\mathrm{f}}$

$\left(\mathrm{Cp}^{\prime} \mathrm{py}\right)_{2} \mathrm{Yb}^{\mathrm{f}}$

(Cppy(s) $)_{2} \mathrm{Yb}^{\mathrm{f}}$

$\left.\mathrm{p}^{\mathrm{p} y(\mathrm{~s})}\right)_{2} \mathrm{Yb}^{\mathrm{f}}$ $\delta(171 \mathrm{Yb}), \mathrm{ppm} \quad$ Solvent $/ T \mathrm{Temp} .\left(^{\circ} \mathrm{C}\right)^{\mathrm{a}}$

$\mathrm{C}_{6} \mathrm{D}_{6} / 25$

toluene- $\mathrm{d}_{8} / 24$

toluene- $\mathrm{d}_{8} / 24$

$\mathrm{Et}_{2} \mathrm{O} / 35$

thf $/ 23$

$\mathrm{NC}_{5} \mathrm{H}_{5} / 65$

toluene-d8/25

toluene- $\mathrm{d}_{8} / 25$

toluene- $\mathrm{d}_{8} / 25$

toluene- $\mathrm{d}_{8} /-30$

toluene- $\mathrm{d}_{8} /-7$

toluene- $\mathrm{d}_{8} /-73$

thf $/-30$

thf/-30

$\mathrm{C}_{6} \mathrm{D}_{6}$, thf $/ 31$

thf $/ 31$

$\mathrm{C}_{5} \mathrm{D}_{5} \mathrm{~N} / 31$

$\mathrm{C}_{6} \mathrm{D}_{6} / 31$
Reference

this work

$46 \mathrm{a}$

$46 a$

$46 \mathrm{~b}$

$46 \mathrm{~b}$

$46 \mathrm{~b}$

Chapter 1

Chapter 1

Chapter 1

this work

this work

this work

$46 c$

$46 c$

$46 \mathrm{~d}$

$46 d$

$46 \mathrm{~d}$

$46 d$

aIt has been reported that ${ }^{171} \mathrm{Yb}$ chemical shifts have a significant temperature dependence. $46 \mathrm{~b}$

bWe have found some evidence for a weak interaction of $\mathbf{1}$ with aromatic solvents such as $\mathrm{C}_{6} \mathrm{D}_{6}$; consequently, these may be averaged values.

${ }^{c} \mathrm{Cp}^{+}=1,3-\left(\mathrm{SiMe}_{3}\right)_{2} \mathrm{C}_{5} \mathrm{H}_{3}$.

dThe ${ }^{171} \mathrm{Yb}$ chemical shifts of th:se complexes are likely averaged values, as fast intermolecular exchange (with solvent) is likely present for these cases.

${ }^{e} \mathrm{Cp}^{\prime}=\mathrm{C}_{5} \mathrm{Me}_{4} \mathrm{P} ; \mathrm{Cp}^{\prime \prime}=\mathrm{C}_{5} \mathrm{Me}_{4} \mathrm{As}$.

fThese $\mathrm{Cp}$ derivatives contain a pendant pyridyl arm: $\mathrm{Cp} p \mathrm{py}=\mathrm{C}_{5} \mathrm{H}_{4}\left[\mathrm{C}(\mathrm{Me})_{2} \mathrm{CH}_{2} \mathrm{C}_{5} \mathrm{H}_{4} \mathrm{~N}-\right.$ 2]; $\mathrm{Cp}^{\prime} \mathrm{py}=\mathrm{C}_{5} \mathrm{H}_{3}\left(\mathrm{SiMe}_{3}\right)\left[\left\{\mathrm{C}(\mathrm{Me})_{2} \mathrm{CH}_{2} \mathrm{C}_{5} \mathrm{H}_{4} \mathrm{~N}-2\right\}-3\right] ; \mathrm{Cppy}(\mathrm{s})=\mathrm{C}_{5} \mathrm{H}_{4}\left[\mathrm{C}(\mathrm{Me})_{2} \mathrm{C}_{5} \mathrm{H}_{4} \mathrm{~N}-\right.$ 2]; $\mathrm{Cp} p y(s)=\mathrm{C}_{5} \mathrm{H}_{3}\left[\left(\mathrm{SiMe}_{3}\right)\left\{\mathrm{C}(\mathrm{Me})_{2} \mathrm{C}_{5} \mathrm{H}_{4} \mathrm{~N}-2\right\}-3\right]$; see ref. $46 \mathrm{~d}$ for details.

In addition, relativistic effects on ${ }^{171} \mathrm{Yb}$ chemical shifts will be significant. ${ }^{47}$ These factors are not well-understood for many metals, ${ }^{48}$ and certainly not for $\mathrm{Cp}^{*}{ }_{2} \mathrm{YbL}_{\mathbf{n}}$ complexes; consequently, information contained within ${ }^{171} \mathrm{Yb}$ chemical shifts remains a mystery. 
References.

(1) (a) Hitchcock, P. B.; Holmes, S. A.; Lappert, M. F.; Tian, S. J. Chem. Soc., Chem. Commun. 1994, 2691. (b) Tilley, T. D.; Andersen, R. A.; Zalkin, A. Inorg. Chem. 1983, 22, 856. (c) Tilley, T. D.; Andersen, R. A.; Zalkin, A. J. Am. Chem. Soc. 1982, 104, 3725. (d) Brennan, J. G.; Stults, S. D.; Andersen, R. A.; Zalkin, A. Organometallics. 1988, 7, 1329, and references therein. (e) Schlesener, C. J.; Ellis, A. B. Organometallics. 1983, 2, 529. (f) Brennan, J. G.; Andersen, R. A.; Robbins, J. L. J. Am. Chem. Soc. 1986, 108, 335. (g) Hitchcock, P. B.; Lappert, M. F.; MacKinnon, I. A. J. Chem. Soc., Chem. Commun. 1988, 1557. (h) Fryzuk, M. D.; Haddad, T. S. J. Chem. Soc., Chem. Commun. 1990, 1088.

(2) The paramagnetic shift induced by $\mathrm{Cp}_{\mathrm{p}}{ }_{2} \mathrm{Eu}$ has been used to study the weak interactions formed between the Eu center and $\mathrm{H}_{2}, \mathrm{C}_{2} \mathrm{H}_{4}, \mathrm{C}_{3} \mathrm{H}_{6}$, and cyclopropane in an indirect way: Nolan, S. P.; Marks, T. J. J. Am. Chem. Soc. 1989, 111, 8538.

(3) All coalescence temperatures given in the text were measured at $300 \mathrm{MHz}{ }^{1} \mathrm{H}$ frequency, and were measured on samples containing 1 eq. excess of 1 . These values may be used as a qualitative measure of the kinetic barrier to intermolecular exchange.

(4) The exchange rate is faster not only for samples containing excess $\mathrm{PR}_{3}$, but also for many of the $1 / 1$ samples, relative to samples containing a slight excess of 1 . Consequently, unless otherwise stated, all stopped-exchange NMR values reported in the text were measured on samples containing $c a .1$ eq. excess of 1 .

(5) Bryant, R. G. J. Chem. Ed. 1983, 60, 933.

(6) The recently-reported $\left[\mathrm{Yb}\left(\mathrm{CH}\left(\mathrm{SiMe}_{3}\right)_{2}\right)_{2}\right.$ (dmpe)] complex ${ }^{1 \mathrm{a}}$ is soluble in toluene; only the exchange-averaged room temperature NMR data were reported.

(7) This coupling is likely unresolved for complexes 2-4 as a result of the broader resonances present at the low temperatures required to slow intermolecular exchange in these systems.

(8) (a) Bax, A.; Griffey, R. H.; Hawkins, B. L. J. Magn. Reson. 1983, 55, 301. (b) Bax, A.; Subramanian, S. J. Magn. Reson. 1986, 67, 565. 
(9) (a) Burns, C. J.; Andersen, R. A. J. Am. ( . Soc. 1987, 109, 5853. (b) The solid-state structure of $\mathrm{Cp}_{2}{ }_{2} \mathrm{Yb}\left(\mathrm{OEt}_{2}\right)$ has a $\gamma-\mathrm{CH}_{3}$. raction involving the methyl group of the diethyl ether ligand: P. L. Watson, personal communication. (c) Also see Chapter 1.

(10) Agostic complexes with unchanged ${ }^{1} \mathrm{~J}_{\mathrm{CH}}$ values are known, see discussion in Chapter 1, and: (a) Neve, F.; Ghedini, M.; Crispini, A. Organometallics. 1992, 11, 3324. (b) Albinat, A.; Pregosin, P. S.; Wombacher, F. Inorg. Chem. 1990, 29, 1812. (c) Albinati, A.; Anklin, C. G.; Ganazoli, F.; Ruegg, H.; Pregosin, P. S. Inorg. Chem. $1987,26,503$.

(11) This assumes that the hybridization of the ${ }^{31} \mathrm{P}$ and ${ }^{171} \mathrm{Yb}$ nuclei are the same in both the $1: 1$ and the $1: 2$ adducts, see ref. 12. Ch. 4 .

(12) Jameson, C. J.; Mason, J. In Multinuclear NMR; Mason, J., Ed.; Plenum Press: New York, 1987; Ch. 3.

(13) While chelation does not appear to affect the enthalpic strength of the Yb-P interactions, based on the NMR data, it does have an affect on the entropic contribution to the $\Delta \mathrm{G}$ (interaction) value, as mentioned later in the text.

(14) Reaction of $\mathrm{Cp}_{2}{ }_{2} \mathrm{Yb}\left(\mathrm{OE} t_{2}\right)$ with $\mathrm{Ph}_{3} \mathrm{PS}$ gives $\left[\mathrm{Cp}_{2}{ }_{2} \mathrm{Yb}(\mu-\mathrm{S})\right]_{2} .{ }^{15}$ Apparently, the base-free derivative 1 also reacts similarly, as a resonance for free $\mathrm{Ph}_{3} \mathrm{P}$ becomes visible in the ${ }^{31} \mathrm{P}\left\{{ }^{1} \mathrm{H}\right\}$ spectrum of this sample over the course of several hours.

(15) Berg, D. J.; Burns, C. J.; Andersen, R. A.; Zalkin, A. Organometallics. 1989, 8, 1865.

(16) Tilley, T. D.; Andersen, R. A.; Spencer, B.; Ruben, H.; Zalkin, A.; Templeton, D. H. Inorg. Chem. 1980, 19, 2999.

(17) Birkofer, L.; Kim, S. M. Chem. Ber. 1964, 97, 2100.

(18) Dixon, D. A. In Ylides and Imines of Phosphorus, Johnson, A. W., Ed.; John Wiley \& Sons, Inc.: New York, 1993; Ch. 2. 
(19) Gilheany, D. G. Chem. Rev. 1994, 94, 1339.

(20) Kaska, W. C. Coord. Chem. Rev. 1983, 48, 1.

(21) Starzewski, K. A. O.; Feigel, M. J. Organomet. Chem. 1975, 93, C20.

(22) Liu, Z.-p.; Schlosser, M. Tet. Letters. 1990, 31, 5753.

(23) Grim, S. O. In Phosphorus-3I NMR Spectroscopy in Stereochemical Analysis: Organic Compounds and Metal Complexes, Verkade, J. G. and Quin, L. D., eds.; VCH Publishers: Deerfield Beach, FL, 1987; Ch. 18.

(24) Schmidbaur, H.; Heimann, M. Z. Naturforsch. 1978, 29b, 485.

(25) These temperatures were chosen as they are well below the $T_{c}$ (intermolecular exchange) temperatures.

(26) (a) Schumann, H.; Reier, F. W.; Dettlaff, M. J. Organomet. Chem. 1983, 255, 305. (b) Werner, H.; Schippel, O.; Wolf, J.; Schulz, M. J. Organomet. Chem. 1991, $417,149$.

(27) Several ${ }^{1} \mathrm{H} /{ }^{13} \mathrm{C}$ HMQC spectra were obtained on a sample of 12 at $-78^{\circ} \mathrm{C}$, however $\mathrm{Yb}-\mathrm{C}$ or $\mathrm{Yb}-\mathrm{H}$ coupling was not resolved in any of them. A ${ }^{1} \mathrm{~J}_{\mathrm{YbC}}$ value of $0.32 \mathrm{~Hz}$ has recently been reported for $\left.\left[\mathrm{Yb}_{\mathrm{b}}\left(\mathrm{NiMe}_{3}\right) \mathrm{C}(\mathrm{tBu}) \mathrm{CH}\left(\mathrm{SiMe}_{3}\right)\right]_{2}\right\} .{ }^{1 a}$ This value is unexpectedly small, considering the ${ }^{1} \mathrm{~J}_{\mathrm{YbC}}$ value of $48 \mathrm{~Hz}$ in (dippe) $\mathrm{Pt}\left(\mu-\mathrm{CH}_{3}\right)(\mu$ H) $\mathrm{YbCp}^{*}{ }_{2}$, Chapter 1 . The ${ }^{1} \mathrm{~J}_{\mathrm{YbC}}$ value for $\mathrm{Yb}\left[\mathrm{C}\left(\mathrm{SiMe}_{3}\right)_{3}\right]_{2}$ was not reported. ${ }^{28}$

(28) Eaborn, C.; Hitchcock, P. B.; Izod, K.; Smith, J. D. J. Am. Chem. Soc. 1994, $116,12071$.

(29) (a) Schumann, H.; Albrecht, I.; Reier, F.-W.; Hahn, E. Angew. Chem., Int. Ed. Engl. 1984, 23, 522. (b) Wong, W.-K.; Guan, J.; Ren, J.; Shen, Q.; Wong, W. -T. Polyhedron. 1993, 12, 2749. (c) Wong, W. -K.; Guan, J. W.; Shen, Q.; Zhang, L. L.; Ling, Y.; Wong, W. -T. Polyhedron. 1995, 14, 277. 
(30) (a) Burns, C. J.; Andersen, R. A. J. Am. Chem. Soc. 1987, 109, 941. (b) Burns, C. J.; Andersen, R. A. J. Am. Chem. Soc. 1987, 109, 915. (c) Also see Chapter 1.

(31) Schumann, H.; Glanz, M.; Winterfeld, J.; Hemling, H.; Kuhn, N.; Kratz, T. Angew. Chem., Int. Ed. Engl. 1994, 33, 1733.

(32) A P $=\mathrm{C}$ double bond distance is $1.665 \AA, 19$ and a $\mathrm{P}-\mathrm{C}$ single bond distance is 1.872 A.. ${ }^{18}$

(33) Pauling, L. In The Nature of the Chemical Bond, 3rd ed.; Cornell University Press: Ithaca, New York, 1960; pp. 260-261.

(34) Such a $\gamma-\mathrm{CH}_{3}$ interaction involving the methyl of an $\mathrm{SiMe}_{3}$ group and $\mathrm{Yb}$ has been reported for $\mathrm{Yb}\left[\left(\mathrm{N}\left(\mathrm{SiMe}_{3}\right)_{2}\right]_{2}\right.$ (dmpe). $1 \mathrm{c}$

(35) (a) Marder, T. B.; Fultz, W. C.; Calabrese, J. C.; Harlow, R.; Milstein, D. J. Chem. Soc., Chem. Commun. 1987, 1543. (b) Kermode, N. J.; Lappert, M. F.; Skelton, B. W.; White, A. H.; Holton, J. J. Organomet. Chem. 1982, 228, C71; and references therein. (c) Buchanan, R. M.; Pierpont, C. G. Inorg. Chem. 1979, 18, 3608.

(36) Movement of the ylide molecule relative to 1 is identical-to movement of 1 relative to the ylide molecule. For clarity, the latter frame of reference will be used for the discussion. Also, while rotation of the $\mathrm{C}(\mathrm{H})\left(\mathrm{SiMe}_{3}\right)$ moiety about the $\mathrm{P}-\mathrm{C}$ bond may be occurring (the barrier to rotation about P-C ylide bonds is small), ${ }^{22}$ this would not have a significant effect on the process under discussion.

(37) Peng, T.-S.; Gladysz, J. A. J. Am. Chem. Soc. 1992, 114, 4174.

(38) Similar interactions involving an olefinic $\mathrm{C}-\mathrm{H}$ bond have been proposed to explain kinetic and isotopic effects in the $\mathrm{Cp}^{*} \operatorname{Ir}\left(\mathrm{PMe}_{3}\right)\left(\mathrm{C}_{2} \mathrm{H}_{4}\right)$ system: (a) Stoutland, P. O.; Bergman, R. G. J. Am. Chem. Soc. 1985, 107, 4581. (b) Stoutland, P. O.; Bergman, R. G. J. Am. Chem. Soc. 1988, 110, 5732.

(39) Elser, V. H.; Dreeskamp, H. Ber. Bunsenges. Phys. Chem. 1969, 73, 619. 
(40) Crabtree, R. H. Angew. Chem., Int. Ed. Engl. 1993, 32, 789. While certain agostic complexes have ${ }^{1} \mathrm{~J}_{\mathrm{CH}}$ values that are relatively unchanged from the "free" ${ }^{1} \mathrm{~J}_{\mathrm{CH}}$ values, this is usually a result of averaging of a smaller agostic ${ }^{1} \mathrm{~J}_{\mathrm{CH}}$ value with larger, unperturbed ${ }^{1} \mathrm{~J}_{\mathrm{CH}}$ values; this is not possible for $\mathbf{1 2}$.

(41) (a) Nief, F.; Ricard, L.; Mathey, F. Polyhedron. 1993, 12, 19. (b) Karsch, H. H.; Ferazin, G.; Steigelmann, O.; Kooijman, H.; Hiller, W. Angew. Chem., Int. Ed. Engl. 1993, 32, 1739. (c) Fryzuk, M. D.; Haddad, T. S.; Berg, D. J. Coord. Chem. Rev. $1990,90,137$.

(42) The reduced coupling constant is given by: $\mathrm{K}=\left(4 \pi^{2} \mathrm{~J}_{\mathrm{AB}}\right) /\left(\mathrm{H} \gamma_{\mathrm{A}} \gamma_{\mathrm{B}}\right)$; all values given in the text are to the $10^{20}$ power, and are in $\mathrm{NA}^{-2} \mathrm{~m}^{-3}$ units.

(43) Blaschke, G.; Schmidbaur, H.; Kaska, W. C. J. Organomet. Chem. 1979, 182, 251.

(44) Feser, R.; Werner, H. Angew. Chem., Int. Ed. Engl. 1980, 19, 940.

(45) Slight exchange broadening of the free and bound $\mathrm{Cp}^{*}$ resonances is present in the $25^{\circ} \mathrm{C}^{1} \mathrm{H}$ spectrum.

(46) (a) Hitchcock, P. B.; Howard, J. A. K.; Lappert, M. F.; Prashar, S. J. Organomet. Chem. 1992, 437, 177. (b) Avent, A. G.; Edelman, M. A.; Lappert, M. F.; Lawless, G. A. J. Am. Chem. Soc. 1989,111, 3423. (c) Nief, F.; Ricard, L.; Mathey, F. Polyhedron. 1993, 12, 19. (d) van den Hende, J. R.; Hitchcock, P. B.; Lappert, M. F. J. Organomet. Chem. 1994, 472, 79.

(47) Mason, J. Chem. Rev. 1987, 87, 1299.

(48) (a) Macchioni, A.; Pregosin, P. S.; Ruegger, H.; Koten, G. v.; van der Schaaf, P. A.; Abbenhuis, R. A. T. M. Magn. Res. Chem. 1994, 32, 235. (b) Pregosin, P. S. In Annual Reports on NMR Spectroscopy, Vol. 17; Webb, G. A., ed.; Academic Press Inc.: London, 1986. 


\section{CHAPTER 4}

\section{Weak Interactions of $\mathrm{Cp}_{2}{ }_{2} \mathrm{Yb}$ with Various Small Molecules $\left(\mathrm{H}_{2}, \mathrm{Xe}, \mathrm{CH}_{4}, \mathrm{CO}\right.$, toluene, etc.)}

\section{Indirect Detection of the ${ }^{171} \mathrm{Yb}$ NMR Spectra of $\mathrm{Cp}^{*}{ }_{2} \mathrm{YbL}_{n}$} Complexes. Throughout this work, ${ }^{171} \mathrm{Yb}$ spectra have been indirectly detected by utilizing a $\mathrm{J}_{\mathrm{YbH}}$ coupling and the $\mathrm{HMQC}$ pulse sequence. ${ }^{1}$ The $\mathrm{Yb}-\mathrm{H}$ coupling has, in all cases, been to a proton on the ligand, $\mathrm{L}$, of a slow-exchange $\mathrm{Cp}^{*}{ }_{2} \mathrm{YbL}_{\mathrm{n}}$ adduct. It is possible that a similar method can be used to indirectly detect ${ }^{171} \mathrm{Yb}$ nuclei using the longrange coupling of ${ }^{171} \mathrm{Yb}$ to the $\mathrm{Cp}^{*}$ ring protons $\left({ }^{3} \mathrm{~J}_{\mathrm{YbH}}\right.$, taking the $\mathrm{Yb}$-ring carbon interaction as a one-bond interaction). Clearly, as the $\mathrm{Yb}-\mathrm{H}$ coupling is intramolecular, intermolecular exchange will not be a problem (with respect to "washing out" of the ${ }^{171} \mathrm{Yb}^{1}{ }^{1} \mathrm{H}$ coupling), as it was for several of the cases discussed above. One potential difficulty is the size of the ${ }^{3} \mathrm{~J}_{\mathrm{YbH}}$ coupling in $\mathrm{Cp}^{*}{ }_{2} \mathrm{YbL}_{\mathrm{n}}$ complexes; the smaller the $\mathrm{J}_{\mathrm{XH}}$ value for an $\mathrm{H} / \mathrm{X} \mathrm{HMQC}$ experiment, the longer the relevant delays. If these delays are too long, sensitivity is reduced by transverse $\left(\mathrm{T}_{2}\right)$ relaxation during the experiment evolution period. $23 \mathrm{~d}$ The technique of using long range $\mathrm{M}-\mathrm{H}$ coupling to indirectly detect $\mathrm{M}$ spectra (for $\mathrm{M}={ }^{187} \mathrm{Os},{ }^{183} \mathrm{~W},{ }^{57} \mathrm{Fe},{ }^{119} \mathrm{Sn}$ ) with increased sensitivity has been reported previously. 3

A saturated solution of $\mathrm{Cp}_{2}^{*} \mathrm{Yb}(1)$ in $\mathrm{C}_{6} \mathrm{D}_{6}$ was used to test the viability of this technique. At $300 \mathrm{MHz}$, a resolution-enhanced ${ }^{4}{ }^{1} \mathrm{H}$ spectrum (the $\mathrm{T}_{1}$ value for the $\mathrm{Cp}^{*}$ protons of this sample is 3.6 seconds) shows ${ }^{171} \mathrm{Yb}$ satellites on the $\mathrm{Cp}^{*}$ resonance (Fig. 1). The ${ }^{3} \mathrm{~J}_{\mathrm{YbH}}$ value is $3.5 \mathrm{~Hz}$. A ${ }^{1} \mathrm{H} /{ }^{171} \mathrm{Yb}$ HMQC experiment on this sample, optimized for a ${ }^{3} \mathrm{~J}_{\mathrm{YbH}}$ value of $8 \mathrm{~Hz}$ (to avoid the long delays discussed above), gives a ${ }^{171} \mathrm{Yb}$ signal at $-30 \mathrm{ppm}\left(w_{1 / 2}=275 \mathrm{~Hz}\right.$, Fig. 2$)$. This confirms the presence of ${ }^{3} \mathrm{~J}_{\mathrm{YbH}}$, as no ${ }^{171} \mathrm{Yb}$ signal would be observed in the absence of such spin-spin communication. 


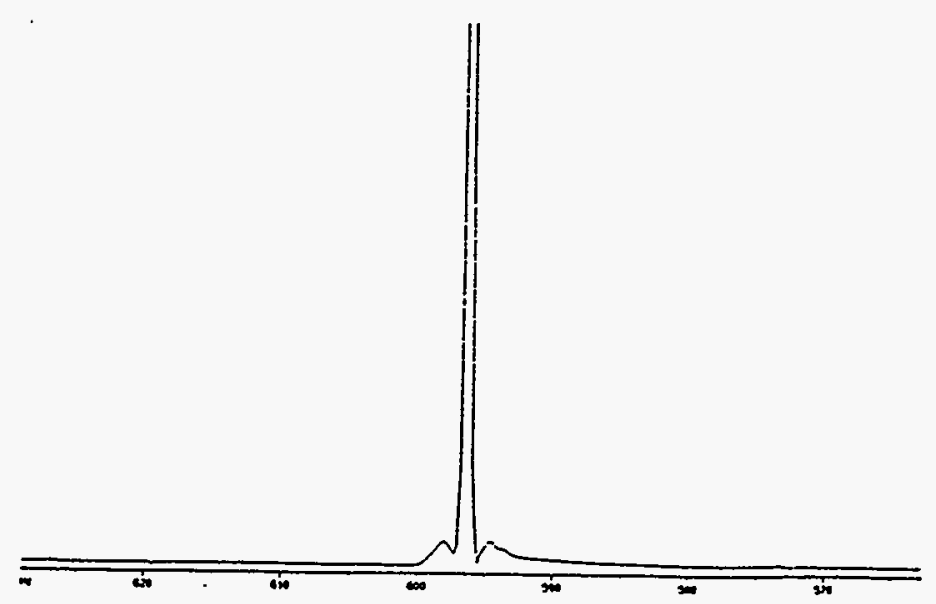

Figure 1. Resolution-enhanced ${ }^{1} \mathrm{H}$ spectrum of 1 in $\mathrm{C}_{6} \mathrm{D}_{6}$, showing ${ }^{171} \mathrm{Yb}$ satellites on the $\mathrm{Cp}^{*}$ resonance. The non-Gaussian lineshapes result from the resolution enhancement, which is necessary to resolve the ${ }^{171} \mathrm{Yb}$ satellites.

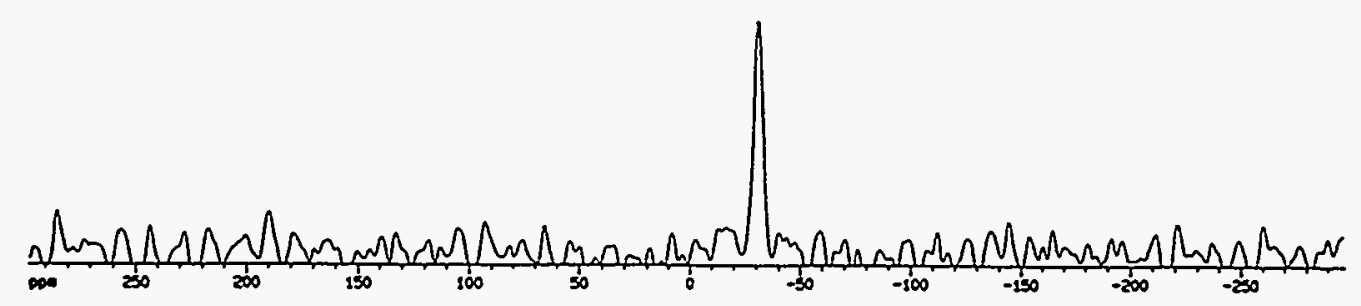

Figure 2. A slice of the ${ }^{171} \mathrm{Yb}$ dimension of the ${ }^{1} \mathrm{H} /{ }^{171} \mathrm{Yb}$ HMQC spectrum of 1 (300 $\mathrm{MHz}, 25^{\circ} \mathrm{C}, \mathrm{C}_{6} \mathrm{D}_{6}$ ).

The signal:noise $(\mathrm{S} / \mathrm{N})$ ratio of the ${ }^{171} \mathrm{Yb}$ resonance in Fig. 2 is ca. 5:1. Using direct detection on a sample of similar concentration (with a 3 second total delay time between scans--the ${ }^{171} \mathrm{Yb} \mathrm{T}_{1}$ was not measured) gives an $\mathrm{S}: \mathrm{N}$ ratio of $c a .3: 1$ after 3 hours; the total experiment time for the ${ }^{1} \mathrm{H} /{ }^{171} \mathrm{Yb}$ HMQC experiment was 2.5 hours. In this case, indirect detection does not give a very large improvement in experiment time; this is a result of the relatively long $T_{1}$ value of the $C_{p}^{*}$ protons, and of the unoptimized ${ }^{3} \mathrm{~J}_{\mathrm{YbH}}$-dependent delays, as discussed above. A more dramatic measure of the power of indirect detection of ${ }^{171} \mathrm{Yb}$ is shown in Chapter 3, Fig. 2; the total acquisition time for this experiment was 40 minutes, and the ${ }^{171} \mathrm{Yb}$ resonance was visible after only ca. 3 minutes. The experiment was optimized for a ${ }^{3} \mathrm{~J}_{\mathrm{YbH}}$ value of $7 \mathrm{~Hz}$; the most intense 
signal arises from the $\mathrm{P}-\mathrm{CH}_{3}$ protons, for which ${ }^{3} \mathrm{~J} \mathrm{YbH}$ is $2.7 \mathrm{~Hz}$ (signal arising from the $\mathrm{Cp}^{*}$ protons is also visible). This shows the sensitivity of the HMQC technique, considering that the resonance is coupled to two phosphorus nuclei, and that the concentration of the sample was $0.028 \mathrm{M}$ in $\mathrm{Cp}_{2}{ }_{2} \mathrm{Yb}\left(1,2-\left(\mathrm{PMe}_{2}\right) \mathrm{C}_{6} \mathrm{H}_{4}\right)$.

The HMQC experiment has several advantages over direct detection, for optimized experiments. There is a $c a$. 100-fold theoretical sensitivity enhancement over direct detection for ${ }^{171} \mathrm{Yb}\left(\left(\gamma_{\mathrm{H}} / \gamma_{\mathrm{X}}\right)^{5 / 2}\right.$ sensitivity enhancement for an $\mathrm{H} / \mathrm{X}$ HMQC spectrum); this translates to a $c a$. 1000-fold enhancement in terms of experiment time. The HMQC experiment allows optimization based on easily-measured ${ }^{1} \mathrm{H}$ pulse widths and $\mathrm{T}_{1}$ relaxation times, in contrast to direct detection, for which measurement of the analogous ${ }^{171} \mathrm{Yb}$ values is more difficult. Also, the signs of any $J_{Y b X}$ coupling constants (and any $\mathrm{J}_{X \mathrm{X}}$ coupling constants present) can be obtained from the 2-D ${ }^{1} \mathrm{H} /{ }^{171} \mathrm{Yb}$ experiment, but not from a 1-D direct-detected spectrum. Lastly, the large sweep width of $171 \mathrm{Yb}$ (ca. $1300 \mathrm{ppm}$ ) makes quicker experiments valuable, as the approximate ${ }^{171} \mathrm{Yb}$ chemical shift can be quickly located using indirect detection, followed by acquisition using a smaller sweep width, for improved resolution.

Based on these advantages, indirect detection using the HMQC pulse sequence is a better method for acquiring ${ }^{171} \mathrm{Yb}$ spectra than direct detection. Theoretically, the ${ }^{171} \mathrm{Yb}$ spectrum of any $\mathrm{CP}_{2}{ }_{2} \mathrm{YbL}_{\mathrm{n}}$ complex can be obtained using this method, as the $\mathrm{J}_{\mathrm{YbH}}$ value involving the $\mathrm{Cp}^{*}$ methyl protons will not vary much with the ligand, $\mathrm{L}$ (of course, only fluxional-averaged ${ }^{171} \mathrm{Yb}$ chemical shifts will be obtained for fast exchange adducts). The exact $\mathrm{J}_{\mathrm{YbH}}$ value is not needed, as the ${ }^{171} \mathrm{Yb}$ signal is obtained even if the Jdependent delays are slightly unoptimized, as mentioned above. More generally, $\mathrm{M}-\mathrm{H}$ spin-spin coupling should be present for any $\mathrm{Cp}^{\#} \mathrm{ML}_{\mathrm{n}}$ complex $\left(\mathrm{Cp}^{\#}=\right.$ a variety of $\mathrm{Cp}$ derivatives, including $\mathrm{Cp}$ and $\mathrm{Cp}^{*}$ ) that contains an NMR-active metal isotope. Consequently, this technique should be applicable for many such complexes, as a means of obtaining the metal NMR spectra with relatively high sensitivity. 3,5 
Synthetic Attempts Towards a $\mathrm{P}_{2} \mathrm{Pt}-\mathrm{YbCp}_{2}{ }_{2}$ Bimetallic Complex. As mentioned in Chapter 1, the energies of the frontier orbitals of a $\mathrm{P}_{2} \mathrm{Pt}$ fragment change dramatically as a function of the P-Pt-P angle. ${ }^{6}$ Specifically, the HOMO (comprised mainly of the metal-based $d\left(x^{2}-y^{2}\right)$ orbital) rises sharply in energy as this angle becomes more acute; thus, as the P-Pt-P angle is decreased, the $\mathrm{P}_{2} \mathrm{Pt}$ fragment becomes highly nucleophilic. Given this it is not surprising that bent $\mathrm{P}_{2} \mathrm{Pt}$ species, formed in situ, ${ }^{7}$ have been found to react with a variety of electrophilic reagents, including oxidative addition of both aromatic and aliphatic $\mathrm{C}-\mathrm{H}$ bonds ${ }^{7 \mathrm{a}-\mathrm{c}}$ to yield square planar $\mathrm{P}_{2} \mathrm{Pt}(\mathrm{R})(\mathrm{H})$ complexes ( $R=$ an aryl or alkyl group). The related $\left(\mathrm{P}_{2} \mathrm{M}\right)_{2}$ dimers $\left(\mathrm{M}=\mathrm{Pd}, \mathrm{P}_{2}=\mathrm{dcype} ; \mathrm{M}=\mathrm{Pt}\right.$, $\mathrm{P}_{2}=\mathrm{dtbpp}$ ) have also been reported to be sources of reactive $\mathrm{P}_{2} \mathrm{M}$ species. ${ }^{8}$ Given the highly nucleophilic nature of these $\mathrm{P}_{2} \mathrm{Pt}$ intermediates, it was thought that they might act as Lewis basic ligands towards 1 ; if the direct $\mathrm{Pt}-\mathrm{Yb}$ interaction were strong enough, the solution state properties and reactivity of this novel bimetallic complex could be studied. There has been only one report of a direct $\mathrm{Yb}$-transition metal interaction, in the "ladder polymer" complex $\left\{\left[\left(\mathrm{CH}_{3} \mathrm{CN}\right)_{3} \mathrm{YbFe}(\mathrm{CO})_{4}\right]_{2}\left(\mathrm{CH}_{3} \mathrm{CN}\right)\right]_{\infty}$ (Fig. 3, the close $\mathrm{Fe}-\mathrm{Yb}$ contact may result merely from geometric constraints). ${ }^{9}$ There have been no reports of a direct $\mathrm{Yb}$-transition metal interaction in the absence of bridging ligands, as would be present in a $\mathrm{P}_{2} \mathrm{Pt}-\mathrm{YbCp}_{2}{ }_{2}$ complex.

Initial attempts at synthesizing a $\mathrm{P}_{2} \mathrm{Pt}-\mathrm{YbCp}^{*}{ }_{2}$ complex involved the use of monodentate phosphine derivatives, $\left(\mathrm{PR}_{3}\right)_{2} \mathrm{Pt}$; for $\mathrm{R}=\mathrm{Et}, \mathrm{Ph}$, these have also been reported to be highly reactive, nucleophilic species. ${ }^{10}$ As mentioned in Chapter 1, a toluene- $\mathrm{d}_{8}$ solution of $(\mathrm{PCy})_{2} \mathrm{Pt}$ and 1 shows no perturbations in the NMR spectral values at $25^{\circ} \mathrm{C}$, relative to the values of the starting materials; the spectra are also unchanged at $-90^{\circ} \mathrm{C}$ (the $\mathrm{PCy}_{3}$ derivative was initially used, as it is an isolable compound ${ }^{11}$ ). This may be a result of steric interactions between the sterically bulky $\mathrm{PCy}_{3}$ alkyl groups and the $\mathrm{Cp}^{*}$ rings of $\mathbf{1}$ (the cone angle of $\mathrm{PCy}_{3}$ is $170^{\circ}$ ). Related to this, the energy needed to bend the large PCy3 ligands towards each other (as is 
necessary upon binding of a third ligand to the linear ( $\left.\mathrm{PCy})_{2}\right)_{2} \mathrm{Pt}$ complex) may partially or totally offset the enthalpy gained from the Pt-Yb interaction.
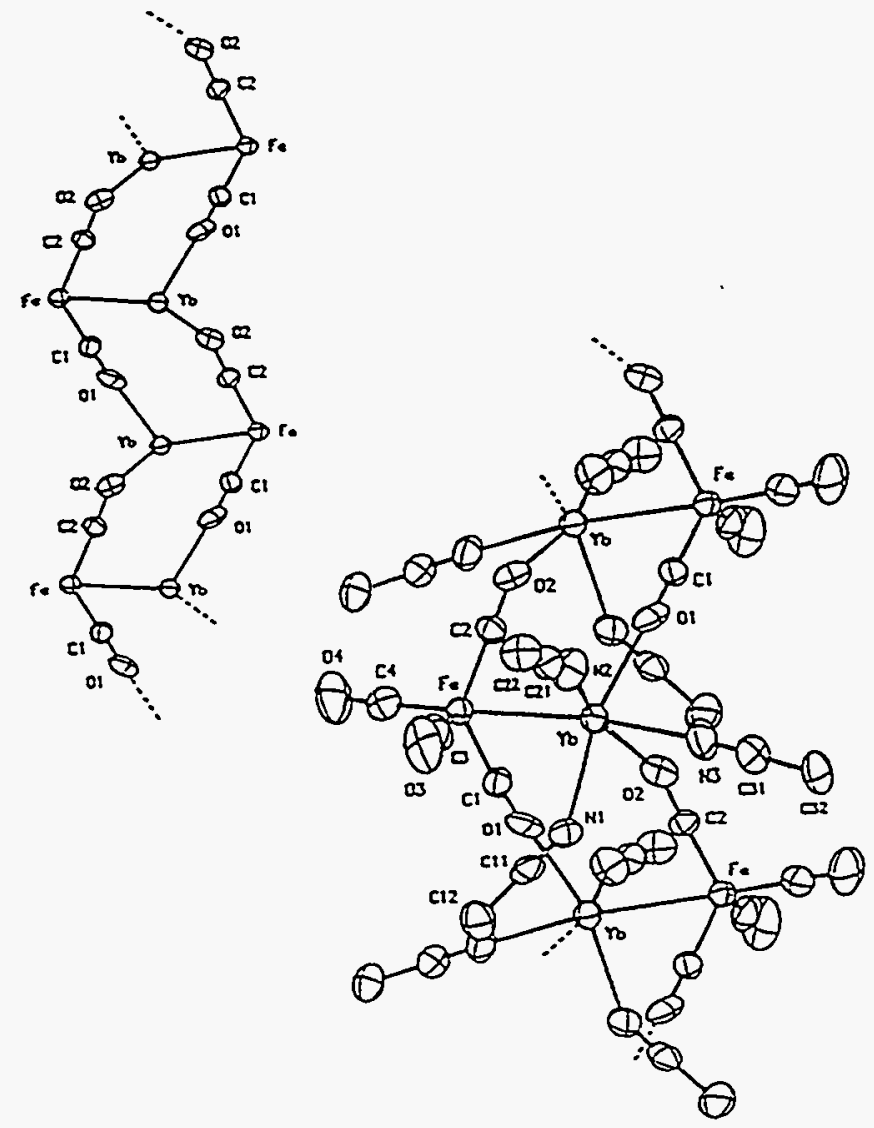

Figure 3. ORTEP drawing of a portion of $\left.\left\{\left[\left(\mathrm{CH}_{3} \mathrm{CN}\right)_{3} \mathrm{YbFe}(\mathrm{CO})_{4}\right]_{2}\left(\mathrm{CH}_{3} \mathrm{CN}\right)\right]\right\}_{\infty}$, $50 \%$ probability ellipsoids $(\mathrm{d}(\mathrm{Yb}-\mathrm{Fe})=3.010(1) \AA)$. Taken from reference 9.

Smaller $\left(\mathrm{PR}_{3}\right)_{2} \mathrm{Pt}$ derivates were therefore investigated. Such species are not isolable, and have been generated in situ by a variety of methods, including photochemical, ${ }^{10 a}$ electrochemical, ${ }^{10 b, c}$ and thermal ${ }^{7 d}$ methods. The photochemical and electrochemical preparations require the use of polar solvents that react with 1 ; consequently, the thermal method of preparing a $\mathrm{P}_{2} \mathrm{Pt}$ derivative was investigated. It has been reported that $\left(\mathrm{PPh}_{3}\right)_{2} \mathrm{Pt}(\mathrm{Me})(\mathrm{H})$, formed at low temperature from $\left(\mathrm{PPh}_{3}\right)_{2} \mathrm{Pt}(\mathrm{Me})(\mathrm{Cl})$ and $\mathrm{MeMgBr}$, reductively eliminates methane upon warming to $-25^{\circ} \mathrm{C}$, giving a reactive $\left(\mathrm{PPh}_{3}\right)_{2} \mathrm{Pt}$ species ${ }^{7 \mathrm{~d}}$ (eq. 1 ; the cone angle of $\mathrm{PPh}_{3}$ is $145^{\circ}$ ). In 
the absence of a trapping agent, decomposition to $\mathrm{Pt}\left(\mathrm{PPh}_{3}\right)_{3}$ and $\mathrm{Pt}$ metal occurs (eq. 2). When a trapping agent, $\mathrm{L}$, is present $\left(\mathrm{L}=\mathrm{PPh}_{3}, \mathrm{PhCCPh}\right)$, a $\left(\mathrm{PPh}_{3}\right)_{2} \mathrm{PtL}$ complex is formed (eq. 3).

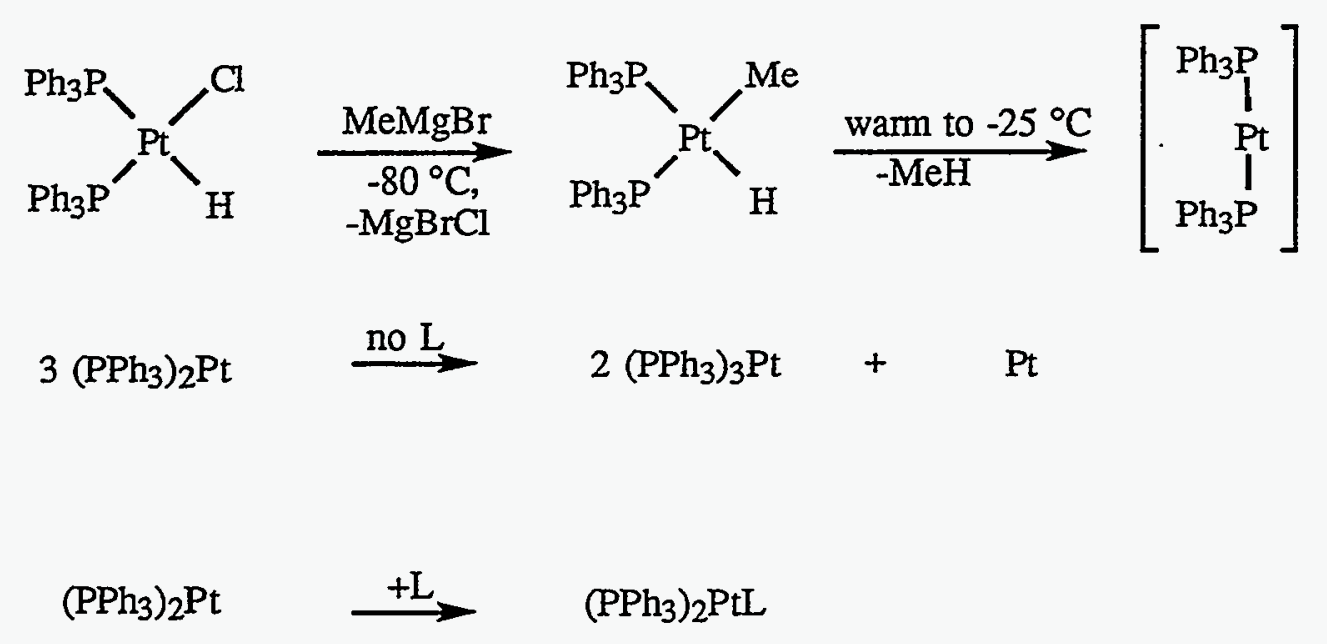

It was found that forming $\left(\mathrm{PPh}_{3}\right)_{2} \mathrm{Pt}(\mathrm{Me})(\mathrm{H})$ in situ at $-80^{\circ} \mathrm{C}$, adding it to a $-80^{\circ} \mathrm{C}$ toluene solution of 1 (after letting the $\mathrm{MgBrCl}$ by-product settle out), and then allowing the resulting solution to warm slowly to room temperature, resulted in a cloudy orangebrown solution. Upon workup, the only product isolated from this reaction was identified as $\left(\mathrm{PPh}_{3}\right)_{3} \mathrm{Pt},{ }^{12}$ on the basis of ${ }^{1} \mathrm{H}$ and ${ }^{31} \mathrm{P}\left\{{ }^{1} \mathrm{H}\right\}$ NMR spectroscopy. The reaction was done several times with identical results. Apparently the Pt-Yb interaction is not thermodynamically strong enough to prevent disproportionation of the $\left(\mathrm{PPh}_{3}\right)_{2} \mathrm{Pt}$ intermediate into $\left(\mathrm{PPh}_{3}\right)_{3} \mathrm{Pt}$ and $\mathrm{Pt}$ metal (eq. 2). ${ }^{13}$

Use of a chelating phosphine should be beneficial with respect to stabilizing the $\mathrm{P}_{2} \mathrm{Pt}-\mathrm{YbCp}{ }_{2}$ complex. The more acute $\mathrm{P}-\mathrm{Pt}-\mathrm{P}$ angle results in a more nucleophilic $\mathrm{P}_{2} \mathrm{Pt}$ fragment, decreased steric interactions between the $\mathrm{Cp}^{*}$ groups of 1 and the alkyl groups of the phosphine ligand, and less "reorganization energy" needed upon binding of $\mathbf{1}$ to the $\mathrm{P}_{2} \mathrm{Pt}$ fragment. Whitesides and co-workers have reported that $(\mathrm{dcype}) \mathrm{Pt}(\mathrm{Np})(\mathrm{H})(2$; $\mathrm{Np}=\mathrm{CH}_{2} \mathrm{CMe}_{3}$ ) reductively eliminates neopentane upon warming above $45^{\circ} \mathrm{C}$, and that the resulting (dcype)Pt intermediate reacts with olefins, alkynes, and aliphatic/aromatic C- 
$\mathrm{H}$ bonds. ${ }^{7 \mathrm{a}-\mathrm{c}} \mathrm{A}$ toluene- $\mathrm{d}_{8}$ solution of $\mathbf{1}$ (slight excess) and 2 undergoes fast intermolecular exchange at $25^{\circ} \mathrm{C}$. Cooling this sample to $-110^{\circ} \mathrm{C}$ results in slight decoalescence of the averaged $\mathrm{Cp}^{*}$ resonance, into free and bound resonances, indicating that the intermediate exchange region has been reached. Apparently, the barrier to intermolecular exchange is relatively low in this system, much lower than for (dippe) $\mathrm{Pt}(\mu-\mathrm{Me})(\mu-\mathrm{H}) \mathrm{YbCp}^{*}{ }_{2}$ (Chapter 1). Most likely, the larger steric size of the Ptbound alkyl group (neopentyl vs. methyl) results in a decreased Yb-hydride interaction, with a coisequent decreased exchange barrier. ${ }^{13}$

With respect to obtaining a (dcype)Pt-YbCp ${ }_{2}$ complex, it was found that heating a cyclohexane solution of $\mathbf{1}$ and $\mathbf{2}$ (cyclohexane is the least reactive solvent with respect to reaction with the (dcype)Pt intermediate ${ }^{7 \mathrm{c}}$ ) to $70^{\circ} \mathrm{C}$ results in the formation of a white precipitate within 30 minutes, and a color change from dark orange to a bright redange. The ${ }^{1} \mathrm{H}$ spectrum of the crude product (the white precipitate is only slightly soluble in aromatic and aliphatic hydrocarbon solvents) contains several multiplets in the aliphatic region and the ${ }^{31} \mathrm{P}\left\{{ }^{1} \mathrm{H}\right\}$ spectrum contains several resonances. Whitesides et al have reported similar results upon heating 2 in neat alkane solvents, stating that such experiments give "poorly characterized white precipitates...(that are) virtually insoluble in hydrocarbon solvents",7c presumably products of reaction of the (dcype)Pt intermediate with the hydrocarbon solvents or itself. We also found that heating a sample of $\mathbf{2}$ in -yclohexane, in the absence of 1 , gives a bright red-orange solution with a white precipitate; the ${ }^{1} \mathrm{H}$ and ${ }^{31} \mathrm{P}\left\{{ }^{1} \mathrm{H}\right\}$ spectra of this mixture are very similar to the spectra obtained from the sample containing both 1 and 2 , above. Apparently, the kinetic barrier of this interaction (i.e., the strength of the interaction ${ }^{13}$ ) is relatively small, resulting in preferential reaction of the (dcype)Pt intermediate with the hydrocarbon solvent.

Heating a cyclohexane-d $d_{12}$ solution of 1 and 2 for 55 hours at a lower temperature, $45^{\circ} \mathrm{C}$, yields a dark brown solution with no precipitate. The hydride region of the ${ }^{1} \mathrm{H}$ spectrum of this sample indicates the presence of a hydride ligand, coupled to cis and 
trans phosphorus nuclei, to ${ }^{195} \mathrm{Pt}$, and also to ${ }^{171} \mathrm{Yb}$. The ${ }^{31} \mathrm{P}\left\{{ }^{1} \mathrm{H}\right\}$ spectrum indicates the presence of two inequivalent phosphorus nuclei, coupled to ${ }^{195} \mathrm{Pt}\left(\mathrm{J}_{\mathrm{PtP}}=2579,1534\right.$ $\mathrm{Hz})$. In addition, one of the resonances also shows coupling to ${ }^{171} \mathrm{Yb}\left(\mathrm{J}_{\mathrm{YbP}}=154 \mathrm{~Hz}\right)$. These spectral data are consistent with (dcype) $\mathrm{Pt}(\mu-\mathrm{H})\left(\mu-\mathrm{CH}_{2} \mathrm{C}_{4} \mathrm{Me}_{4}\right) \mathrm{YbCp}^{*}(3)$, a compound resulting from activation of a $\mathrm{Cp}^{*}$ ring of 1 by the (dcype)Pt intermediate (eq. 4). The ${ }^{1} \mathrm{H}$ spectrum of 3 contains a pseudo-triplet with ${ }^{195} \mathrm{Pt}$ satellites at $\delta 2.85 \mathrm{ppm}$, consistent with a Pt-bound methylene group. In addition, several sharp singlets of roughly equal intensity are present in the aliphatic region of the spectrum (due to overlapping cyclohexyl resonances, this region could not be integrated), consistent with inequivalent $\mathrm{Cp}^{*}$ methyl groups, as would be present in 3 .

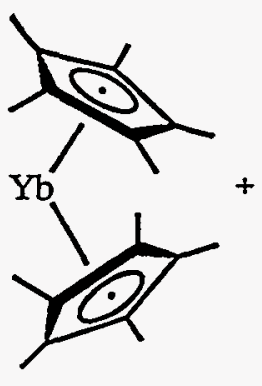

1

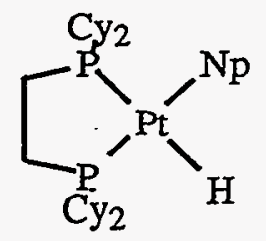

2

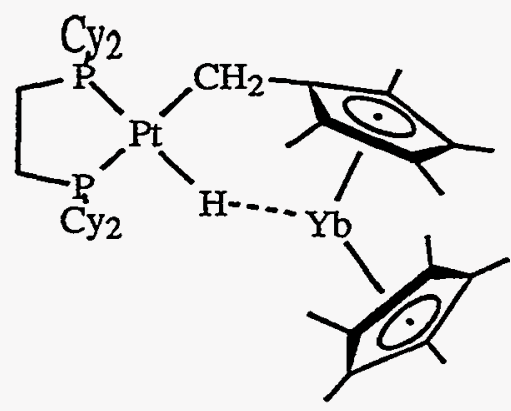

3

Apparently, the lower reaction temperature favors this reaction, over activation of the hydrocarbon solvent, as was observed at $70^{\circ} \mathrm{C}$.

When the synthesis of $\mathbf{3}$ is attempted using pentane as the solvent, production of an insoluble white precipitate occurs (see above), with little conversion to the desired product, 3; apparently, the (dcype)Pt intermediate activates the $\mathrm{C}-\mathrm{H}$ bonds of pentane more easily than those of cyclohexane. $7 c, 14$ In contrast to the reactivity of (dcype)Pt towards 1 at $45^{\circ} \mathrm{C}$, when $\mathrm{Cp}_{2}{ }_{2} \mathrm{Sn}$ and $\mathrm{Cp}_{2}{ }_{2} \mathrm{Cr}$ are reacted with 2 in cyclohexane (46h/45 ${ }^{\circ} \mathrm{C}$ ), production of a white precipitate occurs (with many weak resonances in the ${ }^{31} \mathrm{P}\left\{{ }^{1} \mathrm{H}\right\}$ spectrum); the $\mathrm{Sn}$ and $\mathrm{Cr}$ starting materials remain in solution, unperturbed ( $\left.{ }^{1} \mathrm{H} N M R\right)$. 
Apparently, the $\mathrm{Cp}^{*}$ methyl $\mathrm{C}-\mathrm{H}$ bonds of 1 are more easily activated by 2 than the analogous bonds of $\mathrm{Cp}_{2}{ }_{2} \mathrm{Sn}$ or $\mathrm{Cp}_{2}{ }_{2} \mathrm{Cr}$.

Using the $J_{\mathrm{PtH}}$ and $J_{\mathrm{YbH}}$ values measured from the ${ }^{{ }^{1} \mathrm{H}}$ spectrum of 3 , the ${ }^{1} \mathrm{H} /{ }^{195} \mathrm{Pt}$ and ${ }^{1} \mathrm{H} /{ }^{171} \mathrm{Yb}$ HMQC spectra were obtained, and are shown in Figs. 4 and 5 , respectively.

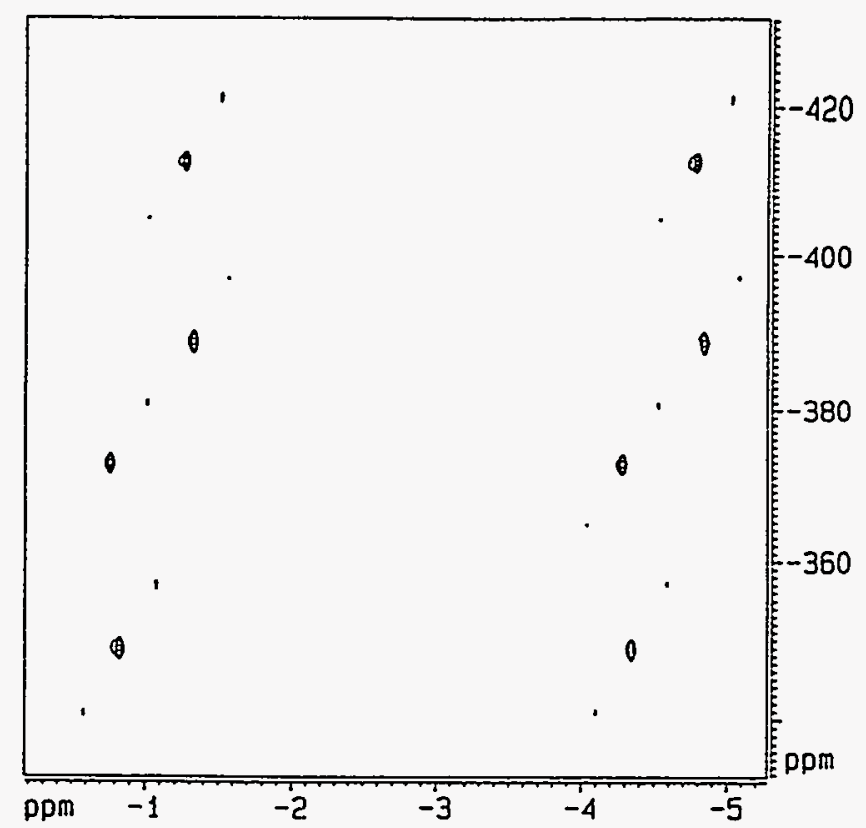

Figure 4. ${ }^{1} \mathrm{H} / 195 \mathrm{Pt}$ spectrum of 3 , hydride region $\left(25^{\circ} \mathrm{C}, 300 \mathrm{MHz}\right.$, cyclohexane- $\left.\mathrm{d}_{12}\right)$.

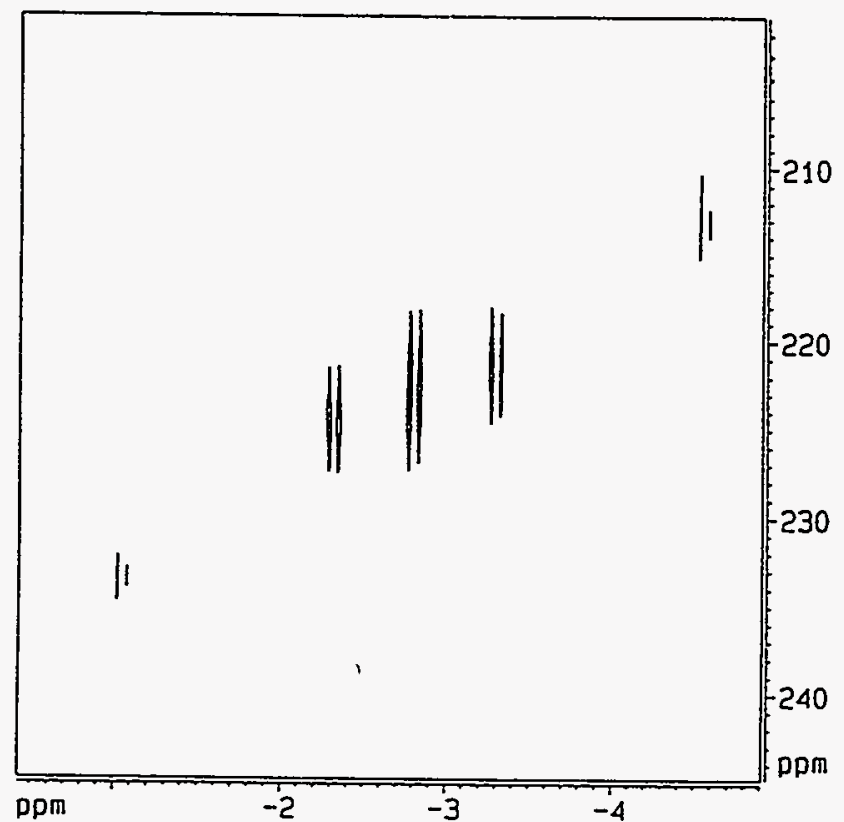

Figure 5. ${ }^{1} \mathrm{H} /{ }^{171} \mathrm{Yb}$ spectrum of 3 , hydride region $\left(25^{\circ} \mathrm{C}, 300 \mathrm{MHz}\right.$, cyclohexane$\mathrm{d}_{12}$ ). 


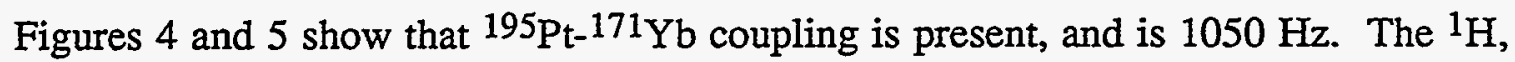
${ }^{31} \mathrm{P},{ }^{195} \mathrm{Pt}$, and ${ }^{171} \mathrm{Yb}$ NMR spectral values for 3 are given in Table 1, along with the spectral data for 2. Comparison of the spectral values of 3 to the analogous values found for (dcype)Pt( $(\mu-\mathrm{H})_{2} \mathrm{YbCp}^{*}{ }_{2}$ and (dippe)Pt $(\mu-\mathrm{Me})(\mu-\mathrm{H}) \mathrm{YbCp}_{2}{ }_{2}$ (see Chapter 1, Tables 1 and 7 , respectively), shows that the $\mathrm{Yb}$-hydride interaction in $\mathbf{3}$ is roughly equivalent (or perhaps slightly stronger) to that found in (dcype) $\mathrm{Pt}(\mu-\mathrm{H})_{2} \mathrm{YbCp}^{*}$, and stronger than the Yb-hydride interaction in (dippe) $\mathrm{Pt}(\mu-\mathrm{Me})(\mu-\mathrm{H}) \mathrm{YbCp}^{*}{ }_{2}$. The perturbations in the ${ }^{2} \mathrm{~J}_{\mathrm{PH}}$, ${ }^{1} \mathrm{~J}_{\mathrm{PtH}},{ }^{1} \mathrm{~J}_{\mathrm{PtP}}$ ( $\mathrm{P}$ trans to the hydride) values are larger for $\mathbf{3}$ (relative to the analogous values for 2) than the analogous perturbations that occur for (dcype) $\mathrm{PtH}_{2}$ upon formation of the interaction with 1 . The JYbP value for $3(154 \mathrm{~Hz})$ is larger than the analogous value for (dcype) $\mathrm{Pt}(\mu-\mathrm{H})_{2} \mathrm{YbCp}^{*}{ }_{2}(93 \mathrm{~Hz})$, while the $\mathrm{J}_{\mathrm{YbH}}$ value for $3(147 \mathrm{~Hz})$ is smaller ( $\mathrm{J}_{\mathrm{YbH}}$ for (dcype)Pt( $(\mu-\mathrm{H})_{2} \mathrm{YbCp}^{*}{ }^{2}, 180 \mathrm{~Hz}$ ). The $\mathrm{J}_{\mathrm{YbPt}}$ value of 3 is very similar to the analogous value that was found for (dippe)Pt $(\mu-\mathrm{Me})(\mu-\mathrm{H}) \mathrm{YbCp}^{*} 2,960 \mathrm{~Hz}$.

Table 1. $1 \mathrm{H}, 31 \mathrm{P}, 195 \mathrm{Pt}$, and $171 \mathrm{Yb}$ NMR Data for 2 and 3 (cyclohexane-d $12,25^{\circ} \mathrm{C}$ ).

$\begin{array}{lcc} & \underline{\mathbf{2}} & \mathbf{3} \\ \delta(\mathrm{Pt}-\mathrm{H}), \mathrm{ppm} & -0.56 & -2.80 \\ 2 \mathrm{~J}_{\mathrm{PH}}(\mathrm{trans}, \mathrm{cis}), \mathrm{Hz} & 199,19 & 148,18 \\ 1 \mathrm{~J}_{\mathrm{PtH}}, \mathrm{Hz} & +1197 & +1055 \\ \delta(\mathrm{P}), \mathrm{ppm}^{\mathrm{a}} & 75.7,62.2 & 65.5,58.7 \\ { }^{1} \mathrm{~J}_{\mathrm{PtP}}, \mathrm{Hz} & +1641,+1768 & +1534,+2579 \\ { }^{1} \mathrm{~J}_{\mathrm{YbH}}^{\mathrm{a}}, \mathrm{Hz} & --- & +147 \\ \mathrm{~J}_{\mathrm{YbP}}, \mathrm{Hz} & --- & +154 \\ \delta(\mathrm{Pt}), \mathrm{ppm} & -394 & -382 \\ \delta(\mathrm{Yb}), \mathrm{ppm} & --- & +223 \\ \mathrm{~J}_{\mathrm{YbPt}}, \mathrm{Hz} & --- & +1050\end{array}$

aListed as $\mathrm{P}$ trans to neopentyl, $\mathrm{P}$ trans to hydride, respectively. 
Based on the above results, it appears that formation of a $\mathrm{P}_{2} \mathrm{Pt}-\mathrm{YbCp}{ }_{2}$ complex will not be trivial, given the apparent weakness of the $\mathrm{Pt}-\mathrm{Yb}$ interaction and the reactive nature of the bent $\mathrm{P}_{2} \mathrm{Pt}$ fragment.

Interactions with Small Molecules (Xe, $\mathrm{H}_{2}, \mathrm{CH}_{4}, \mathrm{CO}$, benzene, toluene). As mentioned in the Introduction, indirect evidence for weak interactions between 1 and various small molecules ( $\mathrm{Xe}, \mathrm{H}_{2}, \mathrm{CH}_{4}, \mathrm{CO}$, benzene, toluene) has been reported. ${ }^{15}$ Several experiments have been done to investigate this possibility in more detail. When a $\mathrm{C}_{6} \mathrm{D}_{6}$ sample of 1 is exposed to a $\mathrm{CH}_{4} / \mathrm{D}_{2}$ mixture (ca. $0.5 \mathrm{~atm}$ of each gas), no H/D isotopic scrambling between the gases is observed ( ${ }^{1} \mathrm{H} N M R$ ), even after heating the sample to $80^{\circ} \mathrm{C}$ for 250 hours. It is known that exposing a solution of 1 to $\checkmark \mathrm{atm} . \mathrm{D}_{2}$ for several weeks causes no color change, and no deuterium incorporation into the methyl groups of the $\mathrm{Cp}^{*}$ rings. ${ }^{15}$

Several experiments have been done in which the perturbations of the ${ }^{1} \mathrm{H}$ and ${ }^{13} \mathrm{C}$ chemical shifts of 1 were monitered as various gases were placed over a solution of 1 in cyclohexane- $\mathrm{d}_{12}$ ( $1 \mathrm{~atm}$. pressure; gases used: $\mathrm{Xe}, \mathrm{N}_{2}, \mathrm{H}_{2}, \mathrm{CH}_{4}$, and $\mathrm{CF}_{3} \mathrm{H}$; cyclohexane-d $\mathrm{d}_{12}$ was used as it is expected to form the weakest interaction with 1 , of all the common NMR solvents). It was hoped that the exchange-averaged values of the ${ }^{1} \mathrm{H}$ and ${ }^{13} \mathrm{C}$ resonances of 1 would be perturbed as a result of a weak interaction with the gas present over (and dissolved in) the solution. Clearly, the success of these experiments depends on the $\mathrm{Yb}$-gas interaction being significantly stronger than the $\mathrm{Yb}$-cyclohexane interaction. The basicity of neutral gas molecules is related to the extent to which they can 1 polarized. 15 As the polarizability of a species is inversely proportional to its first :zation potential, ${ }^{16}$ a qualitative ordering of the following neutral gas molecules can be tained: ${ }^{17} \mathrm{Xe}>\mathrm{H}_{2}>\mathrm{CO}>\mathrm{CH}_{4}>\mathrm{N}_{2}$.

Placing $1 \mathrm{~atm}$. of Xe gas over a $25^{\circ} \mathrm{C}$ cyclohexane-d $\mathrm{d}_{12}$ solution of $1 \mathrm{did}$ not perturb the ${ }^{1} \mathrm{H}\left(\mathrm{Cp}^{*}\right.$ methyl protons, $\left.1.871 \mathrm{ppm}\right)$ and ${ }^{13} \mathrm{C}\left(\mathrm{Cp}^{*}\right.$ ring (114.32 $\left.\mathrm{ppm}\right)$, methyl carbon $(10.60 \mathrm{ppm})$ ) chemical shifts arising from 1 , relative to the values for the sample 
under $\mathrm{N}_{2}\left({ }^{1} \mathrm{H}\right.$ values measured to $0.001 \mathrm{ppm},{ }^{13} \mathrm{C}$ values to $\left.0.01 \mathrm{ppm}\right)$ Given this, it is not very surprising that exposure of the sample to $\mathrm{H}_{2}, \mathrm{CH}_{4}$, and $\mathrm{CF}_{3} \mathrm{H}$ also does not result in perturbed NMR values. While there may be an interaction present between 1 and these gases, the lack of perturbation in the NMR values indicates that the $\mathrm{Cp}_{2}{ }_{2} \mathrm{Yb}+\mathrm{L}$ $=\mathrm{Cp}^{*}{ }_{2} \mathrm{YbL}_{\mathrm{n}}$ equilibrium lies far to the left, at $25^{\circ} \mathrm{C}$ (this also assumes that the slowexchange $\mathrm{Cp}^{*}{ }_{2} \mathrm{YbL}_{\mathrm{n}}$ complexes $\left(\mathrm{L}=\right.$ the various gases) have significantly different ${ }^{1} \mathrm{H}$ and ${ }^{13} \mathrm{C}$ chemical shift values from those of 1 ). The solubility of the gases in cyclohexane may also be a factor in these results; however, resonances for $\mathrm{CH}_{4}, \mathrm{H}_{2}$, and $\mathrm{CF}_{3} \mathrm{H}$ were visible in the relevant ${ }^{1} \mathrm{H}$ spectra, indicating at least slight solubility of these gases in cyclohexane. As mentioned in the Introduction, a hydrocarbon solution of 1 under $7 \mathrm{~atm}$. of ethylene results in the production of polyethylene. ${ }^{15}$ It has also been found that a cyclohexane- $d_{12}$ solution of 1 produces polyethylene within minutes, when only $1 \mathrm{~atm}$. of ethylene is placed over the solution.

Another possible method of showing that an interaction exists between 1 and $\mathrm{H}_{2}$ is by use of the " $\mathrm{T}_{1}$ criterion". 18 This approach is based on the assumption that the spinlattice relaxation time, $T_{1}$, of the coordinated protons in an $\mathrm{ML}_{n}\left(\mathrm{H}_{2}\right)$ complex is dominated by a dipole-dipole interaction between the $\mathrm{H}_{2} /(\mathrm{H})_{2}$ protons; the short $\mathrm{H}-\mathrm{H}$ distance in an $\eta_{2}-H_{2}$ complex will then give rise to short $T_{1}$ times, relative to the $T_{1}$ times for "classical" hydride ligands. This method for distinguishing between classical hydride complexes and $\eta_{2}-\mathrm{H}_{2}$ complexes has been called into question, as the $\mathrm{H}-\mathrm{H}$ dipolar term may, in certain cases, not be the dominant relaxation mechanism. ${ }^{19}$ It is possible, however, that the $\mathrm{T}_{1}\left(\mathrm{H}_{2}\right)$ value of $1 \mathrm{~atm}$. of $\mathrm{H}_{2}$ over a cyclohexane- $\mathrm{d}_{12}$ sample of 1 will be different than the $\mathrm{T}_{1}\left(\mathrm{H}_{2}\right)$ value for an analogous sample that does not contain 1 , as a result of a weak interaction of $\mathrm{H}_{2}$ with the $\mathrm{Yb}$ center of 1 . However, the $\mathrm{T}_{1}$ values of the two samples are identical, $220 \mathrm{~ms}$; the ${ }^{1} \mathrm{H}$ chemical shifts of $\mathrm{H}_{2}$ are also identical for the two samples, $4.54 \mathrm{ppm}$. The excess $\mathrm{H}_{2}$ that is present in the system may result in (averaged) values that are largely unperturbed, or the interaction of 1 with the 
cyclohexane solvent (present in large excess) may be stronger than or competitive with the interaction of 1 with $\mathrm{H}_{2}$.

It has been reported that exposure of a pentane solution of 1 to 2-3 atm. CO results in a color change to dark green; an IR spectrum of this solution shows a $v_{C O}$ band at $2117 \mathrm{~cm}^{-1} .15$ While $\mathrm{CO}$ is insufficiently soluble in hydrocarbon solvents to measure $v_{\mathrm{CO}}$ for free $\mathrm{CO}$ (indicating that the $\mathrm{Yb}-\mathrm{CO}$ interaction helps to "solubilize" the gas), comparison to $v_{\mathrm{CO}}$ values for $\mathrm{CO}$ in a $\mathrm{CH}_{4}$ matrix $\left(2137 \mathrm{~cm}^{-1}\right)^{20 \mathrm{a}}$ and Nujol mull (2130 $\mathrm{cm}-1)^{20 \mathrm{~b}}$ shows that the $\mathrm{Yb}-\mathrm{CO}$ interaction results in a decrease of $v_{\mathrm{CO}}$ by $c a .15 \mathrm{~cm}^{-1}$. To further investigate the details of this interaction, $1 \mathrm{~atm}$. of ${ }^{13} \mathrm{CO}$ was placed over a methylcyclohexane- $d_{14}$ solution of 1 , producing an immediate color change from orange to dark brown. While the perturbations of the ${ }^{1} \mathrm{H}$ and ${ }^{13} \mathrm{C}$ chemical shifts of 1 (relative to a sample under $\mathrm{N}_{2}$ ) are negligible, the ${ }^{13} \mathrm{CO}$ chemical shift is significantly perturbed. In the presence of 1 , this resonance is observed at $203 \mathrm{ppm}$ with a half height width of 425 $\mathrm{Hz}$; the analogous $\delta(\mathrm{CO})$ value, in the absence of 1 , is $185.0 \mathrm{ppm}\left(\mathrm{w}_{1 / 2}=4 \mathrm{~Hz}\right)$. Clearly, the $\mathrm{CO}$ is interacting with 1 ; the broadness of the $\mathrm{CO}$ resonance indicates that a fluxional process is occurring, with a rate that is on the order of the NMR timescale, at 25 ${ }^{\circ} \mathrm{C}$.

To further investigate the nature of the $\mathrm{Yb}-\mathrm{CO}$ interaction, the sample was cooled in the NMR probe. The only change in the ${ }^{1} \mathrm{H}$ and ${ }^{13} \mathrm{C}\left\{{ }^{1} \mathrm{H}\right\}$ spectra, upon cooling to -60 ${ }^{\circ} \mathrm{C}\left(500 \mathrm{MHz}{ }^{1} \mathrm{H}\right.$ frequency), is a downfield shift and broadening of the $\mathrm{CO}$ resonance (at $-30^{\circ} \mathrm{C}, \delta(\mathrm{CO})=215 \mathrm{ppm}, \mathrm{w}_{1 / 2}=2200 \mathrm{~Hz}$ ). At ca. $-70^{\circ} \mathrm{C}$, the $\mathrm{Cp}^{*}$ resonance in the ${ }^{1} \mathrm{H}$ spectrum begins to shift upfield and broaden considerably (Fig. 6a; at $-73^{\circ} \mathrm{C}, \delta\left(\mathrm{Cp}^{*}\right)=$ $1.64 \mathrm{ppm}, \mathrm{w}_{1 / 2}=50 \mathrm{~Hz}$ ). Unfortunately, this resonance shifts into the resonances that arise from the residual $\mathrm{C}_{7} \mathrm{D}_{13} \mathrm{H}$ that is present in the " $\mathrm{C}_{7} \mathrm{D}_{14}$ " solvent. At $-88^{\circ} \mathrm{C}$, just before this occurs, two broad but distinct $\mathrm{Cp}^{*}$ resonances are present in the ${ }^{1} \mathrm{H}$ spectrum, at 1.68 and $1.75 \mathrm{ppm}$ (Fig. 6b). Below $-88^{\circ} \mathrm{C}$, the ${ }^{1} \mathrm{H}$ spectra are relatively uninformative, due to the resonances arising from $\mathrm{C}_{7} \mathrm{D}_{13} \mathrm{H}$; however, the significant 
upfield shift of the $\mathrm{Cp}^{*}$ resonance can be clearly seen in the ${ }^{1} \mathrm{H}$ spectrum taken at $-97^{\circ} \mathrm{C}$ (Fig. 6c).

Over this same temperature range $\left(-70^{\circ} \mathrm{C}\right.$ to $\left.-88^{\circ} \mathrm{C}\right)$, the $\mathrm{CO}$ resonance in the ${ }^{13} \mathrm{C}\left\{{ }^{1} \mathrm{H}\right\}$ spectra also decoalesces into two resonances: at $-73^{\circ} \mathrm{C}, \delta(\mathrm{CO})=225 \mathrm{ppm}$, $\mathrm{w}_{1 / 2}=650 \mathrm{~Hz}$; at $-88{ }^{\circ} \mathrm{C}, \delta(\mathrm{CO})=239 \mathrm{ppm}$ and $198 \mathrm{ppm}$, both with $\mathrm{w}_{1 / 2}=580 \mathrm{~Hz}$ (Fig. 6d). As the sample is cooled further, the lower-field $\mathrm{CO}$ resonance broadens considerably, while the higher-field $\mathrm{CO}$ resonance sharpens; in addition, the $\mathrm{Cp}^{*}$ ring methyl resonance decoalesces into two resonances (the ring carbon resonance may also decoalesce, however the $\mathrm{S} / \mathrm{N}$ is insufficient to state this unequivocally, Fig. 6e). The result is that, at $-107^{\circ} \mathrm{C}$ (Fig. 6e), the ${ }^{13} \mathrm{C}\left\{{ }^{1} \mathrm{H}\right\}$ spectrum contains two sets of resonances for the $\mathrm{CO}$ and $\mathrm{Cp}^{*}$ methyl groups: $\delta 243 \mathrm{ppm}\left(\mathrm{w}_{1 / 2}=2800 \mathrm{~Hz}\right), \delta 199 \mathrm{ppm}\left(\mathrm{w}_{1 / 2}=\right.$ $100 \mathrm{~Hz}) ; \delta 11.2 \mathrm{ppm}\left(\mathrm{w}_{1 / 2}=90 \mathrm{~Hz}\right), \delta 9.0 \mathrm{ppm}\left(\mathrm{w}_{1 / 2}=50 \mathrm{~Hz}\right)$; and also a $\mathrm{Cp}^{*}$ ring resonance at $\delta 113 \mathrm{ppm}\left(\mathrm{w}_{1 / 2}=50 \mathrm{~Hz}\right)$. These changes in the ${ }^{1} \mathrm{H}$ and ${ }^{13} \mathrm{C}\left\{{ }^{1} \mathrm{H}\right\}$ spectra are fully reversible, and do not occur for a sample of 1 under $1 \mathrm{~atm} . \mathrm{N}_{2}$.

These changes in the ${ }^{1} \mathrm{H}$ and ${ }^{13} \mathrm{C}\left\{{ }^{1} \mathrm{H}\right\}$ spectra as a function of temperature show that 1 is interacting with the ${ }^{13} \mathrm{CO}$, and that at least one (and perhaps several) fluxional process(es) is slowed as the temperature is lowered. The ${ }^{1} \mathrm{H}$ data is relatively uninformative except to indicate that a significant upfield shift of the $\mathrm{Cp}^{*}$ resonance occurs, and that two inequivalent $\mathrm{CP}^{*}$ resonances result, from the interaction. The ${ }^{13} \mathrm{C}$ data is more informative: the decoalescence of the fluxional-averaged $\mathrm{CO}$ resonance into two resonances, neither at the chemical shift of "free" CO (185 ppm at $180 \mathrm{~K}$, in $\left.\mathrm{C}_{7} \mathrm{D}_{14}\right)$, is consistent with either: 1) the formation of two different adducts of 1 with $\mathrm{CO}$, or 2) the formation of one adduct, with magnetically inequivalent ${ }^{13} \mathrm{C}$ nuclei. The ${ }^{1} \mathrm{H}$ data (two $\mathrm{Cp}^{*}$ resonances at $-88^{\circ} \mathrm{C}$ ) is also consistent with either of these possibilities, as is the decoalescence of the $\mathrm{Cp}^{*}$ methyl carbon resonance. 


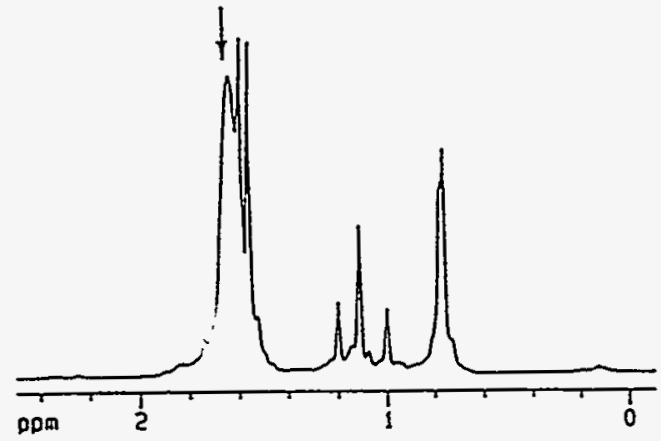

(a)

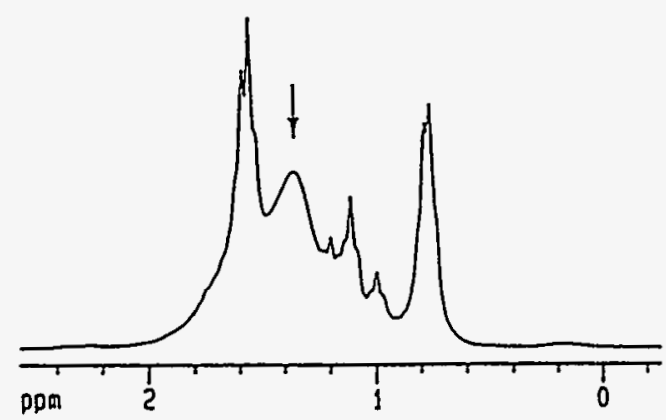

(c)

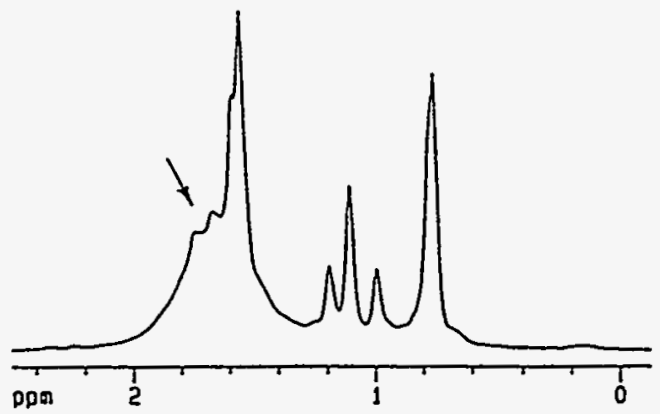

(b)

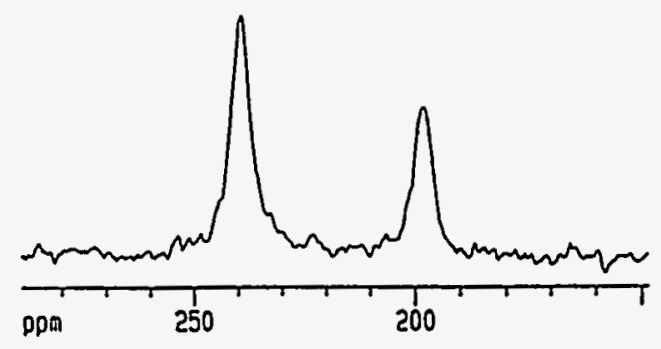

(d)

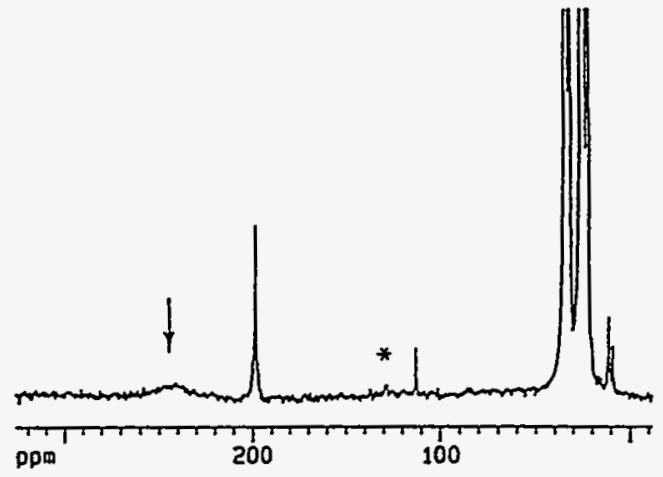

(e)

Figure 6. ${ }^{1} \mathrm{H}$ and ${ }^{13} \mathrm{C}\left\{{ }^{1} \mathrm{H}\right\}$ NMR spectra of a sample of 1 in $\mathrm{C}_{7} \mathrm{D}_{14}$, under $1 \mathrm{~atm}$. ${ }^{13} \mathrm{CO}$; a) ${ }^{1} \mathrm{H}$ spectrum at $-73^{\circ} \mathrm{C}$, the $\mathrm{Cp}^{*}$ resonance is marked with an arrow, the remainder of the resonances arise from residual $\mathrm{C}_{7} \mathrm{D}_{13} \mathrm{H}$ in the solvent; b) ${ }^{1} \mathrm{H}$ spectrum at $-88^{\circ} \mathrm{C}$, showing two distinct $\mathrm{Cp}^{*}$ resonances (marked with an arrow); c) ${ }^{1} \mathrm{H}$ spectrum at $-97^{\circ} \mathrm{C}$, showing the large upfield shift, and broadness, of the $\mathrm{Cp}^{*}$ resonance (marked with an arrow); d) ${ }^{13} \mathrm{C}\left({ }^{1} \mathrm{H}\right\}$ spectrum at $-88^{\circ} \mathrm{C}$, showing the two resonances that arise from ${ }^{13} \mathrm{CO}$, both with $\mathrm{w}_{1 / 2}$ of $\mathrm{ca} .580 \mathrm{~Hz}$; e ${ }^{13} \mathrm{C}\left\{{ }^{1} \mathrm{H}\right\}$ spectrum at $-107^{\circ} \mathrm{C}$, showing the increased broadness of the lower-field ${ }^{13} \mathrm{CO}$ resonance (marked with an arrow), and also the two separate $\mathrm{Cp}^{*}$ methyl resonances (at $c a .10 \mathrm{ppm}$ ). The possible second $\mathrm{Cp}^{*}$ ring resonance (see text) is marked with an asterisk (the FID was treated with an LB of 30 $\mathrm{Hz})$. 
The formation of two discrete adducts of $\mathbf{1}$ with $\mathrm{CO}$ is considered to be the more likely possibility. The broadening of the lower-field $\mathrm{CO}$ resonance at very low temperature apparently results from slowing of a second (or additional) fluxional process. The lack of broadening of the higher-field $\mathrm{CO}$ resonance indicates that this fluxional process does not affect the adduct that gives rise to this resonance. In addition, the results of high pressure $\mathbb{R}$ studies on $\mathbf{1}$ with $\mathrm{CO}$ are consistent with the formation of two different adducts (interestingly, the $\mathrm{K}_{\mathrm{eq}}$ value for the two adducts has been found to be pressure-dependent). ${ }^{21}$ The structures of the adducts cannot be determined from the NMR (or IR) data; many structures (including mono- and bis-CO adducts of 1; bi- and poly-metallic adducts containing $\mu$-CO and/or isocarbonyl interactions; etc) are possible. Unfortunately, ${ }^{171} \mathrm{Yb}-{ }^{13} \mathrm{C}$ coupling involving the $\mathrm{CO}$ resonances is not resolved in any of the ${ }^{13} \mathrm{C}\left({ }^{1} \mathrm{H}\right\}$ NMR spectra, likely a result of the broadness of the resonances.

The downfield shifts of the CO resonances that result from interaction with 1 are consistent with the decreased $\mathrm{CO}$ stretching frequency that is observed in the IR spectrum of a sample of $1+\mathrm{CO}$ (above): there appears to be a general trend for an upfield shift in $\delta(\mathrm{CO})$ for complexes in which $v_{\mathrm{CO}}$ is increased relative to $v_{\mathrm{CO}}$ (free), and vice versa.22,23 Recently, the results of high pressure IR and NMR experiments on the $\mathrm{Cp}_{2}{ }_{2} \mathrm{Ca} / \mathrm{CO}$ system have been reported. ${ }^{23}$ For this system, $v_{\mathrm{CO}}$ is increased by $15 \mathrm{~cm}^{-1}$ and $\delta(\mathrm{CO})$ is shifted slightly upfield, to $180.4 \mathrm{ppm}$. This contrasts with the lowered $v_{\mathrm{CO}}$ stretch and downfield shifts of $\delta(\mathrm{CO})$ for the $1+\mathrm{CO}$ system, above. Also, no evidence for two different $\mathrm{Cp}_{2}{ }_{2} \mathrm{Ca} / \mathrm{CO}$ adducts was observed (only one ${ }^{13} \mathrm{C}$ signal was observed for the $\mathrm{Cp}^{*}$ ring, methyl, and $\mathrm{CO}$ carbon nuclei, from $+30^{\circ} \mathrm{C}$ to $-70^{\circ} \mathrm{C}$ ), in contrast to the above results on the $1+\mathrm{CO}$ system.

The $\mathrm{X}-\mathrm{H}$ bonds of silanes and stannanes are more nucleophilic than the $\mathrm{C}-\mathrm{H}$ bonds of alkanes, ${ }^{24}$ a result of the larger electronegativity difference between the $\mathrm{X}$ and $\mathrm{H}$ nuclei of the former complexes. As a result, $\eta_{2}-\mathrm{X}-\mathrm{H}$ complexes of silanes and stannanes are isolable, in contrast to the hydrocarbon analogues. ${ }^{24,25}$ Consequently, the interactions of 
1 with silanes and stannanes are expected to be stronger than the analogous interactions with alkanes. The NMR values for samples of 1 (in slight excess) with (Mes $2 \mathrm{SiH})_{2}$ (4) and $\mathrm{Me}_{3} \mathrm{SnH}$ (5) are given in Table 2. Addition of 0.5 eq. of the silane 4 to a toluene-d8 solution of 1 results in no color change, and no perturbations in any of the NMR values from the analogous values for free 1 and 4 (Table 2). Cooling this sample to $-90^{\circ} \mathrm{C}$ results in no significant changes in the NMR values, and a sharp, exchange-averaged $\mathrm{Cp}^{*}$ resonance is still present. Similar behavior was observed for the silane $\left(\mathrm{SiMe}_{3}\right)_{3} \mathrm{SiSiMe}_{2} \mathrm{H}$. Addition of 0.5 eq. of the stannane 5 to a toluene-d8 solution of 1 results in a color change to dark red. Minor perturbations in the $\mathrm{Sn}-\underline{\mathrm{H}}$ chemical shift and coupling constant values, relative to the analogous values for free 5 , occur (Table 2); however intermolecular exchange is fast at $-95^{\circ} \mathrm{C}$ on the NMR timescale (one averaged $\mathrm{Cp}^{*}$ resonance). Apparently, interaction with 1 perturbs the $\mathrm{X}-\mathrm{H}$ bond of the stannane 5 more than those of the silanes; however, the barrier to intermolecular exchange (i.e., the strength of the interaction ${ }^{13}$ ) is still too small to allow a detailed study of this system.

Table 2. 1 H NMR Data for Samples of 1 with $\left(\mathrm{Mes}_{2} \mathrm{SiH}_{2}\right.$ (4) and $\mathrm{Me}_{3} \mathrm{SnH}(5)$ at 25 $\left.{ }^{\circ} \mathrm{C}\right)$.

\begin{tabular}{|c|c|c|c|c|}
\hline & $\underline{4}^{a}$ & $1+4^{b}$ & 5 & $1+5^{b}$ \\
\hline$\delta(\mathrm{X}-\underline{\mathrm{H}}), \mathrm{ppm}$ & 5.88 & 5.88 & 4.73 & 4.66 \\
\hline${ }^{1} J_{X H}, H^{c}$ & 185 & 185 & 1739 & 1714 \\
\hline$\delta\left(\underline{\mathrm{CH}}_{3}\right), \mathrm{ppm}$ & $2.37,2.06$ & $2.37,2.06$ & 0.06 & 0.06 \\
\hline$\delta\left(\mathrm{Cp}^{*}\right), \mathrm{ppm}$ & $-\cdots$ & 1.93 & -- & 1.94 \\
\hline$\delta\left(\mathrm{C}_{6} \mathrm{H}_{2}\right), \mathrm{ppm}$ & 6.66 & 6.66 & -- & -- \\
\hline
\end{tabular}

aThe values for the silane samples were measured in $\mathrm{C}_{6} \mathrm{D}_{6}$; those for the stannane samples were measured in toluene-d8.

bThese samples contain a slight excess of 1 .

$c \mathrm{X}={ }^{29} \mathrm{Si}$ or ${ }^{119} \mathrm{Sn}$ (the coupling constant to ${ }^{117} \mathrm{Sn}$ can be easily calculated from the ${ }^{119} \mathrm{Sn}$ value).

As mentioned in the Introduction, indirect evidence for weak interactions of $\mathbf{1}$ with benzene and toluene has also been reported. 15 To further investigate these interactions, a 
sample of 1 in cyclohexane- $\mathrm{d}_{12}$ was reported. Small amounts of $\mathrm{C}_{6} \mathrm{H}_{6}$. were then added (in increments of $1,3,5$, and 10 total equivalents), and the ${ }^{1} \mathrm{H}$ chemical shifts (of the $\mathrm{C}_{6} \mathrm{H}_{6}$ and $\mathrm{Cp}^{*}$ ring protons) and half height widths of the resonances were monitered (any exchange broadening would indicate the presence of a weak interaction of 1 with the $\mathrm{C}_{6} \mathrm{H}_{6}$ ). The half height widths were compared to the half height width of the residual $\mathrm{C}_{6} \mathrm{D}_{11} \mathrm{H}$ in the cyclohexane- $\mathrm{d}_{12}$ solvent, to correct for variable shimming effects. It was found that the $\mathrm{Cp}^{*}$ and $\mathrm{C}_{6} \mathrm{H}_{6}{ }^{1} \mathrm{H}$ chemical shifts and resonance half heights did not change over the course of the $\mathrm{C}_{6} \mathrm{H}_{6}$ addition, indicating that if an interaction does exist between 1 and benzene, it does not perturb the chemical shifts and half height widths. For comparison, the 'reverse' experiment was also done: the ${ }^{1} \mathrm{H}$ spectrum of a cyclohexane- $\mathrm{d}_{12}$ sample with 1 eq. of $\mathrm{C}_{6} \mathrm{H}_{6}$ was measured, followed by addition of 1 eq. of 1 , then incremental addition of more $\mathrm{C}_{6} \mathrm{H}_{6}$ (in identical amounts to the first experiment). Again, no evidence of an interaction was observed (see the Experimental section for details). Apparently, the $\mathrm{Yb}$-benzene interaction is too weak to perturb the ${ }^{1} \mathrm{H}$ NMR values of 1 and benzene. While the interaction of 1 with cyclohexane-d $d_{12}$ is expected to be much weaker than the interaction with $\mathrm{C}_{6} \mathrm{H}_{6}$, the former is present in large excess and consequently, may be competing with benzene for the $\mathrm{Yb}$ center.

Crystallization of 1 from toluene or pentane gives green crystals which turn light brown upon exposure to vacuum; this has been rationalized as resulting from loss of occluded solvent that has been trapped in the crystal lattice. ${ }^{15}$ The solid-state structure of 1 in crystals isolated from pentane has been determined; these crystals contain two molecules of 1 in the asymmetric unit, with intermolecular contacts between the $\mathrm{Yb}$ centers and a $\mathrm{Cp}^{*}$ methyl group on a neighboring molecule resulting in a "linear coordination polymer" (Fig. 7a). ${ }^{15}$ This contrasts with the structures of $\mathrm{Cp}_{2}{ }_{2} \mathrm{M}$ complexes ( $M=S m ; E u ; Y b$, where the crystals are obtained by sublimation) in which such intermolecular interactions result in "coordination dimers" (Fig. 7b). 15 


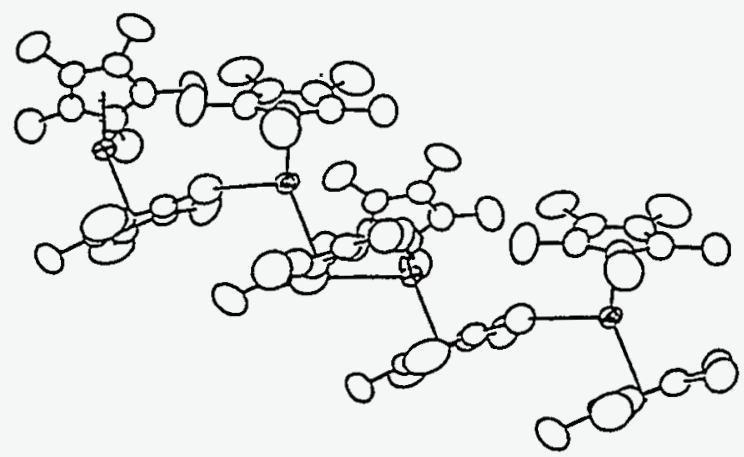

(a)

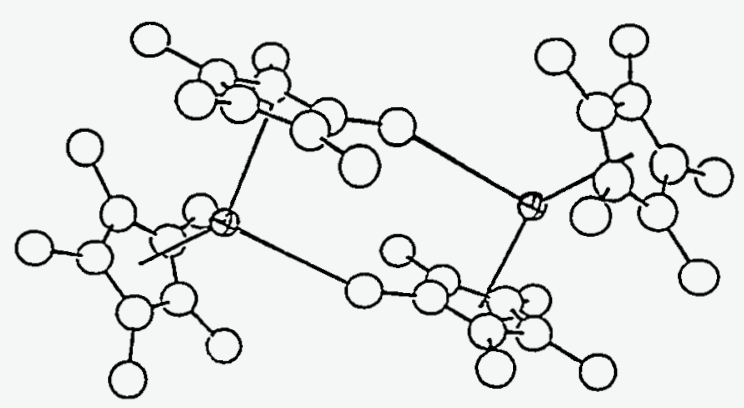

(b)

Figure 7. a) Illustration of the (polymeric) packing mode of 1 , for crystals isolated from pentane; b) Illustration of the (dimeric) packing mode of $\mathrm{Cp}^{*}{ }_{2} \mathrm{M}$ compounds $(\mathrm{M}=\mathrm{Sm}$, $\mathrm{Eu})$, and for crystals of 1 isolated via sublimation. Taken from ref. 15.

It was noticed that not only crystals of $\mathbf{1}$, but toluene and pentane solutions of 1 at low temperature $\left(-80^{\circ} \mathrm{C}\right)$, are also dark green. The dark green solution of 1 in toluene is particularly interesting, given the indirect evidence of an interaction between $\mathbf{1}$ and toluene discussed in the Introduction. Lanthanide compounds involving neutral aromatic donors as ligands are relatively rare. 26

Crystals of 1 obtained from toluene have never been examined in detail. It is possible that a weak, direct $\mathrm{Yb}$-toluene interaction is present in these crystals, consistent with the dark green color of a $-80^{\circ} \mathrm{C}$ toluene solution of 1 . Given this possibility, crystals of 1 obtained from toluene were subjected to an X-ray diffraction study. The crystals were not exposed to reduced pressure; the $-80^{\circ} \mathrm{C}$ mother liquor was removed from cannula from the dark green crystals, which were immediately placed in Paratone oil 
and mounted on the diffractometer. An ORTEP diagram of the presumed $\mathbf{1}$ (toluene) adduct, 6 , is shown in Fig. $8 \mathrm{a}$ and a packing diagram is shown in Fig. $8 \mathrm{~b}$. It can be seen from Fig. 8 that, while toluene is present in the crystal lattice of 6 , the molecules of toluene and of 1 are entirely non-interacting.

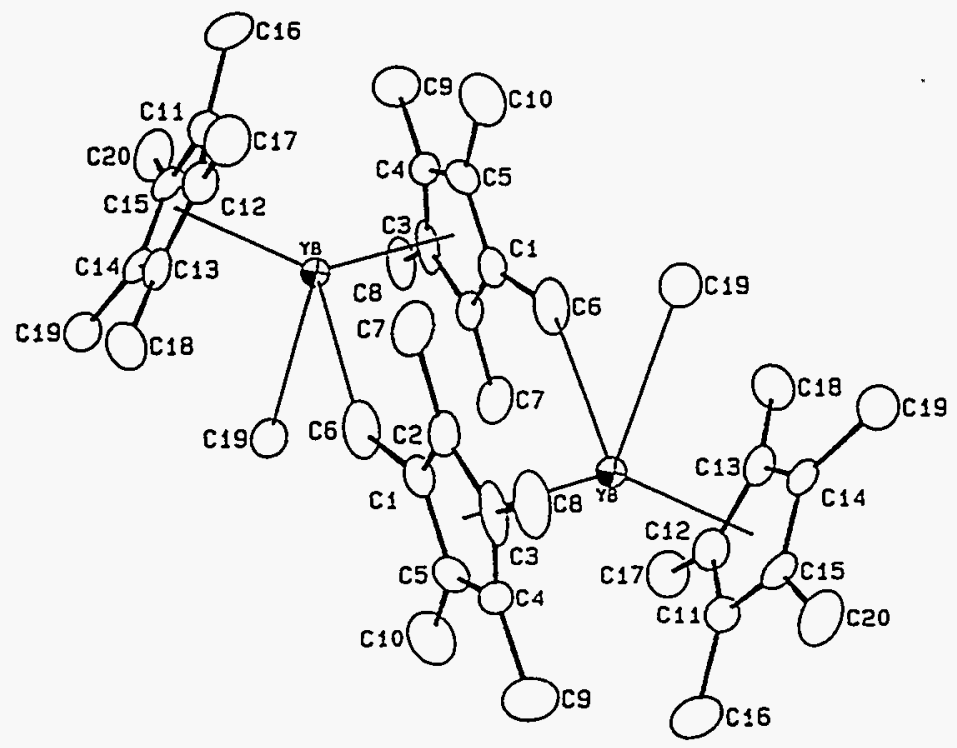

(a)

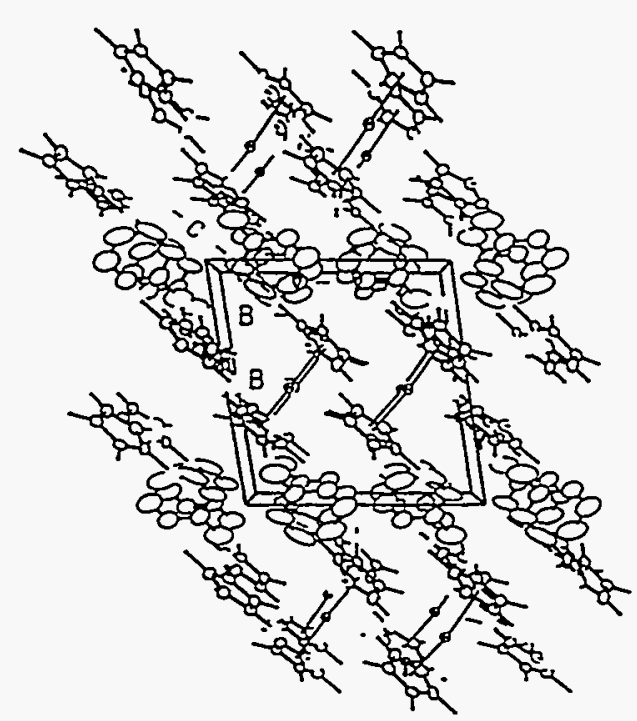

(b)

Figure 8. a) ORTEP diagram of 6,50\% probability ellipsoids; b) Packing diagram of 6. 
As observed in both the "polymeric" and "dimeric" crystallographic forms of 1 , termolecular contacts between the $\mathrm{Yb}$ centers and $\mathrm{Cp}^{*}$ methyl groups on adjacent molecules of 1 (Fig. 7), are also present in 6 . In contrast to the "solvent-free" crystallographic forms of 1 , each $\mathrm{Yb}$ center in 6 has two such intermolecular interactions (Fig. 7a); the result is a crystalline lattice containing layers of polymeric "chains" of $\mathbf{1}$, sandwiched between layers of toluene molecules. The $\mathrm{Yb}$-methyl intermolecular contacts (Yb-C6, 3.10(2); Yb-C19, 2.97(1) $\AA$, respectively) are similar to the analogous distances found in the polymeric form of 1.15 The $\mathrm{C} 6-\mathrm{Yb}-\mathrm{C} 19$ angle is $76.8^{\circ}$. The Yb-ring centroid distances (both $2.38 \AA$ ) and (ring centroid)-Yb-(ring centroid) angle $\left(141^{\circ}\right)$ are within the expected ranges. 15,27

The solid-state packing mode of 6 (Fig. $8 \mathrm{~b}$ ) is very similar to the crystal lattice of

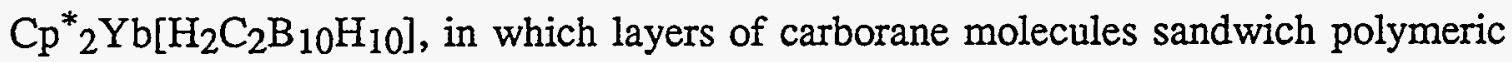
chains of $1 .^{15}$ This carborane compound has been classified as an inclusion, or clathrate, compound; given the similar crystalline lattice of 6 , it is also best classified as a clathrate. Evidently, in both the carborane compound as well as in 6, the $\mathrm{Yb}$-ligand interactions are weaker than the Yb-methyl interactions that are observed in the solid state structures (of course, the observed $\mathrm{Yb}$-methyl interactions may also result from crystal packing effects). For 6, this is reasonable: a methyl group of a negatively-charged $\mathrm{Cp}^{*}$ ring would be expected to be a better ligand towards 1 than the methyl group of toluene (interaction of the $\mathrm{Yb}$ center with the $\pi$-electron aromatic system of toluene is likely disfavored for steric reasons). 
References.

(1) (a) Bax, A.; Griffey, R. H.; Hawkins, B. L. J. Magn. Reson. 1983, 55, 301. (b) Bax, A.; Subramanian, S. J. Magn. Reson. 1986, 67, 565.

(2) Derome, A. E. In Modern NMR Techniques for Chemistry Research; Pergamon Press: Elmsford, New York, 1987, p. 254.

(3) (a) Macchioni, A.; Pregosin, P. S.; Ruegger, H.; Koten, G. v.; van der Schaaf, P. A.; Abbenhuis, R. A. T. M. Magn. Res. Chem. 1994, 32, 235. (b) Bonny, A.; McMaster, A. D.; Stobart, S. R. Inorg. Chem. 1978, 4, 935. (c) Benn, R.; Brevard, C. J. Am. Chem. Soc. 1986, 108, 5622. (d) Benn, R.; Brenneke, H.; Joussen, E.; Lehmkuhl, H.; Lopez Ortiz, F. Organometallics. 1990, 9, 756.

(4) The spectrum was resolution-enhanced by performing a Gaussian multiplication on the FID, with $\mathrm{gb}=0.9$ and a line broadening factor of $-0.5 \mathrm{~Hz}$.

(5) The potential of using this technique for other $\mathrm{Cp}^{\#} \mathrm{ML}_{\mathbf{n}}$ complexes $(\mathrm{Cp} \#=\mathrm{a} \mathrm{Cp}$ derivative; $M=$ an NMR-active metal nucleus) is currently being explored; G. E. Ball, work in progress.

(6) Otsuka, S. J. Organomet. Chem. 1980, 200, 191.

(7) (a) Hackett, M.; Ibers, J. A.; Jernakoff, P.; Whitesides, G. M. J. Am. Chem. Soc. 1986, 108, 8094. (b) Hackett, M.; Ibers, J. A.; Whitesides, G. M. J. Am. Chem. Soc. 1988, 110, 1436. (c) Hackett, M.; Whitesides, G. M. J. Am. Chem. Soc. 1988, 110 , 1449. (d) Abis, L.; Sen, A.; Halpern, J. J. Am. Chem. Soc. 1978, 100, 2915.

(8) (a) Pan, Y.; Mague, J. T.; Fink, M. J. J. Am. Chem. Soc. 1993, 115, 3842. (b) Yoshida, T.; Yamagata, T.; Tulip, T. H.; Ibers, J. A.; Otsuka, S. J. Am. Chem. Soc. 1978, 100, 2063. (c) The details of the interactions of 1 with $[(\mathrm{P}-\mathrm{P}) \mathrm{PtH}]_{2}$ dimers are described in Chapter 2.

(9) Deng, H.; Shore, S. G. J. Am. Chem. Soc. 1991, 113, 8538. 
(10) (a) Paonessa, R. S.; Prignano, A. L.; Trogler. W. C. Organometallics. 1985, 4, 647. (b) Davies, J. A.; Eagle, C. T. Organometallics. 1986, 5, 2149. (c) Davies, J. A.; Eagle, C. T.; Otis, D. E.; Venkataraman, U. Organometallics. 1986, 5, 1264.

(11) Yoshida, T; Otsuka, S. Inorg. Syn. 1990, 28, 113.

(12) Tolman, C. A.; Seidel, W. C.; Gerlach, D. H.J. Am. Chem. Soc. 1972, 94, 2669.

(13) The thermodynamic strengths of the $\mathrm{Yb}-\mathrm{L}$ interactions discussed in this Chapter are expected to be roughly correlated with the barriers to intermolecular exchange; see the discussion in Chapter 3 for a justification of this assumption.

(14) Cyclohexane has been reported to be less prone to $\mathrm{C}-\mathrm{H}$ activation than substrates with primary C-H bonds: (a) Thompson, M. E.; Bercaw, J. E. Pure and Applied Chem. 1984, 56, 1. (b) Fendrick, C. M.; Marks, T. J. J. Am. Chem. Soc. 1986, 108, 425.

(15) Burns, C. J., Ph.D. Thesis, University of California, Berkeley, 1987.

(16) a) Hildenbrand, D. L. J. Chem. Phys. 1968, 48, 3657. b) Blue, G. D.; Green, J. W.; Ehlert, T. C.; Margrave, J. L. Nature. 1963, 199, 804.

(17) DeKock, R. L.; Gray, H. B. "Chemical Structure and Bonding", Benjamin/Cummings Publishing Co., Menlo Park, 1980.

(18) (a) Crabtree, R. H.; Lavin, M.; Bonneviot, L. J. Am. Chem. Soc. 1986, 108, 4032. b) Crabtree, R. H. Acc. Chem. Res. 1990, 23, 95.

(19) Desrosiers, P. J.; Cai, L.; Lin, Z.; Richards, R.; Halpern, J. J. Am. Chem. Soc. $1991,113,4173$.

(20) (a) Rest, A. J.; Whitwell, W. A. G.; Hoyano, J. K.; McMaster, A. D. J. Chem. Soc., Chem. Commun. 1984, 624. (b) Mascetti, J.; Rest, A. J. J. Chem. Soc., Chem. Commun. 1987, 221.

(21) Selg, P.; Brintzinger, H. H.; Andersen, R. A.; unpublished results. 
(22) (a) Dell'Amico, D. B.; Calderazzo, R.; Robino, P.; Segre, A. J. Chem. Soc., Dalton Trans. 1991, 3017. (b) Rack, J. J.; Moasser, B.; Gargulak, J. D.; Gladfelter, W. L.; Hochheimer, H. D.; Strauss, S. H. J. Chem. Soc., Chem. Commun. 1994, 685. (c) Willner, H.; Bodenbinder, M.; Wang, C.; Aubke, F. J. Chem. Soc., Chem. Commun. 1994, 1189. (d) Willner, H.; Schaebs, J.; Hwang, G.; Mistry, F.; Jones, R.; Trotter, J.; Aubke, F. J. Am. Chem. Soc. 1992, 114, 8972. (e) Weber, L. Angew. Chem., Int. Ed. Engl. 1994, 33, 1077.

(23) Selg, P.; Brintzinger, H. H.; Andersen, R. A.; Horvath, I. T. Angew. Chem., Int. Ed. Engl. 1995, 34, 791.

(24) Crabtree, R. H. Angew. Chem., Int. Ed. Engl. 1993, 32, 789.

(25) (a) Schubert, U.; Kunz, E.; Harkers, B.; Willnecker, J.; Meyer, J. J. Am. Chem. Soc. 1989, 111, 2572. (b) Schubert, U.; Muller, J.; Alt, H. G. Organometallics. 1987, 6, 469. (c) Burkey, T. J. J. Am. Chem. Soc. 1990, 112, 8329. (d) Schubert, U. Adv. Organomet. Chem. 1990, 30, 151. (e) Piana, H.; Kirchgassner, U.; Schubert, U. Chem. Ber. 1991, 124, 743. (f) Luo, X.-L.; Kubas, G. J.; Bryan, J. C.; Burns, C. J.; Unkefer, C. J. J. Am. Chem. Soc. 1994, 116, 10312. (g) Luo, X.-L.; Kubas, G. J.; Burns, C. J.; Bryan, J. C.; Unkefer, C. J. J. Am. Chem. Soc. 1995, 117, 1159.

(26) (a) Liang, H.; Shen, Q.; Jin, S.; Lin, Y. J. Chem. Soc., Chem. Commun. 1992, 480. (b) Barnhart, D. M.; Clark, D. L.; Gordon, J. C.; Huffman, J. C.; Vincent, R. L.; Watkin, J. G.; Zwick, B. D. Inorg. Chem. 1994, 33, 3487. (c) The reactivity of $\mathrm{Cp}_{2}{ }_{2} \mathrm{Sm}$ with neutral aromatic compounds has also been reported recently: Evans, W. J.; Gonzales, S. L.; Ziller, J. W. J. Am. Chem. Soc. 1994, 116, 2600.

(27) (a) Burns, C. J.; Andersen, R. A. J. Am. Chem. Soc. 1987, 109, 941. (b) Burns, C. J.; Andersen, R. A. J. Am. Chem. Soc. 1987, 109, 915. (c) Also see Chapters 1 and 3 of this work. 


\section{EXPERIMENTAL DETAILS}

\section{General}

All reactions and product manipulations were carried out under dry nitrogen using standard Schlenk and dry box techniques. Pentane, hexane, diethyl ether and tetrahydrofuran were distilled from sodium benzophenone-ketyl under nitrogen immediately prior to use. Toluene was distilled from sodium under nitrogen immediately prior to use. Dichloromethane was distilled from calcium hydride under nitrogen immediately prior to use. Deuterated solvents for NMR measurements were distilled from either sodium or potassium under nitrogen and stored over sodium. Other chemicals were of reagent grade, and purified according to standard procedures as necessary. ${ }^{1} \mathrm{Cp}_{2}{ }_{2} \mathrm{Yb}\left(\mathrm{OEt}_{2}\right)^{2}$ and $\mathrm{Cp}^{*}{ }_{2} \mathrm{Yb}^{3}$ were prepared according to reported procedures.

Infrared spectra were recorded on a Nicolet 5DX FTIR spectrometer as Nujol mulls between CsI plates. Melting points were measured on a Thomas-Hoover melting point apparatus in capillaries sealed under nitrogen and are uncorrected. Elemental analyses were performed by the microanalytical laboratories at the University of California, Berkeley. Mass spectrometry analyses were obtained at the UCB mass spectrometry facility on a Kratos MS-50 mass spectrometer, and the isotopic cluster of the molecular ion is reported as follows: ion amu (observed intensity, calculated intensity).

All ${ }^{1} \mathrm{H},{ }^{1} \mathrm{P}\left\{{ }^{1} \mathrm{H}\right\},{ }^{195} \mathrm{Pt}\left\{{ }^{1} \mathrm{H}\right\},{ }^{171} \mathrm{Yb}\left\{{ }^{1} \mathrm{H}\right\}$, and 2-D NMR spectra were recorded on Bruker AMX spectrometers operating at $400,162,85.6$, or $70.0 \mathrm{MHz}$, respectively; or at $300,121.5,64.2$, or $52.5 \mathrm{MHz}$, respectively. ${ }^{1} \mathrm{H}$ NMR shifts are relative to tetramethylsilane, the residual protio-resonance was used as an internal reference; ${ }^{31} \mathrm{P}$ shifts are relative to $85 \% \mathrm{H}_{3} \mathrm{PO}_{4}$ at $\delta 0.0$, with shifts downfield of the reference considered positive; ${ }^{195} \mathrm{Pt}$ shifts are referenced to an absolute frequency scale relative to the proton signal of tetramethylsilane at $100.0000 \mathrm{MHz}$ with $\Xi$ defined to be exactly 21.4 
$\mathrm{MHz},{ }^{4}$ and scaled according to the ${ }^{1} \mathrm{H}$ frequency of the particular machine used. A similar method was used for the $171 \mathrm{Yb}$ referencing, with the standard being the reported frequency for $\mathrm{Cp}^{*}{ }_{2} \mathrm{Yb}($ thf $) 2,{ }^{5}$ and again scaled according to the ${ }^{1} \mathrm{H}$ frequency of the particular machine used.

The HMQC or HSQC pulse sequences were used to acquire all of the 2-D spectra; 6 all of the 2-D spectra were acquired on either a Bruker AMX400 or an AMX300 spectrometer. In all cases where metal chemical shifts were being investigated, first a large sweep width in the $\mathrm{X}$ dimension was used, and then the sweep width was narrowed, to assure that the resonances were not folded. In Chapter 3 , the ${ }^{1} J_{C H}$ values for 12,13 , and the free ylides were obtained from ${ }^{13} \mathrm{C}$-filtered ${ }^{1} \mathrm{H}$ spectra, using the standard Bruker pulse sequence, with optimized $90^{\circ}$ pulses and delays. In Chapter 4 , the ${ }^{13} \mathrm{C}\left\{{ }^{1} \mathrm{H}\right\}$ spectra involving the $1 / \mathrm{CO}$ experiments were acquired at $125.7 \mathrm{MHz}$ frequency, using a $90^{\circ}$ pulse width and a ca. $0.8 \mathrm{sec}$ delay between scans (the ${ }^{13} \mathrm{C} \mathrm{T}_{1}$ values were not measured). 


\section{Chapter 1.}

(NOTE: The compound number designations are taken from the text, and pertain to the particular chapters--i.e., the numbering restarts with each chapter, see p. viii for a summary of the compound designations, by chapter.)

\section{(dcype) $\mathrm{Pt}(\mu-\mathrm{H})_{2} \mathrm{YbCp}{ }_{2}$ (5).}

To a solution of $4^{7}(0.15 \mathrm{~g}, 0.24 \mathrm{mmol})$ in toluene $(10 \mathrm{~mL})$ was added a solution of $1(0.11 \mathrm{~g}, 0.25 \mathrm{mmol})$ in toluene $(10 \mathrm{~mL})$. The resulting dark blue solution was stirred at room temperature for $1 \mathrm{~h}$ and then filtered. Slow cooling of the filtrate to $-40^{\circ} \mathrm{C}$ gave 5 as dark maroon crystals. Concentration of the mother liquor, followed by cooling to -80 ${ }^{\circ} \mathrm{C}$ gave a second crop of crystals, for a total yield of $0.19 \mathrm{~g}(75 \%), \mathrm{mp} 308-310^{\circ} \mathrm{C}$ (dec.). The NMR data were measured on a sample made by adding $\mathrm{C}_{6} \mathrm{D}_{6}$ to a mixture of 1 (slight excess) and 4. ${ }^{1} \mathrm{H}$ NMR $\left(\mathrm{C}_{6} \mathrm{D}_{6}\right): \delta 2.42(\mathrm{~s}, 30 \mathrm{H}), 2.10-1.00(\mathrm{~m}, 48 \mathrm{H}),-1.98$ $\left(\mathrm{m}, 2 \mathrm{H},{ }^{1} \mathrm{~J}_{\mathrm{PtH}}=1031 \mathrm{~Hz},{ }^{1} \mathrm{~J}_{\mathrm{YbH}}=180 \mathrm{~Hz},{ }^{2} \mathrm{~J}_{\mathrm{PH}}=152,14 \mathrm{~Hz}\right) \mathrm{ppm} .{ }^{31} \mathrm{P}\left\{{ }^{1} \mathrm{H}\right\} \mathrm{NMR}$ $\left(\mathrm{C}_{6} \mathrm{D}_{6}\right): \delta 75.4\left(\mathrm{~s},{ }^{1} \mathrm{~J}_{\mathrm{PtP}}=2077 \mathrm{~Hz}, \mathrm{~J}_{\mathrm{YbP}}=93 \mathrm{~Hz}\right)$. IR: $2718 \mathrm{w}, 1889 \mathrm{~s}(\mathrm{br}), 1416 \mathrm{w}$, 1379 m, 1345 w, 1293 m, 1271 m, 1195 w, 1173 m, 1119 m, 1109 s, 1043 m, 1004 s, $913 \mathrm{~m}, 888 \mathrm{~m}, 851$ s, $822 \mathrm{~m}, 797$ s, 751 s, 738 m, 724 w, $672 \mathrm{~m}, 650$ m, 527 s, 510 w, 483 w, 393 w, $361 \mathrm{~m} \mathrm{~cm}^{-1}$. Anal. Calcd for $\mathrm{C}_{46} \mathrm{H}_{80} \mathrm{P}_{2} \mathrm{PtYb}: \mathrm{C}, 52.0 ; \mathrm{H}, 7.58$. Found: $\mathrm{C}, 51.6 ; \mathrm{H}, 7.28$.

\section{(dippe)PtMe (8).}

To a solution of dimethyl(1,5-cyclooctadiene)platinum(II) ${ }^{8}(0.33 \mathrm{~g}, 1.0 \mathrm{mmol})$ in $\mathrm{CH}_{2} \mathrm{Cl}_{2}(20 \mathrm{~mL})$ a solution of dippe $(0.26 \mathrm{~g}, 1.0 \mathrm{mmol})$ in $\mathrm{CH}_{2} \mathrm{Cl}_{2}(10 \mathrm{~mL})$ was added dropwise. The resulting light yellow solution was stirred at room temperature for $12 \mathrm{~h}$. The solvent was removed under reduced pressure, and the residue was dissolved in a 2:1 pentane:toluene solution $(20 \mathrm{~mL})$, and the resulting solution was filtered. Slow cooling

of the filtrate to $-40{ }^{\circ} \mathrm{C}$ yielded 8 as white crystals $(0.38 \mathrm{~g}, 78 \%)$, mp $134-136{ }^{\circ} \mathrm{C}$. ${ }^{1} \mathrm{H}$ 
$\operatorname{NMR}\left(\mathrm{C}_{6} \mathrm{D}_{6}\right): \delta 2.05(\mathrm{~m}, 4 \mathrm{H}), 1.23\left(\mathrm{t}, 6 \mathrm{H},{ }^{1} \mathrm{~J}_{\mathrm{PtH}}=68 \mathrm{~Hz},{ }^{2} \mathrm{~J}_{\mathrm{PH}}=7 \mathrm{~Hz}\right), 0.92(\mathrm{~m}$, 28H) ppm. ${ }^{31} \mathrm{P}\left\{{ }^{1} \mathrm{H}\right\}$ NMR $\left(\mathrm{C}_{6} \mathrm{D}_{6}\right): \delta 70.4\left(\mathrm{~s},{ }^{1} \mathrm{~J}_{\mathrm{PtP}}=1816 \mathrm{~Hz}\right) . \mathbb{R}: 3594 \mathrm{~s}, 1409 \mathrm{w}$, 1379 s, 1362 s, 1297 w, 1252 m, 1239 s, 1193 m, 1176 m, 1161 m, 1106 m, 1091 m, 1079 m, 1028 s, 964 w, 926 m, 884 s, 861 m, 791 s, 695 s, 679 s, 651 s, 634 m, 617 s, 522 s, 509 s, $488 \mathrm{~m}, 467 \mathrm{~m}, 424 \mathrm{w}, 386 \mathrm{~m}, 378 \mathrm{~m}, 278 \mathrm{~m} \mathrm{~cm}^{-1}$. Anal. Calcd for $\mathrm{C}_{16} \mathrm{H}_{38} \mathrm{P}_{2} \mathrm{Pt}: \mathrm{C}, 39.4 ; \mathrm{H}, 7.86$. Found: $\mathrm{C}, 39.2 ; \mathrm{H}, 7.59$.

\section{(dippe)Pt( $\mu$-Me ${ }_{2} \mathrm{YbCp}_{2}{ }_{2}$ (9).}

To a solution of $8(0.43 \mathrm{~g}, 0.88 \mathrm{mmol})$ in toluene $(20 \mathrm{~mL})$ was added a solution of $1(0.39 \mathrm{~g}, 0.88 \mathrm{mmol})$ in toluene $(10 \mathrm{~mL})$. Upon addition, the mixture immediately turned deep green and a green precipitate appeared. After stirring at room temperature for $1 \mathrm{~h}$, the mixture was warmed to $50^{\circ} \mathrm{C}$ to dissolve all of the solid. The solution was filtered at $50^{\circ} \mathrm{C}$ and the filtrate was allowed to cool slowly to room temperature. Further slow cooling to $-40{ }^{\circ} \mathrm{C}$ produced 9 as dark green crystals $(0.70 \mathrm{~g}, 86 \%)$. Subsequent recrystallization from a $2: 1$ toluene:pentane solution (slow cooling to $-40^{\circ} \mathrm{C}$ ) yielded $\mathrm{X}$ ray quality crystals, mp $264-266^{\circ} \mathrm{C}$. ${ }^{1} \mathrm{H}$ NMR $\left(\mathrm{C}_{6} \mathrm{D}_{6}\right): \delta 2.28(\mathrm{~s}, 30 \mathrm{H}), 1.92(\mathrm{~m}, 4 \mathrm{H}$, $\left.-\mathrm{CH}\left(\mathrm{CH}_{3}\right)_{2}\right), 0.85(\mathrm{~m}, 28 \mathrm{H}), 0.68\left(\mathrm{t}, 6 \mathrm{H},{ }^{2} \mathrm{~J}_{\mathrm{PtCH} 3}=66 \mathrm{~Hz},{ }^{3} \mathrm{~J}_{\mathrm{PCH} 3}=7 \mathrm{~Hz}\right) \mathrm{ppm}$. ${ }^{31} \mathrm{P}\left\{{ }^{1} \mathrm{H}\right\}$ NMR $\left(\mathrm{C}_{6} \mathrm{D}_{6}\right): \delta 70.0\left(\mathrm{~s},{ }^{1} \mathrm{~J}_{\mathrm{PtP}}=1968 \mathrm{~Hz}\right)$ IR: $2725 \mathrm{~m}, 2285 \mathrm{w}, 1382 \mathrm{~s}$, 1366 m, 1296 w, 1285 w, 1253 m, 1239 w, 1172 w, 1161 w, 1134 w, 1105 w, 1091 w, 1080 w, 1029 s, 927 w, 884 m, 859 m, 797 m, 762 w, 725 w, 703 w, 684 s, 652 s, $620 \mathrm{~m}, 587 \mathrm{w}, 520 \mathrm{~m}, 504 \mathrm{w}, 490 \mathrm{~m}, 466 \mathrm{~m}, 425 \mathrm{w}, 388 \mathrm{w}, 369 \mathrm{~m}, 269 \mathrm{~s} \mathrm{~cm}^{-1}$. Anal. Calcd for $\mathrm{C}_{36} \mathrm{H}_{68} \mathrm{P}_{2} \mathrm{PtYb}: \mathrm{C}, 46.4 ; \mathrm{H}, 7.36$. Found: $\mathrm{C}, 46.2 ; \mathrm{H}, 7.42$.

\section{(dippe)Pt(Me)(OCOPh).}

To a Schlenk tube containing $8(0.66 \mathrm{~g}, 1.4 \mathrm{mmol})$ and benzoic acid $(0.33 \mathrm{~g}, 2.7$ mmol) was added diethyl ether $(40 \mathrm{~mL})$. [It was found that using 1 eq. of benzoic acid results in only partial substitution, giving a mixture of 8 and the desired product.] The 
resulting pale yellow solution was stirred at room temperature for $60 \mathrm{~h}$, during which time the crude product precipitated out of solution as a microcrystalline white solid. The solution was concentrated to $15 \mathrm{~mL}$ under reduced pressure, the solid was allowed to settle, and the solvent was removed via cannula. The white solid residue was washed with diethyl ether ( $2 \times 15 \mathrm{~mL}$, to remove the excess benzoic acid), dissolved in toluene $(20 \mathrm{~mL})$, and the resulting solution was slowly cooled to $-80^{\circ} \mathrm{C}$. Removal of the solvent from the crystals by cannula and drying under reduced pressure resulted in isolation of beige crystals. The mother liquor was concentrated and again cooled to $-80^{\circ} \mathrm{C}$ to yield a second crop of crystals. A third crop was obtained in a similar manner, giving a total yield of $0.41 \mathrm{~g}(51 \%)$, mp $148-155^{\circ} \mathrm{C}$. ${ }^{1} \mathrm{H}$ NMR $\left(\mathrm{C}_{6} \mathrm{D}_{6}\right): \delta 8.70(\mathrm{~m}, 2 \mathrm{H}$, meta-H), 7.21 (m, 3H, ortho/para- $\mathrm{H}), 2.20$ (m, $\left.2 \mathrm{H}, \mathrm{PCH}\left(\mathrm{CH}_{3}\right)_{2}\right), 1.81$ (m, $\left.2 \mathrm{H}, \mathrm{PCH}\left(\mathrm{CH}_{3}\right)_{2}\right), 1.27$ $(\mathrm{m}, 6 \mathrm{H}), 0.92(\mathrm{~m}, 24 \mathrm{H}) \mathrm{ppm} .{ }^{31} \mathrm{P}\left\{{ }^{1} \mathrm{H}\right\} \mathrm{NMR}\left(\mathrm{C}_{6} \mathrm{D}_{6}\right): \delta 74.5\left(\mathrm{~s},{ }^{1} \mathrm{~J}_{\mathrm{PtP}}=1843 \mathrm{~Hz}\right.$, trans to methyl), 70.1 ( $\mathrm{s},{ }^{1} \mathrm{JPtP}_{\mathrm{PtP}}=4025 \mathrm{~Hz}$,trans to benzoate) $\mathbb{R}$ : $1623 \mathrm{~s}(\mathrm{br}), 1575 \mathrm{~s}$, 1560 m, 1534 w, 1507 w, 1419 m, 1410 s, 1386 s, 1366 s, 1347 s; 1320 m, 1298 m, $1280 \mathrm{w}, 1258 \mathrm{~m}, 1246 \mathrm{~s}, 1183 \mathrm{~m}, 1172 \mathrm{~m}, 1161 \mathrm{~m}, 1129 \mathrm{~m}, 1107 \mathrm{w}, 1097 \mathrm{w}, 1080 \mathrm{w}$, 1065 m, 1033 s, 1022 m, 994 w, 965 w, 940 m, 925 m, 884 s, 860 m, 831 m, 793 m, 719 s, 707 s, 690 s, 682 s, 669 s, 651 s, 644 m, 614 m, 580 w, 528 m, 489 m, 469 w, $456 \mathrm{~m}, 426 \mathrm{~m} \mathrm{~cm}^{-1}$. Anal. Calcd for $\mathrm{C}_{22} \mathrm{H}_{40} \mathrm{P}_{2} \mathrm{O}_{2} \mathrm{Pt}$ : $\mathrm{C}, 44.5 ; \mathrm{H}, 6.79$. Found: $\mathrm{C}$, $44.8 ; \mathrm{H}, 6.82$.

(dippe)Pt(Me)(H) (10).

To a stirred thf solution (50 mL) of (dippe) $\mathrm{Pt}\left(\mathrm{CH}_{3}\right)(\mathrm{OCOPh})(2.00 \mathrm{~g}, 3.40 \mathrm{mmol})$ a thf solution $(50 \mathrm{~mL})$ of $\mathrm{NaHB}(\mathrm{OMe}) 3(1.30 \mathrm{~g}, 10.2 \mathrm{mmol})$ was added dropwise. A fine off-white precipitate immediately formed. The suspension was stirred for $12 \mathrm{~h}$, the solvent was removed under reduced pressure, and the residue extracted into toluene ( $2 \mathrm{x}$ $15 \mathrm{~mL}$ ). The solution was filtered and the filtrated was concentrated to $15 \mathrm{~mL}$ under reduced pressure, then $50 \mathrm{~mL}$ pentane was added. Slow cooling of the filtrate to $-80^{\circ} \mathrm{C}$ 
yielded crude 10 as a beige solid. Recrystallization from toluene:pentane (1:2) yielded pure 10 as a pale yellow solid $(1.26 \mathrm{~g}, 79 \%), \mathrm{mp} 63-66^{\circ} \mathrm{C}$. ${ }^{1} \mathrm{H}$ NMR (toluene-d 8 ): $\delta$ $2.04(\mathrm{~m}, 4 \mathrm{H}), 1.82(\mathrm{~m}, 4 \mathrm{H}), 1.44$ (virtual t, 3H, $\left.{ }^{2} \mathrm{~J}_{\mathrm{PtCH} 3}=71 \mathrm{~Hz}\right), 1.08(\mathrm{~m}, 12 \mathrm{H})$, $0.82(\mathrm{~m}, 12 \mathrm{H}), 0.48\left(\mathrm{dd}, 1 \mathrm{H},{ }^{1} \mathrm{~J}_{\mathrm{PtH}}=1158 \mathrm{~Hz},{ }^{2} \mathrm{~J}_{\mathrm{PtransH}}=201 \mathrm{~Hz},{ }^{2} \mathrm{~J}_{\mathrm{PcisH}}=17.5 \mathrm{~Hz}\right)$ ppm. ${ }^{31} \mathrm{P}\left\{{ }^{1} \mathrm{H}\right\}$ NMR (toluene- $\left.\mathrm{d}_{8}\right): \delta 85.5\left(\mathrm{~s},{ }^{1} \mathrm{~J}_{\mathrm{PtP}}=1822 \mathrm{~Hz}\right.$, trans to methyl), 70.1 $\left(\mathrm{s},{ }^{1} \mathrm{~J}_{\mathrm{PtP}}=1747 \mathrm{~Hz}\right.$, trans to hydride) IR: $1965 \mathrm{~s}(\mathrm{br}), 1408 \mathrm{~m}, 1382 \mathrm{~s}, 1361 \mathrm{~s}, 1296$ w, 1256 m, 1237 m, 1183 w, 1161 w, 1142 w, 1103 m, 1088 m, 1078 m, 1031 s, 930 m, 925 m, 885 s, 858 m, 805 m, 795 s, 768 m, 722 w, 697 s, 685 s, 670 s, 649 s, 639 $\mathrm{s}, 608 \mathrm{~m} \mathrm{~cm}^{-1}$. Anal. Calcd for $\mathrm{C}_{15} \mathrm{H}_{36} \mathrm{P} 2 \mathrm{Pt}: \mathrm{C}, 38.0 ; \mathrm{H}, 7.66$. Found: $\mathrm{C}, 38.3 ; \mathrm{H}$, 7.62 .

\section{(dippe)Pt( $(\mu-\mathrm{Me})(\mu-\mathrm{H}) \mathrm{YbCp}_{2}$ (11).}

To a toluene solution $(15 \mathrm{~mL})$ of $1(0.18 \mathrm{~g}, 0.41 \mathrm{mmol})$ was added dropwise a toluene solution $(15 \mathrm{~mL})$ of $\mathbf{1 0}(0.18 \mathrm{~g}, 0.39 \mathrm{mmol})$. The resulting dark brown solution was filtered. Slow cooling of the filtrate to $-40^{\circ} \mathrm{C}$ yielded 11 as gold crystals. Concentration of the mother liquor followed by slow cooling to $-80^{\circ} \mathrm{C}$ gave a second crop of crystals, for a total yield of $0.26 \mathrm{~g}(70 \%), \mathrm{mp} 220^{\circ} \mathrm{C}$ (dec. without melting). The NMR spectra were measured on a sample containing a slight excess of $1 .{ }^{1} \mathrm{H}$ NMR (toluene- $\left.\mathrm{d}_{8}\right): \delta 2.29(\mathrm{~s}, 30 \mathrm{H}), 1.85(\mathrm{~m}, 4 \mathrm{H}), 1.1-0.85(\mathrm{~m}, 16 \mathrm{H}), 0.80-0.60(\mathrm{~m}, 15 \mathrm{H})$, $-2.65\left(\mathrm{dd}, 1 \mathrm{H},{ }^{1} \mathrm{~J}_{\mathrm{PtH}}=1034 \mathrm{~Hz},{ }^{2} \mathrm{~J}_{\mathrm{PtransH}}=163 \mathrm{~Hz},{ }^{2} \mathrm{~J}_{\mathrm{PcisH}}=15 \mathrm{~Hz},{ }^{1} \mathrm{~J}_{\mathrm{YbH}}=114 \mathrm{~Hz}\right)$ ppm. ${ }^{31} \mathrm{P}\left\{{ }^{1} \mathrm{H}\right\}$ NMR (toluene-d8): $\delta 81.3\left(\mathrm{~s},{ }^{1} \mathrm{~J}_{\mathrm{PtP}}=1978 \mathrm{~Hz}\right.$, trans to methyl), 69.2 (s, ${ }^{1} \mathrm{~J}_{\mathrm{PtP}}=2186 \mathrm{~Hz}$, trans to hydride) IR: $2720 \mathrm{~m}, 1895 \mathrm{~s}(\mathrm{br}), 1404 \mathrm{w}, 1382 \mathrm{~s}, 1366$ s, 1252 m, 1240 w, 1190 w, 1162 w, 1137 w, 1106 m, 1091 m, 1081 m, 1029 s, 965 w, 926 w, 885 m, 859 w, 797 m 706 m, 687 s, 654 s, 619 w cm$^{-1}$. Anal. Calcd for $\mathrm{C}_{35} \mathrm{H}_{66} \mathrm{P}_{2} \mathrm{PtYb}: \mathrm{C}, 45.8 ; \mathrm{H}, 7.26$. Found: $\mathrm{C}, 45.6 ; \mathrm{H}, 7.25$. 


\section{Chapter 2.}

\section{(dippe) $\mathrm{PtCl}_{2}$.}

Neat (dippe) ( $0.26 \mathrm{~g}, 1.0 \mathrm{mmol})$ was added dropwise to a room temperature $\mathrm{CH}_{2} \mathrm{Cl}_{2}$ solution $\left(30 \mathrm{~mL}\right.$ ) of (cod) $\mathrm{PtCl}_{2}(0.35 \mathrm{~g}, 0.94 \mathrm{mmol})$. The product began to precipitate from the pale yellow solution after a few minutes, as a microcrystalline colorless solid. The mixture was stirred for $15 \mathrm{~h}$ at room temperature, and then concentrated to $c a .15 \mathrm{~mL}$ under reduced pressure. Addition of hexane $(40 \mathrm{~mL})$ resulted in further precipitation of the product. Removal of the solvents via cannulation, followed by washing of the residue with hexane $(2 \times 15 \mathrm{~mL})$, and drying under reduced pressure, yielded the product as a fine colorless powder $(0.40 \mathrm{~g}, 81 \%)$, which does not melt to $330^{\circ} \mathrm{C}$. ${ }^{1} \mathrm{H}$ NMR $\left(\mathrm{CDCl}_{3}\right): \delta 2.62\left(\mathrm{~m}, 4 \mathrm{H}, \mathrm{C}_{\mathrm{ipso}}-\mathrm{H}\right), 1.73\left(\mathrm{~m}, 4 \mathrm{H}, \mathrm{P}-\mathrm{CH}_{2}\right)$, $1.39\left(\mathrm{dd}, 12 \mathrm{H},{ }^{3} \mathrm{~J}_{\mathrm{HH}}=17.2 \mathrm{~Hz},{ }^{3} \mathrm{~J}_{\mathrm{PH}}=7.1 \mathrm{~Hz},-\mathrm{CH}_{3}\right), 1.20\left(\mathrm{dd}, 12 \mathrm{H},{ }^{3} \mathrm{~J}_{\mathrm{HH}}=15.7\right.$ $\left.\mathrm{Hz},{ }^{3} \mathrm{~J}_{\mathrm{PH}}=7.1 \mathrm{~Hz},-\mathrm{CH}_{3}\right) \mathrm{ppm} .{ }^{31} \mathrm{P}\left\{{ }^{1} \mathrm{H}\right\} \mathrm{NMR}\left(\mathrm{CDCl}_{3}\right): \delta 70.7 \mathrm{ppm}\left(\mathrm{s},{ }^{1} \mathrm{~J}_{\mathrm{PtP}}=\right.$ $3574 \mathrm{~Hz}$ ). IR: $1413 \mathrm{~m}, 1386 \mathrm{~s}, 1377 \mathrm{~m}, 1368 \mathrm{~m}, 1293 \mathrm{~m}, 1267 \mathrm{~m}, 1256 \mathrm{~m}, 1249 \mathrm{~m}$, 1166 w, 1117 w, 1101 w, 1084 w, 1036 s, 966 w, 932 m, 893 m, 886 m, 874 m, 803 s, 713 s, 697 s, 662 s, 629 s, $490 \mathrm{~m}, 476 \mathrm{~m}, 428 \mathrm{w} \mathrm{cm}^{-1}$. Anal. Calcd for $\mathrm{C}_{14} \mathrm{H}_{32} \mathrm{Cl}_{2} \mathrm{P}_{2} \mathrm{Pt}:$ C, 31.8; $\mathrm{H}, 6.10$. Found: $\mathrm{C}, 31.9 ; \mathrm{H}, 5.95$.

\section{(dcype)PtCl 2 .}

To a Schlenk tube containing (dcype) $(0.20 \mathrm{~g}, 0.47 \mathrm{mmol})$ and (cod) $\mathrm{PtCl}_{2}(0.18 \mathrm{~g}$, $0.47 \mathrm{mmol})$ was added $\mathrm{CH}_{2} \mathrm{Cl}_{2}(30 \mathrm{~mL})$. The resulting clear pale yellow solution was stirred for $15 \mathrm{~h}$ at room temperature. The solution was concentrated to $c a .5 \mathrm{~mL}$ under reduced pressure, and pentane $(40 \mathrm{~mL})$ was added, resulting in precipitation of a fine colorless solid. The solvents were removed via cannulation, and the residue was washed with pentane $(2 \times 15 \mathrm{~mL})$ and dried under reduced pressure, yielding the crude product as a white powder. This solid was dissolved in $\mathrm{CH}_{2} \mathrm{Cl}_{2}(5 \mathrm{~mL})$ and the solution was slowly cooled to $-80^{\circ} \mathrm{C}$, yielding the product as colorless crystals $(0.29 \mathrm{~g}, 88 \%), \mathrm{mp} 220^{\circ} \mathrm{C}$ 
(decomp. to a gray powder). ${ }^{1} \mathrm{H} N M R\left(\mathrm{CDCl}_{3}\right): \delta 2.5-1.1(\mathrm{~m}, 48 \mathrm{H}) \mathrm{ppm} .{ }^{31} \mathrm{P}\left\{{ }^{1} \mathrm{H}\right\}$ $\operatorname{NMR}\left(\mathrm{CDCl}_{3}\right): \delta 63.6 \mathrm{ppm}\left(\mathrm{s},{ }^{1} \mathrm{~J}_{\mathrm{PtP}}=3577 \mathrm{~Hz}\right) . \quad \mathbb{R}: 1406 \mathrm{~m}, 1377 \mathrm{~s}, 1366 \mathrm{~m}, 1343$ m, 1327 m, 1303 m, 1294 m, 1272 m, 1208 m, 1180 m, 1173 m, 1117 m, 1080 w, 1049 w, 1043 w, 1028 w, 1007 s, 917 m, 889 s, 869 m, 852 s, 823 m, 803 m, 796 w, 755 s, 748 s, 740 m, 730 w, 677 s, 658 m, 542 s, 533 m, 515 m, 488 m, 475 m, 466 $\mathrm{m}, 438 \mathrm{w}, 411 \mathrm{~m} \mathrm{~cm}^{-1}$. Anal. Calcd for $\mathrm{C}_{26} \mathrm{H}_{48} \mathrm{Cl}_{2} \mathrm{P}_{2} \mathrm{Pt}: \mathrm{C}, 45.4 ; \mathrm{H}, 7.03$. Found: $\mathrm{C}$, $45.0 ; \mathrm{H}, 7.05$.

\section{$\left[(\text { dippe)PtH }]_{2}(1)\right.$.}

A. mixture of (dippe) $\mathrm{PtCl}_{2}(1.2 \mathrm{~g}, 2.3 \mathrm{mmol})$ and $\mathrm{Na} / \mathrm{Hg}(0.8 \%, 50 \mathrm{~g})$ in thf $(150$ $\mathrm{mL})$ was stirred under $\mathrm{H}_{2}(1 \mathrm{~atm})$ at room temperature for $15 \mathrm{~h}$. The mixture was allowed to settle for $4 \mathrm{~h}$, filtered, and the solvent was removed from the filtrate under reduced pressure. The dark brown solid was extracted with hexane $(3 \times 50 \mathrm{~mL})$, the solution was filtered, and the filtrate was concentrated to $c a .40 \mathrm{~mL}$. Slow cooling of this solution to $-40{ }^{\circ} \mathrm{C}$ yielded 1 as light brown crystals $(0.65 \mathrm{~g}, 62 \%), \mathrm{mp} 118-131{ }^{\circ} \mathrm{C}$ (decomp.) ${ }^{1} \mathrm{H}$ NMR $\left(\mathrm{C}_{6} \mathrm{D}_{6}\right): \delta 2.06(\mathrm{~m}, 8 \mathrm{H}), 1.40-1.00(\mathrm{~m}, 56 \mathrm{H}), 0.50$ ('q of q', $2 \mathrm{H}$, $\left.{ }^{1} \mathrm{~J}_{\mathrm{PtH}}=516 \mathrm{~Hz},{ }^{2} \mathrm{~J}_{\mathrm{PH}}=40 \mathrm{~Hz}\right) \mathrm{ppm} .{ }^{31} \mathrm{P}\left\{{ }^{1} \mathrm{H}\right\} \mathrm{NMR}$, see Table 3, Ch. 2. ${ }^{195 \mathrm{Pt}}\left\{{ }^{1} \mathrm{H}\right\}$ NMR (d8-toluene): $\delta+190\left({ }^{1} \mathrm{~J}_{\mathrm{PtP}}=2210 \mathrm{~Hz},{ }^{2} \mathrm{~J}_{\mathrm{PtP}}=410 \mathrm{~Hz}\right) \mathrm{ppm} . \mathrm{IR}: 1939 \mathrm{~s}, 1926$ s, 1406 m, 1378 s, 1358 s 1298 w, 1241 s, 1234 s, 1159 w, 1104 m, 1086 m, 1076 m, 1027 s, 1021 s, 923 m 887 s, 882 s, 856 m, 853 m, 776 s, 680 s, 672 s, 660 s, 652 s, $634 \mathrm{~s}, 577 \mathrm{~m}, 514 \mathrm{~s}, 481 \mathrm{~m}, 465 \mathrm{~m}, 440 \mathrm{~m} \mathrm{~cm}^{-1}$. MS (EI, $\left.50 \mathrm{eV}\right) 914.3(43,32), 915.3$ (77, 72), $916.3(100,100), 917.3$ (69, 76), $918.3(48,51), 919.3$ (24, 26), 920.4 (17, 16), $921.3(5,4), 922.3(2,2)$. Anal. Calcd for $\mathrm{C}_{28} \mathrm{H}_{66} \mathrm{P}_{4} \mathrm{Pt}_{2}$ : C, 36.7; H, 7.26. Found: $\mathrm{C}, 36.9 ; \mathrm{H}, 7.23$. 
$\left[(\text { dcype)PtH }]_{2}\right.$ (2).

A toluene solution $(50 \mathrm{~mL})$ of $5(0.90 \mathrm{~g}, 1.5 \mathrm{mmol})$ was heated at $110^{\circ} \mathrm{C}$ for $16 \mathrm{~h}$ in a Schlenk tube which was kept under a slow flow of $N_{2}$. The flask was allowed to cool to room temperature and the solvent was removed under reduced pressure, yielding a yellow solid. The ${ }^{31} \mathrm{P}\left\{{ }^{1} \mathrm{H}\right\}$ spectrum of the crude product showed the material was a 3:1 mixture of 2:5. This residue was extracted with pentane $(3 \times 30 \mathrm{~mL})$, the solvent was removed from the extract under reduced pressure, and the resulting solid was redissolved in thf $(15 \mathrm{~mL})$. Slow cooling of this solution to $-80^{\circ} \mathrm{C}$ yielded 2 as yellow crystals $(0.53 \mathrm{~g}, 58 \%), \mathrm{mp} 224-231^{\circ} \mathrm{C}$ (decomp). ${ }^{1} \mathrm{H}$ NMR $\left(\mathrm{C}_{6} \mathrm{D}_{6}\right): \delta$ 2.38-0.82 (m, $96 \mathrm{H}$ ), 0.49 ('q of q', $2 \mathrm{H},{ }^{1} \mathrm{~J}_{\mathrm{PtH}}=512 \mathrm{~Hz},{ }^{2} \mathrm{~J}_{\mathrm{PH}}=40 \mathrm{~Hz}$ ) ppm. ${ }^{31} \mathrm{P}\left\{{ }^{1} \mathrm{H}\right\} \mathrm{NMR}$, see Table 3, Ch. 2. IR: 1965 s, 1937 s, 1445 s, 1409 w, 1378 s, 1343 m, 1301 w, 1290 w, 1262 m, 1237 w, 1187 w, 1178 m, 1169 m, 1048 m, 1004 s, 913 m, 887 m, 853 m, 851 s, 818 m, 780 m, 739 s, 648 m, 638 m, 537 m, 523 m, 501 m, $458 \mathrm{~m} \mathrm{~cm}^{-1}$. Anal. Calcd for $\mathrm{C}_{52} \mathrm{H}_{98} \mathrm{P}_{4} \mathrm{Pt}_{2}$ : C, 50.5; $\mathrm{H}, 7.98$. Found: $\mathrm{C}, 50.6 ; \mathrm{H}, 8.04$.

\section{$[(\text { dtbpe }) \mathrm{PtH}]_{2}$ (3).}

A 4:1 hexane:toluene solution ( $60 \mathrm{~mL}$, total) of $6(0.52 \mathrm{~g}, 1.0 \mathrm{mmol})$ was heated at $90^{\circ} \mathrm{C}$ for $16 \mathrm{~h}$ in a Schlenk tube under a slow purge of $\mathrm{N}_{2}$. After cooling to room termperature, the solvent was removed under reduced pressure from the reddish-brown solution, and the residue was extracted with hexane $(3 \times 30 \mathrm{~mL})$. The solvent was removed from the extract under reduced pressure, and the solid residue was redissolved in toluene $(20 \mathrm{~mL})$. Slow cooling of this solution to $-40^{\circ} \mathrm{C}$ yielded 3 as dark orange prisms (0.38 g, 73\%), mp 220-236 ${ }^{\circ} \mathrm{C}$ (decomp). ${ }^{1} \mathrm{H} ~ N M R\left(\mathrm{C}_{6} \mathrm{D}_{6}\right): \delta 1.50(\mathrm{~m}, 8 \mathrm{H})$, $1.35(\mathrm{~m}, 72 \mathrm{H}), 0.05$ ('q of q', $\left.2 \mathrm{H},{ }^{1} \mathrm{~J}_{\mathrm{PtH}}=570 \mathrm{~Hz},{ }^{2} \mathrm{~J}_{\mathrm{PH}}=42 \mathrm{~Hz}\right) \mathrm{ppm} .{ }^{31} \mathrm{P}\left\{{ }^{1} \mathrm{H}\right\}$ NMR, see Table 3, Ch.2. IR: 1975 bm, 1951 bm, 1479 s, 1385 s, 1363 s, 1356 s, 1261 w, 1239 w, 1182 s, 1094 m, 1019 m, 937 m, 851 m, 812 s, 775 s, 664 s, 651 s, 
$644 \mathrm{~s}, 602 \mathrm{~s}, 570 \mathrm{~m}, 495 \mathrm{~s}, 458 \mathrm{~m}, 423 \mathrm{~m} \mathrm{~cm}^{-1}$. Anal. Calcd for $\mathrm{C}_{36} \mathrm{H}_{82} \mathrm{P}_{4} \mathrm{Pt}_{2}: \mathrm{C}$, 42.0; H, 8.03. Found: C, 41.7; H, 7.96.

\section{$\left[(\text { dippe)PtD }]_{2}\left(d_{2}-1\right)\right.$.}

A mixture of (dippe) $\mathrm{PtCl}_{2}(1.1 \mathrm{~g}, 2.1 \mathrm{mmol})$ and $\mathrm{Na} / \mathrm{Hg}(0.8 \%, 50 \mathrm{~g})$ in thf $(150$ $\mathrm{mL})$ was stirred under $\mathrm{D}_{2}(1 \mathrm{~atm})$ at room temperature for $15 \mathrm{~h}$. The mixture was allowed to settle for $4 \mathrm{~h}$, filtered, and the solvent was removed from the filtrate under reduced pressure to yield a dark brown solid. A 1 H NMR spectrum at this point showed that the crude product was an isotopic mixture of the dideuteride, hydridodeuteride, and dihydride complexes. The solid was dissolved in toluene $(80 \mathrm{~mL})$ and stirred at room temperature under $D_{2}(1 \mathrm{~atm}$.) for $30 \mathrm{~h}$. The head space over the solution was evacuated and refilled with $1 \mathrm{~atm}$. of $\mathrm{N}_{2}$ gas, and the sample was stirred at room temperature for $70 \mathrm{~h}$. This process was repeated $\left(\mathrm{D}_{2} / 30 \mathrm{~h}\right.$, then $\left.\mathrm{N}_{2} / 70 \mathrm{~h}\right)$, and the solvent was then removed under reduced pressure. The dark brown solid was extracted with pentane $(3 \mathrm{x}$ $50 \mathrm{~mL}$ ), filtered, and the filtrate was concentrated to $c a .40 \mathrm{~mL}$. Slow cooling of this solution to $-80^{\circ} \mathrm{C}$ yielded the product as a dark brown solid $(0.57 \mathrm{~g}, 60 \%)$, shown to be fully deuterated $d_{2}-1$ by ${ }^{1} \mathrm{H}$ and ${ }^{31} \mathrm{P}\left\{{ }^{1} \mathrm{H}\right\}$ NMR spectroscopy.

\section{(dtbpe)PtD $2\left(d_{2}-6\right) .9$}

A mixture of (dtbpe) $\mathrm{PtCl}_{2}(0.50 \mathrm{~g}, 0.86 \mathrm{mmol})$ and $\mathrm{Na} / \mathrm{Hg}(0.8 \%, 50 \mathrm{~g})$ in the $(150 \mathrm{~mL})$ was stirred under $\mathrm{D}_{2}(1 \mathrm{~atm})$ at room temperature for $15 \mathrm{~h}$. The mixture was allowed to settle for $4 \mathrm{~h}$, filtered, and the solvent was removed from the filtrate under reduced pressure. $\mathrm{A}^{1} \mathrm{H}$ NMR spectrum at this point showed that the crude product was an isotopic mixture of the dideuteride, hydridodeuteride, and dihydride complexes. The dark brown solid was dissolved in toluene $(40 \mathrm{~mL})$ and stirred at room temperature under $D_{2}(1 \mathrm{~atm})$ for $90 \mathrm{~h}$. The head space above the solution was then evacuated and refilled with $\mathrm{D}_{2}$ to a pressure of $1 \mathrm{~atm}$, and the solution was stirred for an additional 48 
h. The solution was filtered and the filtrate was concentrated to $c a .20 \mathrm{~mL}$. Slow cooling of this sclution to $-80^{\circ} \mathrm{C}$ yielded the product, shown to be fully deuterated by ${ }^{1} \mathrm{H}$ and ${ }^{31} \mathrm{P}\left\{{ }^{1} \mathrm{H}\right\}$ NMR spectroscopy, as a beige solid $(0.33 \mathrm{~g}, 74 \%)$.

\section{$\left[(\text { dcype })_{2} \mathrm{Pt}_{2} \mathrm{H}_{3} 7 \mathrm{OH}\right]$.}

To a benzene solution ( $0.5 \mathrm{~mL})$ of $\mathbf{1}(15 \mathrm{mg}), 2$ drops of water were added, and the mixture was stirred for several minutes. The solvent was removed under reduced pressure and the pale yellow solid residue was extracted into $\mathrm{CDCl}_{3}$ and placed in an NMR tube. ${ }^{1} \mathrm{H}$ NMR $\left(\mathrm{CDCl}_{3}\right): \delta 1.60(\mathrm{~m}, 96 \mathrm{H}),-2.81$ ('q of q', $3 \mathrm{H},{ }^{1} \mathrm{~J}_{\mathrm{PtH}}=480 \mathrm{~Hz}$, $\left.{ }^{2 J_{P H}}=39 \mathrm{~Hz}\right) \mathrm{ppm} .{ }^{31} \mathrm{P}\left\{{ }^{1} \mathrm{H}\right\} \mathrm{NMR}$, see Table 4, Chapter 2. 


\section{Chapter 3.}

\section{$\mathrm{Cp}_{2}{ }_{2} \mathrm{Yb}\left(\mathrm{PMe}_{3}\right)_{2}$ (2).}

Trimethylphosphine $(0.086 \mathrm{~mL}, 0.84 \mathrm{mmol})$ was added dropwise to a solution of 1 $(0.18 \mathrm{~g}, 0.41 \mathrm{mmol})$ in toluene $(15 \mathrm{~mL})$. The solution turned bright green and a dark green crystalline solid precipitated from solution within minutes. The mixture was slowly cooled to $-80^{\circ} \mathrm{C}$, yielding the product as dark green crystals $(0.22 \mathrm{~g}, 88 \%), \mathrm{mp} 110^{\circ} \mathrm{C}$ (decomp. to a black solid). ${ }^{1} \mathrm{H}$ NMR $\left(\mathrm{C}_{6} \mathrm{D}_{6}\right): \delta 2.05(\mathrm{~s}, 30 \mathrm{H}), 0.76(\mathrm{~s}, 18 \mathrm{H}) .{ }^{31 \mathrm{p}}\left\{{ }^{1} \mathrm{H}\right\}$ NMR ( $6 \mathrm{C}_{6}$ ): $\delta-55.8$ (s) ppm. IR: $2718 \mathrm{~m}, 1377 \mathrm{~s}, 1367 \mathrm{~m}, 1326 \mathrm{w}, 1304 \mathrm{~s}, 1281$ m, 1017 m, 960 s, 939 s, 839 w, 801 w, 722 m, 710 m, 668 w, 663 w, 624 w, 591 m $\mathrm{cm}^{-1}$. Anal. Calcd for $\mathrm{C}_{26} \mathrm{H}_{48} \mathrm{P}_{2} \mathrm{Yb}$ : C, 52.4; $\mathrm{H}, 8.12$. Found: $\mathrm{C}, 52.3 ; \mathrm{H}, 8.30$.

\section{$\mathrm{Cp}^{*}{ }_{2} \mathrm{Yb}\left(\mathrm{PEt}_{3}\right)$ (3).}

Triethylphosphine $(0.060 \mathrm{~mL}, 0.40 \mathrm{mmol})$ was added dropwise to a toluene solution (15 mL) of $1(0.12 \mathrm{~g}, 0.27 \mathrm{mmol})$. The resulting dark blue solution was concentrated to $\mathrm{ca} .10 \mathrm{~mL}$. Slow cooling to $-80^{\circ} \mathrm{C}$ yielded the product as dark blue crystals $(0.10 \mathrm{~g}, 66 \%), \mathrm{mp} 128^{\circ} \mathrm{C}$ (decomp. to a dark brown oil). ${ }^{1} \mathrm{H}$ NMR $\left(\mathrm{C}_{6} \mathrm{D}_{6}\right): \delta$ $2.04(\mathrm{~s}, 30 \mathrm{H}), 1.27\left(6 \mathrm{H}, \mathrm{qd},{ }^{3} \mathrm{~J}_{\mathrm{HH}}=7.6 \mathrm{~Hz},{ }^{2} \mathrm{~J}_{\mathrm{PH}}=1.6 \mathrm{~Hz}\right), 0.77\left(9 \mathrm{H}, \mathrm{dt},{ }^{3} \mathrm{~J}_{\mathrm{PH}}=\right.$ $\left.14.4 \mathrm{~Hz},{ }^{3} \mathrm{~J}_{\mathrm{HH}}=7.6 \mathrm{~Hz}\right) .{ }^{31} \mathrm{P}\left\{{ }^{1} \mathrm{H}\right\} \mathrm{NMR}\left(\mathrm{C}_{6} \mathrm{D}_{6}\right): \delta-12.6(\mathrm{~s}) \mathrm{ppm}$. IR: $2721 \mathrm{~m}, 1417$ m, 1377 s, 1262 s, 1098 s, 1036 s, 1023 s, 865 w, 803 s, 766 m, 756 m, 702 m, 672 w, $622 \mathrm{w}, 590 \mathrm{w} \mathrm{cm}^{-1}$. Anal. Calcd for $\mathrm{C}_{26} \mathrm{H}_{48} \mathrm{P}_{2} \mathrm{Yb}: \mathrm{C}, 55.6 ; \mathrm{H}, 8.08$. Found: C, $55.5 ; \mathrm{H}, 8.13$.

\section{$\mathrm{Cp}_{2}{ }_{2} \mathrm{Yb}\left(1,2-\left(\mathrm{Me}_{2} \mathrm{P}\right)_{2} \mathrm{C}_{6} \mathrm{H}_{4}\right)(6)$.}

To a toluene solution (15 mL) of $1(0.15 \mathrm{~g}, 0.34 \mathrm{mmol}), 1,2-\left(\mathrm{Me}_{2} \mathrm{P}_{2}\right)_{6} \mathrm{C}_{6} \mathrm{H}_{4}(0.056$ $\mathrm{mL}$ ) was added dropwise. The resulting dark green-brown solution was concentrated to ca. $10 \mathrm{~mL}$, and then filtered. Slow cooling to $-40^{\circ} \mathrm{C}$ yielded the product as maroon crystals $(0.10 \mathrm{~g}, 46 \%)$, which did not melt sharply but darkened to a brown oil over the 
temperature range $260-290{ }^{\circ} \mathrm{C} .{ }^{1} \mathrm{H}$ NMR $\left(\mathrm{C}_{6} \mathrm{D}_{6}\right): \delta 7.11(\mathrm{~m}, 2 \mathrm{H}), 7.04(\mathrm{~m}, 2 \mathrm{H}), 2.06$ $(\mathrm{s}, 30 \mathrm{H}), 1.03(\mathrm{~s}, 12 \mathrm{H}) .{ }^{31} \mathrm{P}\left\{{ }^{1} \mathrm{H}\right\} \operatorname{NMR}\left(\mathrm{C}_{6} \mathrm{D}_{6}\right): \delta-42.5\left(\mathrm{~s}, \mathrm{w}_{1 / 2}=40 \mathrm{~Hz}\right.$ (see text), ${ }^{1} \mathrm{~J}_{\mathrm{YbP}}=650 \mathrm{~Hz}$ ) ppm. IR: $2720 \mathrm{~m}, 1426 \mathrm{~s}, 1376 \mathrm{~s}, 1299 \mathrm{~s}, 1283 \mathrm{w}, 1277 \mathrm{w}, 1134 \mathrm{w}$, 1119 m, 1018 w, 942 s, 907 s, 874 m, 827 w, 799 w, 753 s, 730 m, 718 m, 686 w, $677 \mathrm{w}, 589 \mathrm{w}, 463 \mathrm{~m}, 452 \mathrm{w} \mathrm{cm}^{-1}$. Anal. Calcd for $\mathrm{C}_{30} \mathrm{H}_{46} \mathrm{P}_{2} \mathrm{Yb}: \mathrm{C}, 56.2 ; \mathrm{H}, 7.23$. Found: $C, 56.3 ; \mathrm{H}, 7.39$.

\section{$\mathrm{Cp}^{*}{ }_{2} \mathrm{Yb}\left(\mathrm{OPMe}_{3}\right)(7)$.}

A toluene solution $(10 \mathrm{~mL})$ of $\mathrm{Me}_{3} \mathrm{PO}(0.040 \mathrm{~g}, 0.44 \mathrm{mmol})$ was added dropwise to a stirred solution of $1(0.19 \mathrm{~g}, 0.43 \mathrm{mmol})$ in toluene $(10 \mathrm{~mL})$. The solution turned orange near the end of the addition. The solvent was removed under reduced pressure, giving the crude product as a yellow-orange solid. This solid was washed with pentane $(2 \times 20 \mathrm{~mL})$ and dried under reduced pressure, giving the product as a fine yellow powder $(0.19 \mathrm{~g}, 83 \%), \mathrm{mp} 303-307^{\circ} \mathrm{C}$ (decomp.). ${ }^{1} \mathrm{H}$ NMR $\left(\mathrm{C}_{6} \mathrm{D}_{6}\right): \delta 2.14$ (s, 30H), $0.65\left(\mathrm{~d}, 9 \mathrm{H},{ }^{2} \mathrm{~J}_{\mathrm{PH}}=12.8 \mathrm{~Hz}\right) \mathrm{ppm} .{ }^{31} \mathrm{P}\left\{{ }^{1} \mathrm{H}\right\} \mathrm{NMR}\left(\mathrm{C}_{6} \mathrm{D}_{6}\right): \delta 45.6\left(\mathrm{~s},{ }^{2} \mathrm{~J}_{\mathrm{YbP}}=95 \mathrm{~Hz}\right)$ ppm. IR: 2720 m, 1417 m, 1377 m, 1344 w, 1309 s, 1296 s, 1154 s, 1108 w, 1022 w, $945 \mathrm{~s}, 857 \mathrm{~s}, 799$ w, $747 \mathrm{~m} \mathrm{~cm}^{-1}$. Anal. Calcd for $\mathrm{C}_{23} \mathrm{H}_{39} \mathrm{OPYb}: \mathrm{C}, 51.6 ; \mathrm{H}, 7.34$. Found: C, 51.7; H, 7.08.

\section{$\mathrm{Cp}_{2}^{*} \mathrm{Yb}\left(\mathrm{OPMe}_{3}\right)_{2}(8)$.}

A toluene solution ( $10 \mathrm{~mL}$ ) of $\mathrm{Me}_{3} \mathrm{PO}(0.070 \mathrm{~g}, 0.76 \mathrm{mmol})$ was added dropwise to a toluene solution $(10 \mathrm{~mL})$ of $1(0.15 \mathrm{~g}, 0.34 \mathrm{mmol})$. An orange solid precipitated from the solution during the addition. The solid was allowed to settle, the solvent was removed via cannula, and the solid was washed with toluene $(2 \times 10 \mathrm{~mL})$. Drying under reduced pressure yielded the product as a pumpkin-colored solid (0.080 g, 38\%), mp 290 ${ }^{\circ} \mathrm{C}$ (decomp. to a red-brown oil). ${ }^{1} \mathrm{H}$ NMR (thf-d 8 ): $\delta 1.85\left(\mathrm{~s}, 15 \mathrm{H}, \mathrm{w}_{1 / 2}=1 \mathrm{~Hz}\right.$ ), 1.53 (broad s, $9 \mathrm{H}, \mathrm{w}_{1 / 2}=38 \mathrm{~Hz}$, see text). ${ }^{31} \mathrm{P}\left\{{ }^{1} \mathrm{H}\right\}$ NMR (thf-d 8 ): $\delta 39.3$ (broad s, $\mathrm{w}_{1 / 2}=$ 
$480 \mathrm{~Hz}$, see text) ppm. Free $\mathrm{Me}_{3} \mathrm{PO}$ in thf-d8 has the following values, ${ }^{1} \mathrm{H}$ NMR: 1.34 $\left(\mathrm{d},{ }^{2} \mathrm{~J}_{\mathrm{PH}}=12.8 \mathrm{~Hz}\right.$ ) ppm; ${ }^{31} \mathrm{P}\left\{{ }^{1} \mathrm{H}\right\}$ NMR: 30.5 (s) ppm. IR: $2717 \mathrm{w}, 1377 \mathrm{~m}, 1344 \mathrm{w}$,

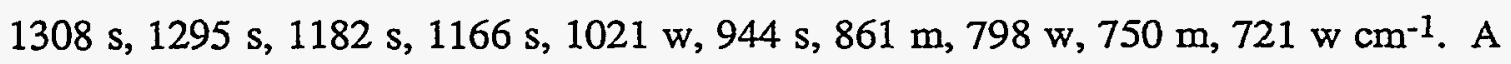
satisfactory elemental analysis was not obtained on this sample, since it was difficult to find a suitable crystallization solvent, see text (the procedure used above gave a product that was consistently $c a .1 \%$ low in carbon).

\section{$\mathrm{Cp}_{2}{ }_{2} \mathrm{Yb}\left(\mathrm{HNPEt}_{3}\right)$ (9).}

A toluene solution $(10 \mathrm{~mL})$ of $\mathrm{Et}_{3} \mathrm{PNH}^{10}(0.045 \mathrm{~g}, 0.34 \mathrm{mmol})$ was added dropwise to a toluene solution ( $10 \mathrm{~mL})$ of $1(0.15 \mathrm{~g}, 0.34 \mathrm{mmol})$. The resulting orange solution was stirred for $30 \mathrm{~min}$ and filtered. Slow cooling of the solution to $-80^{\circ} \mathrm{C}$ gave the product as a fine light orange powder $(0.10 \mathrm{~g}, 51 \%), \mathrm{mp} 240^{\circ} \mathrm{C}$ (decomp. to a dark brown oil). ${ }^{1} \mathrm{H}$ NMR (toluene-d 8 ): $\delta 2.12(\mathrm{~s}, 30 \mathrm{H}), 1.20\left(\mathrm{dq}, 6 \mathrm{H},{ }^{2} \mathrm{~J}_{\mathrm{PH}}=12.1 \mathrm{~Hz}\right.$, $\left.3 \mathrm{~J}_{\mathrm{HH}}=7.8 \mathrm{~Hz}\right), 0.61\left(\mathrm{dt}, 9 \mathrm{H},{ }^{3} \mathrm{~J}_{\mathrm{PH}}=16.8 \mathrm{~Hz},{ }^{3} \mathrm{~J}_{\mathrm{HH}}=7.8 \mathrm{~Hz}\right) \mathrm{ppm}$ (the $\mathrm{N}-\mathrm{H}$ resonance is not observed, see text). ${ }^{31} \mathrm{P}\left\{{ }^{1} \mathrm{H}\right\}$ NMR (toluene-d8): $\delta 60.1\left(\mathrm{~s},{ }^{2} \mathrm{~J}_{\mathrm{YbP}}=92 \mathrm{~Hz}\right) \mathrm{ppm}$. IR: $2721 \mathrm{~m}, 1412 \mathrm{~m}, 1379 \mathrm{~s}, 1283 \mathrm{~m}, 1264 \mathrm{~m}, 1139 \mathrm{~s}, 1046 \mathrm{~m}, 1027 \mathrm{~m}, 1012 \mathrm{~m}, 983$ w, $783 \mathrm{~s}, 769 \mathrm{~s}, 741 \mathrm{w}, 724 \mathrm{~m} \mathrm{~cm}^{-1}$. Anal. Calcd for $\mathrm{C}_{26} \mathrm{H}_{46} \mathrm{NPYb}: \mathrm{C}, 54.2 ; \mathrm{H}, 8.04$. Found: C, 54.4; H, 7.76.

\section{$\mathrm{Cp}_{2}{ }_{2} \mathrm{Yb}\left(\mathrm{Me}_{2} \mathrm{PhPCHSiMe}\right)$ (12).}

To a stirred solution of $1(0.12 \mathrm{~g}, 0.34 \mathrm{mmol})$ in toluene $(10 \mathrm{~mL})$, $\mathrm{Me}_{2} \mathrm{PhPCHSiMe}_{3}{ }^{11}(0.061 \mathrm{~mL})$ was added dropwise. The resulting dark green solution was filtered, and slowly cooled to $-40^{\circ} \mathrm{C}$, yielding the product as dark green crystals $(0.10 \mathrm{~g}, 55 \%), \mathrm{mp} 103{ }^{\circ} \mathrm{C}$ (decomp). ${ }^{1} \mathrm{H}$ NMR (toluene-d8): $\delta$ 7.4-7.0 (m, 5H), 2.14 $(\mathrm{s}, 30 \mathrm{H}), 1.22\left(\mathrm{~d}, 6 \mathrm{H},{ }^{2} \mathrm{~J}_{\mathrm{PH}}=12.5 \mathrm{~Hz}\right), 0.24\left(\mathrm{~d}, 1 \mathrm{H},{ }^{2} \mathrm{~J}_{\mathrm{PH}}=20.5 \mathrm{~Hz}\right), 0.16(\mathrm{~s}, 9 \mathrm{H})$ ppm. ${ }^{31} \mathrm{P}\left\{{ }^{1} \mathrm{H}\right\}$ NMR (toluene-d8): $\delta 10.8$ (s) ppm. IR: $1420 \mathrm{~m}, 1378 \mathrm{~m}, 1329 \mathrm{w}$, 1310 w, 1301 m, 1288 m, 1254 m, 1244 m, 1163 w, 1123 s, 1105 m, 1076 w, 1016 w, 
958 s, 922 s, 917 s, 856 s, 832 s, 767 m, 747 s, 723 w, 697 m, 681 m, 639 m, 590 m, $491 \mathrm{~m}, 421 \mathrm{~m} \mathrm{~cm}^{-1}$. Anal. Calcd ' $\mathrm{C}_{32} \mathrm{H}_{51} \mathrm{PSiYb}: \mathrm{C}, 57.6 ; \mathrm{H}, 7.70$. Found: C, 57.6; $\mathrm{H}, 8.0$.

\section{$\mathrm{Cp}_{2}^{*} \mathrm{Yb}\left(\mathrm{Me}_{2} \mathrm{PhPCH}_{2}\right)(13)$.}

To a stirred solution of $1(0.15 \mathrm{~g}, 0.34 \mathrm{mmol})$ in toluene (10 mL), $\mathrm{Me}_{2} \mathrm{PhPCH}_{2} 11$ $(0.047 \mathrm{~mL})$ was added dropwise. The resulting dark maroon solution was slowly cooled to $-80^{\circ} \mathrm{C}$, yielding the product as reddish-brown crystals $(0.16 \mathrm{~g}, 79 \%)$, mp $166-178{ }^{\circ} \mathrm{C}$. ${ }^{1} \mathrm{H}$ NMR (toluene- $\left.\mathrm{d}_{8}\right): \delta 7.2-6.95(\mathrm{~m}, 5 \mathrm{H}), 2.06(\mathrm{~s}, 30 \mathrm{H}), 1.05\left(\mathrm{~d}, 6 \mathrm{H},{ }^{2} \mathrm{~J}_{\mathrm{PH}}=12.8\right.$ $\mathrm{Hz}$ ), $-0.20\left(\mathrm{~d}, 2 \mathrm{H},{ }^{2} \mathrm{~J}_{\mathrm{PH}}=13.4 \mathrm{~Hz}\right) \mathrm{ppm} .{ }^{31} \mathrm{P}\left\{{ }^{1} \mathrm{H}\right\}$ NMR (toluene-ds): $\delta 18.7(\mathrm{~s}) \mathrm{ppm}$. IR: $2721 \mathrm{~m}, 1437 \mathrm{~s}, 1420 \mathrm{~m}, 1378 \mathrm{~m}, 1367 \mathrm{~m}, 1304 \mathrm{~m}, 1289 \mathrm{w}, 1262 \mathrm{w}, 1182 \mathrm{w}$, 1159 m, 1113 m, 1018 m, 1000 w, 977 m, 953 s, 925 s, 844 m, 819 w, 799 w, 760 m, 744 s, 725 s, 692 s, 667 m, 494 m, $419 \mathrm{~m} \mathrm{~cm}^{-1}$. Anal. Calcd for $\mathrm{C}_{29} \mathrm{H}_{73} \mathrm{PYb}: \mathrm{C}, 58.5$; H, 7.29. Found: C, 58.2; H, 7.36. 


\section{Chapter 4.}

Formation of $\left(\mathrm{PPh}_{3}\right)_{2} \mathrm{Pt}$ in situ, and Reaction with $\mathrm{Cp}_{2}{ }_{2} \mathrm{Yb}, 1$.

To a $-80^{\circ} \mathrm{C}$ toluene solution $(30 \mathrm{~mL})$ of $\left(\mathrm{PPh}_{3}\right)_{2} \mathrm{Pt}(\mathrm{H})(\mathrm{Cl})(0.13 \mathrm{~g}, 0.17 \mathrm{mmol})$, a diethyl ether solution of dimethylmagnesium $(0.34 \mathrm{M}, 0.25 \mathrm{~mL}, 0.086 \mathrm{mmol})$ was added dropwise. The resulting yellow solution was allowed to warm to $-55^{\circ} \mathrm{C}$, and stirred at this temperature for $3 \mathrm{~h}$. A dynamic vacuum was applied to the solution for $1 \mathrm{~h}$ (to remove the $\mathrm{Et}_{2} \mathrm{O}$ ), the solution was re-cooled to $-80^{\circ} \mathrm{C}$, and the $\mathrm{MgCl}_{2}$ by-product was allowed to settle for $4 \mathrm{~h}$. The solution was then transferred via a filter stick to a $-80^{\circ} \mathrm{C}$ toluene solution $(25 \mathrm{~mL})$ of $1(0.080 \mathrm{~g}, 0.18 \mathrm{mmol})$, giving an orange-brown solution. The solution was allowed to slowly warm to room temperature over several hours, and then was stirred at room temperature for $8 \mathrm{~h}$. The resulting cloudy orange-brown solution was filtered and the solvent was removed under reduced pressure, giving an orange-brown solid. The ${ }^{1} \mathrm{H}$ and ${ }^{31} \mathrm{P}\left\{{ }^{1} \mathrm{H}\right\}$ NMR spectra of this crude product indicated that the only $\mathrm{C}_{6} \mathrm{D}_{6}$-soluble $\mathrm{Pt}$-containing product from this reaction is $\left(\mathrm{PPh}_{3}\right)_{3} \mathrm{Pt}$.

\section{(dcype)Pt $(\mu-\mathrm{H})\left(\mu-\mathrm{CH}_{2} \mathrm{C}_{4} \mathrm{Me}_{4}\right) \mathrm{YbCp}^{*}$ (3).}

An NMR sample in a J. Young tube containing $1(6.0 \mathrm{mg}, 0.014 \mathrm{mmol})$ and $2(9.0$ $\mathrm{mg}, 0.013 \mathrm{mmol}$ ) in $0.5 \mathrm{~mL}$ cyclohexane- $\mathrm{d}_{12}$ (an orange solution) was heated to $45^{\circ} \mathrm{C}$ for $12 \mathrm{~h}$, giving an orange-brown solution. The ${ }^{1} \mathrm{H}$ and ${ }^{31} \mathrm{P}\{1 \mathrm{H}\}$ NMR data at this point indicated ca. $50 \%$ conversion to 3 . Further heating at $45^{\circ} \mathrm{C}$ for a total of $55 \mathrm{~h}$ resulted in quantitative, clean conversion to 3 . The ${ }^{1} \mathrm{H},{ }^{31} \mathrm{P}\left\{{ }^{1} \mathrm{H}\right\},{ }^{195} \mathrm{Pt}$, and ${ }^{171} \mathrm{Yb} N M R$ data for 3 are given in Table 1, Chapter 4.

\section{Interaction of 1 with Various Gases--General Procedure.}

The experiments described in the text were done by making up an NMR sample of 1 in the desired solvent in the dry box, in a J. Young NMR tube. The top of the J. Young tube was attached to a Schlenk line with use of a hose clamp, and the hose was 
evacuated and refilled with $\mathrm{N}_{2}$ three times. The solution was frozen by placing the bottom of the NMR tube in liquid nitrogen, and the sample was opened to dynamic vacuum for $c a .1$ minute. The J. Young top was closed, and the sample was thawed; this freeze-pump-thaw degassing cycle was repeated twice. The vacuum manifold of the Schlenk line was filled with $1 \mathrm{~atm}$. of the desired gas, and the J. Young tube (sample under vacuum from the last freeze-pump-thaw cycle) was opened to this manifold for $c a$. $20 \mathrm{sec}$, closed, and removed from the Schlenk line. For the experiment involving 0.5 atm. of $\mathrm{D}_{2}$ and $0.5 \mathrm{~atm}$. of $\mathrm{CH}_{4}$, the Schlenk line vacuum manifold was filled with 0.5 atm. of each gas, and then this manifold was opened to the NMR sample.

\section{Interaction of 1 with $\mathrm{C}_{6} \mathrm{H}_{6}$.}

These experiments involved two NMR samples made up in the dry box, one containing 1 (6 mg, $0.014 \mathrm{mmol})$ and one containing $\mathrm{C}_{6} \mathrm{H}_{6}(1 \mu \mathrm{L}, .011 \mathrm{mmol})$, both in ca. $0.5 \mathrm{~mL}$ of cyclohexane- $\mathrm{d}_{12}$. Both NMR tubes were capped with septa. In addition, a vial containing $6 \mathrm{mg}$ of 1 in $c a .0 .2 \mathrm{~mL}$ cyclohexane- $\mathrm{d}_{12}$, and a vial containing $c a .1 \mathrm{~mL}$ $\mathrm{C}_{6} \mathrm{H}_{6}$, both capped with septa, were prepared. The two NMR samples and the two vials were removed from the box and taken to the NMR machine ( $300 \mathrm{MHz}{ }^{1} \mathrm{H}$ frequency).

For the sample containing 1: the sample was placed in the NMR probe, and the magnet was shimmed. Then, $1 \mu \mathrm{L} \mathrm{C}_{6} \mathrm{H}_{6}$ was added via syringe (from the vial containing the $\mathrm{C}_{6} \mathrm{H}_{6}$ ), a 1 scan ${ }^{1} \mathrm{H}$ spectrum (1 scan for integration purposes) was taken (the magnet was not shimmed again, for this and subsequent spectra), and then $2 \mu \mathrm{L}$ more $\mathrm{C}_{6} \mathrm{H}_{6}$ were added, etc. For the sample containing $\mathrm{C}_{6} \mathrm{H}_{6}$ : the sample was placed in the probe, the magnet was shimmed, and a 1 scan ${ }^{1} \mathrm{H}$ spectrum was taken. The solution of 1 in the other vial was syringed into this sample, the sample was replaced into the NMR probe, the magnet was re-shimmed, and another ${ }^{1} \mathrm{H}$ spectrum was acquired. Then, $2 \mu \mathrm{L} \mathrm{C}_{6} \mathrm{H}_{6}$ were added, etc. (the magnet was not re-shimmed for this spectrum, or subsequent spectra). 
The spectra were all processed with a line broadening factor of $0.3 \mathrm{~Hz}$, and the resonance half height widths were adjusted with respect to the half height width of the residual $\mathrm{C}_{6} \mathrm{D}_{11} \mathrm{H}$ in the sample. As mentioned in the text, no perturbations in the ${ }^{1} \mathrm{H}$ chemical shifts or resonance half height widths, for the resonances arising from 1 and $\mathrm{C}_{6} \mathrm{H}_{6}$, were observed in any of the spectra. 


\section{X-RAY CRYSTALLOGRAPHIC STUDIES}

\section{General}

The following information is common to all of the crystal structure determinations. Several crystals were placed in Paratone $\mathrm{N}$ oil, ${ }^{12}$ a suitable crystal was cut (if too large) or used as is, and was mounted on the end of a cut quartz capillary tube and placed under a flow of cold nitrogen on an Enraf-Nonius CAD4 diffractometer. ${ }^{13}$ The solidified oil held the crystal in place and protected it from decomposition. The temperature was stabilized at the temperature indicated in the individual Tables, with an automated cold flow apparatus.

After centering the crystal in the X-ray beam, the cell dimensions and an orientation matrix were determined by a least-squares fit to the setting angles of the unresolved MoK $\alpha$ components of 24 symmetry-related reflections. Details of the unit cell, collection parameters, and structure refinement are listed in the Tables. A set of three standard reflections, given in the Tables, was chosen to monitor intensity and crystal orientation. The intensity was checked after every hour of X-ray exposure time and the maximum correction for intensity loss is given in the Tables; this is discussed in the text, if necessary. The orientation of the crystal was checked after every 200 reflections and it was reoriented if any of the standard reflections were offset from the predicted position by more than $0.1^{\circ}$. The number of reorientations required over the course of the data collection is given in the Tables.

The raw intensity data were converted to structure factor amplitudes and their esds by correction for scan speed, background, and Lorentz-polarization effects. 14-16 The least-squares program minimized the expression, $\Sigma w\left(\left|F_{0}\right|-\left|F_{c}\right|\right)^{2}$, where $w$ is the weight of a given observation. Where an empirical absorption correction is applied, the correction was based on averaged azimuthal psi scans for three reflections with $\chi>80^{\circ} ; 17$ the variation of $I_{\min } / I_{\max }$ for the average relative intensity curve is given in the text. The $\mathrm{p}$-factor value used for each data set is given in the Tables; this factor was used to reduce 
the weight of intense reflections in the refinements. ${ }^{18}$ The analytical forms of the scattering factor tables for the neutral atoms were used 19 and all non-hydrogen scattering factors were corrected for both real and imaginary components of anomalous dispersion. 20 
(dcype) $\mathrm{Pt}(\mu-\mathrm{H})_{2} \mathrm{YbCp}_{2}{ }_{2}$.

Dark maroon X-ray quality crystals were grown from slow cooling of a toluene solution of $\mathrm{Cp}_{2}{ }_{2} \mathrm{Yb}$ and (dcype) $\mathrm{PtH}_{2}\left(1: 1\right.$ molar ratio) to $-40^{\circ} \mathrm{C}$. No correction for crystal decomposition was necessary (the crystal showed only a $2.1 \%$ loss of intensity ove total exposure time of 15.4 hours). An empirical absorption correction was applici to the data; examination of the azimuthal scans showed a variation of $I_{\min } / I_{\max }=$ 0.84 for the average relative intensity curve.. Details of the unit cell, collection parameters, and structure refinement are listed in Table 1.

The $\mathrm{Pt}$ and $\mathrm{Yb}$ atoms were located from a Patterson map, following which the two $\mathrm{P}$ atoms were located as the two largest peaks in the Fourier difference map $(>2 \mathrm{X})$ larger than the 3rd difference peak). Many difference peaks were located in the expected vicinity of the cyclohexyl groups of the dcype ligand, as well as in the expected location for the two $\mathrm{Cp}^{*}$ rings. However, the crystal suffered from extensive disorder, and unequivocal assignment of these atoms could not be made. Consequently, none of these difference peaks were included in the model. The thermal parameters for all four of the heavy atoms were left isotropic. Attempts at solving the structure using SHELXS-86;21 using Patterson methods prior to performing an absorption correction on the data; and inputting the top 30 peaks from the difference map resulting from the model with the four heavy atoms, as carbon atoms; were made and all of these attempts were also unsuccessful. 
Table 1. Crystal Data for (dcype) $\mathrm{Pt}\left(\mu-\mathrm{H}_{2}\right)_{2} \mathrm{YbCp}_{2}^{*}-2$

chem formula

mol wt.

crystal size (mm)

$\mathrm{T},{ }^{\circ} \mathrm{C}$

space group

a, $\AA$

$\mathrm{b}, \AA$

c, $\AA$

$\mathrm{V}, \AA^{3}$

$\mathrm{Z}$

$\mathrm{F}(000)$

$\mathrm{d}$ (calc.), $\mathrm{g} \mathrm{cm}^{-3}$

$\mu$ (calc.), $\mathrm{cm}^{-1}$

octants measd

$2 \theta$ range

intensity/orientation refns

\# reorientations

no. Iflns collected

max cor for cryst decay

absn corrn (EAC)

no. atoms in least squares

no. unique rflns

no. rflns with $\mathrm{F}_{0}{ }^{2}>3 \sigma\left(\mathrm{F}_{0}{ }^{2}\right)$

$\mathrm{p}$ factor

no. params

$\mathrm{R}$

$\mathrm{R}_{\mathrm{w}}$

$\mathrm{R}_{\text {all }}$

GOF

largest $\Delta / \sigma$ in final LS cycle

diff Fourier $\left(\mathrm{e}^{-} \AA^{-3}\right)$
$\mathrm{C}_{46} \mathrm{H}_{80} \mathrm{P}_{2} \mathrm{PtYb}$

1063.22

$0.61 \times 0.47 \times 0.37$

$-99$

$\mathrm{P} 2{ }_{1} 2_{1} 2_{1}$

$11.955(2)$

$19.420(6)$

19.926(3)

$4626(2)$

4

534

1.526

51.5

$+\mathrm{h},+\mathrm{k},+1$

$3-45^{\circ}$

$(6,2,7),(-2,3,11),(6,-5,1)$

0

3459

not done

$\mathrm{T}_{\max }=0.998, \mathrm{~T}_{\min }=0.690$

4

3383

2042

0.03

17

0.2283

0.2639

0.3366

8.216

0.01

$+17.2,-1.06$ 


\section{(dippe)Pt( $(1-\mathrm{Me})_{2} \mathrm{YbCp}_{2}{ }_{2}$.}

Dark =en blocks of the complex were grown from slow cooling of a ca. 2:1 toluene:pentane solution to $-40^{\circ} \mathrm{C}$. A suitable block was cut from one of the crystals. The dimensions and volume of the unit cell suggested triclinic symmetry with four molecules in the unit cell. Details of the unit cell, collection parameters, and structure refinement are listed in Table 2.

Analysis of the data revealed that a $\mathrm{C}$-centered monoclinic cell was also consistent with the dimensions and volume of the unit cell, and the data were treated accordingly. The following systematic absences: $\mathrm{hkl}, \mathrm{h}+\mathrm{k}$ odd; $\mathrm{h} 01,1$ odd; were present, consistent with the space group C2/c. The symmetry-related data were averaged, resulting in 4687 unique data

The coordinates of the $\mathrm{Pt}$ and $\mathrm{Yb}$ atoms were then determined by Patterson methods. The locations of all non-hydrogen atoms were determined through the use of standard Fourier techniques and refined by least-squares methods. A difference Fourier map indicated that the placement of the hydrogen atoms based on idealized bonding geometry was justified by the quality of the data (excluding the hydrogens on the bridging methyl groups). These atoms were placed in the idealized positions and included in the structure factor calculations but not refined. All hydrogen atoms were given isotropic thermal parameters 1.2 times the $B_{\text {iso }}$ of the atom to which they were bonded.

After final refinement of the structure using isotropic thermal parameters on all atoms a $\emptyset$-independent differential absorption correction (a "DIFABS" correction ${ }^{22}$ ) was .2plied to the raw data, using the isotropic model as a basis. The "difabs-corrected" data were then refined, first on the heavy atoms, then the hydrogen atoms were added (again, they were included in the structure factor calculation but not refined by least squares), and then the non-hydrogen atoms were allowed to go anisotropic.

Examination of a difference Fourier map at this point showed 5 peaks of intensity $0.832-0.477 \mathrm{e} / \AA^{3}$ near the two bridging methyl carbon atoms, at $c a .1 \AA$ from the carbon 
atoms, and oriented roughly tetrahedrally around the carbons. These peaks were assigned as the hydrogen atoms bonded to these carbon atoms, and were included in the structure factor calculation but not refined (they were given isotropic thermal parameters equal to $1.2\left(\mathrm{~B}_{\mathrm{iso}}\right)$ of the carbon atoms to which they are bonded). The sixth hydrogen atom on these two carbon atoms $(\mathrm{H} 2 \mathrm{C})$ was added assuming idealized bonding geometry (i.e, tetrahedral geometry, $d(C-H)=0.95 \AA$ ). Further refinement of the model showed that the inclusion of these atoms was justified $\left(R, R_{W}\right.$ prior to the inclusion of these six hydrogen atoms was $0.031,0.037$, respectively; after inclusion, $0.029,0.034$, respectively).

Many close intermolecular contacts ( $<3.5 \AA$ ) were found, indicating a relatively crowded mode of packing for this complex in the solid state. Several of these close contacts involve the hydrogen atoms of the bridging methyl groups. Inspection of the residuals ordered in the ranges of $\sin (\theta / \lambda), \mid \mathrm{F}_{0} \mathrm{l}$, and parity and value of the individual indexes showed no unusual trends. Most of the positive difference peaks in the final Fourier difference map are located near the $\mathrm{Pt}$ and $\mathrm{Yb}$ atoms. 
Table 2. Crystal Data for (dippe) $\mathrm{Pt}(\mu-\mathrm{Me})_{2} \mathrm{YbCp}_{2}^{*}$.

\begin{tabular}{|c|c|}
\hline chem formula & $\mathrm{C}_{36} \mathrm{H}_{68} \mathrm{P}_{2} \mathrm{PtYb}$ \\
\hline mol wt. & 931.02 \\
\hline crystal size (mm) & $0.56 \times 0.20 \times 0.17$ \\
\hline $\mathrm{T},{ }^{\circ} \mathrm{C}$ & -125 \\
\hline space group & $\mathrm{C} 2 / \mathrm{c}$ \\
\hline $\mathrm{a}, \AA$ & $33.90(2)$ \\
\hline $\mathrm{b}, \AA$ & $11.255(6)$ \\
\hline $\mathrm{c}, \AA$ & $20.535(6)$ \\
\hline$\beta,(\operatorname{deg})$ & $98.41(4)$ \\
\hline $\mathrm{V}, \AA^{3}$ & $7750(7)$ \\
\hline $\mathrm{Z}$ & 8 \\
\hline$F(000)$ & 462 \\
\hline $\mathrm{d}\left(\right.$ calc.), $\mathrm{g} \mathrm{cm}^{-3}$ & 1.596 \\
\hline$\mu($ calc. $), \mathrm{cm}^{-1}$ & 61.4 \\
\hline octants measd & $\pm \mathrm{h}, \pm \mathrm{k},+\mathrm{l}$ \\
\hline $2 \theta$ range & $3-40^{\circ}$ \\
\hline intensity, orientation refns & $(-8,6,2),(-17,3,4),(7,-5,-7)$ \\
\hline \# reorientations & 14 \\
\hline no. rflns collected & 8420 \\
\hline max cor for cryst decay & $2.7 \%$ on $\mathrm{F}$ \\
\hline absn corm (DIFABS) & $\mathrm{T}_{\max }=1.23, \mathrm{~T}_{\min }=0.825$ \\
\hline no. atoms in least squares & 40 \\
\hline no. unique rflns & 3300 \\
\hline no. rflns with $\mathrm{F}_{0}^{2}>3 \sigma\left(\mathrm{F}_{0}^{2}\right)$ & 6159 \\
\hline $\mathrm{p}$ factor & 0.03 \\
\hline no. params & 361 \\
\hline $\mathrm{R}$ & 0.0288 \\
\hline $\mathrm{R}_{\mathrm{W}}$ & 0.0338 \\
\hline $\mathrm{R}_{\text {all }}$ & 0.0288 \\
\hline GOF & 1.168 \\
\hline largest $\Delta \sigma \sigma$ in final LS cycle & 0.00 \\
\hline $\operatorname{diff}$ Fourier $\left(e^{-} \AA^{-3}\right)$ & $+1.0,-0.23$ \\
\hline
\end{tabular}




\section{(dippe)Pt $(\mu-\mathrm{Me})(\mu-\mathrm{H}) \mathrm{YbCp}^{*}{ }_{2}$.}

Dark green-brown blocks of the complex were grown from layering a pentane solution of $\mathrm{YbCp}^{*}{ }_{2}$ on top of a toluene solution of (dippe) $\mathrm{Pt}(\mathrm{Me})(\mathrm{H})$, and allowing the resulting solution to stand overnight at room temperature. A suitable block was cut from one of the crystals. The dimensions and volume of the unit cell suggested monoclinic symmetry with four molecules in the unit cell. Details of the unit cell, collection parameters, and structure refinement are listed in Table 3.

The crystal showed a $0.6 \%$ loss in intensity over the course of the data collection (total exposure time, 27.0 hours); consequently a linear decay correction was not necessary. Analysis of the data revealed the following systematic absences: 0k0, $\mathrm{k}$ odd; h 01,1 odd; consistent with the space group $\mathrm{P} 21 / \mathrm{c}$ (\#14). These reflections were rejected from the data set.

The coordinates of the $\mathrm{Pt}$ and $\mathrm{Yb}$ atoms were determined using direct methods (SHELXS). The locations of all non-hydrogen atoms were determined through the use of standard Fourier techniques and refined by least-squares methods. After final refinement of the structure using isotropic thermal parameters on all atoms a $\theta$ independent differential absorption correction (a "DIFABS" correction ${ }^{22}$ ) was applied to the raw data, using the isotropic model as a basis. The "difabs-corrected" data were then refined isotropically.

The Fourier difference map from the resulting model revealed several cases of disorder in the structure, which were modelled as follows: one $\mathrm{Cp} *$ ring consists of 6 carbon atoms, two of which were assigned multiplicity of 0.5 ; the other $\mathrm{Cp} *$ ring also consists of 6 carbon atoms, with three adjacent atoms assigned a multiplicity of 0.67 ; there are 10 methyl carbon atoms on each $\mathrm{Cp}^{*}$ ring, each of multiplicity 0.5 (a result of two major orientations of the ring, about the ring centroid axis); the $\left(\mathrm{CH}_{2}\right)_{2}$ bridge of the phosphine was modelled as four carbon atoms, each of multiplicity 0.5 (arising from the two possible geometries of this bridge); two of the iso-propyl groups of the phosphine 
were found to be rotationally disordered about the ipso carbon atom, and were modelled by adding a third methyl carbon, and assigning two of the methyl carbons a multiplicity of 0.5 (the third methyl kept at multiplicity 1.0); another of the iso-propyl groups of the phosphine was found to be disordered about the $\mathrm{P}-\mathrm{C}_{\mathrm{ipso}}$ bond (basically a result of two different orientations of this group), and two separate iso-propyl groups were used to model this disorder, one of the iso-propyl groups assigned a muliplicity of 0.67 and the other a multiplicity of 0.33 (amazingly, the fourth iso-propyl group was not disordered!)

A DIFABS absorption correction 22 ( $\theta$-independent) was then applied to the raw data, using this improved model as a basis. The model was then refined isotropically and then anisotropically (only the heavy atoms, and the carbon atoms of multiplicity 1.0 (14 of the 35 total carbon atoms) were refined anisotropically). At this point, 16 reflections were rejected on the basis of large $w(\Delta)^{2}$ values, as well as a trend in hkl: they were all of the form $h, 0,0 ; 2 h, h, 0 ; 3 h, h, 0$; etc. or very nearly so (e.g, $3 h, h, 1)$. Not surprisingly, analysis of the model at this point indicated that inclusion of the hydrogen atoms at idealized locations was not justified by the quality of the data, and so no hydrogens were included in the model. Also, no difference peaks near the bridging methyl carbon or near the expected hydride location could be located.

Inspection of the residuals ordered in the ranges of $\sin (\theta / \lambda),\left|F_{0}\right|$, and parity and value of the individual indexes showed no unusual trends. The final difference Fourier map showed one large peak of $6.5 \mathrm{e} / \AA^{3}$, associated with the $\mathrm{Pt}$ atom. The next-largest peak was $2.3 \mathrm{e} / \AA^{3}$, with the largest negative peak being $-0.47 \mathrm{e} / \AA^{3}$. Most of the positive difference peaks were located near the $\mathrm{Pt}$ and $\mathrm{Yb}$ atoms. 
Table 3. Crystal Data for (dippe)Pt $(\mu-\mathrm{Me})(\mu-\mathrm{H}) \mathrm{YbCp}_{-2}^{*}$.

\begin{tabular}{|c|c|}
\hline chem formula & $\mathrm{C}_{35} \mathrm{H}_{66} \mathrm{P}_{2} \mathrm{PtYb}$ \\
\hline mol wt. & 916.99 \\
\hline crystal size (mm) & $0.40 \times 0.35 \times 0.26$ \\
\hline $\mathrm{T},{ }^{\circ} \mathrm{C}$ & -100 \\
\hline space group & $\mathrm{P} 2_{1} / \mathrm{c}$ \\
\hline $\mathrm{a}, \AA$ & $18.778(5)$ \\
\hline $\mathrm{b}, \AA$ & $10.903(4)$ \\
\hline$c, \AA$ & $20.255(5)$ \\
\hline$\beta$, (deg) & $114.74(2)$ \\
\hline $\mathrm{V}, \AA^{3}$ & $3766(2)$ \\
\hline $\mathrm{Z}$ & 4 \\
\hline$F(000)$ & 454 \\
\hline $\mathrm{d}$ (calc.), $\mathrm{g} \mathrm{cm}^{-3}$ & 1.617 \\
\hline$\mu$ (calc.), $\mathrm{cm}^{-1}$ & 63.1 \\
\hline rflns measd & $\pm \mathrm{h}, \pm \mathrm{k},+1$ \\
\hline $2 \theta$ range & $3-55^{\circ}$ \\
\hline intensity, orientation refns & $(2,-5,-8),(-10,2,9),(4,5,-8)$ \\
\hline \# reorientations & 1 \\
\hline no. rflns collected & 7390 \\
\hline max cor for cryst decay & not done \\
\hline absn corrn (DIFABS) & $\mathrm{T}_{\max }=2.00, \mathrm{~T}_{\min }=0.696$ \\
\hline no. atoms in least squares & 59 \\
\hline no. unique rflns & 6669 \\
\hline no. rflns with $\mathrm{F}_{0}^{2}>3 \sigma\left(\mathrm{F}_{0}^{2}\right)$ & 4710 \\
\hline $\mathrm{p}$ factor & 0.05 \\
\hline no. params & 327 \\
\hline $\mathrm{R}$ & 0.0689 \\
\hline $\mathrm{R}_{\mathrm{W}}$ & 0.0815 \\
\hline $\mathrm{R}_{\text {all }}$ & 0.103 \\
\hline GOF & 2.179 \\
\hline largest $\Delta / \sigma$ in final LS cycle & 0.01 \\
\hline $\operatorname{diff}$ Fourier $\left(\mathrm{e}^{-} \AA^{-3}\right)$ & $+6.6,-0.47$ \\
\hline
\end{tabular}


$[(\text { dippe }) \mathrm{PtH}]_{2}$.

Brown opaque plates of the complex were grown from slow cooling of a hexane solution to $-40^{\circ} \mathrm{C}$. A suitable square plate was cut from one of the crystals and placed in Paratone $\mathrm{N}$ oil. The dimensions and volume of the unit cell suggested orthorhombic symmetry with four molecules in the unit cell. Details of the unit cell, collection parameters, and structure refinement are listed in Table 4.

The crystal showed no appreciable decay over the course of the data collection (2.8\% loss in intensity over a total exposure time of 18.3 hours), and so no decay correction was done. An empirical absorption correction was applied to the data; examination of the azimuthal scans showed a variation of $I_{\min } / I_{\max }=0.75$ for the average relative intensity curve. Analysis of the data revealed the following systematic absences:

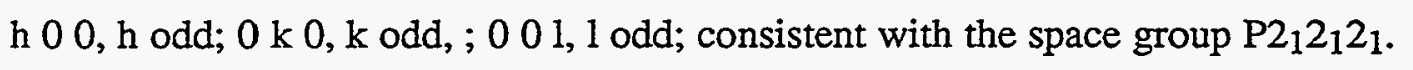

The coordinates of the two independent platinum atoms were determined by Patterson methods. The locations of all non-hydrogen atoms were determined through the use of standard Fourier techniques and refined by least-squares methods. A difference Fourier map indicated that the placement of the hydrogen atoms based on idealized bonding geometry was justified by the quality of the data (excluding the hydrides). These atoms were placed in the idealized positions and included in the structure factor calculations but not refined. All hydrogen atoms were given isotropic thermal parameters 1.3 times the $B$ (iso) of the atom to which they were bonded. Refinement was attempted on both possible enantiomers of the complex. The "incorrect" enantiomer resulted in slightly higher $R$ factors $\left(\Delta R_{W}=0.006\right)$; the enantiomer that gave lower $\mathrm{R}$ factors was used for the remainder of the refinements.

After final refinement of the structure using isotropic thermal parameters on all atoms $\left(R=0.108, R_{W}=0.113\right.$ at this point), a $\theta$-independent differential absorption correction $^{22}$ was applied to the raw data, using the isotropic model as a basis (this was deemed necessary as the value of $\mu$ (calc.) was 81.4 and the azimuthal scans showed a 
large variation in intensity, for a given value of phi). The data were then refined, first on the heavy atoms, then the hydrogen atoms were added (again, they were included in the structure factor calculation but not refined by least squares), and then the non-hydrogen atoms were allowed to go anisotropic. Towards the end of the refinement, examination of the extinction test listing indicated that secondary extinction was occuring; refinement of this parameter resulted in a final value of $4.28 \times 10^{-8}$. Also, one reflection was found to have an anomalously high value of $w(\Delta)^{2}(120$, for the $(3,0,1)$ reflection, next highest $\mathrm{w}(\Delta)^{2}$ value $=30$ ), and was consequently rejected.

No close intermolecular contacts $(<3.5 \AA)$ were found. Inspection of the residuals ordered in the ranges of $\sin (\theta / \lambda),\left|F_{0}\right|$, and parity and value of the individual indexes showed no trend other than the one previously mentioned in connection with secondary extinction.

The highest and lowest peaks in the final difference Fourier map had electron densities of 1.368 and $-0.372 \mathrm{e} / \AA^{3}$, respectively. Due to the presence of a large number of positive peaks with fairly high electron density values (18 peaks with electron densities greater than $0.800 \mathrm{e} / \AA^{3}$ ), many of which are likely associated with the platinum atom peaks, an unambiguous assignment of these peaks to hydride atoms could not be made. Refinement upon all of the atoms (including the ideally-placed hydrogen atoms) was then attempted, in the hopes of improving the model to a point at which the hydride positions could be located. It was found that many of the isotropic thermal parameters of the hydrogen atoms became artificially large and/or artificially negative, indicating that inclusion of the hydrogen atoms in the refinement process was not justified by the quality of the data. Consequently, it was determined that the positions of the hydrides could not be unambiguously determined. 
Table 4. Crystal Data for [(dippe)PtH]2.

\begin{tabular}{|c|c|}
\hline chem formula & $\mathrm{C}_{28} \mathrm{H}_{66} \mathrm{P}_{i_{2}} \mathrm{P}_{4}$ \\
\hline mol wt. & 916.92 \\
\hline crystal size (mm) & $0.48 \times 0.45 \times 0.18$ \\
\hline space group & $\mathrm{P} 2{ }_{1}{ }_{1} 2_{1}$ \\
\hline a, $\AA$ & $9.245(2)$ \\
\hline $\mathrm{b}, \AA$ & $16.966(2)$ \\
\hline$c, \AA$ & $22.690(6)$ \\
\hline$\alpha,(\mathrm{deg})$ & 90 \\
\hline$\beta,(\operatorname{deg})$ & 90 \\
\hline$\gamma,(\operatorname{deg})$ & 90 \\
\hline$V, \AA^{3}$ & $3559(1)$ \\
\hline $\mathrm{Z}$ & 4 \\
\hline$F(000)$ & 450 \\
\hline $\mathrm{d}$ (calc.), $\mathrm{g} \mathrm{cm}^{-3}$ & 1.713 \\
\hline$\mu$ (calc.), $\mathrm{cm}^{-1}$ & 81.4 \\
\hline $\mathrm{T},{ }^{\circ} \mathrm{C}$ & -95 \\
\hline octants measd & $+\mathrm{h},+\mathrm{k},+1$ \\
\hline $2 \theta$ range & $3-55^{\circ}$ \\
\hline intensity, orientation refns & $(5,4,-1),(-2,9,1),(2,5,10)$ \\
\hline \# reorientations & 1 \\
\hline no rflns collected & 4630 \\
\hline max cor for cryst decay & $1.4 \%$ on $\mathrm{F}$ \\
\hline absn corrn (DIFABS) & $\mathrm{T}_{\max }=1.31, \mathrm{~T}_{\min }=0.759$ \\
\hline no atoms in least squares & 34 \\
\hline no. unique rflns & 4567 \\
\hline no. rflns with $F_{0}{ }^{2}>3 \sigma\left(F_{0}{ }^{2}\right)$ & 3646 \\
\hline $\mathrm{p}$ factor & 0.04 \\
\hline no params & 308 \\
\hline $\mathrm{R}$ & 0.0344 \\
\hline $\mathrm{R}_{\mathrm{W}}$ & 0.0371 \\
\hline Rall & 0.0529 \\
\hline GOF & 1.070 \\
\hline largest $\Delta / \sigma$ in final LS cycle & 0.00 \\
\hline diff Fourier $\left(e^{-} \AA^{-3}\right)$ & $+1.4,-0.37$ \\
\hline
\end{tabular}




\section{$\left[(\right.$ dtbpe $) \mathrm{PtH}_{2}$.}

Clear dark orange needles of the complex were grown from slow cooling of a toluene solution to $-40^{\circ} \mathrm{C}$; the crystals were solvent-loss sensitive, and were handled accordingly. A suitable plate was cut from one of the crystals. The dimensions and volume of the unit cell suggested triclinic symmetry with two molecules in the unit cell. Details of the unit cell, collection parameters, and structure refinement are listed in Table 5.

The crystal showed a linear $4.1 \%$ loss in intensity over a total exposure time of 40.2 hours; consequently, a linear isotropic decay correction was applied to the data. An empirical absorption correction was applied to the data; examination of the azimuthal scans showed a variation of $I_{\min } / I_{\max }=0.67$ for the average relative intensity curve. Analysis of the data revealed no systematic absences, consistent with the space group PT.

The coordinates of the two independent platinum atoms were determined by Patterson methods. The locations of all non-hydrogen atoms were determined through the use of standard Fourier techniques and refined by least-squares methods. Based on a difference Fourier map of the heavy atom isotropic model, five of the eight tert-butyl groups of the two phosphine ligands were found to be rotationally disordered (i.e, positive difference peaks were located in between the methyl groups of the disordered tert-butyl groups).

This disorder was modelled by assigning two different carbon atoms to each disordered methyl group, with the multiplicity of each atom assigned on the basis of the intensity ratio of difference peaks (the total multiplicity of the two atoms summing to one). The methyl group of the toluene molecule was also found to be disordered; again a similar modelling technique was used--two methyl carbons were assigned (on adjacent ring carbons), with the total multiplicity summing to one.

As a result of these disorders, no hydrogen atoms were placed into the model. Clearly, the quality of the data is not sufficient to unambiguously locate the hydride 
ligands. All of the heavy atoms were then refined anisotropically, except for the disordered methyl groups of the tert-butyls and also the carbon atoms of the entire toluene molecule (giving a total of 33 anisotropic heavy atoms and 26 isotropic heavy atoms in the final model).

Towards the end of the refinement, examination of the extinction test listing indicated that secondary extinction was occuring; refinement of this parameter resulted in a final value of $2.01 \times 10^{-7}$. Two close intermolecular contacts $(<3.5 \AA)$ were found, both involving pairs of methyl carbons of the tert-butyl groups. Inspection of the residuals ordered in the ranges of $\sin (\theta / \lambda),\left|F_{0}\right|$, and parity and value of the individual indexes showed no trend other than the one previously mentioned in connection with secondary extinction.

The highest and lowest peaks in the final difference Fourier map had electron densities of 3.24 and $-0.287 \mathrm{e} / \AA^{3}$, respectively. Almost all of the positive peaks are associated with the platinum atom peaks. 
Table 5. Crystal Data for $[(\mathrm{dtbpe}) \mathrm{PtH}]_{2}$.

\begin{tabular}{|c|c|}
\hline chem formula & $\mathrm{C}_{36} \mathrm{H}_{82} \mathrm{Pt}_{2} \mathrm{P}_{4}$ \\
\hline mol wt. & 1029.13 \\
\hline crystal size (mm) & $0.50 \times 0.38 \times 0.23$ \\
\hline space group & $\mathrm{PT}$ \\
\hline $\mathrm{a}, \AA$ & $11.552(3)$ \\
\hline $\mathrm{b}, \AA$ & $13.123(3)$ \\
\hline$c, \AA$ & $17.694(4)$ \\
\hline$\alpha$, (deg) & $81.20(2)$ \\
\hline$\beta,(\mathrm{deg})$ & $89.20(2)$ \\
\hline$\gamma,($ deg $)$ & $66.55(2)$ \\
\hline$V, \AA^{3}$ & $2431(1)$ \\
\hline $\mathrm{Z}$ & 2 \\
\hline$F(000)$ & 514 \\
\hline $\mathrm{d}$ (calc.), $\mathrm{g} \mathrm{cm}^{-3}$ & 1.407 \\
\hline$\mu$ (calc.), $\mathrm{cm}^{-1}$ & 59.6 \\
\hline $\mathrm{T},{ }^{\circ} \mathrm{C}$ & -88 \\
\hline octants measd & $+\mathrm{h}, \pm \mathrm{k}, \pm \mathrm{l}$ \\
\hline $2 \theta$ range & $3-50^{\circ}$ \\
\hline intensity, orientation refns & $(-2,-7,3),(1,0,10),(-3,4,-4)$ \\
\hline \# reorientations & 1 \\
\hline no rflns collected & 8658 \\
\hline $\max c o r$ for cryst decay & $2.1 \%$ on $\mathrm{F}$ \\
\hline absn corrn (EAC) & $\mathrm{T}_{\max }=0.998, \mathrm{~T}_{\min }=0.677$ \\
\hline no atoms in least squares & 59 \\
\hline no. unique rflns & 8529 \\
\hline no. Iflns with $\mathrm{F}_{\mathrm{o}}{ }^{2}>3 \sigma\left(\mathrm{F}_{\mathrm{o}}{ }^{2}\right)$ & 6398 \\
\hline $\mathrm{p}$ factor & 0.04 \\
\hline no params & 403 \\
\hline $\mathrm{R}$ & 0.0533 \\
\hline $\mathrm{R}_{\mathrm{W}}$ & 0.0675 \\
\hline $\mathrm{R}_{\text {all }}$ & 0.0753 \\
\hline GOF & 2.212 \\
\hline largest $\Delta / \sigma$ in final LS cycle & 0.00 \\
\hline diff Fourier $\left(e^{-} \AA^{-3}\right)$ & $+3.2,-0.29$ \\
\hline
\end{tabular}




\section{$\mathrm{Cp}_{2}{ }_{2} \mathrm{Yb}\left(\mathrm{Me}_{2} \mathrm{PhPCHSiMe}\right)$.}

Green blocks of the complex were grown from slow cooling of a toluene solution to $-80^{\circ} \mathrm{C}$. A suitable crystal cut from a larger crystal. The dimensions and volume of the unit cell suggested triclinic symmetry with two molecules in the unit cell. Details of the unit cell, collection parameters, and structure refinement are listed in Table 6.

Analysis of the data, collected in triclinic primitive symmetry, suggested Ccentered monoclinic symmetry. A $\theta$-independent differential absorption (DIFABS) correction ${ }^{37}$ was applied to the raw data, using an isotropic model in triclinic symmetry as a basis for the correction (the $\mathrm{Yb}$ atoms were found using Patterson techniques and the non-hydrogen atoms were located using standard least-squares and Fourier techniques 61,62 .

The absorption-corrected data and atomic positions were then transformed to Ccentered monoclinic symmetry. The systematic absences were rejected, and the redundant data were averaged. The model was refined isotropically, and then the heavy atoms were refined anisotropically. As a result of the low quality of the data, the carbon atoms were refined isotropically, and no hydrogen atoms were included in the model. Attempts to refine the carbon atoms anisotropically resulted in irrational thermal parameter values (non-positve definite tensors), for many of these atoms. Attempts to improve this situation (by not performing an absorption correction on the data; by weighting up to 300 reflections to zero in the least squares cycle, on the basis of significant disagreement between $F_{o b s}$ and $F_{c a l c}$ values, the former being smaller than expected) did not result in any significant improvements.

One close intramolecular contact was found, involving Yb and C22 (3.12(2) $\AA$ ), possibly indicative of a weak interaction between these two atoms (perhaps also involving the hydrogens on C22). Many close intermolecular contacts (ca. $3.0 \AA$ ) were found, involving the $\mathrm{Cp}$ * rings, the phenyl ring, and many of the $\mathrm{P}$ - and Si-bound methyl groups; crystal packing effects are clearly significant for this structure. Inspection of the 
residuals ordered in the ranges of $\sin (\theta / \lambda),\left|F_{0}\right|$, and parity and value of the individual indexes showed no unusual trends.

The highest and lowest peaks in the final difference Fourier map had electron densities of 1.03 and $-0.173 \mathrm{e} / \AA^{3}$, respectively. Almost all of the positive peaks were located within $2 \AA$ of the $\mathrm{Yb}$ center. 
Table 6. Crystal Data for $\mathrm{Cp}_{2}^{*}{ }_{2} \mathrm{Yb}\left(\mathrm{Me}_{2} \mathrm{PhPCHSiMe}_{2}\right)$.

\begin{tabular}{|c|c|}
\hline chem formula & $\mathrm{C}_{32} \mathrm{H}_{51} \mathrm{PSiYb}$ \\
\hline mol wt. & 667.86 \\
\hline crystal size (mm) & $0.54 \times 0.43 \times 0.22$ \\
\hline $\mathrm{T},{ }^{\circ} \mathrm{C}$ & -100 \\
\hline space group & $\mathrm{Cc}$ \\
\hline a, $\AA$ & $14.776(8)$ \\
\hline $\mathrm{b}, \AA$ & $14.852(8)$ \\
\hline$c, \AA$ & $15.186(9)$ \\
\hline$\beta,(\operatorname{deg})$ & $104.80(4)$ \\
\hline $\mathrm{V}, \AA^{3}$ & $3222(3)$ \\
\hline $\mathrm{Z}$ & 4 \\
\hline$F(000)$ & 342 \\
\hline $\mathrm{d}$ (calc.), $\mathrm{g} \mathrm{cm}^{-3}$ & 1.377 \\
\hline$\mu($ calc. $), \mathrm{cm}^{-1}$ & 30.0 \\
\hline octants measd & $\pm \mathrm{h}, \pm \mathrm{k},+\mathrm{l}$ \\
\hline $2 \theta$ range & $3-45^{\circ}$ \\
\hline intensity, orientation refns & $(-3,-7,5),(-1,7,-5),(1,9,-1)$ \\
\hline \# orientations & 14 \\
\hline no. rflns collected & 4428 \\
\hline absn corrn (DIFABS) & $\mathrm{T}_{\max }=1.38, \mathrm{~T}_{\min }=0.58$ \\
\hline no. atoms in least squares & 35 \\
\hline no. unique rflns & 2305 \\
\hline no. rflns with $\mathrm{F}_{0}^{2}>3 \sigma\left(\mathrm{F}_{0}^{2}\right)$ & 1874 \\
\hline $\mathrm{p}$ factor & 0.05 \\
\hline no. params & 154 \\
\hline $\mathrm{R}$ & 0.0514 \\
\hline$R_{\mathrm{w}}$ & 0.0633 \\
\hline$R_{\text {all }}$ & 0.0579 \\
\hline GOF & 1.430 \\
\hline largest $\Delta / \sigma$ in final LS cycle & 0.10 \\
\hline diff Fourier $\left(\mathrm{e}^{-} \AA^{-3}\right)$ & $+1.0,-0.17$ \\
\hline
\end{tabular}




\section{$\mathrm{Cp}^{*}{ }_{2} \mathrm{Yb} \cdot$ toluene.}

Green needles of the complex were grown from slow cooling of a ca. 5:1 pentane:toluene solution to $-40^{\circ} \mathrm{C}$. A suitable square plate was cut from one of the crystals. The dimensions and volume of the unit cell suggested triclinic symmetry with two molecules in the unit cell. Details of the unit cell, collection parameters, and structure refinement are listed in Table 7. The peak profiles at this point indicated that the 'crystal' was twinned, consisting of roughly equal amounts of two single crystals.

The crystal showed no appreciable decay over the course of the data collection. An empirical absorption correction was applied to the data; examination of the azimuthal scans showed a variation of $I_{\min } / I_{\max }=0.67$ for the average relative intensity curve. Analysis of the data revealed no systematic absences, consistent with the space group PI.

The coordinates of the one independent ytterbium atom were determined by Patterson methods. The locations of all non-hydrogen atoms were determined through the use of standard Fourier techniques and refined by least-squares methods. At this point 149 reflections were rejected from the data set, based on large $w(\Delta)^{2}$ values as well as asymmetric peak profiles (indicating that for these reflections, the lattice of the other crystal was giving rise to reflections that overlapped with the reflections from the desired crystal lattice). A difference Fourier map indicated that the placement of the hydrogen atoms based on idealized bonding geometry was justified by the quality of the data. These atoms were placed in the idealized positions and included in the structure factor calculations but not refined. All hydrogen atoms were given isotropic thermal parameters 1.2 times the $B_{\text {iso }}$ of the atom to which they were bonded.

After final refinement of the structure using isotropic thermal parameters on all atoms, a $\theta$-independent DIFABS absorption correction 22 was applied to the raw data containing the 149 reflections mentioned above, using coefficients generated by applying a DIFABS correction to the isotropic model. The corrected data were then refined isotropically (the 149 reflections mentioned above were again rejected from the 
refinement), and the above process was repeated. In total, 327 reflections were rejected on the basis mentioned above.

Inspection of the residuals ordered in the ranges of $\sin (\theta / \lambda),\left|\mathrm{F}_{0}\right|$, and parity and value of the individual indexes showed no unusual trends. The highest and lowest peaks in the final difference Fourier map had electron densities of 2.685 and $-0.294 \mathrm{e} / \AA^{3}$, respectively. The former peak is likely a result of the twinning of the crystal; the next highest peak in the positive difference map was $0.635 \mathrm{e} / \AA^{3}$. 
Table 7. Crystal Data for $\mathrm{Cp}^{*}-2$ Yb

\begin{tabular}{|c|c|}
\hline chem formula & $\mathrm{C}_{27} \mathrm{H}_{38} \mathrm{Yb}$ \\
\hline mol wt. & 535.64 \\
\hline crystal size (mm) & $0.52 \times 0.36 \times 0.20$ \\
\hline $\mathrm{T},{ }^{\circ} \mathrm{C}$ & -112 \\
\hline space group & PI \\
\hline $\mathrm{a}, \AA$ & $10.086(6)$ \\
\hline $\mathrm{b}, \AA$ & $10.510(6)$ \\
\hline$c, \AA$ & $11.813(6)$ \\
\hline$\alpha,(\operatorname{deg})$ & $76.31(4)$ \\
\hline$\beta,(\operatorname{deg})$ & $87.63(5)$ \\
\hline$\gamma,(\operatorname{deg})$ & $80.69(6)$ \\
\hline $\mathrm{V}, \AA^{3}$ & $1200(2)$ \\
\hline $\mathrm{z}$ & 2 \\
\hline$F(000)$ & 270 \\
\hline $\mathrm{d}$ (calc.), $\mathrm{g} \mathrm{cm}^{-3}$ & 1.482 \\
\hline$\mu($ calc. $), \mathrm{cm}^{-1}$ & 38.9 \\
\hline octants measd & $\pm h, \pm k,+1$ \\
\hline $2 \theta$ range & $3-45^{\circ}$ \\
\hline intensity, orientation refns & $(-4,0,-5),(1,-6,-2),(2,0,7)$ \\
\hline \# orientations & 9 \\
\hline no. rflns collected & 3301 \\
\hline absn corrn (DIFABS) & $\mathrm{T}_{\max }=1.16, \mathrm{~T}_{\min }=0.86$ \\
\hline no. atoms in least squares & 28 \\
\hline no. unique rflns & 3301 \\
\hline no. rflns with $\mathrm{F}_{0}^{2}>3 \sigma\left(\mathrm{F}_{0}^{2}\right)$ & 3054 \\
\hline $\mathrm{p}$ factor & 0.03 \\
\hline no. params & 253 \\
\hline $\mathrm{R}$ & 0.0360 \\
\hline $\mathrm{R}_{\mathrm{W}}$ & 0.0448 \\
\hline $\mathrm{R}_{\text {all }}$ & 0.0360 \\
\hline GOF & 2.128 \\
\hline largest $\Delta / \sigma$ in final LS cycle & 0.00 \\
\hline diff Fourie $r\left(e^{-} \AA^{-3}\right)$ & $2.68,-0.29$ \\
\hline
\end{tabular}




\section{$\underline{\text { References. }}$}

(1) Perrin, D. D.; Armarego, W. L. F.; Perrin, D. R. In Purification of Laboratory Materials; Pergamon: Oxford, 1980. (b) Gordon, A. J.; Ford, R. A. In The Chemist's Companion: A Handbook of Practical Data, Techniques, and References; WileyInterscience: New York, 1972.

(2) Tilley, T. D., Ph.D. Thesis, University of California, Berkeley, 1982.

(3) Burns, C. J., Ph.D. Thesis, University of California, Berkeley, 1987.

(4) Pregosin, P. S. In Annual Reports on NMR Spectroscopy, Vol. 17; Webb, G. A., ed.; Academic Press Inc.: London, 1986.

(5) Avent, A.; Edelman, M. A.; Lappert, M. F.; Lawless, G. A. J. Am. Chem. Soc. $1989,111,3423$.

(6) Bax, A.; Griffey, R. H.; Hawkins, B. L. J. Magn. Reson. 1983, 55, 301. (b) Bax, A.; Subramanian, S. J. Magn. Reson. 1986, 67, 565.

(7) Cis-(dcype) $\mathrm{PtH}_{2}$ (4) and cis-(dcypp) $\mathrm{PtH}_{2}$ (6) were prepared via Otsuka's procedure (Yoshida, T.; Yamagata, T.; Tulip, T. H.; Ibers, J. A.; Otsuka, S. J. Am. Chem. Soc. 1978, 100, 2063); the spectroscopic properties of both complexes were identical to those reported in: Clark, H. C.; Hampden Smith, M. J. J. Am. Chem. Soc. 1986, 108, 3829.

(8) Clark, H. C.; Manzer, L. E. J. Organomet. Chem. 1973, 59, 411.

(9) The (dcype) deuterated analogue, (dcype) $\mathrm{PtD}_{2},\left(\mathrm{~d}_{2}-5\right)$, was prepared via Otsuka's method (see ref. 7), using deuterium gas instead of hydrogen gas.

(10) Birkofer, L.; Kim, S. M. Chem. Ber. 1964, 97, 2100. This compound was found to be a crystalline white solid, crystallized from diethyl ether, in contrast to a colorless oil as reported.

(11) Schmidbaur, H.; Heimann, M. Z. Naturforsch 1978, 29b, 485. 
(12) Paratone $\mathrm{N}$ oil is a viscous commercial oil available from Exxon Chemical Company, Houston, TX. The oil was degassed prior to use.

(13) Instrumentation at the University of California Chemistry Department X-ray Crystallographic Facility (CHEXRAY) consists of two Enraf-Nonius CAD-4 diffractometers controlled by a DEC Microvax II and equipped with departmentallyconstructed low temperature systems. Both use Enraf-Nonius software as described in the "CAD-4 Operations Manual, Version 5.0," Enraf-Nonius, Delft, The Netherlands, 1977, updated 1989.

(14) All calculations were performed on a DEC Microvax II or a DEC Microvax 4000 using locally modified Nonius-SDP software operating under Micro-VMS operating system.

(15) (a) Frenz, B. A. In Structure Determination Package Users Guide, Texas A \& M University and Enraf-Nonius: College Station, TX and The Netherlands, 1985. (b) Fair, C. K. In MolEN Molecular Structure Solution Procedures, Enraf-Nonius, Delft Instruments, X-ray Diffraction B. V., The Netherlands, 1990.

(16) The data reduction formulae are:

$$
\begin{array}{ll}
F_{o}^{2}=\frac{\omega}{L_{p}}(C-2 B) & \sigma_{o}\left(F_{o}^{2}\right)=\frac{\omega}{L_{p}}(C+4 B)^{1 / 2} \\
F_{o}=\left(F_{o}^{2}\right)^{1 / 2} & \sigma_{o}(F)=\left[F_{o}^{2}+\sigma_{o}\left(F_{o}^{2}\right)\right]^{1 / 2}-F_{o}
\end{array}
$$

where $C$ is the total count in the scan, B is the sum of the two background counts, $\omega$ is the scan speed used in deg/min, and

$$
\frac{1}{L_{p}}=\frac{\sin 2 \Theta\left(1+\cos ^{2} 2 \Theta_{m}\right)}{1+\cos ^{2} 2 \Theta_{m}-\sin ^{2} 2 \Theta}
$$

is the correction for Lorentz and polarization effects for a reflection with scattering angle $2 \Theta$ and radiation monochromatized with a $50 \%$ perfect single-crystal monochromator with scattering angle $2 \Theta_{\mathrm{m}}$.

(17) Reflections used for azimuthal scans were located near $\chi=80^{\circ}$ and the intensities were measured at $10^{\circ}$ increments of rotation of the crystal about the diffraction vector. 
(18) $\quad \mathrm{R}=\frac{\Sigma|| F_{\mathrm{O}}|-| \mathrm{F}_{\mathrm{C}}||}{\Sigma\left|\mathrm{F}_{\mathrm{O}}\right|}$

$$
R_{w}=\sqrt{\frac{\sum w\left(\left|F_{0}\right|-\left|F_{c}\right|\right)^{2}}{\Sigma w F_{o}^{2}}}
$$

$$
\mathrm{GOF}=\sqrt{\frac{\Sigma w\left(\left|F_{0}\right|-\left|F_{c}\right|\right)^{2}}{\left(n_{0}-n_{v}\right)}}
$$

where $n_{0}$ is the number of observations, $n_{v}$ is the number of variable parameters, and the weights, $w$, are given by:

$$
\mathrm{w}=\frac{1}{\sigma^{2}\left(\mathrm{~F}_{0}\right)} \quad \sigma\left(\mathrm{F}_{0}^{2}\right)=\sqrt{\sigma_{0}^{2}\left(\mathrm{~F}_{\mathrm{o}}^{2}\right)+\left(\mathrm{pF}^{2}\right)^{2}}
$$

where $\sigma^{2}\left(\mathrm{~F}_{0}\right)$ was calculated as above from $\sigma\left(\mathrm{F}_{0}{ }^{2}\right)$ and where $\mathrm{p}$ is the factor used to lower the weight of intense reflections.

(19) Cromer, D. T.; Waber, J. T. In International Tables for X-ray Crystallography, Vol. IV, The Kynoch Press: Birmingham, England, 1974, Table 2.2B.

(20) Cromer, D. T., ibid., Table 2.3.1.

(21) Sheldrick, G. M. Acta Crystallogr. 1990, A46, 467.

(22) Walker, N.; Stuart, D. Acta Crystallogr. 1983, A39, 158. 


\section{APPENDIX I.}

\section{Chapter 1:}

p. 168, top: $1 \mathrm{H} / 195 \mathrm{Pt}$ HMQC spectrum of 7 , hydride region $\left(300 \mathrm{MHz}, 25^{\circ} \mathrm{C}\right.$, $\mathrm{C}_{6} \mathrm{D}_{6}$ ).

p. 168 , bottom: ${ }^{1} \mathrm{H} / 171 \mathrm{Yb}$ HMQC spectrum of 7 , hydride region $\left(300 \mathrm{MHz}, 25^{\circ} \mathrm{C}\right.$, $\left.\mathrm{C}_{6} \mathrm{D}_{6}\right)$.

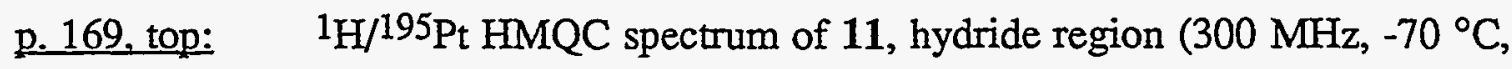
toluene-d8).

p. 169, bottom: ${ }^{1} \mathrm{H} /{ }^{31} \mathrm{P}$ HMQC spectrum of 11 (300 MHz, $-70^{\circ} \mathrm{C}$, toluene-d8). The plotted region shows the major hydride resonance and the ${ }^{31 \mathrm{P}}$ resonance that arises from the phosphorus nucleus that is trans to the methyl group; the ${ }^{1} \mathrm{H}$ dimension is ${ }^{31} \mathrm{P}$ decoupled, and so this resonance is a singlet with ${ }^{171} \mathrm{Yb}$ satellites. The offset of these satellites in the ${ }^{31} \mathrm{P}$ (vertical) dimension is $\mathrm{J}_{\mathrm{YbP}}(c a .3 \mathrm{~Hz}$ ).

\section{Chapter 2:}

p. 170. top: $\quad 195 \mathrm{Pt}$ INEPT spectrum of $1\left(85.6 \mathrm{MHz}, 25^{\circ} \mathrm{C}\right.$, d8-toluene).

p. 170, bottom: ${ }^{1} \mathrm{H} / 195 \mathrm{Pt}\{1 \mathrm{H}\}$ spectrum of $1\left(300 \mathrm{MHz},-90^{\circ} \mathrm{C}\right.$, d8-toluene).

p. 171, top: Simulated ${ }^{195} \mathrm{Pt}\{1 \mathrm{H}\}$ spectrum of 1 at $-90^{\circ} \mathrm{C}$, using the spectral values given in the text.

p.171, bottom: Simulated ${ }^{195} \mathrm{Pt}\left\{{ }^{1} \mathrm{H}\right\}$ subspectrum for the $\mathrm{Pt} /{ }^{195} \mathrm{Pt}$ isotopomer of 1 at $-90^{\circ} \mathrm{C}$.

p. 172, top: Simulated $\left.{ }^{195} \mathrm{Pt}^{1}{ }^{1} \mathrm{H}\right\}$ subspectrum for the ${ }^{195} \mathrm{Pt} / 195 \mathrm{Pt}$ isotopomer of 1 at $-90^{\circ} \mathrm{C}$.

p. 172, bottom: ${ }^{1} \mathrm{H} / 1 \mathrm{P}\left\{{ }^{1 \mathrm{H}}\right\} \mathrm{HMQC}$ spectrum of the "mixed dimer sample", containing 1, 2, and [(dcype)Pt(H)Pt(H)(dippe)] (400 MHz, $25^{\circ} \mathrm{C}$, d8-thf). 

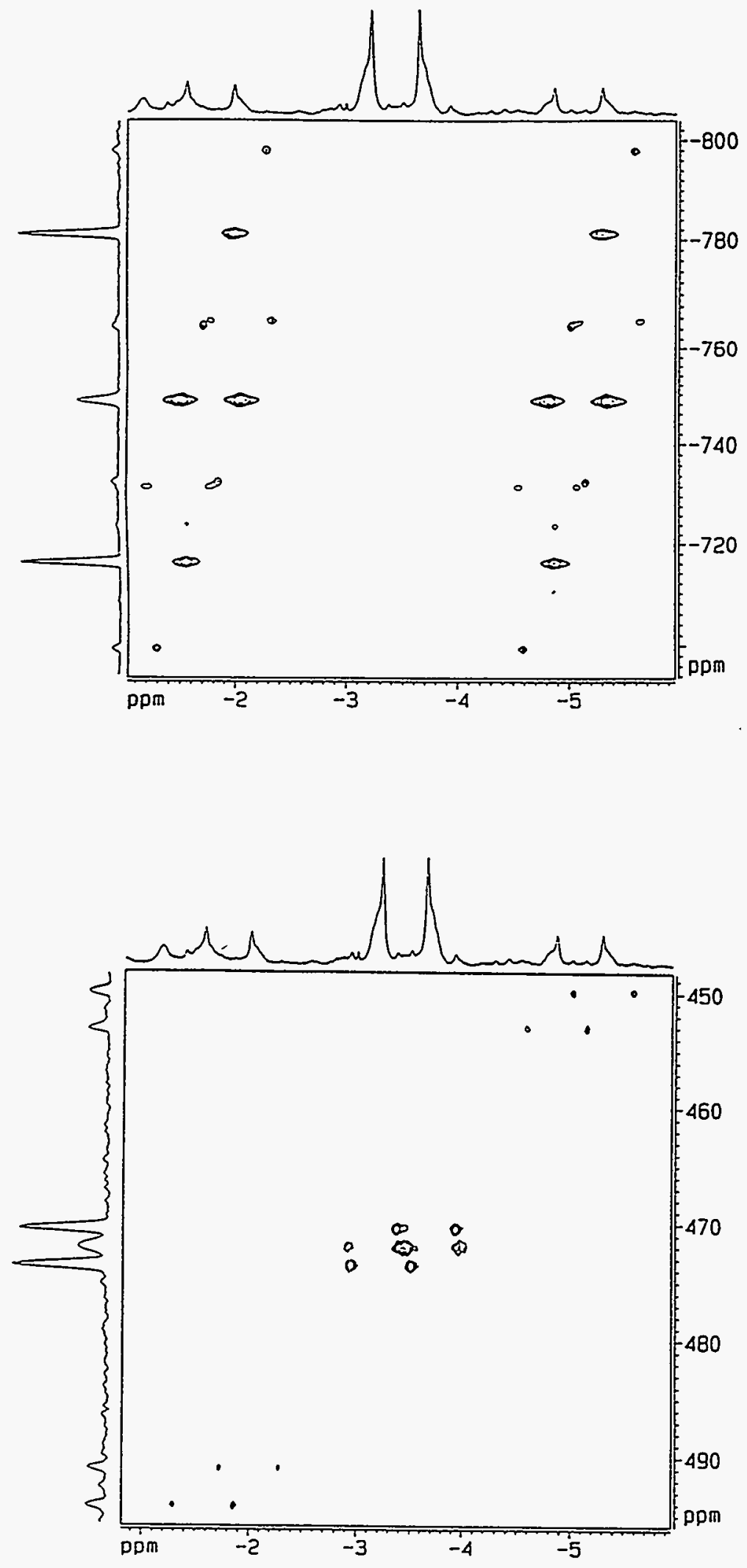

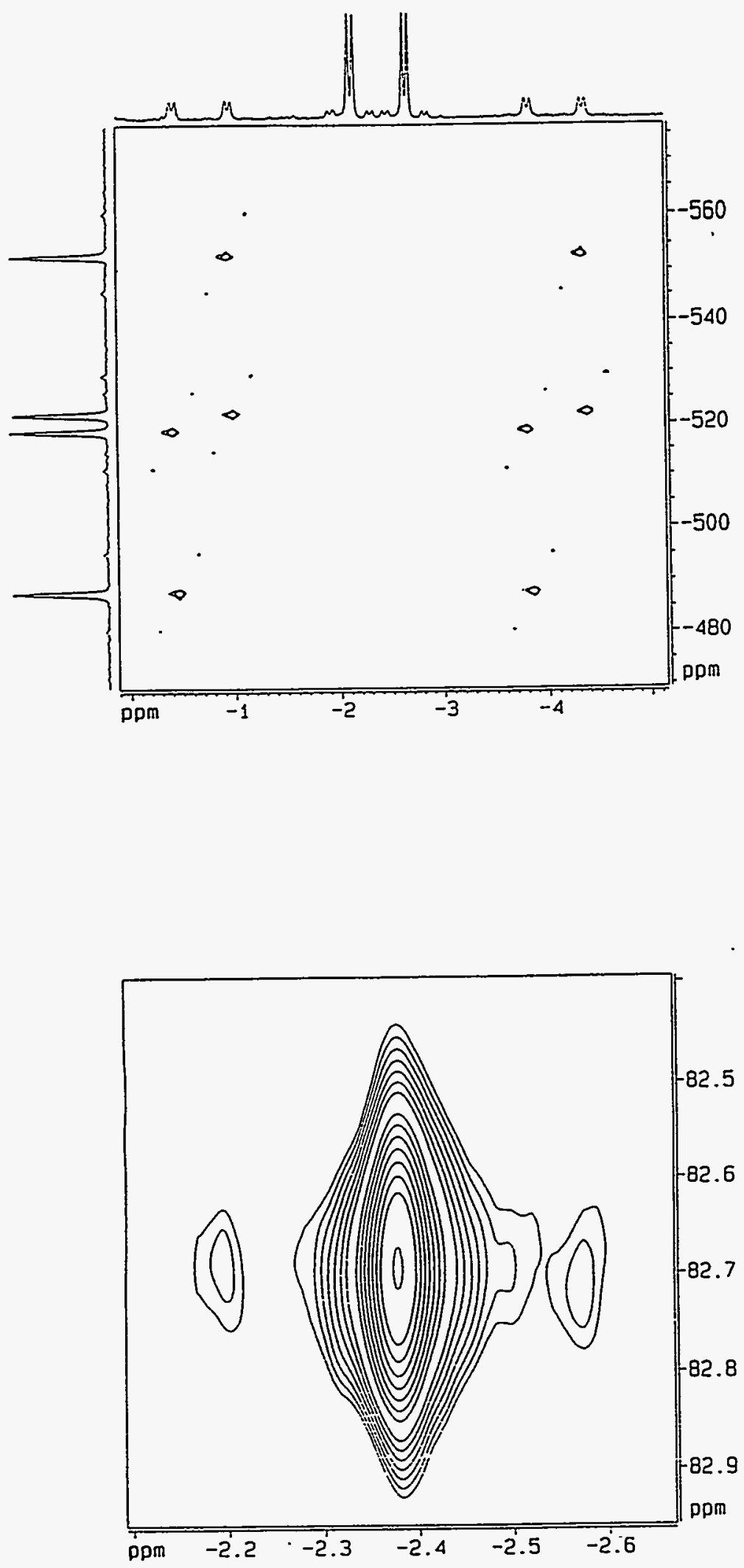

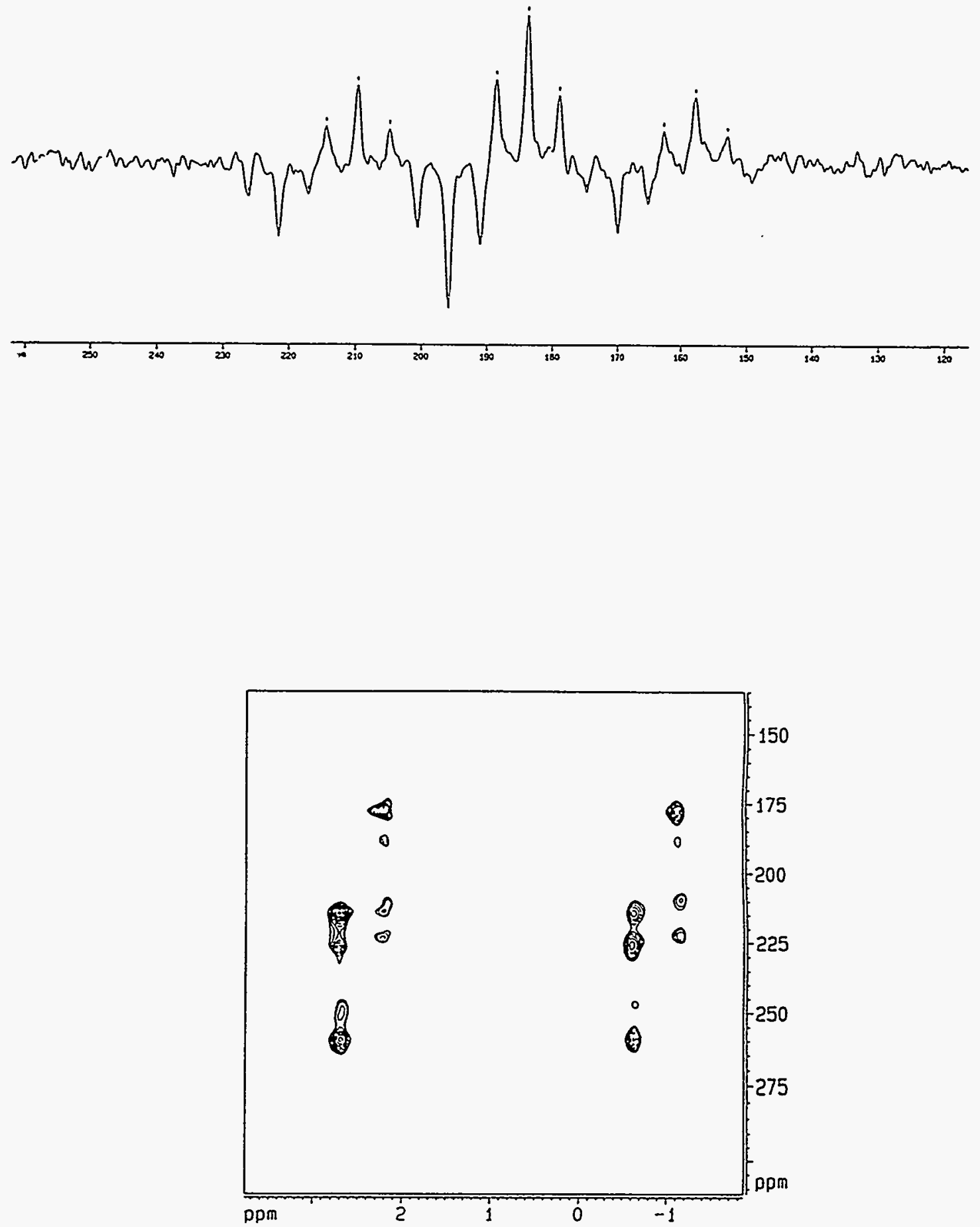

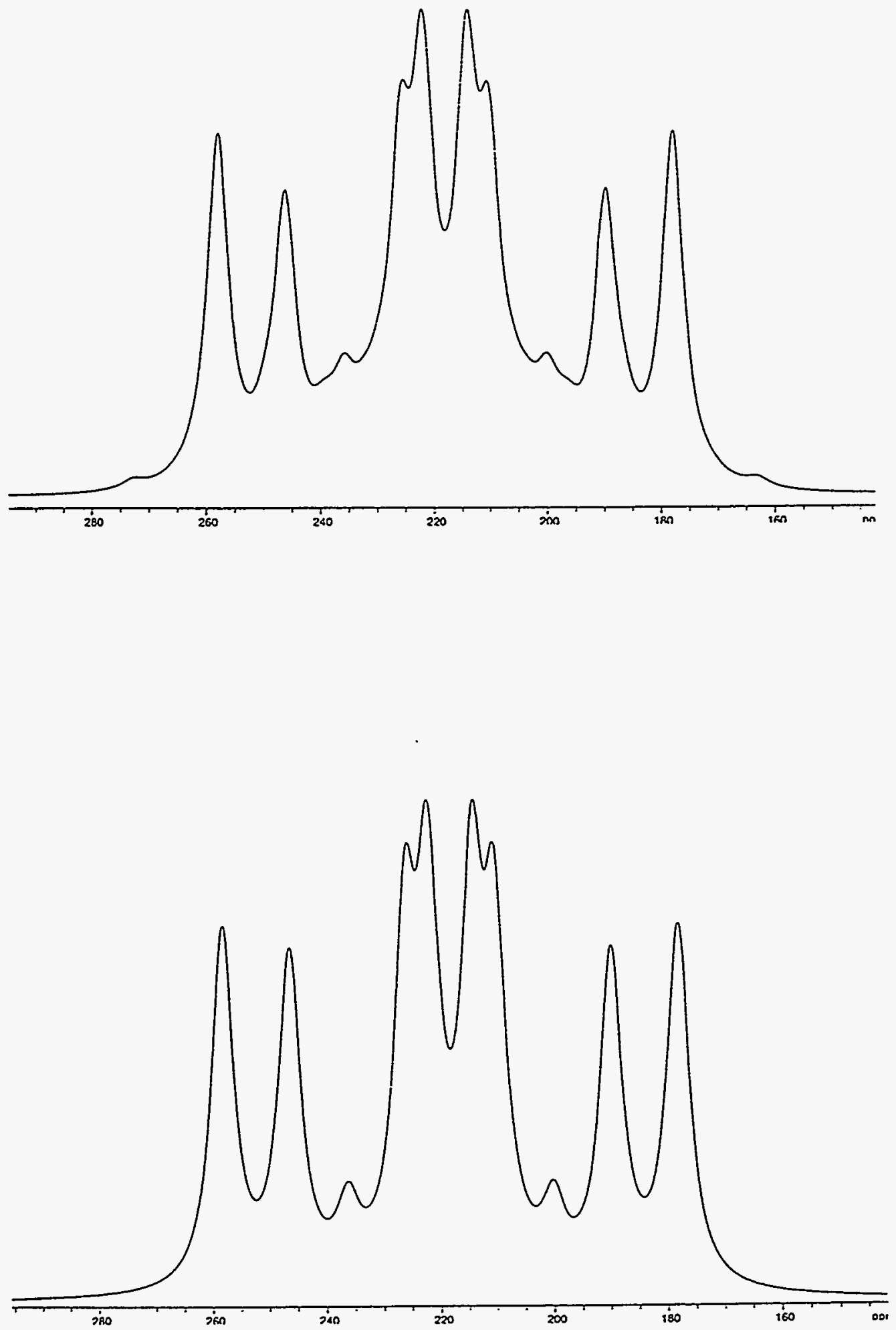

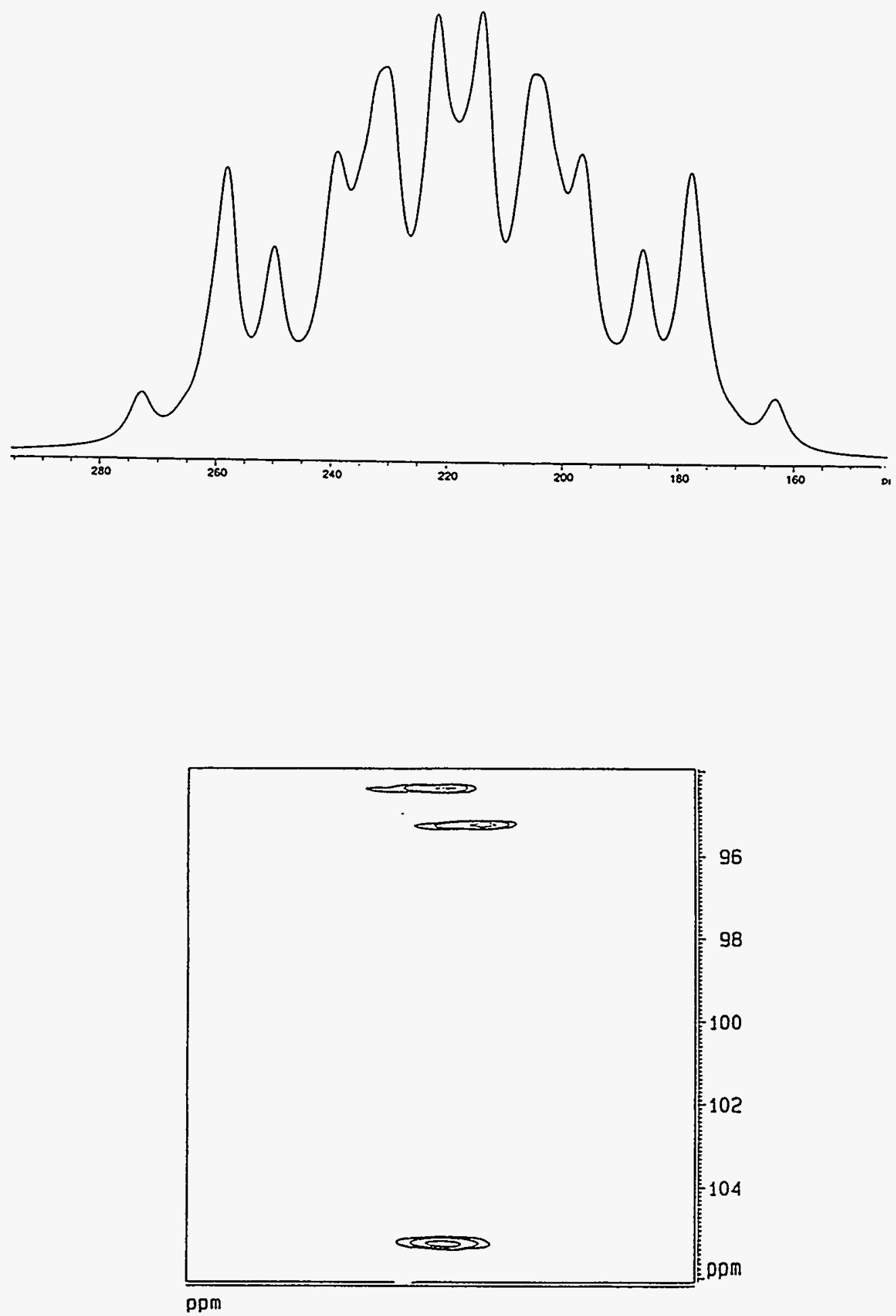
APPENDIX II.

Tables of Positional and Thermal Parameters.

(dcype)Pt( $\mu-\mathrm{H})_{2} \mathrm{YbCp}_{2}{ }_{2}$

\begin{tabular}{lccll} 
atom & $\mathrm{x}$ & $\mathrm{y}$ & $\mathrm{z}$ & $\mathrm{B}\left(\AA^{2}\right)^{2} \mathrm{a}$ \\
\hline $\mathrm{Pt}$ & $0.1214(4)$ & $-0.0001(3)$ & $0.2011(2)$ & $3.21(8)$ \\
$\mathrm{Yb}$ & $-0.0492(4)$ & $0.0148(3)$ & $0.0741(3)$ & $3.1(1)$ \\
$\mathrm{P} 1$ & $0.207(3)$ & $-0.077(2)$ & $0.266(2)$ & $4.1(9)$ \\
$\mathrm{P} 2$ & $0.213(6)$ & $0.072(4)$ & $0.271(4)$ & $14(2)$
\end{tabular}

aAll atoms were included with isotropic thermal parameters. 
(dippe) $\mathrm{Pt}(\mu-\mathrm{Me})_{2} \mathrm{YbCp}_{2}{ }_{2}$

Table of Positional Parameters and Their Estimated Standard Deviations

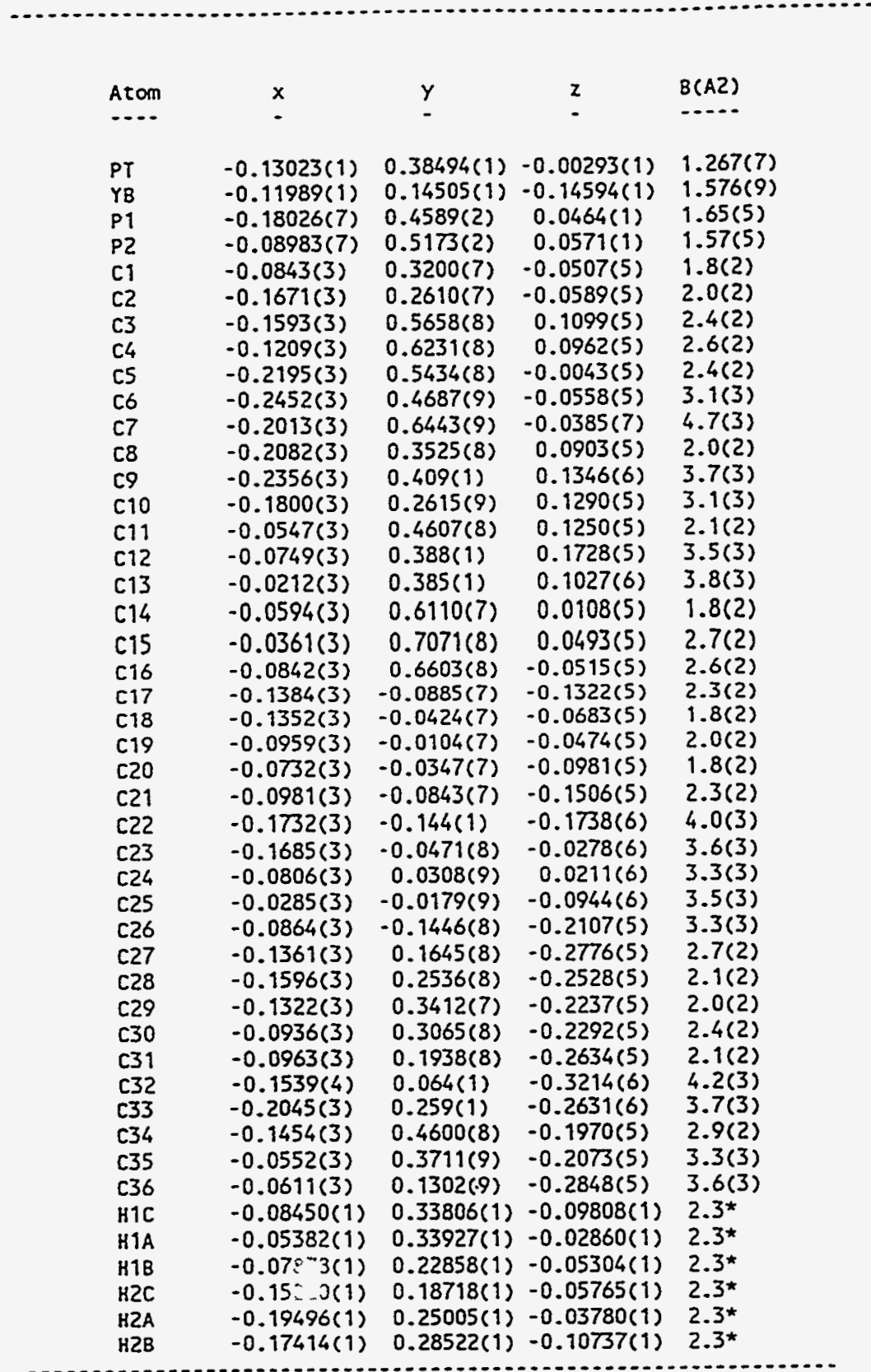

Starred atoms were included with isotropic therma! parameters.

The thermal parameter given for anisotropically refined atoms is the isotropic equivalent thermal parameter defined as:

$(4 / 3) \star\left[a 2^{\star} B(1,1)+b 2 \star B(2,2)+c 2 \star B(3,3)+a b(\cos\right.$ garma $) \star B(1,2)$

$+a c(\cos b e[a) * B(1,3)+b c(\cos$ alpha $) * B(2,3)]$

where $a, b, c$ are real cell parameters, and $B(i, j)$ are anisotropic betas. 
Table of Anisotropic Thermal Parameters - B's

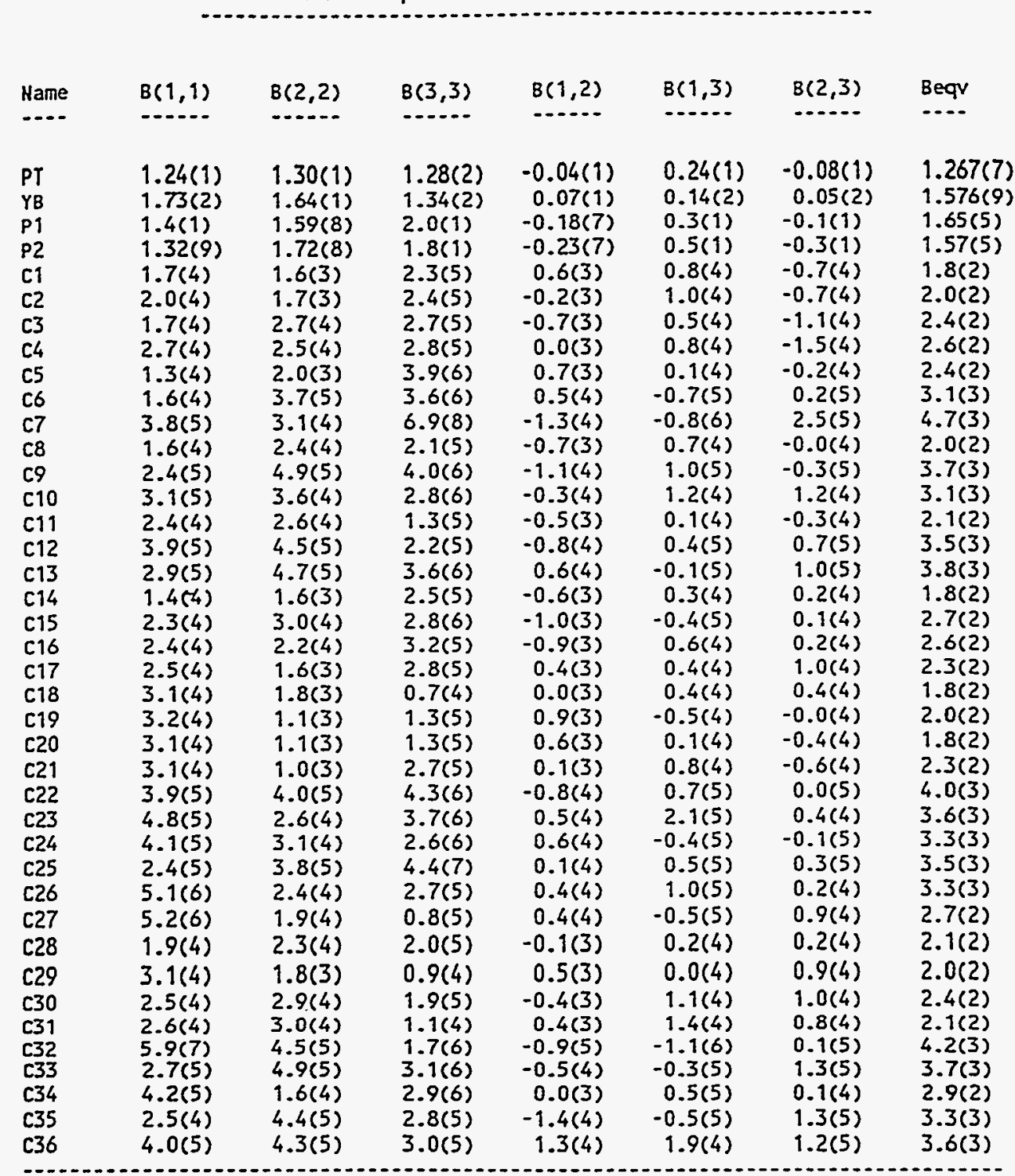

The form of the anisotropic temperature factor is:

$\exp [-0.25(h 2 a 2 B(1,1)+k 2 b 2 B(2,2)+12 c 2 B(3,3)+2 h k a b B(1,2)+2 h l a c B(1,3)$

$+2 k[b c B(2,3)\}]$ where $a, b$, and $c$ are reciprocal lattice constants. 
(dippe)Pt( $(\mu-\mathrm{Me})(\mu-\mathrm{H}) \mathrm{YbCp}_{2}{ }_{2}$

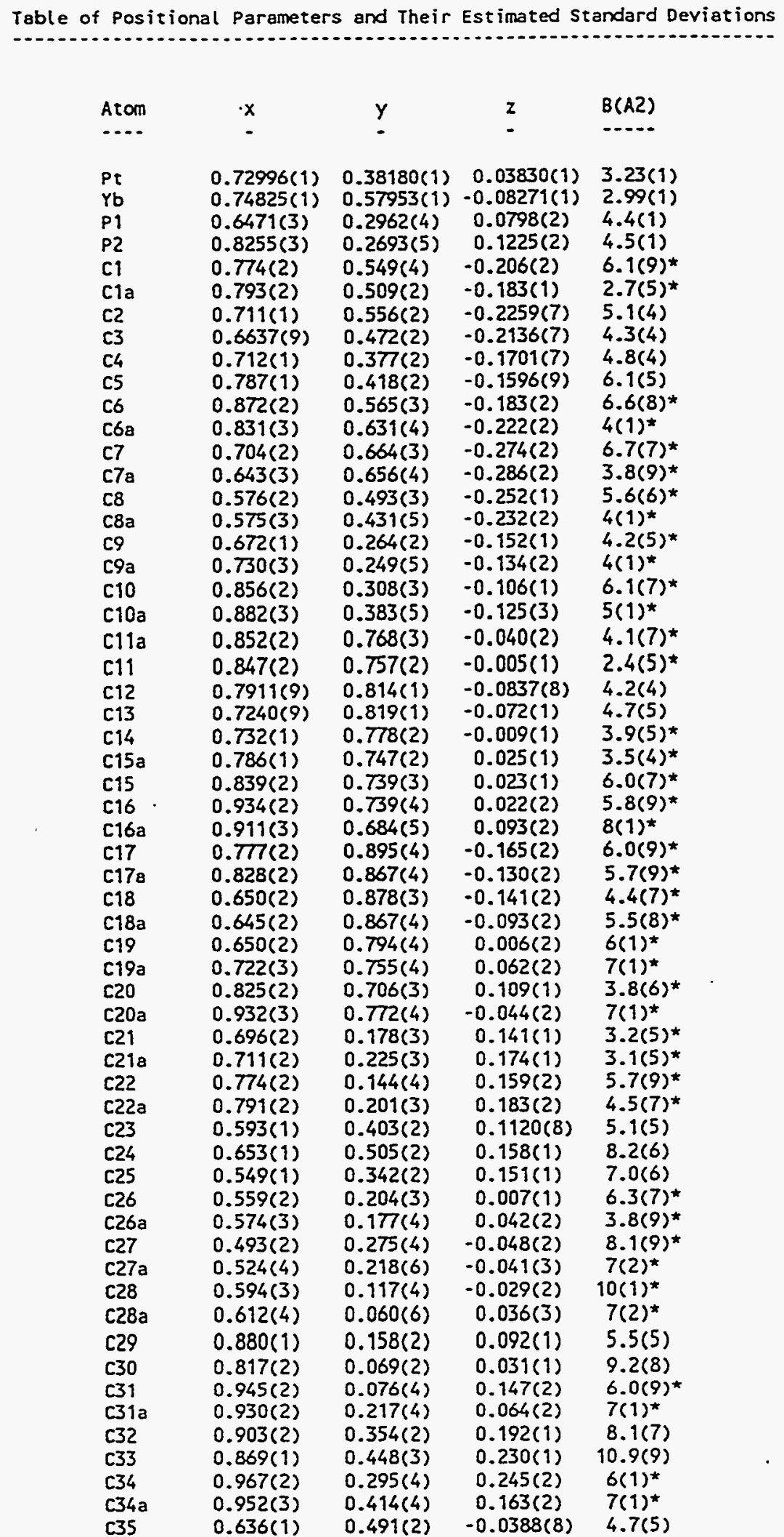


Table of Anisotropic Thermal Parameters - B's

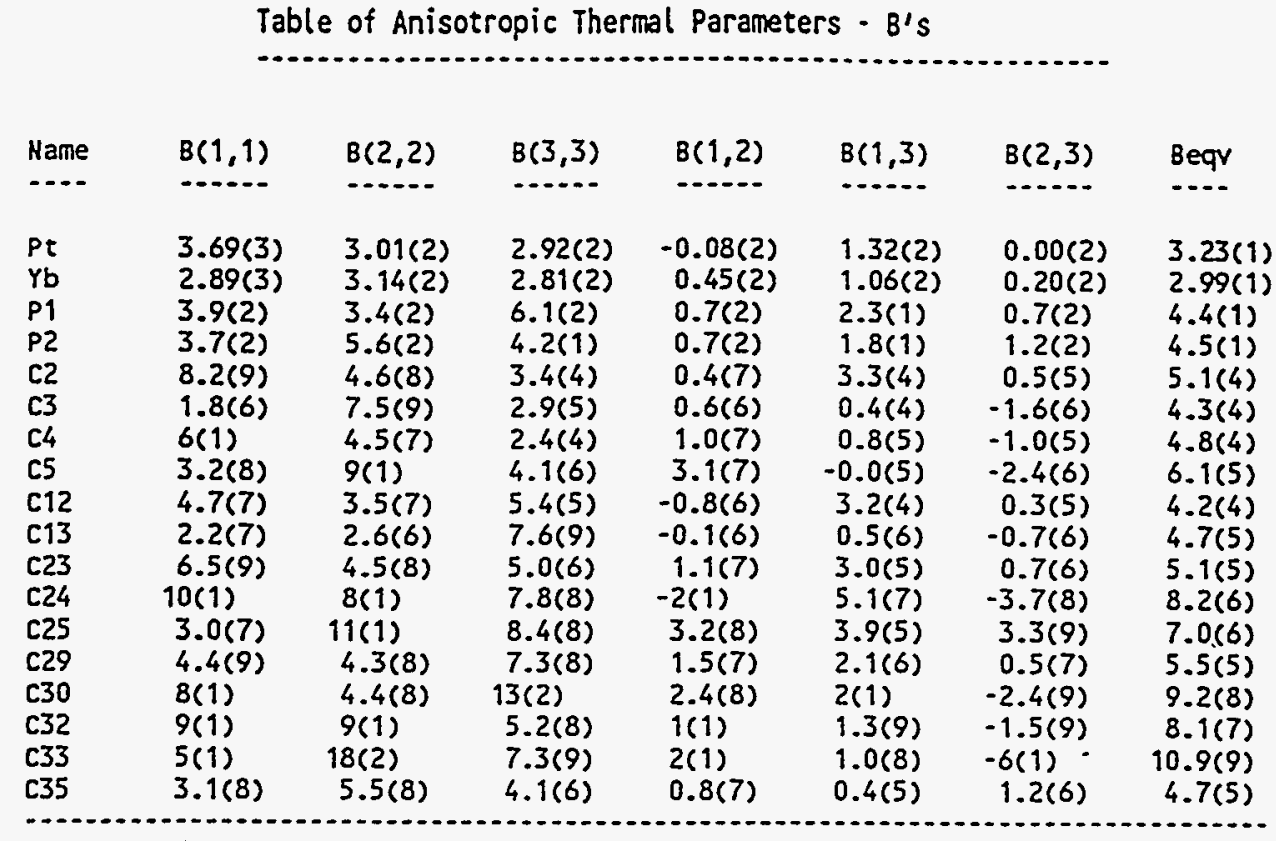

The form of the anisotropic temperature factor is:

$\exp [-0.25(h 2 a 2 B(1,1)+k 2 b 2 B(2,2)+12 c 2 B(3,3)+2 h k a b 8(1,2)+2 h l a c B(1,3)$

$+2 k l b c B(2,3)\}]$ where $a, b$, and $c$ are reciprocal lattice constants. 
$\left[(\text { dippe)PtH }]_{2}\right.$

Table of Positional Parameters and Their Estimated Standard Deviations

Table of Positional Paranecers and Their Estingted stendard Devietions

\begin{tabular}{|c|c|c|c|c|}
\hline Atom & $x$ & $y$ & 2 & $B(A 2)$ \\
\hline$\cdots$ & - & 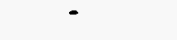 & - & $\cdots$ \\
\hline $\begin{array}{l}\text { PT1 } \\
\text { PT2 }\end{array}$ & $\begin{array}{l}0.40434(1) \\
0.42467(1)\end{array}$ & $\begin{array}{l}0.10695(1) \\
0.09281(1)\end{array}$ & $\begin{array}{l}0.27179(1) \\
0.15894(1)\end{array}$ & $\begin{array}{l}1.015(6) \\
0.975(6)\end{array}$ \\
\hline$\vec{F}$ & $0.4308(4)$ & $-0.0199(2)$ & $0.2998(1)$ & $1.26(5)$ \\
\hline PL & $0.4113(4)$ & $0.1415(2)$ & $0.3671(1)$ & $1.80(6)$ \\
\hline P3 & $0.1906(3)$ & $0.0888(2)$ & $0.1312(1)$ & $1.58(6)$ \\
\hline P4 & $0.4850(3)$ & $0.0976(2)$ & $0.0632(1)$ & $1.28(5)$ \\
\hline c1 & $0.420(2)$ & $-0.0234(6)$ & $0.3820(5)$ & $1.9(2)$ \\
\hline C2 & $0.468(2)$ & $0.0538(7)$ & $0.4111(5)$ & $2.3(3)$ \\
\hline c3 & $0.179(1)$ & $0.1098(8)$ & $0.0509(5)$ & $2.2(2)$ \\
\hline C4 & $0.318(1)$ & $0.0851(7)$ & $0.0182(5)$ & $1.8(2)$ \\
\hline C10 & $0.605(1)$ & $-0.0712(7)$ & $0.2834(5)$ & $1.9(2)$ \\
\hline C11 & $0.296(1)$ & $-0.0922(7)$ & $0.2773(6)$ & $2.1(2)$ \\
\hline $\mathrm{C12}$ & $0.615(1)$ & $-0.0951(7)$ & $0.2193(6)$ & $2.7(3)$ \\
\hline C13 & $0.726(2)$ & $-0.0182(9)$ & $0.3002(6)$ & $3.1(3)$ \\
\hline C14 & $0.323(2)$ & $-0.1766(7)$ & $0.2999(6)$ & $2.9(3)$ \\
\hline c15 & $0.143(2)$ & $-0.0654(9)$ & $0.2930(7)$ & $3.1(3)$ \\
\hline C20 & $0.246(2)$ & $0.1762(7)$ & $0.4047(5)$ & $2.1(3)$ \\
\hline C21 & $0.550(2)$ & $0.2142(7)$ & $0.3876(5)$ & $3.3(3)$ \\
\hline C22 & $0.125(2)$ & $0.1161(9)$ & $0.3992(6)$ & $4.2(3)$ \\
\hline $\mathrm{c23}$ & $0.197(2)$ & $0.2541(9)$ & $0.3799(7)$ & $4.0(4)$ \\
\hline $\begin{array}{l}C 24 \\
C 25\end{array}$ & $\begin{array}{l}0.696(2) \\
0.568(2)\end{array}$ & $\begin{array}{l}0.197(1) \\
0.2245(9)\end{array}$ & $\begin{array}{l}0.3583(7) \\
0.4560(6)\end{array}$ & $\begin{array}{l}4.0(3) \\
5.2(4)\end{array}$ \\
\hline C30 & $0.099(2)$ & $-0.0067(8)$ & $0.1387(5)$ & $2.6(3)$ \\
\hline c31 & $0.060(1)$ & $0.1608(8)$ & $0.1607(6)$ & $2.5(3)$ \\
\hline C32 & $0.186(2)$ & $-0.0730(8)$ & $0.1097(7)$ & $3.8(3)$ \\
\hline C33 & $-0.057(2)$ & $-0.0087(9)$ & $0.1160(7)$ & $3.6(3)$ \\
\hline C34 & $0.121(2)$ & $0.2464(8)$ & $0.1580(6)$ & $3.2(3)$ \\
\hline c35 & $0.012(2)$ & $0.1404(9)$ & $0.2240(6)$ & $2.9(3)$ \\
\hline$C 40$ & $0.612(1)$ & $0.0264(7)$ & $0.0299(5)$ & $2.2(2)$ \\
\hline C4i & $0.561(2)$ & $0.1930(7)$ & $0.0397(5)$ & $2.3(3)$ \\
\hline 042 & $0.573(2)$ & $-0.0577(7)$ & $0.0446(5)$ & $3.1(3)$ \\
\hline $\mathrm{C} 43$ & $0.634(2)$ & $0.0386(9)$ & $-0.0365(6)$ & $3.4(3)$ \\
\hline C44 & $0.714(2)$ & $0.2018(9)$ & $0.0630(5)$ & $3.0(3)$ \\
\hline C45 & $0.463(2)$ & $0.2606(7)$ & $0.0604(5)$ & (3) \\
\hline
\end{tabular}


Table of Anisotropic Thermal Parameters - B's

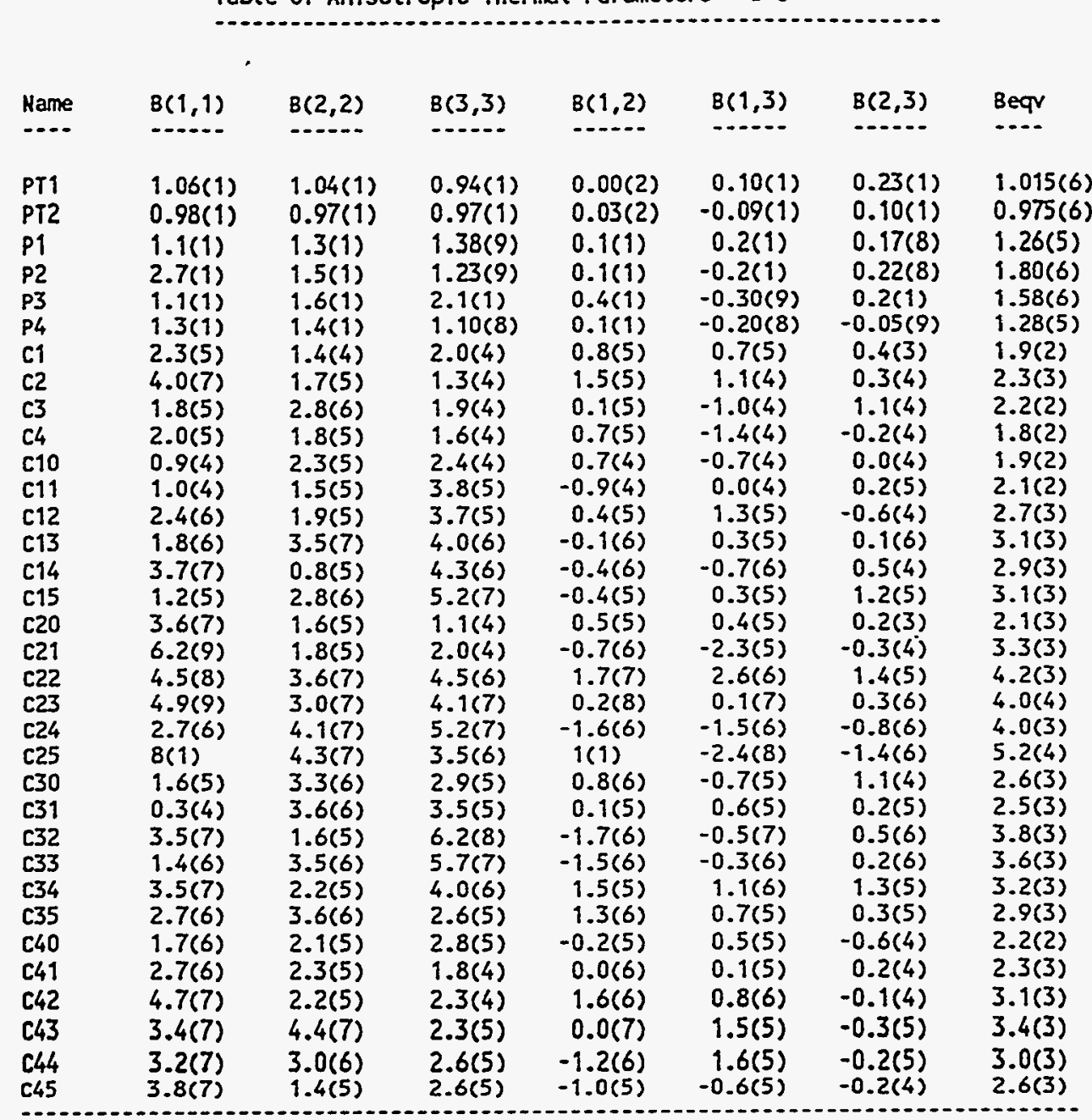

The form of the anisotropic tenoerature factor is:

$\exp [-0.25(\mathrm{~h} 2 \mathrm{a} 2 \mathrm{~B}(1,1)+k 2 \mathrm{~b} 2 \mathrm{~B}(2,2)+12 \mathrm{c} 2 \mathrm{~B}(3,3)+2 \mathrm{hkabB}(1,2)+2 \mathrm{hlacB}(1,3)$

$+2 k(b c B(2,3)\}]$ where $a, b$, and $c$ are reciprocal lattice constants. 
$[(\text { dtbpe }) \mathrm{PtH}]_{2}$

Table of Positional Parameters and Their Estimated Standard Deviations

\begin{tabular}{|c|c|c|c|c|}
\hline Atom & $x$ & y & $z$ & $B(A 2)$ \\
\hline$\cdots$ & - & - & - & $\cdots$ \\
\hline $\begin{array}{l}\text { PT1 } \\
\text { PT2 }\end{array}$ & $0.09551(1)$ & $0.23233(1)$ & 0.30281 (i) & $1.594(9)$ \\
\hline$P 2$ & $-0.0631(3)$ & $\begin{array}{l}0.4004(2) \\
0.3169(2)\end{array}$ & $\begin{array}{l}0.2611(2) \\
0.3766(2)\end{array}$ & $\begin{array}{l}2.00(7) \\
1.82(6)\end{array}$ \\
\hline P3 & $0.2296(3)$ & $-0.0261(3)$ & $0.1760(2)$ & $\begin{array}{l}1.82(6) \\
2.04(7)\end{array}$ \\
\hline P4 & $0.4687(3)$ & $-0.0937(2)$ & $0.2913(2)$ & $\begin{array}{l}2.04(7) \\
1.82(6)\end{array}$ \\
\hline C1 & $-0.015(1)$ & $0.506(1)$ & $0.3114(9)$ & $3.7(3)$ \\
\hline$c 2$ & $-0.080(1)$ & $0.465(1)$ & $0.3688(9)$ & $4.3(4)$ \\
\hline c3 & $0.477(1)$ & $-0.193(1)$ & $0.2264(9)$ & $4.6(3)$ \\
\hline C4 & $0.357(1)$ & $-0.170(1)$ & $0.1806(9)$ & $4.2(4)$ \\
\hline $\begin{array}{l}\text { C5 } \\
\text { C6 }\end{array}$ & $0.259(1)$ & $0.414(1)$ & $0.2892(8)$ & $2.9(3)$ \\
\hline $\begin{array}{l}\text { C6 } \\
\text { C7 }\end{array}$ & $\begin{array}{r}0.063(1) \\
-0.028(1)\end{array}$ & $0.463(1)$ & $0.1566(8)$ & $3.0(3)$ \\
\hline C8 & $\begin{array}{l}-0.028(1) \\
-0.230(1)\end{array}$ & $0.264(1)$ & $0.4826(8)$ & $3.7(4)$ \\
\hline C9 & $\begin{array}{r}-0.230(1) \\
0.223(1)\end{array}$ & $0.331(1)$ & $\begin{array}{l}0.3508(9) \\
0.0720(8)\end{array}$ & $4.7(4)$ \\
\hline C10 & $\begin{array}{l}0.223(1) \\
0.087(1)\end{array}$ & $\begin{array}{r}0.039(1) \\
-0.065(1)\end{array}$ & $\begin{array}{l}0.0720(8) \\
0.1930(8)\end{array}$ & $3.2(3)$ \\
\hline c11 & $0.487(1)$ & $-0.179(1)$ & $\begin{array}{l}0.1930(8) \\
0.3880(9)\end{array}$ & $\begin{array}{l}2.9(3) \\
3.8(4)\end{array}$ \\
\hline $\mathrm{C12}$ & $0.618(1)$ & $-0.070(1)$ & $0.270(1)$ & $4.6(4)$ \\
\hline$C 13$ & $0.371(1)$ & $0.334(1)$ & $0.249(1)$ & $5.6(5)$ \\
\hline $\begin{array}{l}C 14 \\
-15\end{array}$ & $0.253(1)$ & $0.537(1)$ & $0.269(1)$ & $4.1(4)$ \\
\hline $\begin{array}{l}215 \\
c 16\end{array}$ & $\begin{array}{l}0.274(2) \\
0.026(2) .\end{array}$ & $\begin{array}{l}0.379(1) \\
0.592(1)\end{array}$ & $0.376(1)$ & $5.7(4)$ \\
\hline C17 & $\begin{array}{l}0.026(2) \\
0.174(2)\end{array}$ & $\begin{array}{l}0.592(1) \\
0.404(1)\end{array}$ & $0.136(1)$ & $5.2(5)$ \\
\hline $\mathrm{c18}$ & $-0.050(1)$ & $\begin{array}{l}0.404(1) \\
0.433(1)\end{array}$ & $\begin{array}{l}0.1072(9) \\
0.135(1)\end{array}$ & $\begin{array}{l}5.3(5) \\
6.3(5)\end{array}$ \\
\hline C19 & $-0.121(2)$ & $0.335(1)$ & $0.5338(9)$ & $\begin{array}{l}6.3(5) \\
5.0(4)\end{array}$ \\
\hline C20 & $-0.051(2)$ & $0.144(2)$ & $0.497(1)$ & $\begin{array}{l}5.0(4) \\
3.8(5)^{\star}\end{array}$ \\
\hline $\mathrm{C} 2 \mathrm{O}^{\prime}$ & $0.045(4)$ & $0.145(3)$ & $0.511(3)$ & $\begin{array}{l}3.8(5)^{\star} \\
5(1)^{*}\end{array}$ \\
\hline$c 21$ & $0.114(2)$ & $0.222(2)$ & $0.499(1)$ & $\begin{array}{l}5(1)^{\star} \\
3.7(5)^{\star}\end{array}$ \\
\hline $\mathrm{C} 21^{\prime}$ & $0.084(3)$ & $0.321(3)$ & $0.498(2)$ & \\
\hline$c 22$ & $-0.332(1)$ & $0.391(1)$ & $0.401(1)$ & $\begin{array}{l}3.3(7)^{\star} \\
4.7(4)\end{array}$ \\
\hline $\mathrm{C} 23$ & $-0.272(2)$ & $0.430(2)$ & $0.274(1)$ & $\begin{array}{l}4.7(4) \\
3.5(5) *\end{array}$ \\
\hline$c 23^{\prime}$ & $-0.240(4)$ & $0.327(4)$ & $0.271(3)$ & $6(1)^{\star}$ \\
\hline C24 & $-0.232(2)$ & $0.225(2)$ & $0.335(2)$ & $4.2(6)^{\star}$ \\
\hline C24' & $-0.207(3)$ & $0.182(3)$ & $0.394(2)$ & $4.0(8) \star$ \\
\hline $\mathrm{C25}$ & $0.208(2)$ & $-0.024(1)$ & $0.0116(9)$ & $4.9(4)$ \\
\hline c26 & $0.369(2)$ & $0.024(2)$ & $0.063(1)$ & $3.5(5)^{\star}$ \\
\hline C26' & $0.328(3)$ & $0.090(3)$ & $0.066(2)$ & $3.7(8)^{*}$ \\
\hline $\mathrm{C} 27$ & $0.119(3)$ & $0.154(1)$ & $0.058(1)$ & $8.9(8)$ \\
\hline C28 & $-0.035(1)$ & $0.046(1)$ & $0.176(1)$ & $4.7(4)$ \\
\hline C29 & $0.077(1)$ & $-0.146(1)$ & $0.141(1)$ & $4.5(4)$ \\
\hline C30 & $0.099(1)$ & $-0.118(1)$ & $0.2764(9)$ & $6.7(4)$ \\
\hline $\mathrm{C} 31^{\circ}$ & $0.365(4)$ & $-0.152(3)$ & $0.426(3)$ & $2.9(9)^{\star}$ \\
\hline C31 & $0.390(2)$ & $-0.244(2)$ & $0.380(1)$ & $4.0(5)^{*}$ \\
\hline $\mathrm{c} 32^{\prime}$ & $0.521(4)$ & $-0.093(4)$ & $0.446(3)$ & $3.0(9)^{*}$ \\
\hline $\mathrm{c} 32$ & $0.439(2)$ & $-0.114(2)$ & $0.452(1)$ & $4.9(5)^{*}$ \\
\hline $\mathrm{c} 33$ & $0.608(2)$ & $-0.287(1)$ & $0.408(1)$ & $4.7(4)$ \\
\hline C34 & $0.592(2)$ & $0.021(2)$ & $0.205(1)$ & $4.0(5)^{\star}$ \\
\hline C34' & $0.608(4)$ & $-0.045(4)$ & $0.171(3)$ & $3(1)^{\star}$ \\
\hline $\mathrm{c} 35^{\prime}$ & $0.638(4)$ & $0.015(3)$ & $0.296(2)$ & $2.5(8)^{\star}$ \\
\hline $\mathrm{C} 35$ & $0.635(2)$ & $-0.010(2)$ & $0.349(1)$ & $3.9(5)^{\star}$ \\
\hline c36 & $0.738(1)$ & $-0.174(1)$ & $0.273(1)$ & $4.0(4)$ \\
\hline C37' & $0.509(5)$ & $0.567(5)$ & $0.117(4)$ & $4(1)^{*}$ \\
\hline $\mathrm{c} 37$ & $0.608(2)$ & $0.636(2)$ & $0.069(2)$ & $6.6(7)^{\star}$ \\
\hline c38 & $0.497(2)$ & $0.662(2)$ & $0.017(2)$ & $9.2(7)^{*}$ \\
\hline c39 & $0.480(2)$ & $0.717(2)$ & $-0.051(1)$ & $6.2(5)^{\star}$ \\
\hline$C 40$ & $0.366(2)$ & $0.737(2)$ & $-0.100(1)$ & $7.6(6)^{*}$ \\
\hline $\mathrm{C} 41$ & $0.280(2)$ & $0.695(2)$ & $-0.069(1)$ & $7.6(6)^{\star}$ \\
\hline$C 42$ & $0.318(2)$ & $0.633(2)$ & $0.008(2)$ & $10.6(8) *$ \\
\hline 243 & $0.414(2)$ & $0.609(1)$ & $0.052(1)$ & $5.7(4)^{\star}$ \\
\hline
\end{tabular}

starred atoms were included with isotropic thermal parameters. The thermal parameter given for anisotropically refined atoms is the isotropic equivalent thermal parameter defined as: $(4 / 3) *\left[a 2^{\star} B(1,1)+b 2^{\star} B(2,2)+c 2^{\star} B(3,3)+a b(\cos\right.$ gama $) \star B(1,2)$ $+a c(\cos$ beta $) \star B(1,3)+b c(\cos a[p h a) \star B(2,3)]$ where $a, b, c$ are real cell parameters, and $B(i, j)$ are anisotropic betas. 
Table of Anisotropic Thermal Parameters - B's

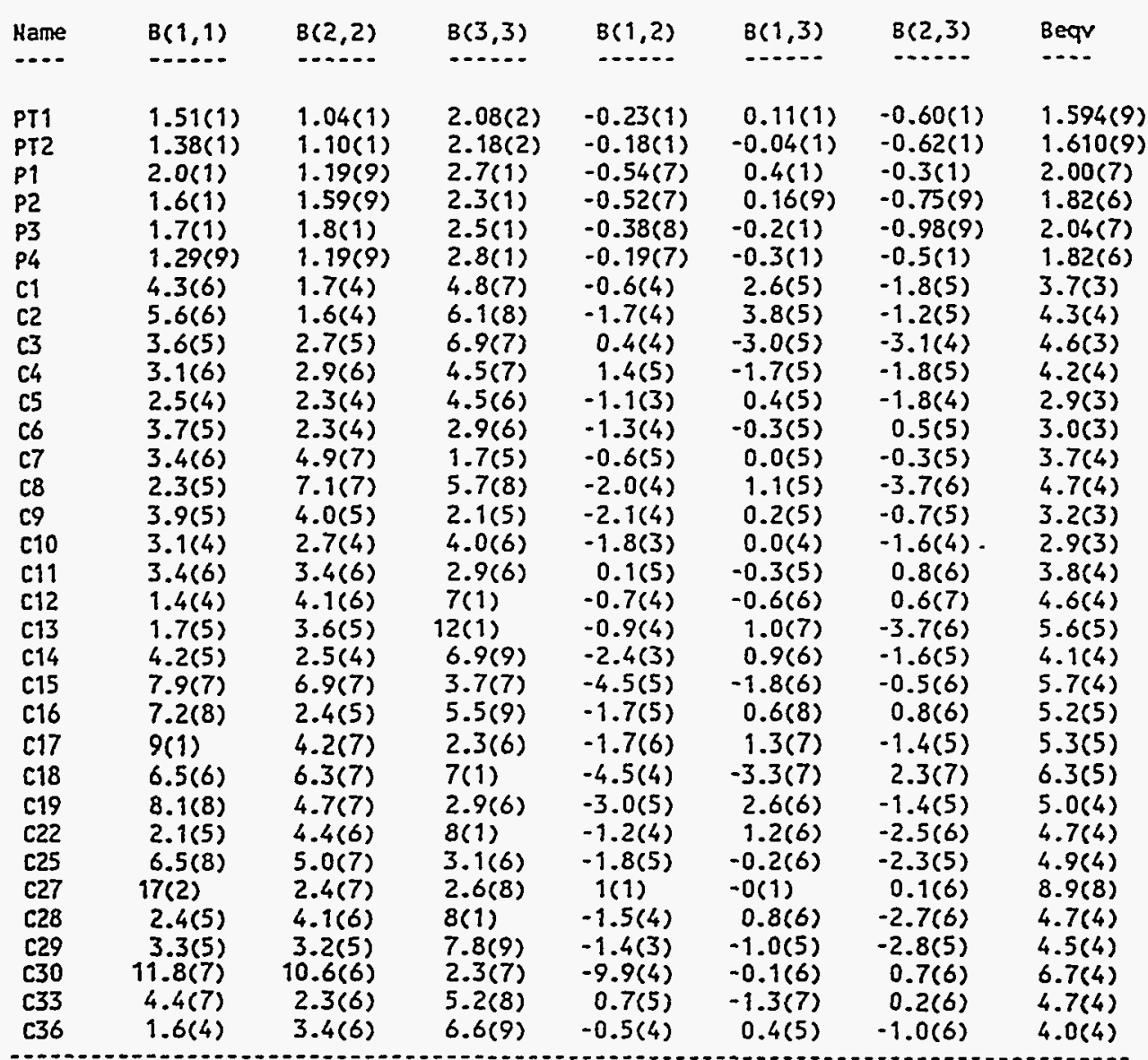

The form of the anisotropic temperature factor is:

$\exp [-0.25(h 2 a 2 B(1,1)+k 2 b 2 B(2,2)+12 c 2 B(3,3)+2 h k a b B(1,2)+2 h l a c B(1,3)$

$+2 k(b c B(2,3)\}]$ where $a, b$, and $c$ are reciprocal lattice constants. 


\section{$\mathrm{Cp}_{2}{ }_{2} \mathrm{Yb}\left(\mathrm{Me}_{2} \mathrm{PhPCHSiMe}\right)$}

Table of Positional Parameters and Their Estimated Standard Deviations

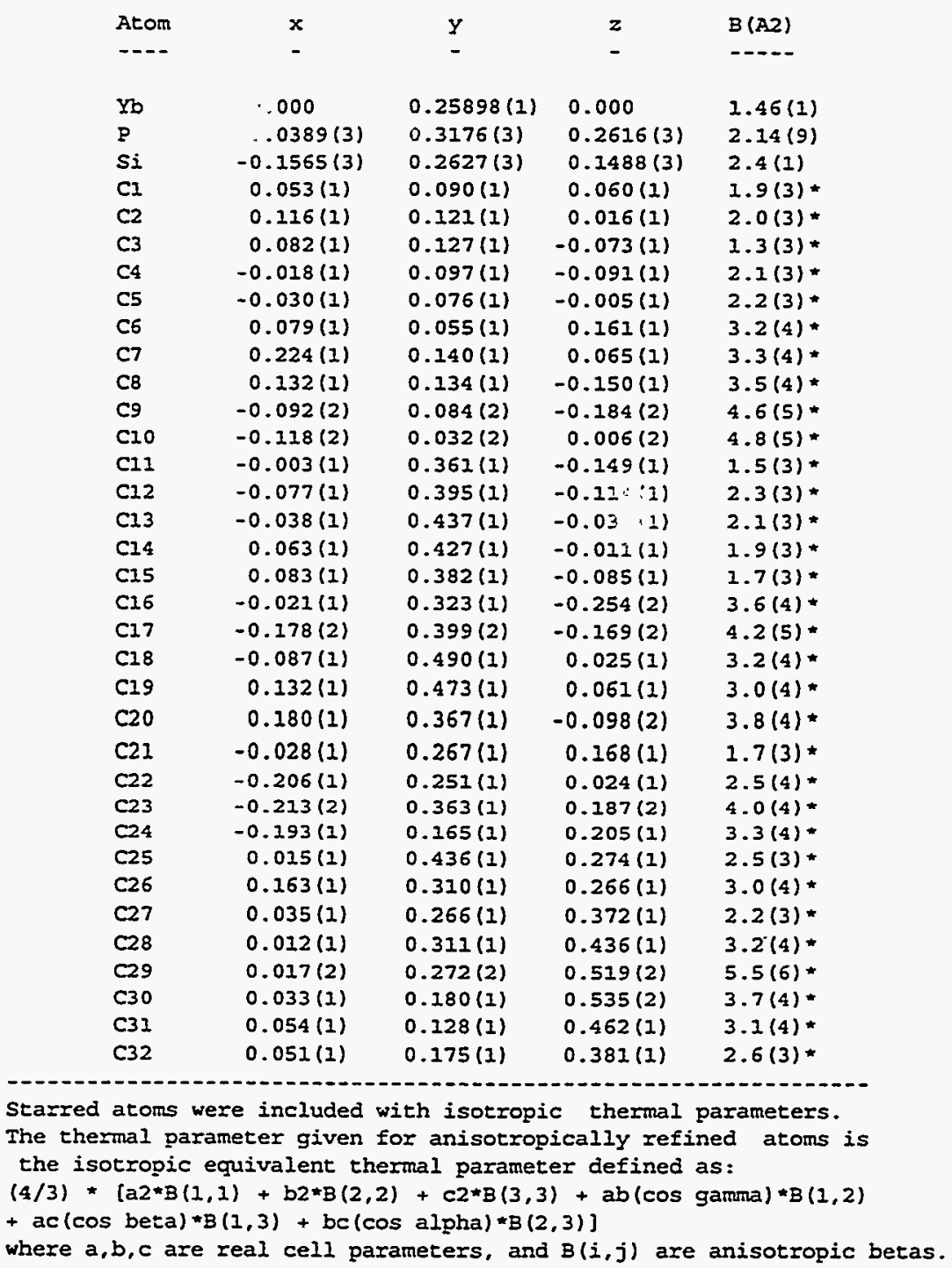


Table of Anisotropic Thermal Parameters - B's

\begin{tabular}{|c|c|c|c|c|c|c|c|}
\hline Name & $B(1,1)$ & $B(2,2)$ & $B(3,3)$ & $B(1,2)$ & $B(1,3)$ & $B(2,3)$ & Beqr \\
\hline$\cdots$ & $-\cdots$ & $\cdots$ & $-\cdots$ & $-\ldots$ & ........ & -.... & $\ldots$ \\
\hline$Y b$ & $1.49(2)$ & $1.64(2)$ & $1.23(2)$ & $-0.31(5)$ & $0.34(1)$ & $-0.54(4)$ & $1.46(1)$ \\
\hline $\mathbf{p}$ & $2.5(2)$ & $2.3(2)$ & $1.8(2)$ & $-0.0(1)$ & $0.8(1)$ & $-0.3(1)$ & $2.24(9)$ \\
\hline Si & $1.9(2)$ & $3.5(2)$ & $1.9(2)$ & $-0.5(2)$ & $0.6(2)$ & $-0.8(2)$ & $2.4(1)$ \\
\hline
\end{tabular}

The form of the anisotzopic temperature factor is:

$\exp [-0.25(h 2 a 2 B(1,1)+k 2 b 2 B(2,2)+12 c 2 B(3,3)+2 h k a b B(1,2)+2 h l a c B(1,3)$

$+2 k l b c B(2,3)\}]$ where $a, b$, and $c$ are reciprocal lattice conseants. 


\section{Cp ${ }_{2}^{*} \mathrm{Yb}($ toluene $)$}

Table of Positional Parameters and Their Estimated Standard Deviations -

\begin{tabular}{lllll} 
Atom & \multicolumn{1}{c}{$\mathrm{x}$} & $y$ & $z$ & $B(A 2)$ \\
$\cdots$ & - & - & - & $\cdots$ \\
YB & $0.25416(1)$ & $0.49754(1)$ & $0.36848(1)$ & $1.519(7)$ \\
C1 & $0.5063(8)$ & $0.3648(8)$ & $0.3838(7)$ & $2.2(2)$ \\
C2 & $0.4263(8)$ & $0.2690(7)$ & $0.4394(7)$ & $2.1(2)$ \\
C3 & $0.3430(8)$ & $0.2508(7)$ & $0.3503(8)$ & $2.8(2)$ \\
C4 & $0.3734(9)$ & $0.3315(8)$ & $0.2450(7)$ & $2.2(2)$ \\
C5 & $0.4726(8)$ & $0.4051(8)$ & $0.2632(7)$ & $2.2(2)$ \\
C6 & $0.6198(9)$ & $0.4052(9)$ & $0.4382(9)$ & $3.4(2)$ \\
C7 & $0.439(1)$ & $0.190(1)$ & $0.5619(9)$ & $3.7(2)$ \\
C8 & $0.2472(9)$ & $0.1491(9)$ & $0.370(1)$ & $3.6(2)$ \\
C9 & $0.320(1)$ & $0.324(1)$ & $0.1306(8)$ & $4.5(3)$ \\
C10 & $0.544(1)$ & $0.495(1)$ & $0.172(1)$ & $4.5(3)$ \\
C11 & $0.1410(8)$ & $0.6627(8)$ & $0.1752(7)$ & $2.2(2)$ \\
C12 & $0.1795(9)$ & $0.7430(8)$ & $0.2445(8)$ & $2.3(2)$ \\
C13 & $0.0982(8)$ & $0.7329(8)$ & $0.3465(7)$ & $2.1(2)$ \\
C14 & $0.0099(8)$ & $0.6438(8)$ & $0.3396(7)$ & $1.9(2)$ \\
C15 & $0.0368(8)$ & $0.5981(8)$ & $0.2362(7)$ & $2.0(2)$ \\
C16 & $0.184(1)$ & $0.664(1)$ & $0.0518(8)$ & $3.6(2)$ \\
C17 & $0.279(1)$ & $0.8392(9)$ & $0.2020(9)$ & $3.2(2)$ \\
C18 & $0.095(1)$ & $0.8152(8)$ & $0.4343(8)$ & $3.1(2)$ \\
C19 & $-0.1091(9)$ & $0.6186(9)$ & $0.4182(8)$ & $2.9(2)$ \\
C20 & $-0.043(1)$ & $0.5103(9)$ & $0.1930(9)$ & $3.7(2)$ \\
C21 & $0.215(1)$ & $0.941(1)$ & $-0.205(1)$ & $4.8(3)$ \\
C22 & $0.351(1)$ & $0.926(1)$ & $-0.197(1)$ & $4.8(3)$ \\
C23 & $0.412(2)$ & $1.000(1)$ & $-0.146(1)$ & $7.2(4)$ \\
C24 & $0.338(2)$ & $1.100(1)$ & $-0.100(1)$ & $7.9(4)$ \\
C25 & $0.206(2)$ & $1.121(1)$ & $-0.104(2)$ & $9.1(5)$ \\
C26 & $0.141(2)$ & $1.038(1)$ & $-0.159(1)$ & $6.1(4)$ \\
C27 & $0.153(2)$ & $0.856(1)$ & $-0.258(1)$ & $8.5(4)$ \\
& & & &
\end{tabular}

